UNIVERSITY OF SAO PAULO

COLLEGE OF ECONOMICS, BUSINESS, AND ACCOUNTING

DEPARTMENT OF ACCOUNTANCY AND ACTUARIAL SCIENCE

GRADUATE PROGRAM IN CONTROLLERSHIP AND ACCOUNTING

Quality in the Process of Scientific Production in Accounting in Brazil

Qualidade no Processo de Produção Científica em Contabilidade no Brasil

José Renato Sena Oliveira

Advisor: Prof. Dr. Gilberto de Andrade Martins 
Dr. Marco Antonio Zago

Rector of the University of Sao Paulo

Dr. Adalberto Américo Fischmann

Dean of the College of Economics, Business, and Accounting

Dr. Gerlando Augusto Sampaio Franco de Lima

Chairman of the Department of Accountancy and Actuarial Science

Dr. Luiz Paulo Lopes Fávero

Coordinator of the Graduate Program in Controllership and Accounting 
JOSÉ RENATO SENA OLIVEIRA

Quality in the Process of Scientific Production in Accounting in Brazil

Qualidade no Processo de Produção Científica em Contabilidade no Brasil

Dissertation submitted to the Graduate Program in Controllership and Accounting of the Department of Accountancy and Actuarial Science at the College of Economics, Business, and Accounting at the University of Sao Paulo, as a partial requirement to obtain the Doctoral degree in Science.

Advisor: Prof. Dr. Gilberto de Andrade Martins

Corrected version

(original version available at College of Economics, Business, and Accounting) 
The reproduction and total or partial disclosure of this work is authorized by any conventional or electronic means for the purpose of study and research, provided that the source is mentioned.

\title{
CATALOGUING DATA
}

Prepared by Seção de Processamento Técnico do SBD/FEA/USP

\author{
Oliveira, José Renato Sena \\ Quality in the process of scientific production in accounting in Brazil / \\ José Renato Sena Oliveira. - São Paulo, 2016. \\ $167 \mathrm{p}$. \\ Tese (Doutorado) - Universidade de São Paulo, 2016. \\ Orientador: Gilberto de Andrade Martins. \\ 1. Contabilidade - Pesquisa 2. Produção científica 3. Pesquisa cien- \\ tífica 4. Pós-graduação I. Universidade de São Paulo. Faculdade de Eco- \\ nomia, Administração e Contabilidade. II. Título.
}

CDD -657.07 
Name: Oliveira, José Renato Sena

Title: Quality in the Process of Scientific Production in Accounting in Brazil

Dissertation submitted to the Graduate Program in Controllership and Accounting of the Department of Accountancy and Actuarial Science at the College of Economics, Business, and Accounting at the University of Sao Paulo, as a partial requirement to obtain the Doctoral degree in Science.

Approved on: 04/28/2016.

Dissertation Committee:

Prof. Dr. Gilberto de Andrade Martins (advisor and president)

Institution: University of Sao Paulo Signature:

Prof. Dr. Ana Maria Afonso Ferreira Bianchi

Institution: University of Sao Paulo Signature:

Prof. Dr. Jacqueline Veneroso Alves da Cunha

Institution: Federal University of Minas Gerais Signature:

Prof. Dr. Marcia Martins Mendes De Luca

Institution: Federal University of Ceara Signature:

Prof. Dr. Romualdo Douglas Colauto

Institution: Federal University of Parana Signature:

Sao Paulo (Brazil), April 28, 2016. 

This dissertation is dedicated to Brazilian accounting researchers with the hope that they feel challenged both to reflect on the quality of the knowledge produced in the field and to seek continuous improvement in their research practices. 



\section{ACKNOWLEDGMENTS}

First, I would like to thank God for my life, opportunities, and the strength to overcome challenges.

I am grateful to my family, my safe harbor at all times: my parents, Antonio Aderaldo de Oliveira and Zenilda de Almeida Sena; my siblings, Adauto, Antonio Romeu, and Elenilda; Levi (my nephew and godson) and little Camila (my niece). I also thank Monica and Mosana, my sisters-in-law. I apologize for my absence during these long years. Thank you my uncle Luiz Júlio Carneiro (in memoriam) and my aunt Noélia Maria de Oliveira Carneiro: I am indebted to them for much of what I am today. Thank you for everything. Additionally, I am grateful to my uncle and godfather Otoniel Oliveira: it was hard being away and not being able to say a final goodbye. Rest in peace.

Special acknowledgment goes to my advisor, Professor Dr. Gilberto de Andrade Martins. Since the first moment that we began to discuss ideas about research quality, he has believed and embraced this proposal. Many of the ideas in this study have been inspired by our conversations and our concerns about how to produce knowledge in accounting with rigor and usefulness with the objective of bringing best practices to the science and our best contributions to society. He is tirelessly enthusiastic in discussing issues that might lead accounting knowledge to a higher scientific level, an idea that inspired this proposal. I also thank David Carter and Artur Roberto do Nascimento, who helped me to organize ideas in order to build the research design to apply for the graduate program.

I would like to thank the members of the qualifying board, Dr. Marcia Martins Mendes De Luca and Dr. Romualdo Douglas Colauto, for their significant contributions to improving this study. Additionally, I am extremely grateful to the faculty members in Brazilian graduate programs in accounting that kindly and voluntarily agreed to participate in this study; they were essential to helping me better understand the issues surrounding the quality and scientific research process of the accounting field in Brazil. I also thank the coordinators of Brazilian graduate programs in accounting who kindly forwarded requests to faculty members to participate in this study.

I thank the University of Sao Paulo (USP) for this great opportunity. I am grateful to the faculty of the Graduate Program in Accounting at FEA/USP for their lessons throughout the course. Special thanks to the professors who went to Feira de Santana City in 2012 to lead us through the early stages of the Interinstitutional Doctorate (DINTER): Dr. Gerlando Lima and Dr. Gilberto Martins (first half) and Dr. Bruno Salotti and Dr. Nelson Carvalho (second half). Thank you to Professor Dr. Edgard Cornacchione Jr, former Chairman of the Department of Accountancy and Actuarial Science at the FEA/USP, who was responsible for facilitating my time as a visiting scholar at University of Illinois at Urbana-Champaign (UIUC). Thank you to the DINTER coordinators at USP: Dr. Silvia Casa Nova and Dr. Luis Afonso (first stage) and Dr. Lucas Barros and Dr. Andson Aguiar (current stage). Finally, thank you to Professor Dr. Andson Aguiar and Professor Dr. Romualdo Colauto, my supervisors in Teaching Monitoring I and II, who gave me the opportunity for new experiences in undergraduate education.

I would like to thank the UIUC for accepting me to the Visiting Scholar Program of the Department of Educational Psychology (Epsy) at the College of Education and for providing me with support for carrying out my activities as visiting scholar during the 20142015 academic year. Additionally, I am grateful to Professor Jennifer C. Greene (Epsy/UIUC) both for having supervised me in the program and for her invaluable contributions to improving my research proposal for this dissertation. You are an example for the values of simplicity, competence, and professionalism. Thank you for everything. Thank you to 
Professor Thomas Schwandt, who allowed me to audit his Introduction to Evaluation Theory class, and to Mrs. Amy Hager, visa coordinator of the College of Education. Finally, thank you to Jeff Arrigo, lecturer of the Advanced Academic Writing I and Advanced Presentation Skills I classes in the ESL Program of the Department of Linguistics/UIUC, for his valuable contributions to improving my English skills and for inspiring me to accept the challenge of writing this dissertation in English.

I thank the State University of Feira de Santana (UEFS), for all its support. Thank you to my friends from the Finance and Accounting Office, especially Carlos Roberto Suzarte, Chawelly Filgueiras, Fatima Parente, and Flor Morais, for encouraging me to accept the challenge of the doctoral program. Thank you to my colleagues and friends in the Department of Applied Social Sciences, and to Vilânia Santana and the team at the Research and Graduate Dean's Office (PPPG). Special thanks to my friends Professors Rosembergue Valverde and Rossine Cerqueira da Cruz, local coordinators of the DINTER at UEFS, who agreed to conduct the program with all its challenges. Thank you to my friend Tania Cristina Azevedo, who could not be with us on this journey, and Professor Marluce Maria Araújo Assis, former Pro-Rector for Research and Graduate at UEFS. Both of them were directly responsible for the realization of this DINTER, thus contributing immensely to the building project submitted to USP and CAPES.

To my DINTER colleagues - Ana Lucia Carvalho, Edmilson Sousa, Emilio Maltez, Iracema Raimunda Aragão, Marcia D'Souza, Raimundo Lima Filho, Robson Braga, and Sandra Maria Silva - thank you for the friendship, companionship, and persistence. I know how hard it was for each of you. Special thanks to Ana Lucia, Iracema and Sandra Maria, my Feira de Santana partners in the program. Up, up and away! Also to Sandro Soares and Bruna Camargos, friends who we met during the doctoral program.

I could not forget my friends who believed me and who kept me stimulated throughout. Thank you to Cláudia Cruz, my friend and my example of humility and competence as a researcher. Thank you also to Josue Braga and Renata Braga, for their friendship, encouragement, and support: I will forever remember the good moments in Urbana, IL, particularly those accompanied by Papa John's pizzas. Thank you to so many friends from Bahia who always cheered for my success, particularly Adriano Cosme Lima, Alcione Carvalho, Carlos Adriano Gomes, Cleberton Santos, Erivaldo Carneiro Júnior, Giminiano Santos, Graciela Barbosa, Jorge Rodrigues, Madalena Sousa, Maria Helena Martins, Naiana Vasconcelos, Norma Bernardo, Robério Souza, Ronaldo Nascimento, Thais Gabriele Ribeiro, and Wilson Jesus. Finally, thank you to my friends Gerlando Lima, Rodolfo Ferrari and Veronica Santana, partners in learning and fun moments at the office of the USP Conference in Accounting: the doctorate was less difficult because of those pranks and jokes: Good morning, Congress! Good afternoon, Congress! Thank you to the staff of PPGCC and EAC/FEA/USP for your support and friendship: Marcia Bento, Janaína Nogueira, Janaína Silva, Juliana Meneghim, Belinda Ludovici, Evandro Figueiredo, and Maria José Medeiros.

I thank my friends from Urbana-Champaign, who made my days in the US more pleasant: Débora Gonçalves and her family, Hélio Emmendoerfer Jr, Karulliny Vianna, Maria Carolina Hidalgo, and Rejane Canha and her family. Additionally, I want to thank my ESL colleagues at Parkland College (Champaign, IL), where I learned to overcome the challenges of a new language and learned to 'build bridges' with the help of Cheryl Lehman, George Uricoechea, Tracey Brown, and Wendy Patriquin, our ESL instructors.

Finally, I thank the Bahia State Support Foundation for Research (FAPESB), whose funding supported the Interinstitutional Doctorate in Accounting in the partnership between FEA/USP, UEFS and associates. 
The value of scientific research is partially dependent on the ability of individual researchers to demonstrate the credibility of their findings.

LeCompte and Goetz (1982).

The most important purpose of evaluation is not to prove, but to improve.

Daniel Stufflebeam (2000). 



\begin{abstract}
Oliveira, José Renato Sena. Quality in the process of scientific production in Accounting in Brazil. (Doctoral dissertation). College of Economics, Business, and Accounting at University of Sao Paulo. Sao Paulo, 2016.
\end{abstract}

This study aims to analyze the building process of scientific production in accounting in light of the quality attributes of good research. In so doing, it attempts to identify the stages of the research process in which these characteristics are revealed, to compare the literature on research attributes with the attributes identified in respondents' practices, and to present an approach based on the attributes of good research to judge the quality of scientific production in the accounting field. This research uses the Modified Delphi Technique, which indicates that the first inputs came from the literature. The expert panel consisted of 37 faculty members from 19 Brazilian graduate programs in accounting who were recommended/recognized by the CAPES Foundation. Based on the literature, especially Brinberg and McGrath (1985), Spencer et. al. (2003), and Mays and Pope (2006), an orientation matrix was developed with 53 attributes/relationships related to general quality criteria and nine key features. Experts gave each proposition a grade from 1 to 10 based on their level of agreement regarding adherence to their research practices. The Delphi was applied in two rounds using online questionnaires with customized access. The findings reveal that most of the respondents obtained their doctoral degree in accounting at a national institution other than the one at which they currently work and that more than $70 \%$ of the respondents have been working as teachers or coordinators in graduate programs for fewer than seven years. With respect to the respondents' research experience, most serve on journals' editorial boards, act as journal referees, and at some point have obtained research funding from development institutions. Approximately one-third have received research productivity grants and almost one-half either currently serve or has served as a journal editor. Approximately $3 / 4$ of the propositions achieved a strong level of agreement, and the following 10 propositions achieved a Delphi relative score of more than $90 \%$ : voluntary participation of subjects, goal/problem shown precisely, confidentiality of participants' data, conclusions versus aim, results comparison with other studies, checklist of findings versus purpose, literature review versus main concepts, theory to support propositions, useful strategy for purpose, and previous findings versus hypotheses. Those attributes that demonstrated low or moderate levels of agreement involved items that may compromise the quality and integrity of research, including those related to ethical principles, demonstrations of how researchers addressed errors and biases, and disclosure of the impact of the research team's participation on the results. The approach chosen meant discussing the relationships between criteria and fundamental features versus levels of agreement, followed by presentation of a logic model to evaluate the research process. The research concludes that certain current practices employed by Brazilian researchers in accounting - combined with the local institutional environment - contribute to reduce the quality of accounting research. This position is supported by the high dispersion of answers on various items and the low acceptance of attributes related to ethics, both of which are mandatory requirements under Brazilian law. Additionally, the low level of agreement on issues regarding the criteria of rigor and internal validity/credibility or defensibility - in addition to items related to rigor, integrity, and feasibility - reached only the moderate level.

Keywords: accounting - research, scientific production, scientific research, graduate studies, research quality, quality criteria. 



\section{RESUMO}

Oliveira, José Renato Sena. Qualidade no processo de produção científica em Contabilidade no Brasil. (Tese de doutorado). Faculdade de Economia, Administração e Contabilidade da Universidade de São Paulo. São Paulo, 2016.

O propósito deste estudo é analisar o processo de construção da produção científica em Contabilidade à luz dos atributos de qualidade de uma boa pesquisa. Buscou-se observar em quais estágios do processo de pesquisa estes atributos são revelados, comparar os atributos da literatura com aqueles identificados nas práticas dos respondentes, e apresentar uma abordagem baseada em atributos de uma boa pesquisa para o julgamento da qualidade da produção científica na área. A metodologia utilizada foi a Técnica Delphi Modificada, em que as primeiras entradas têm origem na literatura. O painel de especialistas foi composto por 37 docentes de 19 Programas Brasileiros de Pós-Graduação (PPG) Stricto Sensu em Contabilidade recomendados/reconhecidos pela CAPES. Com base na literatura, especialmente Brinberg e McGrath (1985), Spencer et. al. (2003) e Mays e Pope (2006), foi elaborada uma matriz de orientação com 53 atributos/relações vinculados a critérios gerais de qualidade e a nove características-chave. Os especialistas atribuíram uma nota de 1 a 10 para cada atributo de acordo com o nível de concordância quanto à aderência às suas práticas de pesquisa. A Delphi foi aplicada em duas rodadas com o uso de questionários online e com acesso personalizado. Os achados revelaram que a maioria dos (das) respondentes tem Doutorado em Contabilidade obtido em uma Instituição nacional diferente da que atua, e mais de $70 \%$ têm até 7 anos de docência ou coordenação de PPG. Sobre a experiência de pesquisa, a maioria faz parte de conselhos editoriais de periódicos da sua área, atua como avaliador de periódicos e tem, ou já obteve, financiamento de instituições de fomento para pesquisa. Cerca de um terço tem bolsa de produtividade em pesquisa e quase metade atua ou já atuou como editor de periódico. Aproximadamente $3 / 4$ das proposições receberam nível forte de concordância, e 10 delas alcançaram percentual superior a $90 \%$ no escore relativo da Delphi: participação voluntária dos sujeitos, objetivo/problema mostrado precisamente, confidencialidade dos dados dos participantes, conclusões versus objetivos, comparação de resultados com outros estudos, checar links entre achados versus propósito, revisão de literatura versus principais conceitos, teoria para suportar as proposições, estratégia útil ao propósito, e achados anteriores versus hipótese. Por outro lado, atributos que atingiram níveis baixo ou moderado de aceitação mostraram itens que podem comprometer a qualidade e integridade da investigação, como aqueles relacionados aos princípios éticos, à demonstração de como os pesquisadores lidaram com erros e vieses, e à divulgação dos impactos da participação da equipe de pesquisa sobre os resultados. A abordagem proposta consistiu na discussão das relações entre critérios e características-chave versus níveis de concordância, seguida da apresentação de um modelo lógico para avaliar o processo de pesquisa. Concluiuse que algumas práticas correntes utilizadas por pesquisadores da área contábil no Brasil, combinadas com o ambiente institucional local, contribuem para a diminuição da qualidade da pesquisa no campo. Esta posição é apoiada pela elevada dispersão das respostas em vários itens e pela baixa aceitação de atributos relacionados à ética e que são requisito obrigatório pela legislação brasileira. Adicionalmente, pelo baixo nível de concordância sobre questões relacionadas com o rigor e a validade interna/credibilidade ou defensibilidade, bem como para itens relativos ao rigor, integridade e viabilidade, que atingiram o nível moderado.

Palavras-chave: contabilidade - pesquisa, produção científica, pesquisa científica, pósgraduação, qualidade da pesquisa, critérios de qualidade. 



\section{LIST OF ILLUSTRATIONS}

Figure 1: The VNS System: domains, levels, and paths................................................ 34

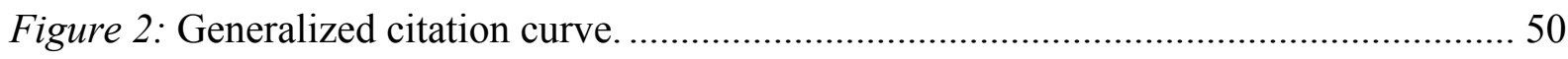

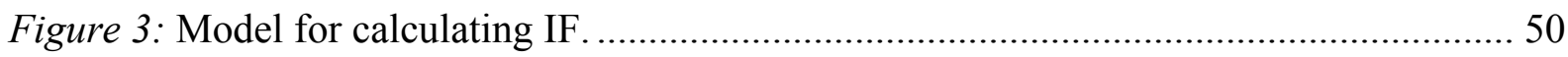

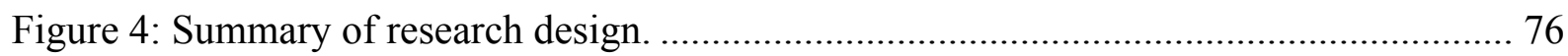

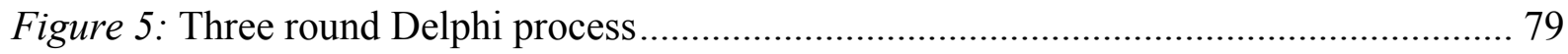

Figure 6: Initial screen to access the data collection instrument.......................................... 86

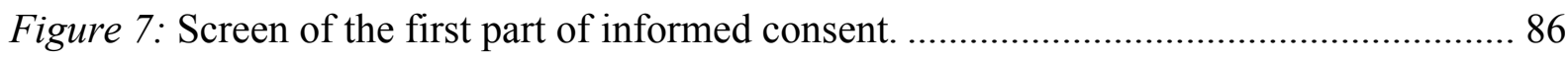

Figure 8: Screen with fields to insert the respondent's code and to declare agreement. ........87

Figure 9: Second page of the first round's tool (research design, research subjects, and

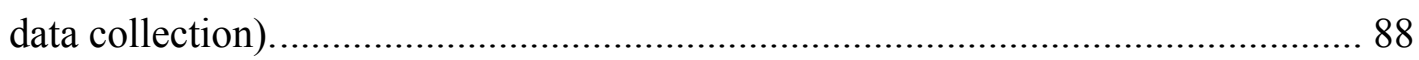

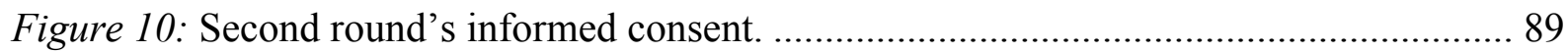

Figure 11: Second page of the online data collection instrument (second round)................. 90

Figure 12: Third page of the second round's tool with the new alternative of response. ....... 90

Figure 13: Distribution of statements by criteria. ......................................................... 91

Figure 14: Summarized logic model to evaluate the research process. ............................... 93

Figure 15: Distribution of the respondents by number of papers published in the last

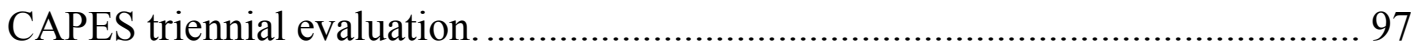

Figure 16: Distribution of the respondents by the characteristics of their graduate

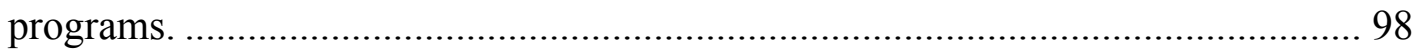

Figure 17: Distribution of the graduate programs represented in the Delphi by level........... 98

Figure 18: Distribution of the graduate programs by their current grades (CAPES)............. 98

Figure 19: Distribution of statements by agreement levels.............................................. 115

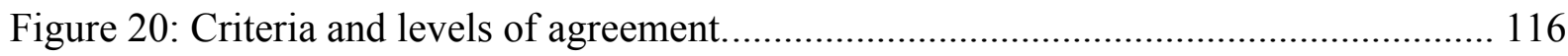

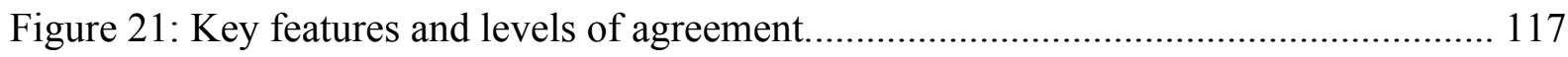

Figure 22: Logic model to evaluate the research process. ................................................ 120 



\section{LIST OF TABLES}

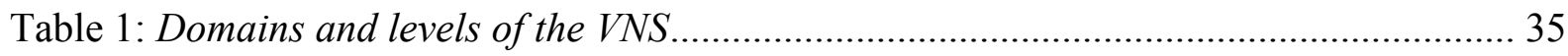

Table 2: The VNS system: validities and stages of the research process. .............................. 36

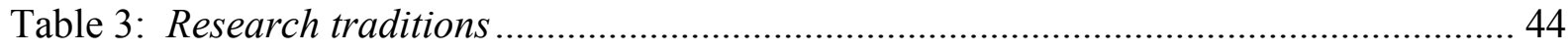

Table 4: 'Quantitative' and 'qualitative' research paradigms .............................................. 45

Table 5: Framework for assessing qualitative evaluations ................................................. 55

Table 6: Summary of general scientific criteria and their meanings..................................... 56

Table 7: Summary of previous studies of research quality in accounting ............................. 61

Table 8: Reasons that English articles are not published in leading American accounting

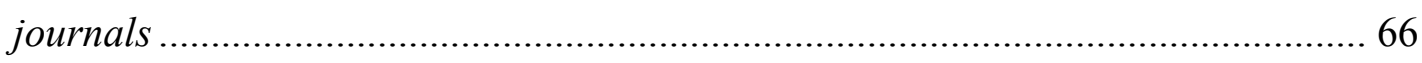

Table 9: Evaluation criteria to judge journals by the Qualis/CAPES in quadrennial

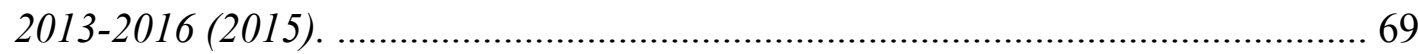

Table 10: Matrix of general criteria and their attributes/relationships ............................... 73

Table 11: Criteria for classifying the statements in accordance with agreement levels. ........ 85

Table 12: Characteristics of the respondents' professional qualifications and experience.... 96

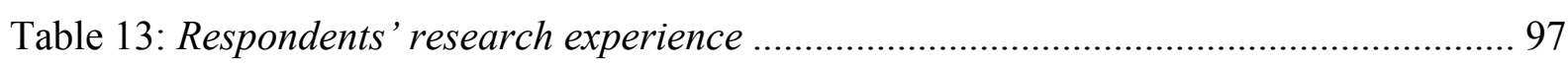

Table 14: First round - research design (descending order of percentage of grades $\geq 8$ ) ...... 99

Table 15: First round - research subjects (descending order of percentage of grades $\geq 8$ ) . 100

Table 16: First round - data collection (descending order of percentage of grades $\geq 8$ ) ..... 100

Table 17: First round - analysis (descending order of percentage of grades $\geq 8$ ) ................ 100

Table 18: First round - findings (descending order of percentage of grades $\geq 8$ ) ................ 101

Table 19: First round - reporting (descending order of percentage of grades $\geq 8$ ) ............... 102

Table 20: First round - reflexivity and neutrality (descending order of percentage of

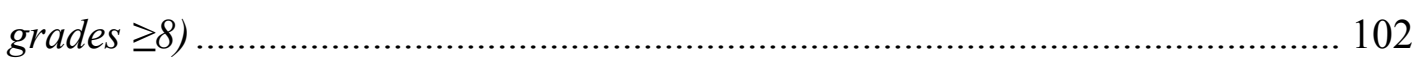

Table 21: First round - auditability (descending order of percentage of grades $\geq 8$ ) ........... 103

Table 22: Second round - research design (descending order of percentage of grades $\geq 8$ )

Table 23: Second round - research subjects (descending order of percentage of grades $\geq 8$ ).

Table 24: Second round - data collection (descending order of percentage of grades $\geq 8$ ).. 104

Table 25: Second round - analysis (descending order of percentage of grades $\geq 8$ ) ............ 104

Table 26: Second round - findings (descending order of percentage of grades $\geq 8$ )............. 105

Table 27: Second round - reporting (descending order of percentage of grades $\geq 8$ ) .......... 105 
Table 28: Second round - reflexivity and neutrality (descending order of percentage

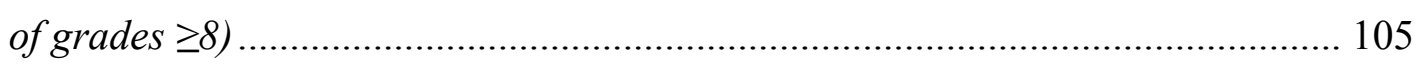

Table 29: Second round - ethical issues (descending order of percentage of grades $\geq 8$ ) .... 106

Table 30: Second round - auditability (descending order of percentage of grades $\geq 8$ ) ....... 106

Table 31: Distribution of respondents based on valid cases. ............................................... 107

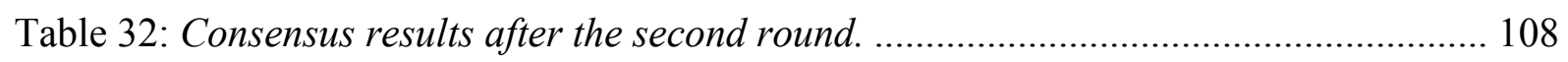

Table 33: Final classification - attributes/relationships with strong level of agreement. .... 110

Table 34: Final classification - attributes/relationships with moderate level of agreement. 111

Table 35: Final classification - attributes/relationships with low level of agreement.......... 112

Table 36: Final classification - attributes/relationships with unformed consensus.............. 113 


\title{
LIST OF ABBREVIATIONS AND ACRONYMS
}

\author{
AEA American Evaluation Association \\ ANPAD Associação Nacional de Pós-Graduação e Pesquisa em Administração \\ (National Association of Graduate and Research in Administration) \\ CAPES Coordenação de Aperfeiçoamento de Pessoal de Nível Superior \\ (Coordination for the Improvement of Higher Level Personnel) \\ CAR Contemporary Accounting Research \\ CEP Comitê de Ética em Pesquisa com Seres Humanos \\ (Ethics Committee for Research with Human Beings) \\ CNS Conselho Nacional de Saúde \\ (Brazilian National Health Council) \\ CONEP Comissão Nacional de Ética em Pesquisa \\ (National Research Ethics Commission) \\ DAV Diretoria de Avaliação \\ (Evaluation Board) \\ DINTER Doutorado Interinstitucional \\ (Interinstitutional Doctorate)
}

ENANPAD Encontro da Associação Nacional dos Programas de Pós-Graduação em Administração

(Meeting of the National Association of Graduate Programs in Administration)

FAPESB Fundação de Amparo à Pesquisa do Estado da Bahia (Bahia State Support Foundation for Research)

FAPESP Fundação de Amparo à Pesquisa do Estado de São Paulo (Sao Paulo Research Foundation)

FEA Faculdade de Economia, Administração e Contabilidade (College of Economics, Business, and Accounting)

HEI Higher Education Institutions

IF Impact Factor

ISI Institute for Scientific Information

JAR The Journal of Accounting Research

JCR Journal Citation Report

KEC Key Evaluation Checklist

OADS Office of the Associate Director for Science

PPG Programa de Pós-Graduação

(Graduate Program)

PPGCC Programa de Pós-Graduação em Controladoria e Contabilidade (Graduate Program in Controllership and Accounting)

PPPG Pró-Reitoria de Pesquisa e Pós-Graduação (Research and Graduate Dean's Office) 
PTC Points to Consider

RAE Research Assessment Exercises

SciELO Scientific Electronic Library Online

TCLE Termo de Consentimento Livre e Esclarecido (Informed Consent)

UEFS Universidade Estadual de Feira de Santana (State University of Feira de Santana)

UIUC University of Illinois at Urbana-Champaign

UK United Kingdom

USP Universidade de São Paulo

(University of Sao Paulo)

VNS Validity Network Schema 


\section{TABLE OF CONTENTS}

page

CHAPTER 1 - INTRODUCTION

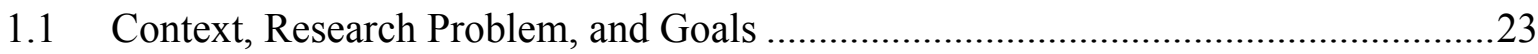

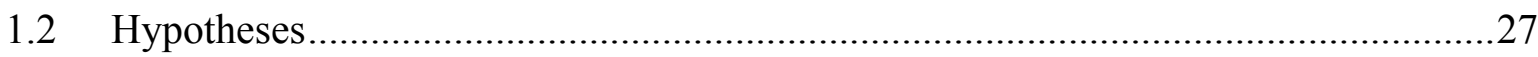

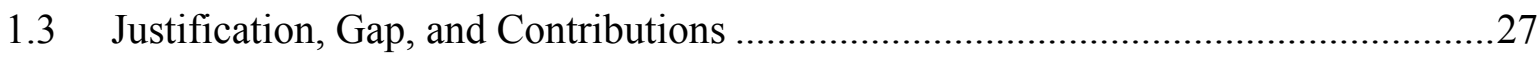

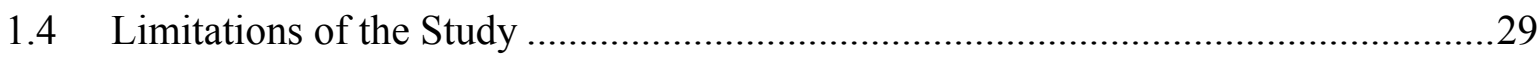

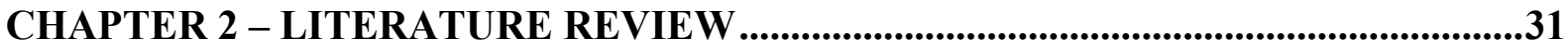

2.1 What is Quality in the Research Context? ............................................................ 31

2.1.1 The integration of the research process and scientific investigation domains.....33

2.1.2 Relevance, validity, rigor, and integrity as elements of research quality..............38

2.1.3 Good research practices ............................................................................... 40

2.2 How Should We Evaluate Quality in the Research Process? ....................................42

2.2.1 Influence of research traditions on the research process ...................................43

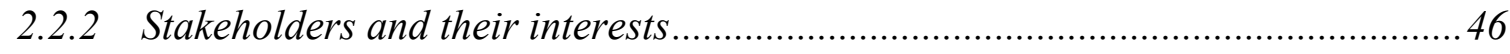

2.2.3 Judging the research quality of journals: perception studies based on surveys

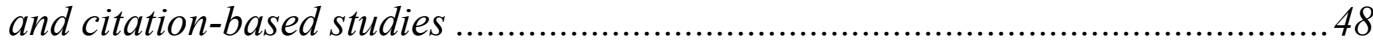

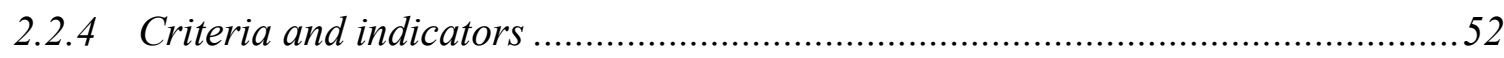

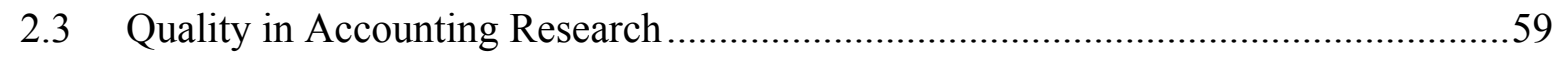

2.3.1 Prior studies of research quality in business and accounting .............................59

2.3.2 Research quality in accounting graduate programs under the regulatory view

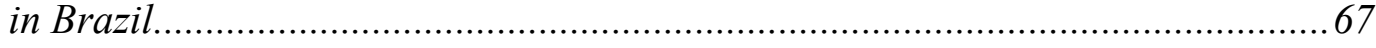

2.3.3 Quality criteria and research practices in the steps of the research process

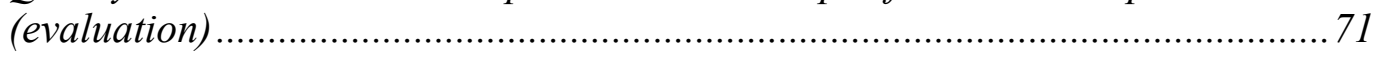

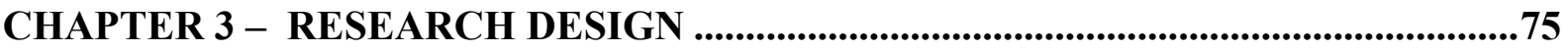

3.1 Method Choice and Steps of Research Development...........................................75

3.2 Stage 1: Identifying the Attributes of Good Research in the Literature .....................77

3.3 Stage 2: Data Collection with the Delphi Technique for Consensus-Building ..........78

3.3.1 Number of rounds, composition, and selection of panel members ......................80

3.3.2 Instrumentation: preparation of data collection instruments ...............................82

3.3.3 Measurement of consensus and classification of agreement levels of evidence...84

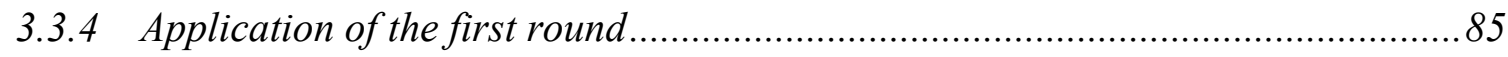

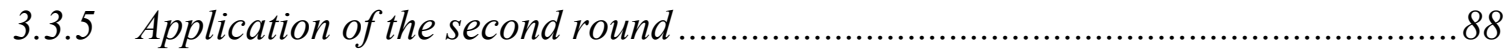

3.4 Stage 3: Comparing the Literature with the Findings............................................92

3.5 Stage 4: An Approach to Judge the Quality of the Research Process in Accounting... 


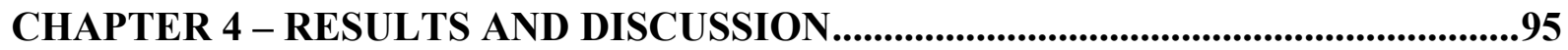

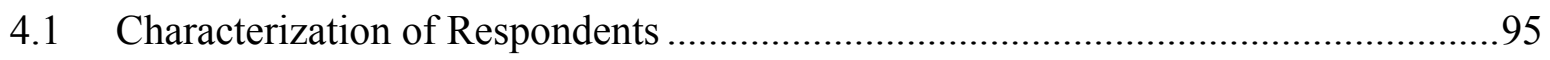

4.2 Application of the Delphi Technique ...................................................................99

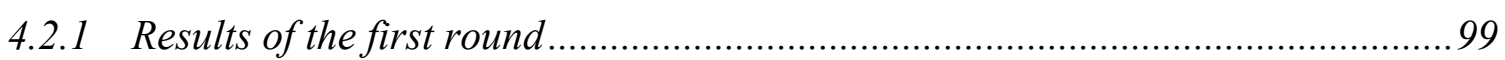

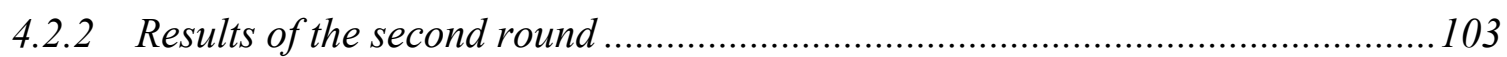

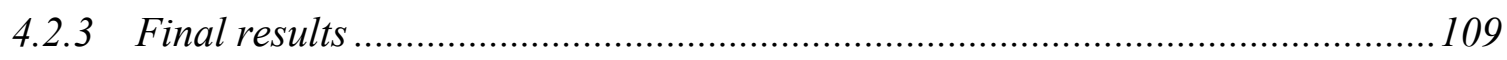

4.3 An Approach to Judging the Quality of the Research Process in Accounting .........115

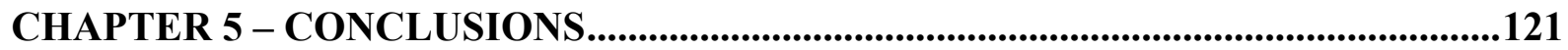

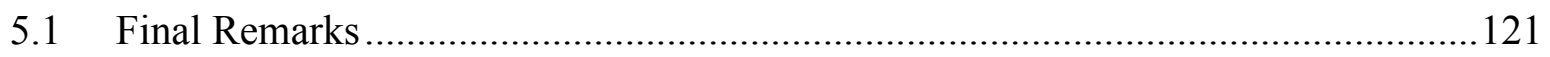

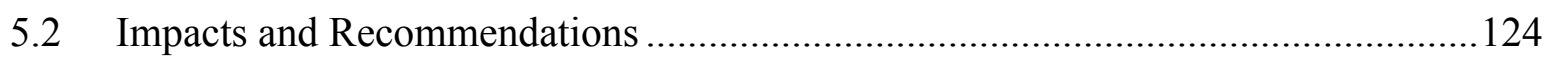

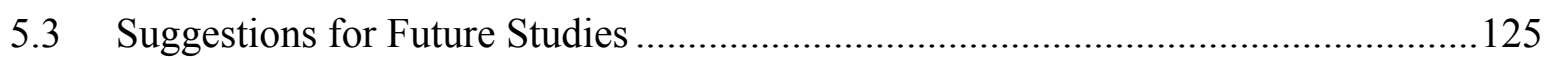

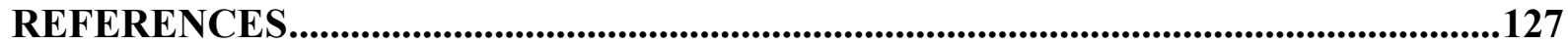

Appendix A: Matrix of Orientation for Data Collection Instruments (Delphi Online) .137

Appendix B: Matrix of Orientation for Data Collection Instruments (Delphi Online) (in Portuguese) .................................................................................................142

Appendix C: Registration with the Ethical Committee for Human Beings

(in Portuguese) ......................................................................................................147

Appendix D: List of Selected Graduate Programs (in Portuguese) .................................148

Appendix E: Invitation Letter to the Researchers (in Portuguese)..................................149

Appendix F: Invitation Letter to the Graduate Coordinators (in Portuguese) ...............150

Appendix G: Data Collection Instrument - First Round (in Portuguese).......................151

Appendix H: Informed Consent (in Portuguese) ..............................................................156

Appendix I: Invitation Letter for Delphi First Round (in Portuguese) .............................158

Appendix J: Customized Report for Experts (in Portuguese).............................................159

Appendix K: Invitation Letter - Second Round (in Portuguese) ....................................160

Appendix L: Data Collection Instrument - Second Round (in Portuguese) .....................161

Appendix M: Thank You Letter for Participating in the Delphi Panel

(in Portuguese) ............................................................................................164

Appendix N: Summary of Final Results ........................................................................165

Appendix O: Summary of Statements by Criterion, Key Feature, and Level of Agreement 


\section{CHAPTER 1 -}

The purpose of this chapter is to show a comprehensive and detailed overview of this research. The first topic provides the study's context and presents the research problem and goals. The second topic posits the study's hypotheses and the statement of the thesis to be defended. The third topic discusses the study's justifications, the research gap, and the study's expected contributions. Finally, the fourth topic acknowledges the study's limitations.

\subsection{Context, Research Problem, and Goals}

Research is an important activity at educational institutions. Research may develop and improve techniques, work strategies, and action courses in multiple fields of activity. Additionally, it is essential to both advancing knowledge and finding or framing solutions to social problems. The Belmont Report (National Institutes of Health, 1979), which establishes ethical principles for the practice of research involving human subjects, describes research as follows:

The term 'research' designates an activity designed to test an hypothesis, permit conclusions to be drawn, and thereby to develop or contribute to generalizable knowledge (expressed, for example, in theories, principles, and statements of relationships). Research is usually described in a formal protocol that sets forth an objective and a set of procedures designed to reach that objective.

This definition highlights certain features of research that every person or institution involved in research activity must consider, particularly when that research activity is conducted for the purpose of acquiring knowledge. According to the scientific view, which is presented in the Belmont Report, the production of scientific knowledge implies organized and concatenated actions that can both generate generalizable knowledge and expand the boundaries of science. Moreover, this concept could be associated with the "step-by-step" logic of knowledge building. Another definition of research is "a systematic investigation including research development, testing, and evaluation, designed to develop or contribute to generalizable knowledge" (OHRP \& DHHS, 2009). In this context, generalization relates to the researcher's intention (i.e., whether he/she intends to contribute to expanding knowledge). Both definitions are consistent with the idea of domains in scientific investigation (Brinberg \& McGrath, 1985; Brinberg, 1982), in which research is essentially a study of relations 
between units (or unit elements). These units are embedded and involve some content of interest (the substantive domain), ideas that yield meaning (the conceptual domain), and techniques and procedures by which those ideas can be studied (the methodological domain).

The institutional environment of research in Brazil sets basic productivity standards for graduate programs (Masters and Ph.D.). These patterns are consistent with the requirements of governmental agencies that provide funding and grants to researchers and institutional infrastructure for research; these requirements are established by the Brazilian Federal Agency for the Support and Evaluation of Graduate Education. On the one hand, these standards encourage scientific production in several fields; on the other, the need to reach productivity goals may reduce the quality of the knowledge produced. In other words, as a result of the eagerness to publish the results of research, the attention to scientific rigor and relevance maybe be pushed into the background. Thus, the institutional environment justifies studies that analyze the quality of scientific production and "how it is done," also known as the research process. Under this approach, the research process "is the identification, selection, combination, and use of elements and relations from the conceptual, methodological, and substantive domains" (Brinberg \& McGrath, 1985, p. 16).

Crotty (1998) argues that research planning can be based on two main questions: "First, what methodologies and methods will we be employing in the research we propose to do? Second, how do we justify this choice and use of methodologies and methods?" To do so, the research process in the context of the social sciences involves four elements: (a) methods; (b) methodology; (c) theoretical perspective; and (d) epistemology."

The order of these elements is not fixed, perhaps because philosophical (theoretical and epistemological) assumptions will typically be revealed prior to the research. Assumptions must be considered by a researcher during the planning, i.e., before the implementation and accomplishment of the research. A carefully planned research project gives the researcher more confidence about each step that he/she should follow, how to mitigate risks and limitations, and how to identify matters that can compromise feasibility. By following a plan, it becomes possible to obtain consistent outcomes that are both valid and reliable.

By adopting an international approach, some accounting studies that involve different views of accounting research might be highlighted, such as those studies involving innovation and relevance in the field (Reiter \& Williams, 2002), experimental research in financial accounting with a predictive validity framework (Libby, Bloomfield, \& Nelson, 2002), and different approaches in managerial accounting (Baxter \& Chua, 2003). Another example 
involves a survey of UK accounting and finance academics that analyzes why those academics do not publish in top American journals (Brinn, Jones, \& Pendlebury, 2001). That study analyzes respondents' perceptions to present a set of reasons for this failure to publish in such journals, including methodological and research-quality problems.

Studies on the evaluation of accounting research at international level address multiple aspects, such as productivity and quality involving university business departments (Chan, Chang, Tong, \& Zhang, 2012; M.J. Jones, Brinn, \& Pendlebury, 1996; Lowe \& Locke, 2005). Other studies address research quality criteria, such as impact (Brown \& Gardner, 1985; Carmona, 2006); relevance (Reiter \& Williams, 2002); rigor (Evans, Feng, Hoffman, Moser, $\&$ Van der Stede, 2015; Williams, 2014); and validity (Libby et al., 2002). Finally, a set of studies explores citation analysis (Brown \& Gardner, 1985; Dunbar \& Weber, 2014); and perceptions of accounting journals quality, also called peer reviews (Ballas \& Theoharakis, 2003; Brinn et al., 2001; Brown \& Huefner, 1994; Lowe \& Locke, 2005; Lowensohn \& Samelson, 2006; Taylor, 2011). Such studies, though not specifically focused on the quality attributes of good research, explore quality criteria and their relationship with productivity and quality evaluation of what is published in scientific journals in the area.

In the Brazilian environment, epistemological studies of accounting research have adopted various approaches. For example, some studies present a bibliometric perspective and address aspects of methodological paths used in theses and other publications in major journals and conferences (Mendonça Neto, Riccio, \& Sakata, 2009; Miranda, Azevedo, \& Martins, 2011; Theóphilo \& Iudícibus, 2005). Other studies address ethical issues in accounting research (Andrade, 2011; Antunes, Mendonça Neto, Oyadomari, \& Okimura, 2011), citation analysis in accounting journals (Aragão, Oliveira, \& Lima, 2014). Conversely, another study analyzes academic productivity (Martins \& Lucena, 2014), and specifically faculty productivity in Brazilian graduate accounting programs. That study investigates the profile and main scientific production practices of those programs' faculty. It highlights the issue that arises when various parts of the results from a single study are published in various papers (a practice known as "salami science"). Additionally, following rejection by journals with higher impact, researchers submit papers to less-prestigious journals until they are accepted for publication.

These studies and their issues stress that bibliometric characterization based on reports and publications is inadequate to reveal research shortcomings in the accounting field research process. Accounting research must be reflected throughout the construction and development process - from the topic choice of the investigation until submission of the 
report for scientific dissemination. Therefore, the practices that can provide those studies with both suitability and scientific character must be understood; thus, a reflection on the elements that contribute to increasing scientific quality is important in this regard. Notably, other knowledge areas, such as health (Davies \& Dodd, 2002; Kalichman \& Plemmons, 2007) and education (Hostetler, 2005) have explored the concept of good research in their investigation practices.

Good research practices are defined as rules that researchers can follow to "assure the quality, objectivity, and integrity of research data" (Shamoo \& Resnik, 2003). A good research idea is associated with choices of research strategies characterized as "fit for purpose," which means that some strategies are more appropriate than others for addressing specific research questions (Denscombe, 2010). In particular, the latter author advocates that the most important aspect of good research is that the research report shows that the choices made are reasonable and explicit.

Aiming to discuss and define research quality, Valentine (2009) argues that the answer to the question of " "what are the characteristics of a high quality study' depends in part on why the judgment is being done". Each study can have a wide range of stakeholders among whom the meaning of quality varies. The author describes quality as a fit (i.e., an adequate link) "between the study's goals and the study's design and implementation characteristics". This description might be associated both with the idea of domains (Brinberg \& McGrath, 1985; Brinberg, 1982) and with the description of the research process (Crotty, 1998). In turn, the perception of quality in accounting research has been presented from different angles. For instance, an essay published in Accounting and Finance (Clarkson, 2012) defends the notion of research quality associated with three main factors: contribution, scientific credibility, and communication. Another study (Lowe \& Locke, 2005) analyzes the association (in the perception of accounting researchers) between research paradigms and the quality of journals in the UK. Journal quality, as highlighted by these authors, has essentially been studied from two approaches: citation-based studies and perception studies based on surveys.

Based on this variety of concepts, it is understood that the attributes of good research (or research with quality) involve the entire research-building process. In other words, good research involves the foundations and adequate practices of scientific investigation to achieve the most appropriate answer to the proposed research problem. Given this context, the research question of the present study is as follows: What quality attributes can draw good research practices in the building process of scientific production in accounting? Moreover, the study is guided by two evaluation questions about research quality: Which practices are 
presented in the research production process in accounting? Which attributes can delineate the quality evaluation of these practices? The building process of scientific production in this study involves the key features or different stages (Mays \& Pope, 2006; Spencer, Ritchie, Lewis, \& Dillon, 2003) in the process of planning, execution, and outcomes evaluation in a scientific investigation (Brinberg \& McGrath, 1985).

This study aims to analyze the building process of scientific production in accounting in light of the quality attributes of good research. Additionally, as its specific goals, this study intends to do the following: (a) to identify the stages of the research process in which these attributes are revealed in the practices of Brazilian accounting researchers; (b) to compare features of the literature with those identified in accounting research practices; and (c) to present an approach based on the attributes of good research to assess the quality of scientific production in the field of accounting.

\subsection{Hypotheses}

The investigation is focused on assessing the adequacy of the following hypotheses as possible answers to the research problem:

Hypothesis 1: Current practices used in the building process of scientific production in accounting in Brazil do not fulfill the quality attributes of good research that are described in the literature;

Hypothesis 2: The Brazilian institutional environment contributes to the lesser quality of scientific production in accounting as a result of institutional failures that may impact research integrity.

It is assumed as the stated thesis that certain current practices of investigation used by Brazilian accounting researchers, combined with the local institutional environment, contribute to the lower quality scientific production in the field of accounting in Brazil.

\subsection{Justification, Gap, and Contributions}

The first subject is academic relevance. This study is justified by the importance of research production based on new approaches to and alternative views about its construction. This study can contribute to improving knowledge in accounting based on new methods of analysis. The comprehension and analysis of scientific production practices are relevant to evaluating research quality. Thus, this study can help redirect actions, redefine practical and 
methodological strategies, and facilitate access to research funding in the field by illuminating how to achieve greater acceptance of academic production by the scientific community.

The Coordination for the Improvement of Higher Level Personnel (CAPES), a Brazilian governmental foundation of the Ministry of Education, is responsible for evaluating graduate programs in Brazil. For this purpose, CAPES has a system called "Qualis" to assess journals, and "books classification" to assess books, as part of its quality evaluation. The "Qualis" system formulates a grade (denominated "stratum") by classifying each journal into scaled strata according to specific criteria based on formal features and impact. This mechanism helps classify and judge programs' scientific production during their quadrennial evaluation process.

With respect to the criteria for evaluating journals, the Area Documents for 2012 and 2013 (CAPES, 2012, 2013) have presented a set of standards to assess the scientific production of faculty members in Brazilian graduate programs in administration, accounting, and tourism that are notably based on shape criteria. However, the second document indicates that homogeneity of form has ceased to be a quality differentiating criterion for classifying journals in the Qualis/CAPES strata, as discussed in the 2012 document. This difficulty in stratification has had practical consequences for assessing the journals; In particular, it led to framing some national journals relevant to the area in a stratum higher than their classification if the established criteria were followed. According to the Area Document (CAPES, 2013), those journals' editors should make extra efforts to consolidate and include the periodical in databases that extend the impact of national production in their areas of interest. The need to find alternative and complementary ways to evaluate the quality of scientific production in graduate programs creates the opportunity to do this by evaluating aspects of the research process to increase the quality of scientific production during the stages of planning, implementing, and disseminating results.

Although CAPES is concerned with evaluating the quality of graduate programs (and to do so, also analyzes the quality of journals and books), it focuses on outcomes, i.e., publications. Thus, a gap emerges because the evaluation that uses indicators to measure and classify the scientific production of graduate programs is limited to informing programs and researchers about their failures in the research process. Therefore, it is necessary to engage in a systematic reflection about possible improvements in the process by which scientific knowledge is produced in graduate accounting programs in Brazil. The purpose of this reflection should be to offer ways to improve such practices by thinking about every step of 
the research process in an integrated manner to address planning through publication and by taking quality criteria into account.

The second aspect is that of practical relevance. Studies focused on evaluating research practices may impact the field by helping researchers to identify weaknesses, limitations, and points to consider to improve the steps and methodological choices used to develop their studies. Each stage of the research process has a set of procedures that are designed to meet best scientific practices, to improve the possibility of obtaining research funding, and to have the chance to publish studies in journals with higher impact. Additionally, the aspect of practical relevance may present an opportunity to be both more productive and more notable in the field. The expectation is that the approach presented herein may be useful to increase the acceptability of Brazilian accounting research in the research community.

Obtaining a detailed understanding of the building process of scientific production in accounting contributes to the evaluation of research quality. As a result, this understanding may aid in the self-assessment process of what is produced. This self-assessment helps generate studies with greater adherence to scientific criteria that are generally recognized in the scientific community. As an effect, studies tend to receive greater acceptance in the submission process for publication in the official channels of scientific dissemination (Godoy, 2005). Self-assessment can also help shorten the submission process because it tends to diminish the number of required revisions for acceptance in journals. Furthermore, studies that are of higher quality, that make a clear contribution and that have an impact are taken into account in resource allocation, faculty recruitment, student enrollment decisions and accreditation, among other factors (Chan et al., 2012).

As with expected impact, quality improvement of the scientific production of graduate accounting programs contributes to increasing the likelihood that papers will be published in relevant international journals. Additionally, quality improvement may create new opportunities for research funding, for collaboration in international partnerships, and for increased relevance of the country's scientific output in the international scientific community.

\subsection{Limitations of the Study}

Scientific research requires the researcher to make numerous decisions and choices in order to make the study both feasible and scientifically acceptable. Brinberg and McGrath (1985) emphasize that the research process involves three conflicting desiderata, i.e., 
generalizability, precision, and realism, and that it is up to the researcher to consider the intensity of these factors in his or her design choices and in conducting the investigation. In effect, these options lead to study limitations because it is impossible to maximize all three characteristics. In the present study, some limitations were identified:

(a) The choice of the general criteria for the researcher because there may be discrepancies in various stakeholders' assessments of them;

(b) The risk of having biases due to the number of panelists;

(c) The limitations of the technique that was chosen, such as the lack of interaction between experts, which might lead to different results;

(d) the four stakeholder groups interested in the research process (researchers, bureaucrats - development institutions and the regulator -, academic journals editors, and readers) are not adequately represented in Delphi.

To mitigate the limitations of the choice of criteria, an association was made with similar standards used by other theoretical lenses that was based on the common element of connection between them. Regarding the risk of limitations because of the number of panelists, a decision was made to invite all faculty members in Brazilian graduate accounting programs to participate in the Delphi experiment. To minimize the possible effects of the lack of interaction among the participants, data collection tools helped induce suggestions for inclusion and change to increase reliability. Finally, to minimize the lack of an adequate representation of the interested groups, it was decided to identify the experts who participated from the panel and who develop activities representing these groups and explore their representation in the sample characterization. 


\section{CHAPTER 2 -}

\section{LITERATURE REVIEW}

The purpose of this chapter is to provide an understanding of the main concepts that involve research quality. The chapter is organized into three sections. The first section presents the concepts of quality, attribute, and the research process. Additionally, it introduces the integration of the research process and scientific investigation domains (Brinberg \& McGrath, 1985). Finally, it describes some quality elements such as relevance, validity, rigor, and integrity, along with a discussion of good research practices. The second section discusses how to evaluate the quality of the research process, considering not only research traditions but also stakeholders and their interests. Complementarily, the types of studies used to judge the quality of journals, along with a debate about criteria and indicators, are also presented. The third section, which discusses the quality of accounting research, covers prior studies of accounting research quality, the role of the regulator in graduate programs, and the quality criteria used to evaluate the steps in the research process.

\subsection{What is Quality in the Research Context?}

To properly understand the purpose of this study, it is important to be clear about the meaning of its central elements: quality, attribute and the research process. In a generic sense, quality is described as an attribute, a natural condition, a property by which something or someone is individualized that distinguishes it from others. Additionally, quality is defined as a way of being, essence, or nature. It can be further defined as the degree of perfection, precision, and compliance with a particular standard (Michaelis, 2012). In scientific research, Valentine (2009) notes that the answer to the question, "What are the characteristics of a high quality study?" depends, in part, on why the judgment is being made because different stakeholders attribute different meanings to their judgments. He argues that quality refers to an adequate link between the goals of the study and the design and purpose involved in implementing the study. Regarding accounting research, Clarkson (2012) argues as follows:

Here, the notion of 'quality' speaks to the study's ability to 'inform the debate' which in turn is tied directly to three fundamental factors: (i) contribution - the importance of the study's focus and the extent of its innovation; (ii) the rigor with which the study has been conducted (scientific credibility); and (iii) the ability of the document itself to convey the study in a transparent and accessible fashion (communication). 
These elements may guide an evaluation of research quality in various fields because they represent the general attributes of good research. Similar elements are presented by Webster and Watson (2002), whose study mentions the following questions associated with each of these elements: (a) contribution ('what's new?'); (b) impact ('so what?'); (c) logic ('why so?'); and (d) thoroughness ('well done?'). The first two aspects refer to a study's 'substance': i.e., its research problem, its foundations, the identified gap, its justification, and its possible effects on a field. The study's logic is associated not only with building a theoretical framework but also with choosing a research design. The last question involves the rigor and ethical aspects associated with the conduct of the research. Another perspective based on quantitative social research (Given, 2008) involves a judgment of the quality of research in two stages, as follows:

\footnotetext{
For quantitative social researchers, given their empiricist and realist philosophical dispositions, there has been a general agreement that there is a two-stage process appropriate for judging the quality of research. First, judgments about good versus bad research are based on whether or not the researcher employed the proper methods; this judgment is then followed by a judgment as to the value of the findings in a practical and/or theoretical sense. (p. 752)
}

The concept of attribute also has a variety of meanings, including the following: (1) that which is proper and peculiar to someone or something; and (2) a condition, property, or quality of something. Grammatically, an attribute modifies a noun by expressing its quality or determination (Michaelis, 2012). In modern philosophy, attribute is used in the logicalgrammatical sense predicate (Abbagnano, 2007).

Finally, the research process is defined as "the identification, combination, and use of elements and relations of the conceptual, methodological, and substantive domains" that is divided into three stages with different perspectives on validity (Brinberg \& McGrath, 1985, p. 16). Another definition of the research process in social sciences considers philosophical aspects, notably, theoretical perspective and epistemology. Additionally, this definition includes practical elements that embrace both methods (techniques and procedures) and methodology (strategy) (Crotty, 1998). Furthermore, the research process may be described based on the following steps (or stages): findings, design, sample, data collection, analysis, and reporting (Mays \& Pope, 2006; Spencer et al., 2003).

Given these definitions, the quality attributes in the research process described in this study include a set of characteristics that demonstrate links between the object of interest, the evidence, the explanatory theory and the researcher's methodological choices. Quality can 
occur in various stages of research planning and execution, permeated by the underlying research tradition.

\subsubsection{The integration of the research process and scientific investigation domains}

A detailed understanding of the research process may have a positive effect on researchers' practices and help them develop better studies; delimiting the domains of scientific investigation represents a strategy to achieve this goal. As discussed above, Brinberg and McGrath (1985) describe research as a study of relations and present an analytical approach to the research process supported by the concept of validity in various stages of research. According the authors, "validity is not a commodity that can be purchased" but instead represents an ideal state. It is associated with "integrity, character, or quality, to be assessed relative to purposes and circumstances". This approach (or system) is called the Validity Network Schema (VNS). It is focused on the behavioral and social sciences and is organized into domains, levels, stages, and paths, with the following assumptions about each:

(1) Domains. Research involves three interrelated but analytically distinct domains: the conceptual, the methodological and the substantive.

(2) Levels. With respect to each of these domains, research involves relations between elements within an embedding system. The nature of the elements, relations, and embedding system differs among the domains.

(3) Stages. The complete research process involves three major stages, each with several paths.

(4) Validity. The concept of validity takes on fundamentally different meanings within each of the three stages.

(5) Paths. There are three alternative paths for carrying out the central stage of the research process. These paths reflect different styles of doing research and encounter different validity issues. (Brinberg \& McGrath, 1985, p. 15-16)

Brinberg and McGrath illustrate the VNS system in a scheme that involves the connections between the domains in research design and their relationships with the sets of observations and hypotheses (Figure 1). 


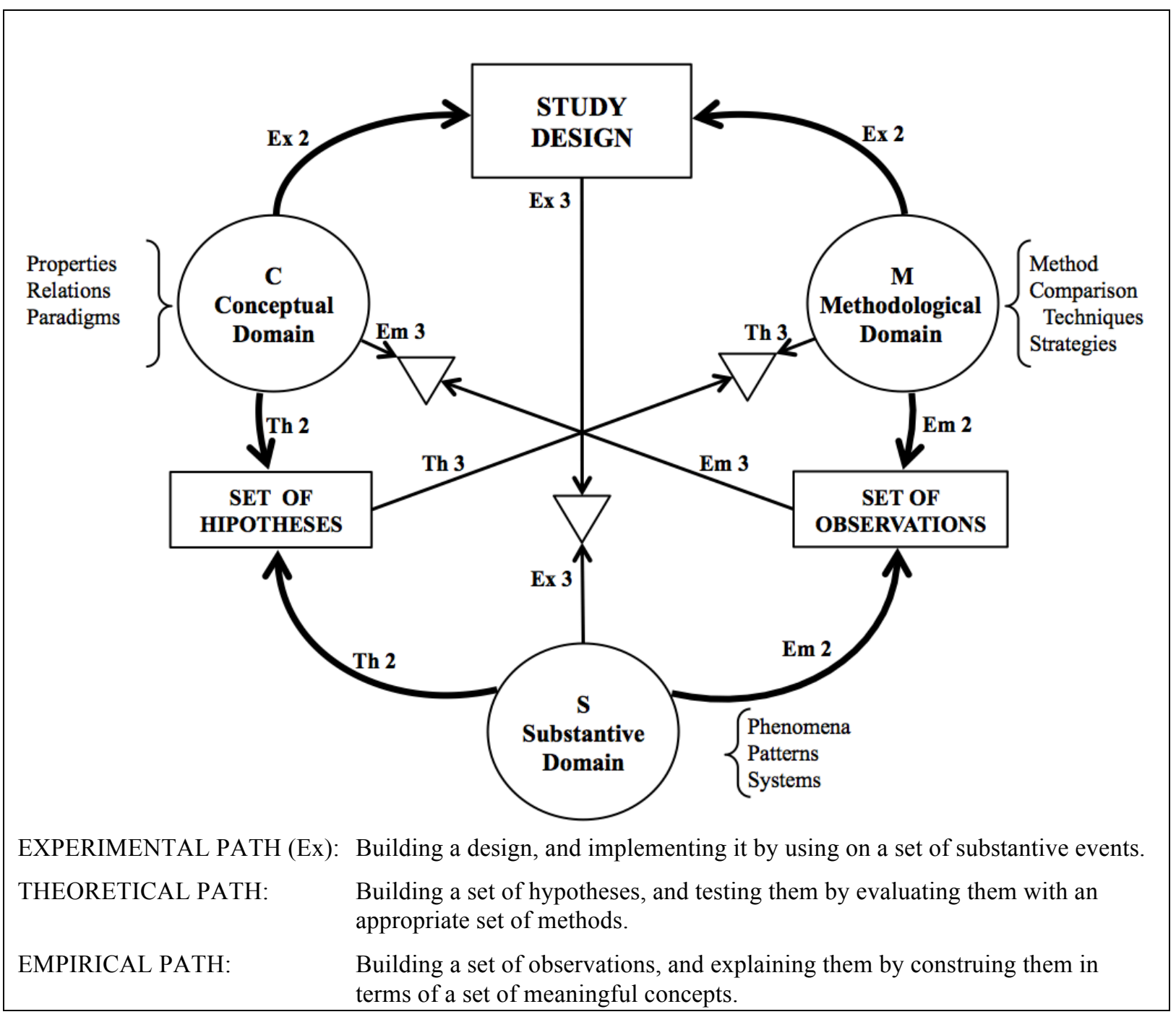

Figure 1: The VNS System: domains, levels, and paths.

Font: Brinberg and McGrath (1985, p. 22). (Adapted).

In this integrated approach, the scientific investigation contains elements and relations of three basic domains (Brinberg, 1982):

(a) The conceptual domain, which includes concepts and relations considered in an abstract way;

(b) The methodological domain, which encompasses tools and techniques for obtaining observations and correlating the set of observations; and

(c) The substantive domain, which embraces events, processes, and phenomena in the real world.

According to the authors, any research design should contain elements and relations of each one of these domains, which vary based on their central object, as summarized in Table 1. 
Table 1:

Domains and levels of the VNS

\begin{tabular}{|c|c|c|c|}
\hline \multirow{2}{*}{ Domain } & \multicolumn{3}{|c|}{ Levels } \\
\hline & Element & $\begin{array}{r}\text { Relation } \\
\end{array}$ & Embedding System \\
\hline Substantive & $\begin{array}{l}\text { Phenomena }- \text { states and } \\
\text { actions of entities (agents and } \\
\text { objects, human or } \\
\text { nonhuman). }\end{array}$ & $\begin{array}{l}\text { Patterns of phenomena - } \\
\text { relation between two or more } \\
\text { states and actions of entities; } \\
\text { the process of interest. }\end{array}$ & $\begin{array}{l}\text { Substantive systems - } \\
\text { temporal, locational and } \\
\text { situational context within } \\
\text { which entities are embedded. }\end{array}$ \\
\hline Conceptual & $\begin{array}{l}\text { Attributes or properties of } \\
\text { phenomena - ideas and } \\
\text { concepts to describe and } \\
\text { explain a phenomenon. }\end{array}$ & $\begin{array}{l}\text { Conceptual relations - } \\
\text { temporal, logical, and causal } \\
\text { pattern specified among two or } \\
\text { more concepts. }\end{array}$ & $\begin{array}{l}\text { Conceptual paradigm - the set } \\
\text { of philosophical assumptions } \\
\text { within witch the concepts and } \\
\text { their relations are embedded. }\end{array}$ \\
\hline Methodological & $\begin{array}{l}\text { Methods or modes of } \\
\text { treatment - methods for } \\
\text { measuring, manipulating, and } \\
\text { controlling variables } \\
\text { (properties of phenomena) to } \\
\text { gather information about the } \\
\text { phenomena. }\end{array}$ & $\begin{array}{l}\text { Comparison techniques }- \text { to } \\
\text { make comparison or assess } \\
\text { covariation among the } \\
\text { variables. }\end{array}$ & $\begin{array}{l}\text { Research strategies in which } \\
\text { the elements and relations are } \\
\text { embedded. }\end{array}$ \\
\hline
\end{tabular}

Source: Adapted from Brinberg and McGrath (1985).

Each domain has its own perspective. Whereas the phenomenon is the central object in the substantive domain, the conceptual domain involves identifying concepts and attributes that can contribute to an explanation of the phenomenon studied. In other words, the purpose of the conceptual domain is to identify a theory (or theoretical lens) that can underpin the analysis of the observations regarding a phenomenon. The methodological domain presents and describes the means for accomplishing the study. In essence, the connection between the object of interest (represented by the substantive domain) and the conceptual relationship, denoted by its properties (theory) leads to a set of hypotheses being generated. As a result, the set of hypotheses might explain the phenomenon. For its part, the connection between the object and the methodological domain relates to the strategies used for the systematic collection of a set of observations that are supported by the evidence and support the findings.

Brinberg and McGrath (1985) argue that the relations level is the main focus of the research process. In support of this position, they argue as follows: relations in the conceptual domain are symbolic representations (abstractions); relations in the methodological domain are procedures; and relations in the substantive domain are processes of interest. In this sense, the materials in each domain serve different functions: the conceptual domain specifies levels; the methodological domain distinguishes among levels of features of the relations; and the substantive domain displays whichever level of features of relations can occur in the "realworld" substantive system.

The VNS system presents the research process organized into three stages, and for each, the validity is addressed from a distinct perspective (Table 2). Stage One, also called the 
"Pre-study or Preparatory Stage," considers validity as value (or worth) and "involves generation, development, clarification, and evaluation of elements and relations within each one of the three domains". This stage should be performed before the two following stages and reflects the generative or constructionist paradigm in the research process.

Table 2:

The VNS system: validities and stages of the research process.

\section{Stage One: Validity as Value}

(Central tasks of the stage one: Identification, development; and clarification of

elements, relations, and embedding systems, for each of the three domains).

Domain Criteria for Evaluating Elements, Relations

Conceptual (C) Parsimony, internal consistency, subsumptive power, testability, etc.

Methodological (M) Efficiency, power, unbiasedness, explicitness, reproducibility, etc.

Substantive (S) System effectiveness, cost/benefit, feasibility, etc.

\section{Stage Two: Validity as Correspondence}

(Central tasks of stage two: selection, combination, and use of elements and relations from all three domains to produce a set of empirical findings).

\begin{tabular}{llll} 
Paths & \multicolumn{1}{c}{ Step 2 } & \multicolumn{1}{c}{ Step 3 } & Product \\
\hline Experimental $(\mathrm{Ex})$ & Study design & Implementation & A set of \\
Theoretical $(\mathrm{Th})$ & Set of hypotheses & Test of hypotheses & $\longrightarrow$ empirical findings \\
Empirical $(\mathrm{Em})$ & Set of observations & Interpretation & $\longrightarrow$ em
\end{tabular}

Stage Three: validity as Robustness

(Central tasks of stage three: verification extension; and delineation of particular stage two findings.)

Replication:

Convergence Analysis:

Are the (stage two) findings reproduced when all facets of C, M and S are kept the same?

findings hold?

Boundary search: $\quad$ Beyond what range (of values of all the facets of $\mathrm{C}, \mathrm{M}$ and $\mathrm{S}$ ) do the (stage two) findings fail to hold?

Source: Brinberg and McGrath (1985, p. 23).

According to Brinberg and McGrath (1985) Stage Two or the Central Stage consists of conducting the research, which "involves developing a set of empirical findings by combining subsets of elements and relationships of each of the three domains." It reflects the logical empiricist paradigm or hypothetical-deductive. They divide this stage into three interrelated steps:

1. Choosing the elements and relations of one of the domains, the central element of the researcher's interest;

2. Combining the elements and relations of this domain with the elements and relations of a second domain to form an intermediate or instrumental structure; and

3. Introducing the elements and relations from a third domain inside this structure to generate a set of empirical findings. 
When a researcher chooses the main domain from his/her perspective to begin a study and adds a second domain to establish the instrumental structure, he/she is choosing a particular path through which to conduct the study. For instance, there are three paths in the VNS system: experimental, empirical, and theoretical. The "experimental path" is employed when the researcher combines the methodological and conceptual domains (Step 1), which results in an instrumental structure known as study design (Step 2). In the next step, the researcher chooses a substantive phenomenon that enables the research design to be applied to produce empirical findings (implementation). Likewise, the "theoretical path" presents the combination between the conceptual and substantive domains. In turn, the "empirical path" mixes the methodological and substantive domains in the first step. Both add the third domain to reach a set of empirical findings. In summary, this stage refers to the research itself, in which the three domains are combined and the options (paths) are defined in the research design in search of results (Sakamoto, 2011), i.e., the research implementation.

Stage Three involves monitoring the Stage Two findings. Brinberg and McGrath (1985) note that this occurs "by replication and by a systematic search for both the range and the boundaries of those findings" and reflects the paradigm of credibility or generalization. The relevance of this stage is to identify the boundaries in which the study can expand knowledge - in other words, what is the study's effective contribution?

Another perspective on realizing the research process is presented in Spencer, Ritchie, Lewis, and Dillon (2003) and Mays and Pope (2006), whose framework is oriented to evaluate evidence toward nine key features and processes:

(1) findings - this characteristic is associated with judgment on elements as the credibility of the findings, how knowledge is expanded by the study, detailing the scope of inference, and the fulfillment of aims and original purposes;

(2) design - justification for research design (methodological choices);

(3) sample - criteria evaluation for the design and selection of the sample, as well as inclusion and exclusion cases;

(4) data collection - evaluation of the conduction of data collection;

(5) analysis -factors such as depth and complexity of data, choice of approach and formulation analysis, context of data sources, and diversity of perspectives;

(6) reporting - assessment of links between data, interpretations, and conclusions, as well as the overall coherence of the report;

(7) reflexivity and neutrality - clarity on the assumptions, theoretical perspectives, and values that guide the study, and care of errors and biases; 
(8) ethics - assessment of how the researcher and his team deal with ethical issues;

(9) auditability - a judgment on compliance with formal procedures and documentation of the study conducting process for future inspections.

This perspective is based on a qualitative inquiry and might be understood as another way to examine the research based on large elements (or aspects). Although findings are not described as a step of the research process, the authors argue that they should be assessed beforehand. In the next step, the authors group elements 2-6 as the various stages of the research process. Finally, although the key features do not belong to step groups, the last three key features represent the general characteristics of the conduct of research.

The research process contains three mutually incompatible desiderata: generalizability, precision and realism (Brinberg \& McGrath, 1985). For these authors, generalizability is related to the population to which the information applies; precision is related to the measurement and control of the variables involved; and realism "has to do with the contexts, or concrete behaviors system, to which that information is intended to apply." The authors highlighted the combination of these elements, producing limitations that do not emanate from the choices, preferences, or insufficient resources but that are "inherent in the research process itself." Conversely, steps and key features are judged by criteria and quality questions that will be treated as their own topic.

\subsubsection{Relevance, validity, rigor, and integrity as elements of research quality}

Research conducted in the university environment must simultaneously exhibit quality and relevance; otherwise it will not be justified. To be relevant, research must have quality; however, the converse is not true because relevance may mean different things to different people (Schwartzman, 1988). Schwartzman argues that the quality of research depends not only on a thorough knowledge of the scientific field but also on an innovative contribution. In practice, the scientific community can only measure this quality by means of its various action forums (journals, conferences, evaluation committees, etc.). Therefore, in practice, there is no quality research without adequate peer-review mechanisms. However, the relevance of research depends not only on its quality but also on its eventual applications to scientific, educational or applied purposes. Finally, Schwartzmann adds that evaluating a study's scientific relevance depends on the scientists themselves; reviews of other forms of relevance require the participation of other interested sectors. One aspect to consider is the importance of peer review as an element of research quality. In a sense, a study judged and 
accepted by evaluators who dominate the topic becomes validated in academia. For this reason, the creation of more objective criteria or principles to guide the peer review process is an important task for the scientific community.

Validity might assume a variety of concepts and meanings in the social sciences, including "convergence, correspondence, differentiation, equivalence, generality, repeatability, and some others" (Brinberg \& McGrath, 1985). However, these meanings make sense in different steps (or stages) of the research process. In the first stage, which involves planning, validity is associated with the concept of value as merit, "value," or relevance. In the second stage, when the research is executed, validity is associated with correspondence, i.e., with the internal validity of designs (for example, the internal validity proposed in experimental studies). Finally, in the third stage, whose purpose is to observe the findings, validity is considered in terms of the evidence related to the robustness of the findings. In other words, its purpose is to check, extend and delimit the earlier stage results, preceding the action proposed as part of the existing body of knowledge. In this phase, validity as robustness is consistent with external validity in experimental studies (Brinberg \& McGrath, 1985; Brinberg, 1982; McGrath \& Brinberg, 1983; Sakamoto, 2011)

Certain key elements may adequately represent rigor, which has particular importance in the following situations: (a) when the results to be evaluated are complex, difficult to observe or consist of many elements that react in various ways; (b) when the decisions that follow are significant and expensive; and (c) when evidence is required to convince others about the validity of one's conclusions (Weiss, 1997). Other characteristics involve full and faithful recording as an element of data quality and a clear account of the analytical procedure. Additionally, a study should be presented as a careful documentation of the research process that enables both auditability (audit trail) and an evaluation of the researcher's skills, which is particularly important in qualitative research (Spencer et al., 2003). To sum up, it involves good practices in data collection, analysis, and transparency. However, the perception of rigor is diverse, non-consensual, and may depend on the research method adopted by the researcher. For instance, Davies and Dodd (2002) argue as follows:

If rigour is understood only in terms of a structured, measurable, systemized, ordered, uniform and neutral approach, then other research methods, that allow flexibility, contradictions, incompleteness, or values will always appear 'sloppy', epitomizing everything that is 'nonrigour' and therefore lacking credibility (Davies \& Dodd, 2002, p. 280).

A good example to illustrate how the absence of rigor may compromise the quality of a study is presented by André (2001), who focuses on the education field; her work is based 
on previous studies in which she cites the lack of knowledge about assumptions and research methods and techniques. She notes problems in that field's research process, such as methodological weaknesses of studies and surveys resulting from their use of very reduced portions of reality. Additionally, she mentions the limited number of observations and subjects, the use of poor instruments in opinion surveys, poorly founded analyses, and interpretations without theoretical support.

Research integrity reveals a set of principles that direct researchers' actions. These principles present rules of conduct or codes of practice that people and organizations involved in scientific research should follow: (a) honesty in communication; (b) reliability in performing research; (c) objectivity; (d) impartiality and independence; (e) openness and accessibility; (f) the duty of care; (g) fairness in providing references and giving credit; and (h) responsibility to future scientists and researchers (European Science Foundation, 2011). Integrity is an important element of quality because research conducted without high ethical standards mars the quality of the findings and poses a risk to those involved. For instance, the Belmont Report (National Institutes of Health, 1979) argues that research involving human subjects must guarantee three basic principles: respect for persons, beneficence, and justice. Another perspective with respect to integrity is associated with responsive research, whose principles are honesty, accuracy, efficiency, and objectivity (Steneck, 2007). In summary, if research practices do not observe these core principles, then the research itself does not comply with the minimum requirements of honesty and quality. In a practical sense, failure to observe the principles can be evidence of research misconduct.

\subsubsection{Good research practices}

Given its subjective and evaluative character, the definition of good research is neither easy to define nor consensual. Shamoo and Resnik (2003) argue that people in leadership positions in research can play a key role in developing a culture in which ethical attitudes and good research practices prevail. These authors argue that if principal investigators, managers, companies and government agencies demonstrate and tolerate unethical attitudes and poor research practices, then those attitudes and practices will prevail. For Shamoo and Resnik, the research culture (attitudes and behaviors) sets the tone for the importance of the objectivity, quality and integrity of one's data and results. Their perception of good research practices is that such practices represent rules that researchers can follow to help ensure the quality, objectivity, and integrity of their data. 
Another view that might be helpful in comprehending the elements or attributes of good research is described as a set of managerial dimensions by Cooper and Schindler (2003): (1) clearly defined purpose; (2) detailed research process; (3) full research planning; (4) the application of high ethical standards; (5) frankly admitting evidence limitations; (6) analysis adequate to decision-makers' needs; (7) results presented in a non-ambiguous way; (8) justified conclusions; and (9) honest reflections on the research experience.

The expression "horses for courses" is used to illustrate the meaning of good social research (Denscombe, 2010). In general terms, it can be understood as the most appropriate course/path; in other words, some strategies are more suitable than others to answer certain research questions. Denscombe presents three elements to consider:

(1) Approaches are selected because they are appropriate for particular types of investigations and problems. Depending on the nature of the research problems, there are paths to be chosen that reveal themselves as more appropriate for a particular study. Such paths allow the collection of evidence that is more robust than the alternatives.

(2) "Strategic" decisions aim to place the social researcher in the best possible position to achieve the inquiry's best outcomes. The choice of the path best suited to analyze the phenomenon or object of study is intended to provide the researcher with an insider's view to obtain more appropriate results.

(3) Good research choices are (a) reasonable and (b) are an explicit part of every research report. Good research requests disclose the researcher's decisions related to paths and object analysis techniques, and those decisions are both clearly and duly justified.

The notion of good research is associated with rules that investigators can follow to help them guarantee data quality, objectivity, and integrity. To do so, it is necessary to include reasonable and explicit choices as part of every research component (Denscombe, 2010; Shamoo \& Resnik, 2003). In this context, rigor and quality exhibit a strong relationship because it is not possible to obtain high-quality research if the process is poorly executed. Thus, the Sao Paulo Research Foundation (FAPESP) ${ }^{1}$ is a governmental development institution that has published its Code of Good Scientific Practice (FAPESP, 2012a, 2012b) in order to guide researchers and institutions in the conduct of activity and scientific research, characterized as (FAPESP, 2012a):

\footnotetext{
${ }^{1}$ FAPESP is the development institution of the State of Sao Paulo, Brazil. It is one of the most significant development agencies in Brazil.
} 
Scientific activity is herein understood to be any activity that directly aims to conceive and conduct scientific research, communicate the results thereof, encourage scientific interaction among researchers and mentor or supervise researchers in training processes.

Scientific research is herein understood to be any original investigation that aims to contribute to the constitution of a science. A science is understood to be any body of rationally systematized and justified knowledge obtained through the methodical use of observation, experimentation, and reasoning. This broad definition applies to the exact, natural and human sciences, technological disciplines and disciplines usually included among the so-called humanities (p. 9).

The Scientific Director's letter presenting good scientific practices to the Foundation's board of directors (FAPESP, 2011), indicates an intention to form a solid, deep-seated culture embodying ethical integrity in research. This best-practices policy aims to achieve this goal through a series of sustained action strategies based on three interdependent foundations: (1) education; (2) prevention; and (3) fair and strict sanction and investigation. As a result, the Foundation has published an ordinance (FAPESP, 2013) to establish criteria for publicizing cases that have violated good research practices. The summaries of the first nine cases are publicly available on the Foundation's website (http://www.fapesp.br/8577).

\subsection{How Should We Evaluate Quality in the Research Process?}

People are always evaluating something. The theoretical basis of evaluation helps us understand the effects of evaluation, along with the focus that involves its various purposes. For instance, a government policy, a government program, or a nonprofit entity can be the object of evaluation. Weiss (1997) presents the concept of evaluation as follows:

Evaluation is the systematic assessment of the operation and/or the outcomes of a program or policy, compared to a set of explicit or implicit standards, as a means of contributing to the improvement of the program or policy.

Weiss (1997) adopts a general view that calls for attention to evaluation as a social practice involving two foci: process and outcome. Process describes how the program/policy is implemented. The outcome is described as an end (or result) for its audience and in this context, the concept of impact as the net effect of a program or policy on the audience is important. In an outcome evaluation, the central aspect is variance. Another method treats foci as models, e.g., the process model and the variance model (Van de Ven \& Poole, 2005; Webster \& Watson, 2002), with meanings similar to those presented by Weiss.

These highlighted keywords in the evaluation concept refer to main aspects that cover a broad comprehension of evaluation. First, a systematic assessment is related to the step-bystep building of a description of the program or policy, e.g., whether it is analyzed with a 
process or a variance evaluation. Weiss, (1997) argues that the evaluator needs must consider whether there is a constant interaction among questions, methods, and data sources.

\subsubsection{Influence of research traditions on the research process}

The literature addresses building knowledge - including scientific knowledge - based on various views. A study exploring educational research raised issues about the scientific research that may guide questions about this production based on three major points. First, what characterizes a scientific study? What is the relationship between scientific and other types of knowledge? These are questions concerning research purposes and the nature of the knowledge produced. Second, how can we judge what is good research? Who defines such criteria? These questions involve the criteria for assessing the quality of scientific work. Third, what procedures must be followed to maintain rigor in the collection and analysis of data? These questions relate to the assumptions of research methods and techniques, both in situations focusing on local issues and in situations addressing a large number of observations (André, 2001). In discussing research quality, the second and third questions are particularly important because they explore two concepts analyzed in that paper: rigor and quality of the knowledge produced.

Nevertheless, judging research quality requires that the particular assumptions and perspectives of each type of research should be considered. Thus, in a study on implementing and evaluating critical interpretive research, Pozzebon (2004) argues that the existence of different paradigms (or research traditions) leads to different ways of perceiving scientific evidence. As a result, this author posits that it is inappropriate to use the criteria of one research tradition for evaluating research quality driven by another paradigm. Nevertheless, there is no consensus on this issue, and criteria and indicators are analyzed as a stand-alone topic below.

The literature presents distinct modes of fitting studies into different paradigms (or research traditions) based on their idiosyncratic characteristics. One of the most classical modes presents four paradigms that compete in qualitative research: positivism, postpositivism, critical theory and constructivism (Guba \& Lincoln, 1994). The authors of this latter study conceptualize the paradigm as a basic belief system or worldview that guides the investigator - not only in the choice of the method but also in fundamental ontological and epistemological paths. These authors emphasize that methodological questions are secondary 
to the choice of paradigm; in other words, the paradigmatic view, including its ontology and epistemology, defines the method to be chosen to answer the research questions.

To underline the different views in each research tradition in the business field, Gephart (1999) presents another classification using three groups: positivism, interpretivism, and critical theory/postmodernism. A comparison of these groups considers the following elements: (a) assumptions; (b) key focus or ideas; (c) key theories in the paradigm; (d) key figures (main authors); (e) the goal of paradigms; (f) the nature of knowledge or the form of theory; (g) criteria for assessing research; (h) the unit of analysis; and (i) the research methods and type(s) of analysis. The study by Gephart (1999) is important because it offers criteria for judging research within each paradigm. For positivist studies, the author notes that the main aspect in this tradition is prediction = explanation, and the main criteria are rigor, internal/external validity, and reliability. Conversely, interpretivism focuses on trustworthiness and authenticity. Finally, judgment in the context of critical theory/postmodernist research is based on theoretical consistency, and the criteria include historical insights, transcendent interpretations, and change potential and mobilization.

Attempting to outline these various classifications, Rynes and Gephart (2004) summarize the research traditions didactically based on views of different elements (Table 3 ).

Table 3:

Research traditions

\begin{tabular}{|c|c|c|c|}
\hline Tradition & $\begin{array}{l}\text { Positivism and } \\
\text { Postpositivism }\end{array}$ & Interpretive Research & Critical Postmodernism \\
\hline $\begin{array}{l}\text { Assumptions } \\
\text { about reality }\end{array}$ & $\begin{array}{l}\text { Realism: Objective reality } \\
\text { that can be understood by } \\
\text { mirror of science: } \\
\text { definitive/probabilistic }\end{array}$ & $\begin{array}{l}\text { Relativism: Local } \\
\text { intersubjective realities } \\
\text { composed from subjective } \\
\text { and objective meanings: } \\
\text { represented with concepts of } \\
\text { actors }\end{array}$ & $\begin{array}{l}\text { Historical realism: } \\
\text { Material/symbolic reality } \\
\text { shaped by values and } \\
\text { crystallizes over time }\end{array}$ \\
\hline Goal & Discover truth & $\begin{array}{l}\text { Describe meanings, } \\
\text { understanding }\end{array}$ & $\begin{array}{l}\text { Uncover hidden interests and } \\
\text { contradictions: critique, } \\
\text { transformation, and } \\
\text { emancipation }\end{array}$ \\
\hline Tasks & $\begin{array}{l}\text { Undertake explanation and } \\
\text { control of variables: discern } \\
\text { verified hypotheses or } \\
\text { nonfalsified hypotheses }\end{array}$ & $\begin{array}{l}\text { Produce descriptions of } \\
\text { members' meanings and } \\
\text { definitions of situation: } \\
\text { understand reality } \\
\text { construction }\end{array}$ & $\begin{array}{l}\text { Develop structural or } \\
\text { historical insights that reveal } \\
\text { contradictions and allow } \\
\text { emancipation, spaces for } \\
\text { silenced voices }\end{array}$ \\
\hline Unit of analysis & Variable & Verbal or nonverbal action & $\begin{array}{l}\text { Contradictions, critical } \\
\text { incidents, signs and symbols }\end{array}$ \\
\hline Methods focus & $\begin{array}{l}\text { Uncover facts, compare these } \\
\text { to hypotheses or propositions }\end{array}$ & $\begin{array}{l}\text { Recover and understand } \\
\text { situated meanings, systematic } \\
\text { divergences in meaning }\end{array}$ & $\begin{array}{l}\text { Understand historical } \\
\text { evolution of meanings, } \\
\text { material practices, } \\
\text { contradictions, inequalities }\end{array}$ \\
\hline
\end{tabular}

Source: Rynes and Gephart (2004). Note: According to the authors, this table is based on Gephart (1999), Guba and Lincoln (1994), and Lincoln and Guba (2000). 
The assumptions shown in Table 3 represent the worldview of the researcher and are consistent with his/her adopted paradigm (or research tradition). The definition of paradigm is “... an integrated set of assumptions about the nature of the social world, about the character of the knowledge we can have about the social world, and about what is important to know." (Greene, 2007, p. 15). Each paradigm or research tradition brings both its respective worldview and its ontological and epistemological assumptions (Pozzebon, 2004). For that reason, the focus of research varies, as summarized by Rynes and Gephart (2004) in Table 3. For instance, in the positivist and post-positivist traditions, the variable is the main unit of analysis, and comprehension occurs when hypotheses are measured and tested (positive view), or trying to falsify them. Consequently, the likelihood obtained in the relationship between independent and dependent variables is considered an adequate measure to explain the phenomena, as it considers quantitative features, and allows generalization. Conversely, the tasks of interpretative research are directed to identify meaning and definitions (and sometimes occurrence patterns); however, generalization is less important in this worldview.

Although both positivism and post-positivism share common features, they have conceptual differences. Gephart (1999) argues that post-positivism is a recent evolution of positivism. Although post-positivism is consistent with positivism in assuming that the objective world exists, post-positivism nevertheless assumes that "the world might not be readily apprehended and that variable relations or facts might be only probabilistic, not deterministic". In this case, post-positivism focuses on falsification instead of verification, given the complexity of real-world phenomena. Whereas positivism uses experimental and quantitative methods, post-positivism attempts to include qualitative elements "to gather broader information outside of readily measured variables".

Finally, Spencer et al. (2003) compare the paradigms that consider quantitative and qualitative approaches (Table 4), although they recognize that these are labels that represent not only paradigms but also research approaches, some types of research methods, and philosophical assumptions.

Table 4:

'Quantitative' and 'qualitative' research paradigms

\begin{tabular}{ll}
\hline \multicolumn{1}{c}{ Quantitative } & \multicolumn{1}{c}{ Qualitative } \\
\hline Scientific & Naturalistic \\
Positivist & Interpretivist/hermeneutic \\
Realist & Idealistic/relativist/constructivist \\
Objectivist/materialist & Subjectivist \\
Foundational & Fallibilistic/anti-foundational \\
Experimental & Ethnographic \\
\hline
\end{tabular}

Source: Spencer et al. (2003, p. 45.) 
Given the characteristics of current accounting research in Brazil, it might be effectively argued that positivist and post-positivist traditions predominate. There are many theoretical and empirical studies involving accounting and market variables. Additionally, graduate business programs' educational model is powerfully influenced by the American model of business and accounting research, which focuses on market issues.

\subsubsection{Stakeholders and their interests}

By studying quality from the perspective of qualitative research, Flick (2009) argues it might be argued that the question about research quality (qualitative) can be addressed at four different levels involving four different groups of actors:

1. Researchers' interest in knowing why research is good or bad;

2. Development institutions' interest in assessing what should be or previously has been funded;

3. Academic journal editors' interest in deciding what and what not to publish; and

4. Readers of research guidelines' interest in which research to trust and which research not to trust.

Based on a literature review, one study has listed four stakeholder groups, which are referred to as parts of publishing process (Adler \& Liyanarachchi, 2011; Moizer, 2009): (1) editors; (2) reviewers; (3) authors; and (4) development institutions (bureaucrats). Although not explicitly mentioned, in Brazil, the graduate regulator (CAPES) might also be included in the category of bureaucrats because its policies influence research in various fields of knowledge (including administration, accounting, and tourism).

Stakeholders interested in knowledge have different aims when seeking to identify what constitutes the meritorious aspects of research, and their views are not restricted to the qualitative perspective. Beyond the particular use of each group presented by Flick, it is important to consider that stakeholders' interests are not limited to particular types of or approaches to research. However, each group may have different expectations about what to evaluate in an investigation, policy, or program (Adler \& Liyanarachchi, 2011; André, 2001; J. G. Greene, 1988; Moizer, 2009; Rossi, Lipsey, \& Freeman, 2004; Stufflebeam, 2000; Weiss, 1997; Yarbrough, Shulha, Hopson, \& Caruthers, 2011). As a result, regardless of the paradigm or predominant approach, stakeholder groups may be large and share common interests among members that belong to the above-mentioned groups (Flick, 2009; Moizer, 
2009). Even if each group's focus on judging quality is different, shared concern is possible based on assumptions adopted by these distinct worldviews (or research traditions).

Independent of the stakeholders of a study, rigor is essential to conduct research carefully to offer the best evidence that can fulfill stakeholders' particular needs, particularly concerning qualitative inquiries, in which the researcher/agent plays a key role. Research in education, for instance, has received some criticism involving the space between theory and practice (i.e., actors and researchers' roles, which are difficult to reconcile in science or intervention policy) and rigor helps address these issues (André, 2001). For André, ${ }^{2}$ there are many relevant questions that have not yet been formulated and other issues that must be discovered and/or resolved; therefore, there are many opportunities for all types of research. However, rigor requires careful systematization and data control; properly planned research work; data collection through strict procedures; and dense and well-founded analysis. The report clearly describes the methods and the results obtained. Rigor cannot be disregarded in any type of research or evaluation to diminish those risks.

With respect to its bureaucratic role as the regulatory agent, CAPES establishes policies that delineate requirements and rules to evaluate graduate programs in Brazil. For example, a minimum number of scientific production "points" (based on a scale) are required for the faculty members of graduate programs. Additionally, these policies set standards to classify faculty members' scientific production (i.e., published papers and books) (CAPES, 2012,2013 ) and to compare and evaluate the quality of graduate programs. Until 2012, this evaluation was carried out every three years, and the next evaluation will cover four years.

Two other interested groups deserve attention in the evaluation of the research process: the first consists of graduate programs, which are responsible for training new researchers and that care about assessing the quality of what is produced by its graduates and faculty. Evaluating research is one way that this group helps create high-level researchers that generate studies with high academic and social impact. The second group involves the development institutions, which are interested in determining which studies should be financed. These institutions play an important role because they provide scholarships, funds for the acquisition of research infrastructure, and resources to facilitate partnerships among institutions to increase the scope and relevance of their studies. Their role, particularly in the

\footnotetext{
2 São tantas as perguntas relevantes que ainda não foram formuladas, tantas as problemáticas que ainda precisamos conhecer, que sobram espaços para todo tipo de investigação, desde que se cuide da sistematização e controle dos dados. Que o trabalho de pesquisa seja devidamente planejado, que os dados sejam coletados mediante procedimentos rigorosos, que a análise seja densa e fundamentada e que o relatório descreva claramente o processo seguido e os resultados alcançados. (André, 2001, p. 57)
} 
Brazilian context, is important both because there is not as much governmental research funding available and because there is competition among many research fields.

In summary, research stakeholders have different interests based on their position or the group to which they belong. Just as in the evaluation practices, it is up to the researcher not only to conduct its investigations with the care necessary to offer these stakeholders consistent results but also to consider the audience during planning, executing and disseminating the results of research. These steps summarize a conception of what might be discussed when evaluating research based on an epistemological view, i.e., in monitoring its quality.

\subsubsection{Judging the research quality of journals: perception studies based on surveys and citation-based studies}

Evaluating the various stages of research is a task involving multiple stakeholders. On the one hand, development institutions are (typically) initially interested in the results of the planning phase (the project itself) that identifies criteria such as relevance, impact, and feasibility to define what should be funded. On the other, the researcher and his team are concerned with observing the quality attributes that enable them to systematically and rigorously lead the study, i.e., the execution of the research to obtain the best evidence. Finally, other stakeholders focus on evaluating the quality of the 'research product', i.e., scientific publications, which select the best studies. The academic community has used surveys of scientific community members (e.g., referees, editors, researchers) to identify their quality perceptions of certain journals and measures based on the citations of these studies (the resonance of scientific production among the peers).

Surveys that evaluate research quality based on perception assess a journal by considering the opinion of the groups that form the scientific community, which may be undertaken in many fields. For example, surveys are used to judge quality in fields such as the humanities (Hug, Ochsner, \& Daniel, 2013) and accounting (Brinn et al., 2001; Lowe \& Locke, 2005; Lowensohn \& Samelson, 2006; Northcott \& Linacre, 2010). Another method is to judge the quality of evidence using surveys as the technique for the studies' data collection (Van der Stede, Young, \& Chen, 2005). Additionally, some contextual factors affect perceptions about quality, such as the researcher's geographic origin, research orientation, and the respondent's affiliation with a journal (Ballas \& Theoharakis, 2003). Geographic origin is a factor that can explain respondents' preferences for a journal (or a set of journals) based on 
the region in which they live. As a result, American researchers have a list of "best quality" journals that is different from the list made by European researchers of their own popular periodicals. Similar results can be observed among periodicals with different research orientations or approaches (focusing on qualitative or quantitative studies, for example) or that are either specialized or generic. Finally, affiliation is relevant because researchers that publish in a journal (or who act as reviewers or members of that journal's editorial board) tend to assess that journal as having the best quality. These types of survey-based evaluations are also referred to as peer reviews.

Lowe and Locke (2005) note that citations-based studies consider the number of citations received by a journal's papers during a given period. The quantity of citations generates an Impact Factor (IF) (Amin \& Mabe, 2007; Garfield, 1972, 1999). The concept of the IF has received criticism because citations in some fields cannot be fairly measured just two years after publication, which is the time used (duration) to calculate IF (Le Pair, 1995). Nevertheless, perception studies based on surveys consider quality criteria chosen by researchers; these criteria can vary according to the research tradition in which the research is conducted. In a practical sense, it is inappropriate to use quality criteria for a specific tradition (positivism, for instance) to judge scientific knowledge constructed in a different tradition (like interpretativism) because the assumptions of the two traditions are different (Pozzebon, 2004).

Scientometrics is a field of study that uses measures and indexes to evaluate journals. It has two main applications: (1) evaluating the scientific literature for the distribution of research funds and (2) developing quality criteria to guide readers in selecting the best scientific evidence (Pinto, 2008). The first application has been widely used by development agencies and similar agencies that seek objective criteria (measures) to define which projects should be supported insofar as their financing activities are concerned. The second aims to identify the most scientifically relevant publications based on certain criteria, such as the journals' IF, published annually by the Institute for Scientific Information (ISI).

The ISI has created the Science Citation Index (SCI), which was originally presented in a study published in the early 1970s based on an analysis of approximately one million citations received by articles published in 2,200 global multidisciplinary journals in 1969 (Garfield, 1972). Thus, SCI began in order to provide periodic evaluation metrics according to their IF, which prompted researchers to submit the results of their studies to be published in the indexed journals considered the most relevant by the scientific community. Journals indexed by SCI began to have their IF calculated and reported by the ISI in the Journal 
Citation Reports (JCR) (Garfield, 1999). The graphical representation in Figure 2 summarizes the ISI IF model (Amin \& Mabe, 2007):

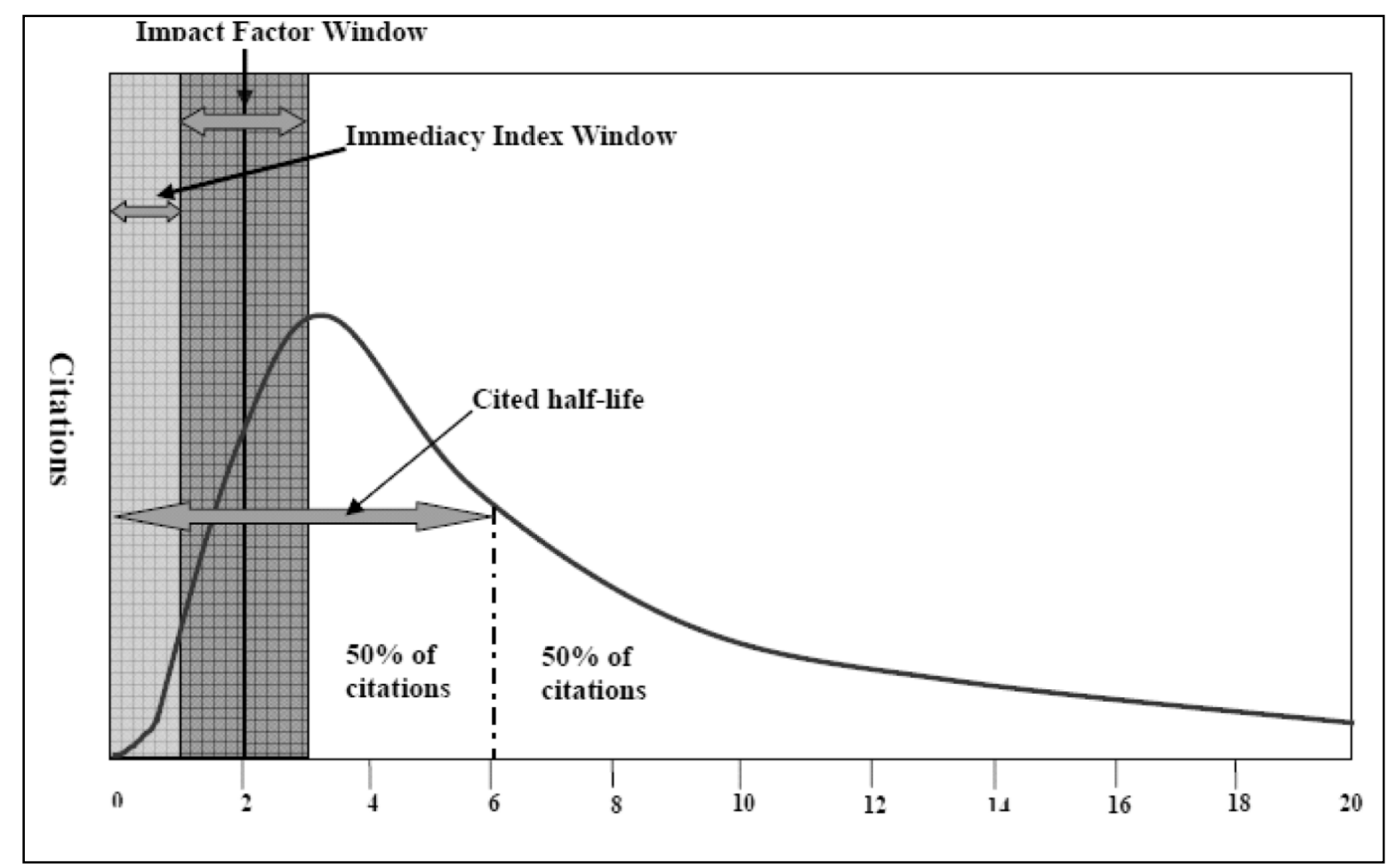

Figure 2: Generalized citation curve.

Source: Amin and Mabe (2007).

The immediacy index window is equivalent to the first year of an article's publication and is discarded in estimating the IF because it was considered too recent for the scientific community to have had access to and to use the text in subsequent studies. The Impact Factor Window considers citations received in the two years following publication; according to Amin and Mabe, this is the window during which articles receive the highest number of citations. According to the IF model, $50 \%$ of the total citations received by an article occur in the first six years after the publication, and the peak of the curve occurs at the end of the third year. Thus Garfield (1972) calculates the impact of a journal, as shown in Figure 3:

FI $($ Year 3$)=$ Total of citations received in Year 3 \# papers published in Years 1 and 2

Figure 3: Model for calculating IF. Adapted from Garfield (1972).

Nevertheless, even presenting objective criteria for judgment, the IF model has been criticized for its lack of comparability and its failure to adequately portray the characteristics of articles in some fields. For example, it is inadequate to compare journals from different 
fields because papers in areas of larger interest - which attract more researchers and readers tend to receive more citations; this does not necessarily mean that a study in such a field is of higher quality than studies in fields with few investigators and/or studies whose audience is limited (Pinto, 2008). Alternatively, Le Pair (1995) argues that although the SCI tool is interesting, the view expressed by peers as the most relevant texts differ considerably from the citation count when analyzing articles in the fields of thermonuclear research and materials science, for example. Moreover, there is a gap in the citations of applied scientific works, such as technological works, which indicates a lack of bibliometric recognition because indicators based on citations are linked to a more conventional notion of books and scientific papers as the main sources of research results. Texts produced in fields with new discoveries, such as technological research, are thus frequently not recognized by the IF. Moreover, Le Pair (1995) claims to have serious doubts about the general validity of the IF method as applied to all areas. Finally, two additional criticisms are merit highlighting: by analogy, similar situations may occur with studies considered seminal in other fields of knowledge in which most citations tend to occur after the first six years of the publication. Such works would not be adequately recognized in the FI model. Another aspect occurs when the IF is calculated only for English-language journals based on Thomson Reuters databases. In effect, there are relevant non-English language journals, which will result in similar limitations to the calculation of impact. However, the parameters used in the index do not lose their usefulness as a result of evaluation criteria based on citations by peers.

Another mechanism that assesses research quality by considering citations is the $\mathrm{H}$ Index. This measure is primarily used to evaluate researchers and reflects both numbers of publications and citations (Pinto, 2008). For example, a scientist with an H-index of 8 has published eight articles, each of which has been cited at least eight times (like a matrix). The H-index has become popular since the advent of the tool that allows us to create a researcher profile on the Google Scholar platform. Each researcher may create his/her personal profile, validate it with an institutional e-mail account, and register all of his/her publications. After it is created, the profile can be made public. The platform will periodically identify the citations of those studies and will show the H-index of the researcher in the profile automatically. The primary advantage of this platform is that it identifies citations regardless of their language. As a result, there is a quality measure with a greater range than the IF when considering the analysis of researcher productivity (Amara, Landry, \& Halilem, 2015; Amara \& Landry, 2012; Aragão et al., 2014). 
To summarize, both the IF and the H-Index are quantitative measures that are also representations of quality by presenting scientific production's resonance among peers.

\subsubsection{Criteria and indicators}

According to the definition of the Joint Committee for Standards for Educational Evaluation, a criterion is "a standard by which something can be judged." (Yarbrough et al., 2011). Another definition involves the dimension of merit, i.e., if something is valuable or not or if it is good or bad (Davidson, 2005). A third concept describes criteria as a set of standards that define acceptability (Brinberg \& McGrath, 1985, p. 41). Finally, another possibility is to refer to a 'characterizing trait' or 'a standard against which to make a judgment' (Smith, 1984, p. 383), although with certain features, these conceptions generally designate criteria as standards. However, each evaluator's judgment tends to be different based on his or her purpose. According to Weiss (1997), evaluators use different gauges in the evaluation process, and although the word "evaluation" covers judgment based on broad perspectives it is essentially focused on merit. For the author, yardsticks depend on their purpose and can be explicit or implicit, have an aesthetic approach, or can be concerned with concepts like effectiveness or efficiency. Other measures can address questions about equity and justice, along with the acceptability of community standards.

An indicator is either a gauge or a measure of a variable. In the research context, it “... is a sign of the presence or absence of the concept we're studying." (Babbie, 2010, p. 131). To apply the framework proposed by Spencer et al. for assessing the quality of qualitative research evidence, Mays and Pope (2006) emphasize that it may be possible to use “... a series of quality indicators that point to the kinds of information needed to judge whether or not the quality feature concerned has been achieved". These indicators may be associated with each appraisal question.

Concerns about criteria for evaluating scientific production arose during the nineteenth century, when social scientists began to question the traditional model of research. This model was based on classic scientific criteria such as validity, reliability and generalization (André, 2001), but social investigators believed that traditional standards could not address new research approaches, particularly because qualitative studies sought to understand human and social phenomena. Discussing quality and credibility focused on qualitative research, Patton (2002, p. 542) argues as follows: "Judging quality requires criteria. Credibility flows from those judgments. Quality and credibility are connected in that judgments of quality constitute 
the foundation of perceptions of credibility." This author then presents sets of criteria to judge research under its particular research tradition. ${ }^{3}$

There is no consensus related to which criteria are best for judging research quality. For instance, some authors argue that it is impossible to have only one set of criteria to do this in qualitative and quantitative research because of the differences involved in the conduct of these two types of research (Pozzebon, 2004; Smith, 1984; Whittemore, Chase, \& Mandle, 2001). LeCompte and Goetz (1982) defend the possibility of using common criteria for qualitative and quantitative research. To judge research quality, particularly mixed-method social inquiries, Greene (2007) proposes a classification of two challenges to inquiry quality when the researcher must choose a set of criteria to judge an inquiry based on different research traditions: (a) to guarantee the 'quality of method' and data obtained, use criteria to judge the inquiry according to its tradition; (b) to guarantee the 'quality of the inferences', which includes conclusions and data interpretations, use different sets of criteria focused on the available data. Another approach combines evaluation and research, in which evaluation is understood in a broader context to include program evaluation, policy research, and studies of practice (Patton, 2002; Spencer et al., 2003). Considering the final view, which is notably related to a study of practice, this work uses a combination of different sources to show a set of general criteria that was judged as possible to use, after taking the appraisal questions that drive the judgment of scientific evidence into account.

André (2001) argues that some broader criteria and other criteria more specific to each study group might be defined. However, building these standards should be a collective and long-term task. The broader criteria to judge scientific production can be summarized as follows: (a) studies must have scientific and social relevance, i.e., they must be inserted into a theoretical framework and contribute to current knowledge; (b) research should have a welldefined object, aims or issues that are clearly formulated, a methodology that is appropriate for its objectives, and sufficiently described and justified methodological procedures; and (c) studies should contain a dense and grounded analysis that presents statements and conclusions supported by findings and demonstrations of what it adds to current knowledge. Conversely, although the author mentions more specific criteria for ethnographic research and action research, she argues that these criteria depend on each specific approach or research strategy, which is particularly true for qualitative research that is built/developed using different paths and techniques for data collection and analysis.

\footnotetext{
${ }^{3}$ Details are available in Chapter 9 (Patton, 2002).
} 
Another study that discusses evaluation criteria highlights those that "are most relevant in five Key Evaluation Checklist (KEC) checkpoints,' including 'consumers,' 'values,' 'process evaluation,' 'outcome evaluation' and 'comparative cost-effectiveness' (Davidson, 2005). Consumers are related to the audience. Values are the main aspect of the evaluation because they represent the substantive domain or "the essence" in the VNS (Brinberg \& McGrath, 1985). Process and outcome are related to implementation and results, respectively (Webster \& Watson, 2002; Weiss, 1997). Cost-effectiveness is associated with feasibility.

The purpose of the framework for assessing research evidence (Mays \& Pope, 2006; Spencer et al., 2003) is to serve as a reference that helps evaluate the development and implementation of social policy, practices, and programs. Although the latter study is based on frameworks of qualitative research, it notes four central principles guiding proposal content that can be extended to other types of research, considering the concepts previously presented:

- Contributory in advancing wider knowledge or understanding about policy, practice, theory or a particular substantive field.

- Defensible in design by providing a research strategy that can address the evaluative questions posed.

- Rigourous in conduct through the systematic and transparent collection, analysis and interpretation of qualitative data.

- Credible in claim through offering well-founded and plausible arguments about the significance of the evidence generated. (Mays \& Pope, 2006, p. 93; Spencer et al., 2003).

Contributory and credible aspects can be understood as part of the substantive domain (Brinberg \& McGrath, 1985; Brinberg, 1982), whose perspective discusses validity such as value (or worth) in the VNS. Rigor and credibility are associated with the methodological domain of the VNS, when researchers must consider their best choices to achieve the best answers to their research questions. Rigor is an important element in the research process because it can bring scientific credibility through systematic data collection and analysis (André, 2001; Clarkson, 2012; Denscombe, 2010; National Institutes of Health, 1979). Credibility is a scientific criterion associated with peer acceptance (by scientific community members) by means of adequate peer review verifying whether specific knowledge fulfills the requirements for being considered scientific (Schwartzman, 1988).

A match among the concepts presented in the first topic of this chapter and the principles for qualitative evaluation cited by Spencer et al. (2003) might be possible. The contributory characteristic is related to relevance because of its applicability to the reality or solution of practical/theoretical problems. Rigor in conduct is directly related both to rigor 
itself and to integrity. Spencer et al. (2003) argue that defensible design includes three aspects: the logic of inquiry (clarity of the research question, a clear theoretical orientation, and a method able to generate that type of knowledge and others), the choice of particular methods and sampling (well and carefully defined). Similar to rigor, the logic of inquiry may also help collect sufficient evidence to support the claims of the research: this is an element of credibility. The framework presents 18 appraisal questions grouped into nine key features, as shown in Table 5.

Table 5:

Framework for assessing qualitative evaluations

\begin{tabular}{ll}
\hline \multicolumn{1}{c}{ Key feature } & \multicolumn{1}{c}{ Appraisal questions } \\
\hline Findings & 1. How credible are the findings? \\
2. How has knowledge/understanding been extended by the research? \\
3. How well does the evaluation address its original aims and purpose? \\
4. Scope for drawing wider inference - how well is this explained? \\
5. How clear is the basis of evaluative appraisal? \\
6. How defensible is the research design? \\
7. How well defended is the sample design/target collection of \\
Sample \\
8. Sample composition/case inclusion - how well is the eventual coverage \\
9. How well was the data collection carried out? \\
Analysis \\
10. How well has the approach to and formulation of the analysis been conveyed? \\
11. Contexts of data sources - how well are they retained portrayed? \\
12. How well has diversity of perspective and content been explored? \\
13. How well has detailed, depth and complexity (i.e. richness) of the data been \\
Reporting \\
14. How clear are the links between data, interpretation and conclusions - i.e. \\
Reflexivity and neutrality \\
15. How clear and coherent is the reporting? \\
16. How clear are the assumptions/theoretical perspectives/values that have \\
shics
\end{tabular}

Source: Spencer et al. (2003).

Although this evaluation framework clearly mentions that its scope is based on certain premises regarding the nature of qualitative research, the quality patterns presented in the 18 central questions - grouped in various stages of the research process - may be useful in any type of research to address the quality indicators used to judge research evidence.

In light of these perspectives, it is important to clarify that the present work adopts the opinion that it is possible to have a set of general standards that include some changes of labels but that judge the same central element. Based on the literature and the various frameworks, a set of more general criteria was chosen to orient the analysis of the research process in accounting, which is summarized in Table 6. 
Table 6:

Summary of general scientific criteria and their meanings

\begin{tabular}{|c|c|c|}
\hline Criterion & Meaning/summary & Sources \\
\hline $\begin{array}{l}\text { Contribution / quality of } \\
\text { theoretical perspective }\end{array}$ & $\begin{array}{l}\text { The extent to which the target } \\
\text { population might directly use the } \\
\text { findings; the extent to which the study } \\
\text { advances wider knowledge or } \\
\text { understanding about the object. }\end{array}$ & $\begin{array}{l}\text { (André, 2001; Mays \& Pope, 2006; } \\
\text { Meyrick, 2006; Spencer et al., 2003; } \\
\text { Webster \& Watson, 2002) }\end{array}$ \\
\hline $\begin{array}{l}\text { External validity or } \\
\text { generalization/fittingness }\end{array}$ & $\begin{array}{l}\text { The application of results in other } \\
\text { contexts to generalize to other } \\
\text { populations, or how well the } \\
\text { hypotheses might fit in a different } \\
\text { context from that which was } \\
\text { generated. Factor: applicability. }\end{array}$ & $\begin{array}{l}\text { (Beck, 1993; Brinberg \& McGrath, 1985; } \\
\text { Brinberg, 1982; McGrath \& Brinberg, } \\
\text { 1983; Spencer et al., 2003; Uncles \& } \\
\text { Kwok, 2013; Valentine, 2009; } \\
\text { Yarbrough et al., 2011) }\end{array}$ \\
\hline Feasibility & $\begin{array}{l}\text { The extent to which resource and other } \\
\text { factors enable an evaluation to be } \\
\text { conducted in a satisfactory manner. } \\
\text { Evaluate whether resources are }\end{array}$ & $\begin{array}{l}\text { (Campbell, Braspenning, Hutchinson, \& } \\
\text { Marshall, 2002; Davidson, 2005; Rossi et } \\
\text { al., 2004; Weiss, 1997; Yarbrough et al., } \\
\text { 2011) }\end{array}$ \\
\hline
\end{tabular}

Impact sufficient to perform the study. A change in the target population or (Carmona, 2006; Rossi et al., 2004; social conditions that has been created Stufflebeam, 2000; Webster \& Watson, by the study.

Integrity The rigor of research questions, design, conduct, and theorizing.

2002; Weiss, 1997)

(Andrade, 2011; Antunes et al., 2011; European Science Foundation, 2011; FAPESP, 2011, 2012a, 2012b; OADS, 2012)

Internal validity/credibility A measure of the significance of the or defensibility independent variable to the dependent variable, or how well and faithfully represented the phenomenon is. Factor: truth value.

Relevance The capacity of the research to help a group of practitioners solve problems. The relevance of the research depends on the potential applications for scientific, educational or applied purposes.

Reliability/auditability Measure of the instrument's (Beck, 1993; Brinberg \& McGrath, 1985; Brinberg, 1982; Libby et al., 2002; Mays \& Pope, 2006; Schwartzman, 1988; Spencer et al., 2003)

(André, 2001; Mays \& Pope, 2006; Reiter \& Williams, 2002; Schwartzman, 1988; Weiss, 1997; Yarbrough et al., 2011) consistency in obtaining similar results or the ability of another investigator to follow the audit trail.

Factor: consistency.

Rigor/thoroughness Full and faithful recording. Rich, detailed, and complex data.

(Beck, 1993; LeCompte \& Goetz, 1982;

Mays \& Pope, 2006; Rossi et al., 2004; Yarbrough et al., 2011)

(André, 2001; Denscombe, 2010; Evans et al., 2015; Mays \& Pope, 1995; National Institutes of Health, 1979; Schwartzman, 1988; Van der Stede et al., 2005; Webster \& Watson, 2002; Williams, 2014)

Suitability Choosing a strategy that will likely bring success to achieve the research objectives and that clearly and (Creswell, Klassen, Clark, \& Smith, 2011; Denscombe, 2010; Healy \& Perry, 2000) explicitly justifies its choice.

An understanding of the meaning of each of the general criteria selected for this study was formed from the various sources used. As a result, some criteria have previously been addressed in Topic 2.1.1, whereas others are presented in a brief overview as follows:

- Contribution or the quality of the theoretical perspective: this criterion is 
characterized by the identification of knowledge gaps and description of the study contribution. In addition, as highlighted by André (2001) and Brinberg and McGrath (1985), this criterion can expand knowledge in the field and may offer solutions to the target audience's problems;

- External validity/generalization (or fittingness): whereas external validity is associated with the application of results in other contexts to generalize to other populations, in a qualitative approach, fittingness is related to the possibility of perceiving how well the hypotheses can fit into a different context from that in which they were generated. In both situations, the factor is applicability (Beck, 1993). In a general sense (Spencer et al., 2003), the validity concept is linked to the idea of "accurate correspondence with reality";

- Feasibility: this criterion can be defined as "the extent to which resource and other factors allow an evaluation to be conducted in a satisfactory manner." (Yarbrough et al., 2011, p. 288). To evaluate whether a study is feasible, it is important to consider data access, available resources, the research team's skills, time constraints, and other factors that may hinder the study. As highlighted by Davidson (2005), this criterion also contains a judgment about cost-effectiveness;

- Impact: in the program evaluation, impact may be defined as "a change in the target population or social conditions that has been brought about by the program, that is, a change that would not have occurred had the program been absent." (Rossi et al., 2004, p. 232). Similarly, in the case of scientific research, impact refers to the changes that occur because of or were induced by the study's results;

- Integrity: this criterion was discussed in Topic 2.1.2;

- Internal validity (or credibility/defensibility): in quantitative studies, internal validity "measures whether or not the manipulation of the independent variable really makes a significant difference in the dependent variable." The parallel in qualitative studies is credibility, which "... measures how vivid and faithful the description of the phenomenon is" (Beck, 1993, p. 264); both have truth value as their main factor. LeCompte and Goetz (1982, p. 31) argue that "the value of scientific research is partially dependent on the ability of individual researchers to demonstrate the credibility of their findings." In a general sense, validity is defined as "the extent to which a measure actually measures what it is intended to measure" (Rossi et al., 2004, p. 232); 
- Relevance: this criterion was discussed in Topic 2.1.2;

- Reliability or auditability: reliability in quantitative research is the measure of the instrument's consistency in obtaining similar results. As a counterpoint, auditability has arisen as a measure in qualitative studies. Auditability is described as "... the ability of another investigator to follow the decision of audit trail." (Beck, 1993, p. 264). In other words, reliability is "the extent to which a measure produces the same results when used repeatedly to measure the same thing" (Rossi et al., 2004, p. 433). Another, more detailed definition is “... consistency and precision, freedom from random error" (Yarbrough et al., 2011). In these definitions, therefore, consistency is the primary factor;

- Rigor (or thoroughness): this criterion was discussed in Topic 2.1.2;

- Suitability: according to Denscombe (2010), whether a research strategy is good or bad - or right or wrong - is not a matter of definition. Suitability involves not only identifying and choosing a strategy that might bring success in achieving one's research objectives but also clearly and explicitly justifying one's strategic choices. In practice, suitability concerns how useful and how appropriate they are to solve the proposed research problem. As noted by André (2001), the central notion is to use an appropriate methodology for one's research purposes.

Another criterion is objectivity, which "requires facts capable of proof, and transparency in the handling of data" (European Science Foundation, 2011). In practice, this is part of integrity, however, there is no consensus regarding the possibility of application in different contexts and types of research. According to Spencer et al. (2003), although objectivity has been described as difficult to achieve (or as unachievable), it is reasonable. The issue addresses bias caused by one's methodology (selectivity of data, for example) or epistemology, particularly regarding certain types of qualitative inquiries that require the researcher to be immersed in the context to analyze the phenomenon, which involves a subjectivity that does not allow the separation of researcher and context. As a result, another aspect that appears is neutrality, which cannot be achieved in these types of research because of the researcher's influence. 


\subsection{Quality in Accounting Research}

Both the international literature and the Brazilian scientific literature have presented a set of studies involving features related to the quality of accounting research. As is the case with other fields of knowledge, these studies have focused on parts (or stages) of the research process, along with an analysis of the performance and productivity of university business departments. The studies that were found are also mostly based on outcomes and involve the use of metrics to evaluate quality. In Brazil, some accounting studies have focused on the methodological paths described in theses, dissertations, and other studies published in leading journals and conferences. Others have addressed the ethical issues involved in research in the area. More recently, there have been studies discussing journals' IF, along with certain aspects of research practices in graduate programs.

\subsubsection{Prior studies of research quality in business and accounting}

To identify accounting studies that address quality attributes and research practices in the field, a search was performed in databases and journals, along with the use of the Google Scholar online tool. This resource reveals important evidence about the average performance of business scholars, such as the number of contributions, citations, and the h-index is much higher when performances are assessed using Web of Science (Amara \& Landry, 2012), so, it can be considered useful to identify the best sources. The focus of the selected set of studies covers citation analysis (Aragão et al., 2014; Brown \& Gardner, 1985; Dunbar \& Weber, 2014); perceptions of the quality of accounting journals, also called peer reviews (Ballas \& Theoharakis, 2003; Brinn et al., 2001; Brown \& Huefner, 1994; Lowe \& Locke, 2005; Lowensohn \& Samelson, 2006; Taylor, 2011); productivity and quality in university business departments (Chan et al., 2012; Doyle \& Arthurs, 1995; M.J. Jones et al., 1996; Martins \& Lucena, 2014); quality criteria, such as validity (Libby et al., 2002); rigor (Evans et al., 2015; Williams, 2014); relevance (Reiter \& Williams, 2002); impact (Carmona, 2006); and integrity (Andrade, 2011; Antunes et al., 2011); and research practices and features (Martins \& Lucena, 2014; Mendonça Neto et al., 2009; Miranda et al., 2011; Taylor, 2011; Theóphilo \& Iudícibus, 2005).

One investigation has treated business schools from the United Kingdom as a research-quality case study (Doyle \& Arthurs, 1995). These authors explored citation analysis to judge aspects such as quality, excellence, and influence. Despite the good results obtained 
by the departments of these schools in the 1992 governmental evaluation known as the UK Research Assessment Exercise, it is not the same as good results based on other judgments. For instance, seven of the departments studied achieved the highest score (on a scale of 1-5), equivalent to a level of international excellence. However, their applications for research grants have met with little success. Thus, Professor George Bain of the London School of Economics was appointed to chair a commission created by the Council for Economic and Social Research. The commission's goal was to analyze the reasons for the schools' low success rate, and its report concluded that "much research has lacked the rigor and critical reflection more common in other social science disciplines. Studies have tended to be atheoretical and non-comparative" (p. 258).

Doyle and Arthurs (1995) argue that judging research quality necessarily involves differentiating research quality from the concepts of influence and international excellence. For those authors, influence "may be measured by the extent to which work is cited by others, particularly where it is cited by people from other countries" (p. 259). However, a work's international excellence might be judged based on measurements by peers from outside the country. Finally, the authors propose "to use publication in journals (and in particular, in the top journals) as a measure of international influence, where 'top' is defined by the historic tendency of such journals to be cited, so that instead of working with actual citations, we work with expected citations." To assess the performance of business schools, Doyle and Arthurs (1995) suggest two approaches: the use of experts in the field (typically departmental chairs) to rate other departments, and the use of publicly available data to measure performance. Although this suggestion is driven to evaluate performance, it might easily be applied to judge research quality, and a parallel with the types of studies used to judge journal quality (i.e., citations and surveys about perceptions) can be made.

To understand different perspectives on perceiving and analyzing the quality of accounting research, select previous studies are summarized in Table 7. 
Table 7:

Summary of previous studies of research quality in accounting

\begin{tabular}{lll}
\hline \multicolumn{1}{c}{ Reference } & \multicolumn{1}{c}{ Approach } & \multicolumn{1}{c}{ Source } \\
\hline $\begin{array}{l}\text { Brown and Gardner } \\
(1985)\end{array}$ & $\begin{array}{l}\text { Theoretical- } \\
\text { empirical }\end{array}$ & Paper in journal \\
\end{tabular}

\section{Data}

Citations of article from CAR published between 1976 and 1982 in other four journals.

Survey (367 senior faculty)
Paper in journal empirical

Brown and Huefner (1994)

Jones et al. (1996)

Theoreticalempirical

Paper in journal

Documentary

(comparing with peer review studies)

Purpose and main results (fragments)

Purpose: to assess the overall impact of major research journals on contemporary accounting research (CAR), and to identify the specific articles with the greatest impact on CAR.

Citation analysis was applied to assess the contribution of four accounting journals to CAR, and those accounting articles with the most influence in this regard were identified. The Journal of Accounting Research (JAR) exhibited the highest impact in the three periods studied: 1963-1975, 1976-1978, and 1979-1982.

Purpose: to determine the familiarity of senior faculty at Business Week's "best 40 MBA programs" with and quality perceptions of 44 accounting journals.

The findings revealed that five journals were nearly universally known, and 15 had wide recognition. Financial, managerial, and auditing faculty exhibited similar familiarity patterns, whereas tax faculty exhibited a somewhat different pattern. With respect to quality perceptions, relatively few journals were considered high quality. There was, however, general consensus across the various subject-area faculty members as to the top journals. Purpose: to contribute to and develop the discussion initiated by Doyle and Arthurs (1995) on the publishing patterns of UK academics.

The authors found that the fundamental argument of Doyle and Arthurs - that UK businessschool academics do not publish in US journals - is confirmed by peer-reviewed studies in accounting. The main reasons for this are as follows: first, British academics are networked into the UK academic community; and second, British academics work mainly with British data that are not of primary interest to Americans.

Brinn et al. (2001) Empirical Paper in journal $\begin{aligned} & \text { Survey (134 } \\ & \text { respondents }\end{aligned}$

Purpose: there are two major issues: to determine how familiar are UK academics with the top US journals and to determine what UK academics' perceptions are of the reasons for their collective failure to publish in US journals?

This paper presents eight possible reasons for UK accounting faculty's failure to publish in US journals: general explanations include (a) they do not believe they will succeed (b) they believe publishing in UK is easier; specific explanations include: (c) networking (non-US network) (d) content (non-US data); (e) existence of 'gatekeepers'; (f) methodology; (g) research quality; and (h) English and grammar.

Purpose: to present a predictive validity framework that accounts for methodological considerations regarding the efficiency and effectiveness of the experimental research design in accounting.

A discussion of the link between theory and hypotheses, the operationalization of dependent and independent variables, the choice of levels of the dependent variables and other aspects that can help the researcher choose the path of experimental research. 


\begin{tabular}{llll}
\hline \multicolumn{1}{c}{ Reference } & \multicolumn{1}{c}{ Approach } & \multicolumn{1}{c}{ Source } & Data \\
\hline $\begin{array}{l}\text { Reiter and Williams } \\
(2002)\end{array}$ & $\begin{array}{l}\text { Critical- } \\
\text { theoretical }\end{array}$ & Paper in journal & None \\
$\begin{array}{l}\text { Ballas and Theoharakis } \\
(2003)\end{array}$ & $\begin{array}{l}\text { Theoretical- } \\
\text { empirical }\end{array}$ & Paper in journal & $\begin{array}{l}\text { Survey (1,230 } \\
\text { respondents). }\end{array}$
\end{tabular}

Lowe and Locke (2005) Theoreticalempirical

Theóphilo and Iudícibus (2005) empirical

Paper in journal

Documentary study (238 articles, dissertations, and theses).

Theoreticalempirical
Paper in journal

Web-based survey (149 respondents)
Carmona (2006)

Paper in journal

Documentary $(410$ papers published in
Purpose and main results (fragments)

Purpose: to study the accounting research based on the progress view (defined as innovation and relevance).

The authors critically assessed that structural barriers lead to inadequate transformative criticism, which contributes to the lack of progress in accounting research programs.

Purpose: to examine how contextual factors such as a researcher's location and research orientation may influence perceptions regarding journal quality and readership patterns. Perceived quality was measured using four metrics: journal familiarity, average rank position, the percentage of respondents who classify a journal as top-tier, and readership. The results showed that there is significant variation in journal quality perceptions based on a researcher's geographic origin, research orientation, and journal affiliations.

Purpose: to elicit the views of academics in British accounting and finance departments regarding journal paradigm and quality.

This paper used only two paradigms for classification: functionalist/positivist and critical/interpretative. Differences in the rankings of well-known accounting journals by capital markets and finance researchers compared to researchers from all other areas were statistically significant. Additionally, there was a broad similarity in the perceived quality of the top five journals and even the top ten journals. According to the respondents' perceptions, the top five journals consist of the following: Accounting, Organizations and Society; The Accounting Review; Journal of Accounting Research; Journal of Accounting and Economics; and Contemporary Accounting Research.

Purpose: to identify and critically assess the epistemological, theoretical, methodological, and technical dimensions, manifest and latent, observed in the scientific accounting literature.

There is an assessment of empirical studies in terms of the closest approach to a scientific format. Conversely, studies have revealed difficulties in the use of certain methodological instruments, along with limited use of various methodological alternatives. the period 19901999)
Purpose: to address the roles played by publications, such as journal articles and research monographs, in disseminating accounting research.

The study concentrates on accounting history. According to the author, the data shown in this paper indicate the superiority of generalist over specialist journals in the diffusion of accounting research, question the use of journal rankings, and suggest that books and research monographs have substantial impact on the diffusion of accounting research. 


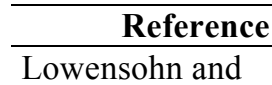

Samelson (2006)

Samelson (2006)

Theoretical-

empirical

Source

Paper in journa

Data

Survey (517 faculty Purpose: to identify top-quality research publication outlets in five specialized areas of

members of 5 areas accounting, as perceived by accounting faculty familiar with these areas.

of the American

Accounting

The five areas chosen include: accounting, behavior and organizations; American taxation

association; government and nonprofit; information systems; and management accounting.

Association - AAA) Results show that although there are multiple outlets for high-quality research in specialized fields, many of these outlets are relatively new and have been overlooked in prior studies. Additionally, accounting academics in at least two specialized areas of accounting research (government and nonprofit and information systems) may experience difficulties substantiating the quality of their research

Mendonça Neto et al. Theoretical- Paper in journal 405 papers

(2009) empirical

published in the

conference

proceedings (1996- approach was applied exclusively in $13 \%$ of them. The share of positive approaches proved to 2005)

Survey $(85$

respondents)

Andrade (2011) $\quad \begin{aligned} & \text { Theoretical } \\ & \text { empirical }\end{aligned}$

Purpose: to analyze the works presented in the 1996-2005 editions of the Meeting of the

National Association of Graduate Programs in Administration (ENANPAD).

There was a predominance of positive research in $82 \%$ of the studies, and a normative

be increasing over the period, and the data showed a low productivity of the authors based on the coefficients of the bibliometric model of the generalized Lotka's Law.

Purpose: to examine the attitudes of accounting researchers related to misconduct in accounting research.
Theoretical- Dissertation

empirical (Doctorate)

Miranda et al. (2011)

Theoretical-

empirical

Paper in journal

Antunes et al. (2011)

Theoretical-

empirical

Conference

proceedings

Survey (56

respondents)

There is evidence of accounting researchers' involvement in inappropriate practices, such as sharing study authorship with a person who did not contribute in exchange for participation in another paper to which the first author will not contribute. Additionally, authors extend section references with citations to sources that they have not read but have merely seen mentioned in other articles to bolster their credibility.

Content analysis (50 Purpose: to analyze the thesis statements of dissertations defended at the Graduate Program in dissertations) Controllership and Accounting at the University of Sao Paulo (USP) between 2004 and 2008. There is a predominance of theoretical and empirical studies that are characterized as "quasiexperiments." The dissertations presented statements of research problems and/or aims and although the hypotheses to be investigated were largely enunciated, they fall short of the desired levels of scientific criteria. It is only since 2007 that authors have begun to clearly state the thesis (statement) of their research.

Purpose: to understand how accounting academics realize the ethical aspects of research in the following dimensions: a) the research process; b) the guidance of students and c) relationships with peers and knowledge dissemination.

Although almost all the ethical issues were considered important by the respondents, the paired analysis of the differences in responses between the importance of an ethical aspect and the practice shows that revealed belief is not always consistent with the practice adopted. These results suggest that some values considered important are not practiced with the same intensity; whereas other values regarded as extremely important are intensely practiced. 


\section{Reference \\ Taylor (2011)}

Approach
$\begin{aligned} & \text { Theoretical- } \\ & \text { empirical }\end{aligned}$

Paper in journal

Research

Exercises (RAEs)

Chan et al. (2012)

Theoretical-
empirical

Paper in journal

$$
\text { empirical }
$$

Aragão et al. (2014)

Theoreticalempirical

Paper in journal related to 577 articles).

Theoreticalempirical

(2014)

Martins and Lucena (2014)
Theoreticalempirical
29,384 articles (48 period 1991-2010) journals in the

Paper in journal Citation analysis $(165,314$ citations related to 3,538 papers).

Data
Outcomes of 2008
Research

Citation analysis $(1,675$ citations

Purpose and main results (fragments)

Purpose: to investigate the extent to which the outcomes of the 2008 Research Assessment Exercise in the UK, as determined by peer review, can be explained by a set of quantitative indicators.

The study tested whether three cognate units of assessment - business and management $(\mathrm{B} \& \mathrm{M})$, economics and econometrics $(\mathrm{E} \& \mathrm{E})$ and accounting and finance $(\mathrm{A} \& \mathrm{~F})$ - are correlated with a set of quantitative indicators related to research activity. The main finding is that each of the three components of research activity (namely, research output, prestige, and research environment) is highly correlated with various quantitative indicators.

Purpose: to assess the research productivity of the accounting and finance community in Australian and New Zealand Higher Education Institutions (HEIs) using high-quality accounting and finance journals.

Australian and New Zealand HEIs publish approximately 1,658 and 299 weighted articles, representing 5.6 per cent and 1.0 per cent of the total, respectively. The HEIs' research output steadily increased during the 20 -year period. It is a challenge for academics to publish multiple articles. If an author manages five total appearances over a 20 -year period, he/she is in the top 15 percent of all authors.

Purpose: to identify which characteristics of papers published in Brazilian accounting journals are associated with their resonance in scientific production.

Associations were found between the journal, year of publication, language, and citations

received per citation vehicle; associations were also found between the language of the paper and the country of the citation. The resonance of the scientific production analyzed was considered low; data variability is related to the characteristics of the articles/journals; and the distance among the journals' IFs has decreased. Purpose: to identify individual research that have had a strong influence on contemporary accounting research.

The authors present and discuss lists of the individual works that are most heavily cited in each category (audit, financial, managerial, tax, and other) and methodological approach (archival, experimental, theoretical, and other). Papers from nine journals were analyzed.

Purpose: to identify the profile and scientific practices of professors of postgraduate programs in accounting.

There is evidence that respondents tend to separate the results of their research into different publishable parts, and when rejected from the highest-impact journals, the research is submitted to lower-impact journals until it is accepted for publication. Respondents do not, on average, name others as authors who have not participated effectively in the study. 


\begin{tabular}{|c|c|c|c|c|}
\hline Reference & Approach & Source & Data & Purpose and main results (fragments) \\
\hline Williams (2014) & Theoretical & Paper in journal & None & $\begin{array}{l}\text { Purpose: to describe two significant flaws in the claim that the prevailing form of rigorous } \\
\text { accounting research is actually as rigorous as claimed, when considered only in terms of how } \\
\text { rigor is conceived within that prevailing form. } \\
\text { The author submits a severe criticism of the supposed rigor adopted in accounting research, } \\
\text { considering that some studies apply rigor only as a rhetorical device, given the strength of the } \\
\text { adjective 'rigorous'. Most of the accounting research is predicated on the putative quantitative } \\
\text { nature of accounting data. However, accounting numbers are not particularly precise because } \\
\text { they are operational numbers, not quantities, and the likely intractability of the data problems } \\
\text { suggests that this research methodology is not the only path to accounting understanding. }\end{array}$ \\
\hline Evans et al. (2015) & Theoretical & Paper in journal & None & $\begin{array}{l}\text { Purpose: to help accounting researchers, particularly those who are less experienced, improve } \\
\text { the quality of their research and more clearly communicate how they address key issues. } \\
\text { The article presents a list of Points to Consider (PTCs) when conducting empirical accounting } \\
\text { research. PTCs are organized into the following five issues: research question, theory, } \\
\text { contribution, research design and analysis, and interpretation of results and conclusions. }\end{array}$ \\
\hline
\end{tabular}


A study on perceptions conducted a survey of 134 UK accounting and finance academics on the topic of why such scholars do not publish in top American journals (Brinn et al., 2001). That study thus addresses two major questions: (1) how familiar are UK academics with the top US journals; and (2) what are UK academics' perceptions of the reasons for their collective failure to publish in US journals. The findings revealed eight answers, which were classified by the authors as two general explanations and six specific explanations, as shown in Table 8.

Table 8:

Reasons that English articles are not published in leading American accounting journals

\begin{tabular}{|c|c|}
\hline Reason & Perception \\
\hline \multicolumn{2}{|l|}{ General } \\
\hline $\begin{array}{l}\text { Researchers believe they will not succeed } \\
\text { achieving publication }\end{array}$ & $\begin{array}{l}\text { The perception among these authors is that their articles will not } \\
\text { be published, and they do not submit papers as a result. As a } \\
\text { consequence, it becomes a self-fulfilling prophecy because if the } \\
\text { article is not submitted, it will certainly never be published. }\end{array}$ \\
\hline It is easier to publish in the United Kingdom & $\begin{array}{l}\text { British academics prefer to submit their papers to journals in the } \\
\text { UK, where they believe the chance of success is greater than in } \\
\text { the US. }\end{array}$ \\
\hline \multicolumn{2}{|r|}{ (6) } \\
\hline Networking (outside the American network) & $\begin{array}{l}\text { UK academics believe that being outside of the American } \\
\text { academic network is a major impediment to publishing in } \\
\text { American journals. }\end{array}$ \\
\hline Content & American journals are only interested in US data. \\
\hline The existence of gatekeeping & $\begin{array}{l}\text { There is a perception of gatekeeping, defined as American } \\
\text { faculty's tendency to favor submissions from the US to the } \\
\text { detriment of authors who are not from the US. }\end{array}$ \\
\hline Methodology & American journals adopt highly empirical methodologies. \\
\hline Research quality & $\begin{array}{l}\text { American journals have a higher quality differential. They are } \\
\text { more demanding and their key criterion is contribution to } \\
\text { knowledge. Additionally, Americans' academic background and } \\
\text { innovative capacity are, in general, better. }\end{array}$ \\
\hline English and grammar & $\begin{array}{l}\text { English and grammar are a major contributory factor to the lack of } \\
\text { UK success. }\end{array}$ \\
\hline
\end{tabular}

Source: Brinn et al. (2001). Adapted.

Some of these explanations are particularly interesting to a non-native speaker of English. Although UK researchers tend to be native English speakers, the English language constitutes a barrier for publishing in the US because the language that English academics use in their articles may not resonate with American English speakers, reflecting some characteristics of regional or national idiomatic usage. Another issue is that UK academics believe that American researchers' have better academic backgrounds than their own, which is a factor that contributes to the higher quality of research published in the US. To break some of these barriers, based on the results, the authors argue that some respondents "recommended collaboration with a US author as a way to circumvent the US network issue" (Brinn et al., 2001, p. 230). 


\subsubsection{Research quality in accounting graduate programs under the regulatory view in Brazil}

The CAPES Foundation, which regulates and is responsible for evaluating Brazil's graduate programs, uses metrics to judge and classify journals per strata using the Qualis system, which is the standard for assessing scientific journals in various fields of knowledge in Brazil. In the area of administration, accounting, and tourism, this process has involved the use of a set of criteria that defines the stratum in which a journal should be classified, as explained in documents pertaining to each area of study.

The content of the document from the Board of Assessment that relates to the area of administration, accounting and tourism (CAPES, 2012, p. 3) was applied to the electronic version of Qualis/CAPES (entitled "Webqualis") for journals published during the 2007-2009 period, along with Coleta CAPES data ${ }^{4}$ related to articles published in 2010. The document emphasizes that there will be discussions in the area of study to establish new quality indicators focused on journals' content; those indicators will be added to existing shape criteria. This position indicates that area members of the regulators of Brazilian graduate programs recognize the need to define evaluation criteria for paper content. Judgment is based on considerations in addition to the shape of journals, which was done in previous Qualis assessment processes.

The Area Document for administration, accounting and tourism for 2010-2012 (CAPES, 2013) demonstrates the need for greater acceptance of scholarly production. CAPES sets up projects funded by agencies or organizations that promote scientific research, and projects selected for funding through competitive processes that use peer review are particularly valued. Accordingly, CAPES indicates that the existence of projects funded by development institutions is a quality indicator for a graduate program. The resulting scientific production of funded projects tends to be understood as higher quality because the proposals for such projects were previously judged by the funding evaluators. Consequently, funding is an important criterion that indicates a program's quality.

With respect to quality criteria, the 2013 Area Document (CAPES, 2013) stressed that its evaluation of journals used the same criteria as the previous assessment, plus quality references created for the area based on previous discussions with editors. The regulator recognizes an evolution in journals during the period, but once more, it highlighted that the

\footnotetext{
${ }^{4}$ Coleta CAPES was an online platform used by graduate programs to send data about these programs to the regulator. It was replaced by the Sucupira Platform.
} 
shape's homogeneity ceased to be a differentiating criterion of quality for classifying periodicals in the Qualis/CAPES strata, as noted in 2012. According to CAPES, this evolution may be credited both to the induction process generated by previous reviews and to the National Association of Graduate and Research in Administration's (ANPAD) discussions with editors about good publication practices.

These criteria detailed in the Area Document published in 2013 were primarily based on the shape elements of the journal ${ }^{5}$ and are not focused on assessing the content of what is published. Nonetheless, some of the strata criteria for quality elements relate to content, such as peer review and IFs such as H-Scopus and JCR, which are taken into account in the classification of the superior levels (A1, A2, and B1). In this case, the number of Brazilian accounting journals in these layers is small: most such journals do not have a JCR IF because they are published in Portuguese. The area documents have indicated that content criteria should be included in the assessment process of the next three years, given the difficulty of differentiating the periodicals. Therefore, in the next quadrennial evaluation, new criteria will likely have to be defined to judge the quality of the graduate programs' scientific production.

In 2015 CAPES conducted a classification process of the area journals for the quadrennium 2013-2016, and the report was published in May of that year (CAPES, 2015b). To do so, a preliminary assessment of scientific production of graduate programs concerning 2013 and 2014 was carried out, based on data reported by the programs through Sucupira Platform. This assessment allows a projection for the quadrennium 2013-2016 from the experience of its first two years and the previous triennial evaluation. The report shows that about two-thirds of journals with Brazilian production in the area of administration, accounting, and tourism in 2013-2014 - already classified and that have impact factor - are not on the list of journals that belong to the areas of administration, business, accounting, tourism and hospitality, and public administration on the Thomson Reuters SCImago, SciELO, and Redalyc databases. Based on data, the report itself points out that it is likely that the participation of published journals outside Brazil grow in the 2013-2016 assessment, but not necessarily in journals belonging to the core of the area. This evidence suggests that

\footnotetext{
${ }^{5}$ According to the Report (CAPES, 2015b), previous evaluations were based on a list of formal parameters of quality: description of mission and focus; having defined and reported periodicity on its website; having peer review; showing submission standards; reporting name and affiliation of the editor; informing name and affiliation of the members of the editorial board; the editorial board composition should be diverse regarding the membership of its members; annually disclose of the reviewers' nomination; having at least two issues per year; reporting complete data of articles in the article itself; reporting affiliation of the authors; informing address of at least one of the authors; reporting the formalities assessment/approval; reporting the evaluation process (responsible editor, date of receipt of the article and the phases of the evaluation process and acceptance); presenting the bibliographical legend of the journal in each article; chief editor cannot be author.
} 
Brazilian researchers in the field may be having difficulty inserting their scientific production in international journals recognized as the core of the area and, therefore, choose to submit their manuscripts to journals from other areas, which tend to have less weight on the definition of quality scientific production in administration, accounting, and tourism.

The set of current evaluation criteria from Qualis/CAPES is shown in Table 9.

Table 9:

Evaluation criteria to judge journals by the Qualis/CAPES in quadrennial 2013-2016 (2015).

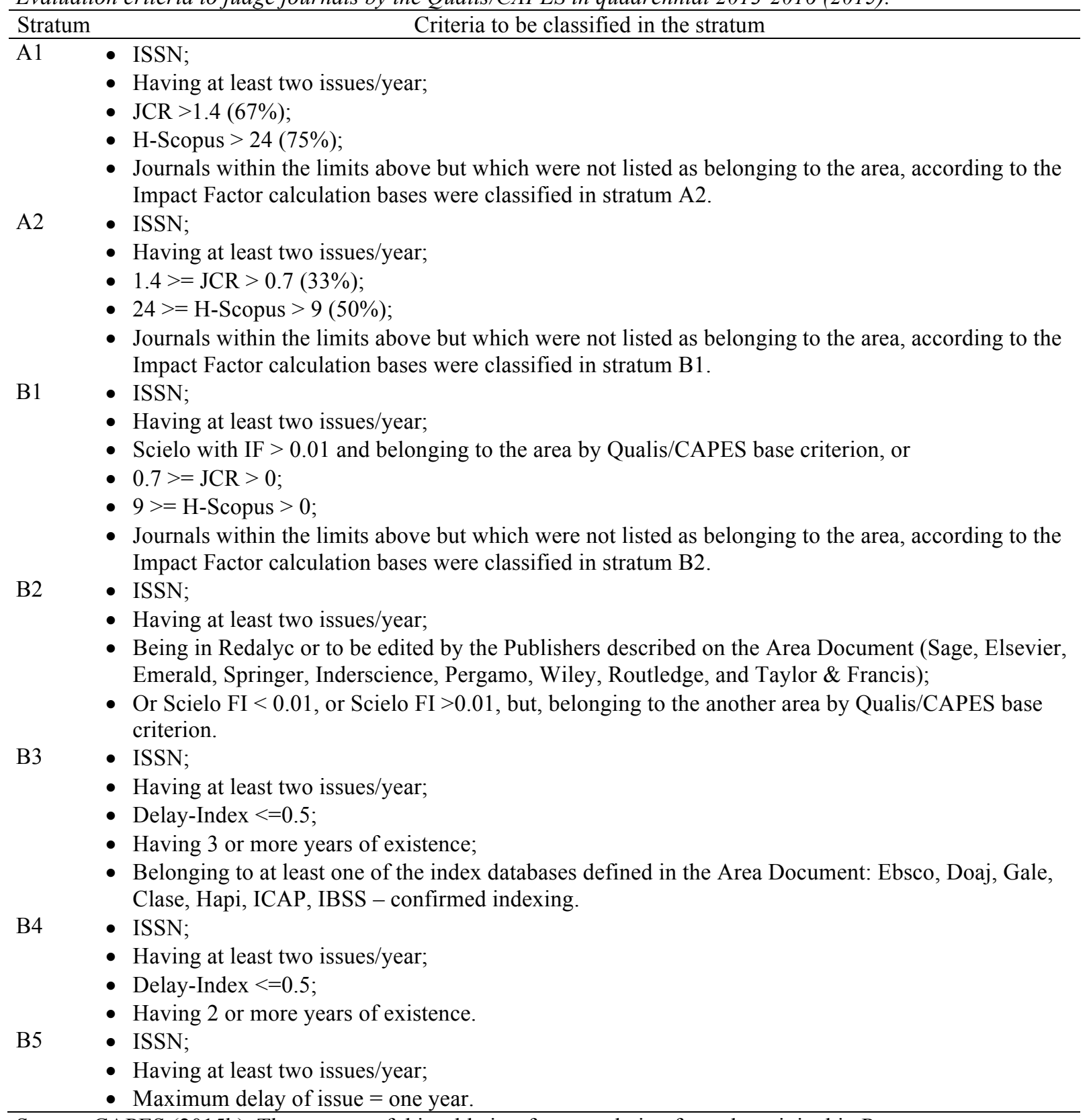
Source: CAPES (2015b). The content of this table is a free translation from the original in Portuguese.

In the Report 2015, CAPES took an important step to establish that, given the homogeneity of the compliance of formal parameters of previous evaluations, discrimination 
passes the focus on criteria that may indicate the impact and relevance of journals and supposedly - indirectly articles published by them. The upper strata were occupied by journals with impact factor calculated by one of the bases considered by the area. The classification in one of the lower strata was due to issues related to periodic management and age. Thus, only the journals with impact factor were classified as B1, a requirement that was not present in the previous evaluations. In addition, the CAPES took an action that discourages the practice of publishing in journals from other areas to establish that these journals that meet the requirements of a particular stratum will be classified at a lower level than those of the area itself. It is an important incentive mechanism for researchers to publish in their field journals to increase the visibility and relevance of the Brazilian production, as well as it improves productivity indicators to inhibit publications on low-impact journals to the area.

Unlike the triennial evaluation of graduate programs, the strata that Qualis/CAPES assigns to journals in each area have been updated at different moments: during the PPGs' assessment and, at least, once more at some time over the three/four-year period. As a result, the quality of the graduate program is influenced by the publication vehicle for the scientific production of faculty and students in the PPG and its respective stratum, after considering the publication year and the channel by which such scientific dissemination occurred.

After judging and defining the stratum for each journal, such information is used for two purposes in the evaluation: to calculate the productivity rate for each faculty member of the graduate program and to measure the quality of each graduate program, based on the journals in which the papers considered in the evaluation were published. There is a yardstick to measure the value of an article: $\mathrm{A} 1=100$ dots; $\mathrm{A} 2=80$ dots; $\mathrm{B} 1=60$ dots; $\mathrm{B} 2=50$ dots; $\mathrm{B} 3=30$ dots; $\mathrm{B} 4=20$ dots; $\mathrm{B} 5=10$ dots; and $\mathrm{C}=0$ dots. Additionally, if a paper has more than one author who is also a faculty member (co-authoring among faculty members of the same program), the dots for that article in the program evaluation are distributed evenly among the co-authors to judge the quality of the program. For example, if a paper was published in a journal whose stratum is A1 (100 dots) and the paper has three faculty members listed as co-authors, each member will be awarded 1/3 of the credit (i.e., 33 dots). Unlike the proportional distribution of the dots of co-authorship papers made to qualify the program, dots are fully allocated to assess each co-author's productivity - faculty member individually. During the period of the last triennial evaluation, each faculty member had to earn at least 150 dots.

In conclusion, it is important to note that on September 21, 2015, the CAPES Evaluation Board (DAV/CAPES) released Circular Letter nº 022/2015 (CAPES, 2015a), 
whose subject was the publication of the updated Qualis for journals for 2013 and 2014. The results are available for public access on the Sucupira platform. ${ }^{6}$ However, the next Area Document was not published until December 31; consequently, it is understood that the standards established by the previous official paper remained valid (CAPES, 2013). Notably, this is only one dimension used by the triennial/quadrennial evaluation to define program quality, in addition to other elements such as an evaluation of books published by faculty members and the quality of the program's proposal.

\subsubsection{Quality criteria and research practices in the steps of the research process (evaluation)}

After defining the list of general criteria and considering the elements presented in the Framework for Assessing Research Evidence, a matrix was built to guide the structuring of collection instruments.

First, the matrix included the list of 10 general scientific criteria selected based on the literature, as shown in Table 6. Next, the nine key features presented in the evaluation framework were added: design, sample, data collection, analysis, findings, reporting, reflexivity and neutrality, ethics, and auditability. In this dissertation, these characteristics are treated as synonyms of phases (or stages) of the research process. In the next step, the appraisal questions from the framework, as proposed by Spencer et al. (2003) and Mays and Pope (2006), have been incorporated. The key features and appraisal questions were presented in Table 5. To adequately describe the main characteristics of this study, the 'sample' label was replaced by 'research subjects' because the intention is to offer a comprehensive proposal that can help assess the various designs of and approaches to the accounting research process.

Relationships and attributes were identified in the literature to help guide the assessment at each stage of the research process, and they were then added to the array. Although the main sources to do this have been Spencer et al. (2003) and Mays and Pope (2006), a dozen other sources were considered, such as the validity schema network (Brinberg \& McGrath, 1985), points to consider (Evans et al., 2015), principles of evaluation (AEA, 2004; Yarbrough et al., 2011), and legislation regarding ethics in research using human subjects (Brasil, 2012, 2013; National Institutes of Health, 1979). Additionally, the focus of each relationship/attribute was indicated. Although the definitions of the indicators were not

\footnotetext{
${ }^{6}$ Available at: http://sucupira.capes.gov.br/sucupira/public/consultas/index_consultas.jsf.
} 
used because of their measuring characteristics, some attributes are clearly associated with those indicators.

In summary, Table 10 shows the matrix with these elements. However, an entire matrix, including VNS domains, the stages of the research process, and statements for Delphi, is presented in Appendix A (English version) and Appendix B (Portuguese version). 
Table 10:

Matrix of general criteria and their attributes/relationships

\begin{tabular}{|c|c|c|c|c|}
\hline Criterion & Key feature & Focus & Appraisal question (Spencer et al.) & Attribute/relationship \\
\hline \multirow[t]{4}{*}{$\begin{array}{l}\text { Contribution/quality of } \\
\text { theoretical perspective }\end{array}$} & Findings & $\begin{array}{l}\text { Advancement of } \\
\text { knowledge }\end{array}$ & How has knowledge/understanding been extended by the research? & Insights for thinking about the field \\
\hline & & $\begin{array}{l}\text { New areas for future } \\
\text { studies }\end{array}$ & How has knowledge/understanding been extended by the research? & New areas based on the findings \\
\hline & Reporting & Boundaries & How has knowledge/understanding been extended by the research? & Boundaries of the study \\
\hline & & Limitations & How has knowledge/understanding been extended by the research? & Disclosure of limitations \\
\hline \multirow[t]{2}{*}{$\begin{array}{l}\text { External validity or } \\
\text { generalization/fittingness }\end{array}$} & Findings & Applicability & How credible are the findings? & $\begin{array}{l}\text { Comparison of results with those of } \\
\text { other studies }\end{array}$ \\
\hline & Reporting & Scope & Scope for drawing wider inference - how well is this explained? & Explicit possibility of generalization \\
\hline \multirow[t]{3}{*}{ Feasibility } & Design & $\begin{array}{l}\text { Access to data } \\
\text { sources }\end{array}$ & How defensible is the research design? & Access to the data \\
\hline & & Audience & How defensible is the research design? & Research strategy $\mathrm{x}$ target audience \\
\hline & & Time constraints & How defensible is the research design? & Time constraints \\
\hline Impact & Reporting & $\begin{array}{l}\text { Advancement of } \\
\text { knowledge }\end{array}$ & How has knowledge/understanding been extended by the research? & Discussion of impact on knowledge \\
\hline \multirow[t]{10}{*}{ Integrity } & Data collection & Ethics & What evidence is there of attention to ethical issues? & Formal agreement from humans \\
\hline & & Ethics & What evidence is there of attention to ethical issues? & Voluntary participation of subjects \\
\hline & Analysis & Logic of inquiry & $\begin{array}{l}\text { How well has the approach to and formulation of the analysis been } \\
\text { conveyed? }\end{array}$ & Description of nature and form of data \\
\hline & Reporting & Limitations & How well does the evaluation address its original aims and purpose? & Reasons for limitations \\
\hline & $\begin{array}{l}\text { Reflexivity and } \\
\text { neutrality }\end{array}$ & Robustness & $\begin{array}{l}\text { How clear are the assumptions/ theoretical perspectives/values that } \\
\text { have shaped the form and output of the evaluation? }\end{array}$ & How to address errors and biases \\
\hline & & Robustness & $\begin{array}{l}\text { How clear are the assumptions/ theoretical perspectives/values that } \\
\text { have shaped the form and output of the evaluation? }\end{array}$ & $\begin{array}{l}\text { Impact of team participation on the } \\
\text { research }\end{array}$ \\
\hline & Ethics & Code of Ethics & What evidence is there of attention to ethical issues? & Use of the principles of an ethics code \\
\hline & & Confidentiality & What evidence is there of attention to ethical issues? & Confidentiality of participants' data \\
\hline & & $\begin{array}{l}\text { Respect for human } \\
\text { subjects }\end{array}$ & What evidence is there of attention to ethical issues? & Formal respect for human subjects \\
\hline & & & What evidence is there of attention to ethical issues? & Strategy to mitigate possible harm \\
\hline \multirow{3}{*}{$\begin{array}{l}\text { Internal validity/ } \\
\text { credibility or } \\
\text { defensibility }\end{array}$} & $\begin{array}{l}\text { Research } \\
\text { subjects }\end{array}$ & Logical coherence & $\begin{array}{l}\text { Sample composition/case inclusion - how well is the eventual } \\
\text { coverage described? }\end{array}$ & Representativeness of subjects \\
\hline & & Representativeness & $\begin{array}{l}\text { How well defended is the sample design/target collection of } \\
\text { cases/documents? }\end{array}$ & Criteria to design/select subjects \\
\hline & Findings & Logical coherence & How clear is the basis of evaluative appraisal? & $\begin{array}{l}\text { Impact from the nature of any } \\
\text { divergences }\end{array}$ \\
\hline
\end{tabular}




\begin{tabular}{|c|c|c|c|c|}
\hline Criterion & Key feature & Focus & Appraisal question (Spencer et al.) & Attribute/relationship \\
\hline & & & How credible are the findings? & Path to achieve conclusions \\
\hline & & & How well does the evaluation address its original aims and purpose? & Check links of findings $x$ purpose \\
\hline & & $\begin{array}{l}\text { Support for data and } \\
\text { evidence }\end{array}$ & How credible are the findings? & Link between findings $\mathrm{x}$ evidence \\
\hline & Reporting & Logical coherence & How clear and coherent is the reporting? & Literature review $\mathrm{x}$ main concepts \\
\hline & & & How clear and coherent is the reporting? & Theory to support propositions \\
\hline & & & $\begin{array}{l}\text { How clear are the links between data, interpretation and conclusions - } \\
\text { i.e. how well can the route to any conclusions be seen? }\end{array}$ & Appreciation of drafts by colleagues \\
\hline \multirow{3}{*}{ Relevance } & & & How well does the evaluation address its original aims and purpose? & Conclusions $\mathrm{x}$ aim \\
\hline & Analysis & Significance & $\begin{array}{l}\text { How well has detailed, depth and complexity (i.e. richness) of the data } \\
\text { been conveyed? }\end{array}$ & Significance of data to reaching goals \\
\hline & Findings & Gap & How well does the evaluation address its original aims and purpose? & Previous findings $\mathrm{x}$ hypothesis \\
\hline \multirow[t]{7}{*}{ Reliability/auditability } & Analysis & Consistency & Contexts of data sources - how well are they retained and portrayed? & Context $\mathrm{x}$ impact on data analysis \\
\hline & & & How well has diversity of perspective and content been explored? & Other views provided to explain context \\
\hline & Findings & Robustness & Scope for drawing wider inference - how well is this explained? & Does the context allow replication \\
\hline & Auditability & Consistency & How adequately has the research process been documented? & Records of the reasons for changes \\
\hline & & & How adequately has the research process been documented? & Safeguard databases for checks \\
\hline & Auditability & Methodological rigor & How adequately has the research process been documented? & Guard documents to reduce risks \\
\hline & & & How adequately has the research process been documented? & Records of design changes \\
\hline \multirow[t]{8}{*}{ Rigor/thoroughness } & Data collection & Methodological rigor & How well was the data collection carried out? & Notes for divergent events \\
\hline & & & How well was the data collection carried out? & Notes for each research step \\
\hline & Analysis & Logic of inquiry & $\begin{array}{l}\text { How well has detailed, depth and complexity (i.e. richness) of the data } \\
\text { been conveyed? }\end{array}$ & Implicit/explicit links - findings $\mathrm{x}$ aims \\
\hline & & Methodological rigor & $\begin{array}{l}\text { How well has the approach to and formulation of the analysis been } \\
\text { conveyed? }\end{array}$ & Description of tools and procedures \\
\hline & Ethics & Ethics & What evidence is there of attention to ethical issues? & Compulsory submission to the CEP \\
\hline & & & What evidence is there of attention to ethical issues? & $\begin{array}{l}\text { Registration of the study with the Ethics } \\
\text { Committee (CEP) }\end{array}$ \\
\hline & & & What evidence is there of attention to ethical issues? & Formal submission to the CEP \\
\hline & & & What evidence is there of attention to ethical issues? & $\begin{array}{l}\text { Rules for registering studies with the } \\
\text { CEP }\end{array}$ \\
\hline \multirow[t]{6}{*}{ Suitability } & Design & Appropriateness & How defensible is the research design? & Clear overview that guides the study \\
\hline & & & How defensible is the research design? & Goal/problem shown precisely \\
\hline & & & How defensible is the research design? & Overview x strategy \\
\hline & & & How defensible is the research design? & Overview $\mathrm{x}$ theory \\
\hline & & Usefulness & How defensible is the research design? & Arguments for technique choices \\
\hline & & & How defensible is the research design? & Useful strategy for purpose \\
\hline
\end{tabular}

Note: The table is ordered by criterion, key feature (or stage of the research process), and focus. 
This chapter presents the research design and discusses the tools and techniques used both to obtain the observations and to relate them to one another. Moreover, this chapter helps identify the attributes of good research and the collection of primary data to build consensus about the predicates of research practices. Furthermore, the criteria from the literature are compared with criteria determined as the consensus on research practices in Brazilian accounting research, after considering not only factors that demonstrate the links among the substantive, conceptual, and methodological domains but also key features used to evaluate the research process. Finally, an approach is presented that discusses the attributes of good research to judge the quality of scientific production in accounting at various stages of the research process. Based on that perspective, the chapter addresses the act of conducting research to obtain a set of evidence that supports its arguments carefully and logically.

\subsection{Method Choice and Steps of Research Development}

The study is based on the inductive perspective with the use of mixed methods. First, the research is quantitative, with data collection conducted by applying questionnaires using iterative queries in rounds of the Delphi Technique. The research is also qualitative and is focused on building a theoretical and conceptual approach to obtaining a more detailed understanding of quality in the process of developing good academic research based on best practices. The study is designed in the following four stages:

1. Bibliographical research to identify the attributes of good research as described in the literature;

2. Gathering primary data from accounting researchers using the Modified Delphi Technique in two rounds to build a consensus about the attributes of good research that are present in the respondents' research practices;

3. Comparing the attributes identified in the literature with those resulting from the Delphi consensus about practices in the research process, considering factors that demonstrate linking among the substantive, conceptual, and methodological domains, along with key features to evaluate the research process; and 
4. Presenting an approach that discusses the attributes of good research to help judge the quality of scientific production in accounting at various stages of the research process.

Based on the Validity Schema Network (Brinberg \& McGrath, 1985), the research design of this study is summarized in Figure 4:

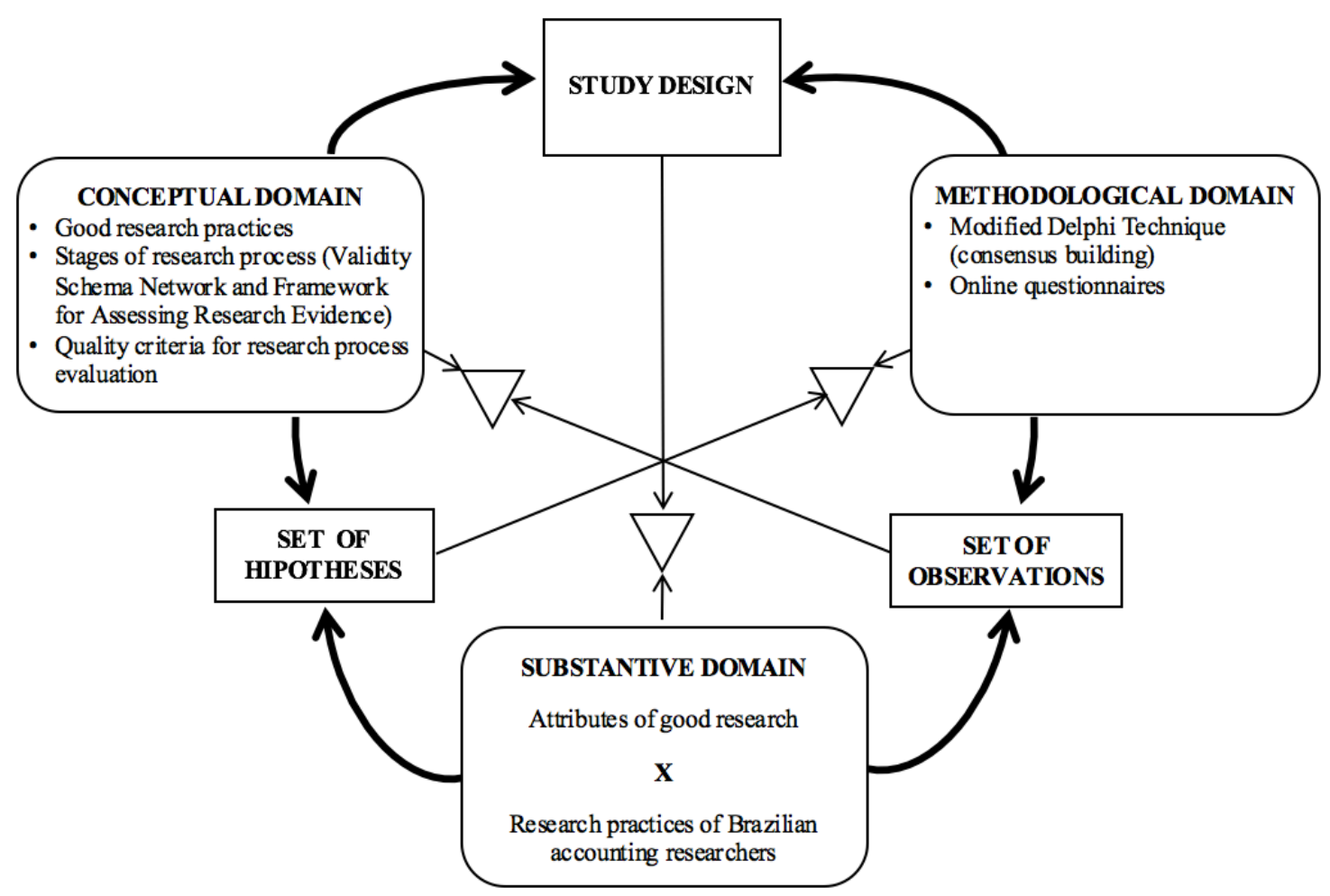

Figure 4: Summary of research design.

The research design was submitted to the Ethics Committee for Research with Human Beings at the State University of Feira de Santana (CEP/UEFS) through Plataforma Brasil (http://plataformabrasil.saude.gov.br/) ${ }^{7}$ in September 2015, and the CEP/UEFS Committee approved the design (Appendix C). The summarized version of the design and the informed consent were prepared using Resolution CNS n. 466/2012 (Brasil, 2012) and Operational Standard CNS n. 001/2013 (Brasil, 2013) complementary to that resolution; both the resolution and the standard were obtained from the Brazilian National Health Council (CNS). These legal instruments are Brazil's primary regulatory basis for research involving humans.

\footnotetext{
${ }^{7}$ Plataforma Brasil is a national platform created by the Brazilian federal government to unify the registration of research involving human beings. Research designs are submitted and evaluated through it, and a summary of each study is available for public consultation over the Internet. It covers studies registered at the local or institutional Research Ethics Committees (CEP) levels, along with at the National Research Ethics Commission (CONEP) level. The CEP/CONEP system is under the jurisdiction of the National Health Council, which is linked to the Brazilian Ministry of Health.
} 
The informed consent was written in the form of an invitation letter and presented all the information required by the Ethics Committee and current legislation regarding the study's goals, risks and benefits, guarantees of confidentiality and privacy, and other legal issues.

\subsection{Stage 1: Identifying the Attributes of Good Research in the Literature}

At this stage, the attributes of good research have been identified in the literature. Elwyn et al., (2006) have built a framework for quality criteria to assess instruments for helping patients make decisions. The authors used an initial list of quality areas proposed by an earlier study. The list was submitted for consideration by the delegates of the International Shared Decision Making Conference, which was held in Swansea (Wales) in 2003. One hundred and eighty-one delegates discussed the validity and created a list of 12 broad "quality domains," which the authors used as the basis for their study, grouping the statements from a data collection instrument designed to apply the Delphi methodology. According to the researchers, 80 criteria were included for evaluation by respondents. That paper served as the reference for developing the data collection instrument.

The purpose of this stage was to find elements to create the instrument to apply in the first round of the Delphi. The focus was an attempt to identify relationships that might be useful to understanding respondents' perceptions regarding the quality attributes of research practices. To do so, an orientation matrix for building the instrument (Appendixes A and B) was made based on the theoretical platform. Initially, the stages of the research process and the domains of scientific research (Brinberg \& McGrath, 1985) were inserted into the matrix. Next, matching was performed for the nine key characteristics (here regarded as synonymous of stages) of the research process (Mays \& Pope, 2006; Spencer et al., 2003). The nine key features include findings, design, sample, data collection, analysis, reporting, reflexibility and neutrality, ethics, and auditability. In this manner, the appraisal questions for assessing research evidence were introduced, and each issue was split into its respective quality indicators (Spencer et al., 2003) and the quality criteria (or attributes) identified in the literature. Wider criteria were associated with relationships and more specific criteria to give the study more of a practical sense. Finally, based on these indicators, criteria, and relations, the propositions were elaborated to compose the data collection instrument.

The data collection tool was written in Portuguese and the propositions were grouped into those nine essential features, with some modifications, considering the nature of this 
study. The findings were changed to the fifth position, and the 'sample' label was replaced by 'subjects of research.'

\subsection{Stage 2: Data Collection with the Delphi Technique for Consensus-Building}

The Delphi technique is defined as a set of iterative procedures applied to a nonattendance group to obtain the consensus opinion on an issue or a set of issues for which there are insufficient or contradictory data (Justo, 2005). The Delphi technique for consensusbuilding is used to achieve a convergence of opinion. In the medical field, the Delphi technique is used to build frameworks and guidelines in studies to choose the best clinic criteria for a particular disease (Graham, Regehr, \& Wright, 2003), or to identify risk factors associated with a particular illness (Deckers et al., 2015). Additionally, it is used to build evaluation frameworks for judging quality criteria (Elwyn et al., 2006). It is also used in other fields such as the humanities (Hug et al., 2013), food (Kim, O’Bryan, Crandall, Ricke, \& Neal, 2013) and accounting (Michael John Jones \& Xiao, 2004).

Graham et al., (2003) summarize some of the advantages of using the Delphi technique for consensus-building that are described in the literature:

(1) Not having to gather participants in person increases the feasibility and significantly reduces the cost;

(2) There are less likely to be constraints on the group's size or composition because participants can be recruited from various geographical locations;

(3) The group's consensus reliability for the question being analyzed improves as the number of panel members increases. It is easier to achieve an appropriate panel size for the issue at hand because of the inherent feasibility of the Delphi process;

(4) "The anonymous nature of the exercise ensures that a single influential participant will not have a disproportionate impact on the outcome of the group, as can occur with other group processes.” (p. 1.150).

By contrast, Graham et al., (2003) also present criticisms of the use of Delphi technique from the literature:

(1) It is "subject to bias because the investigator limits the scope of the issue assessed by the panelists." Consequently, the issue in question is at least partially controlled by the researcher, and the consensus can thus be somewhat distorted;

(2) Panelists do not meet, as they do in other group processes that depend on interaction among participants as a source of new insights into a problem; 
(3) "[D]ue to the nature of Delphi, no discussion takes place, and any consensus that the group appears to have developed can only derive from information provided to it by the investigator," and the consensus reached in other types of group processes may thus be significantly different; and

(4) Criteria have not been established to determine whether group consensus was reached (p. 1,151).

To mitigate the risks of possible biases in applying the technique, this study's strategy for drawing up a data collection instrument involved an optional open field for suggestions and comments on the propositions and on the tool itself. While participants were responding, they could comment on attributes described in the literature. Additionally, they were invited to highlight points considered relevant in research practice that either were not mentioned or were unclear during the first-round statements.

Tetzlaff, Moher, and Chan, (2012), from the Clinical Epidemiology Program of the Ottawa Hospital Research Institute, drew up a consensus-forming survey using the Delphi Technique to develop a guideline for creating a clinical study protocol. The panel consisted of 96 specialists, including trial investigators, methodologists, research ethics board members, funders, industry, regulators, and journal editors. The response rate was between 88 and $93 \%$ in each round.

Skulmoski, Graham, and Krahn, (2007) present a flowchart of planning and conducting research using the Delphi Technique over three rounds (Figure 5).

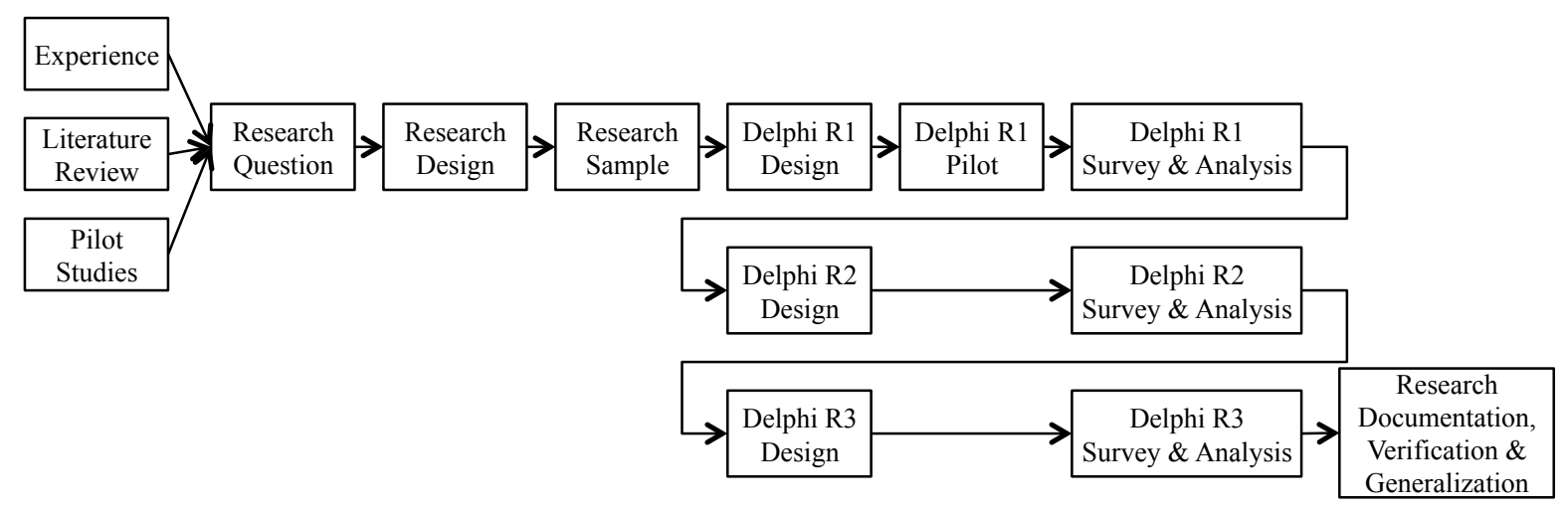

Figure 5:

Three round Delphi process

Source: Skulmoski, Hartman \& Krahn (2007, p. 3).

The flowchart (Figure 5) helped define the steps taken in this work. Kelbaugh (2003) uses the modified Delphi Technique to obtain consensus on identifying the success factors of teamwork in extension programs. According to Kelbaugh, in the classic Delphi, the first 
round of the research is open and allows each participant to provide a single entry. The ideas and items so generated are then used to develop the next phase of the research. The modified technique is so named because the researcher creates the first-round propositions based on an exhaustive literature review and his or her experience in the subject area. To do this, Kelbaugh (2003) uses an intentional sample. The expert panel featured 25 extension professors from American universities financed from governmental land concessions (called "land grant" institutions). The experts took part in three rounds. The areas of the studied extension program include agriculture and natural resources, family and consumer sciences, youth and community and economic development. Kelbaugh (2003) also indicates that the modified Delphi was used in the first round of statements and the survey used a 6-point Likert scale. The study was conducted using a Web-based survey instrument, which enables quick answers and the ability to analyze the data in real time.

The online Delphi Technique is appropriate in the context of this study for enabling the collection of various individuals' attitudes and opinions. The Delphi facilitates the involvement of people from different geographical regions because in-person participation is not required. Moreover, the use of the Internet makes the Delphi Technique low-cost and feasible. These features further allow the sample size to be increased without many resources.

\subsubsection{Number of rounds, composition, and selection of panel members}

In the literature, there is no consensus on the numbers of rounds and members needed to form a Delphi. To analyze the diversity of sample size and the number of rounds in the application of the technique, Skulmoski et al., (2007) identify 16 articles published between 1973 and 2005. Nine of those articles are in the field of information systems/technology information, and seven are not. There were between one and three rounds in these studies, and the sample size ranged from 3-171 participants. In turn, Graham et al., (2003) use the technique in two rounds, with 14 participants in the first round and 12 in the second round. Elwyn et al., (2006) construct an assessment framework to evaluate patient decision aids with the use of a consensus-building, two-round Delphi. Overall, 212 members were invited to join the panel, 122 of whom participated in the first round, and 104 of whom participated in the second round. To ensure a balance (equal weight) among the four groups of represented stakeholders, the authors obtained a weighted average for each cluster by calculating the cumulative distribution function of each subset. 
The reality in accounting studies is the same, and there is variation in the number of members surveyed. Worrell, Di Gangi, and Bush, (2013) summarize 16 studies in the area of accounting information systems that used the Delphi technique and were published between 1987 and 2011. They were between 9 and 83 participants in those studies and the number of rounds was not analyzed. In Brazil, Cunha (2007) conducted a study with doctors of accounting that included 15 members and lasted three rounds.

Based on the literature (Adler \& Liyanarachchi, 2011; Moizer, 2009), there were identified four stakeholder groups, referred to in terms of their roles in the publishing process: (1) publishers; (2) referees; (3) authors; and (4) funding institutions (the bureaucrats). These activities were considered for purposes of identifying the respondents' profiles. Considering that there are researchers involved in all these activities, the experts panel from the faculty of Brazilian graduate programs in accounting was chosen because many of the researchers who belong to these programs frequently perform the above-mentioned activities. Preliminarily, the study was designed to have three rounds.

The information-gathering process to form the list of invited participants included the following steps:

(a) The CAPES website was accessed to identify Graduate Academic Programs (PPGs) in accounting, as recognized/recommended by the regulator. Given their characteristics, professional programs ${ }^{8}$ were disregarded. This process identified 23 academic programs in accounting (Appendix D), labeled in Brazil as programs in accounting science, accounting, or controllership (September 2015);

(b) Searches on the Plataforma Sucupira/CAPES (http://sucupira.capes.gov.br/) were undertaken to identify all the faculty members of the selected programs (September 2015). Three hundred and twenty-seven participants in these PPGs, including both permanent and collaborating professors, were identified. Visiting professors were excluded because of the temporality of the bond in the program (sometimes those professors are foreign specialists who teach a short-term class and do not maintain a constant presence in the program). Eight duplicates were found (bonds with more than one PPG), along with the present study's advisor. Both were excluded from the list, paring the research subjects down to 318 specialists;

\footnotetext{
${ }^{8}$ In Brazil, there are Professional Masters programs, but they are less academic and more technological in nature. For example, although theses in these programs can follow the traditional model, they can also be a process, piece of software, product, etc., with a focus on innovation. In this study, only the academic programs, awarding Master of Science and Doctor of Science (Ph.D.) degrees, were considered.
} 
(c) Each researcher's email address was identified from the official website of the applicable graduate program. Alternatively, when that information was unavailable, an attempt was made to find it on the institutional website of the academic unit (department or college) to which the professor is connected. When these attempts failed, an attempt was made to find the e-mail address in recently published journal articles authored by the researchers, using the Google Scholar tool (http://scholar.google.com).

After identifying the e-mail addresses, an invitation letter (Appendix E) was e-mailed to the 318 researchers. An answer was requested within 11 days, which was extended by another five days via a reminder e-mail. To increase the possibility of securing a larger number of respondents, the coordinator of the University of Sao Paulo's graduate program in accounting kindly sent an email to the managers of the other 22 academic graduate programs in accounting at the advisor's request (Appendix F). The faculty members in those programs were selected to comprise the list of participants, and the purpose of the message was to ask the coordinators to encourage them to participate in the expert Delphi panel. After the messages, 74 people responded positively, confirming their willingness to participate on the experts' panel. Only respondents to this initial message received the second e-mail with instructions for participation in the first round. Considering their experience, it is important to observe that participants may or may not be senior researchers.

\subsubsection{Instrumentation: preparation of data collection instruments}

Preparation of the data collection instrument for the first round was performed by organizing the propositions in key features presented in the theoretical platform. According to the foundations of the Delphi Technique, the data collection instrument was made available electronically and the answers were controlled by the researcher. Because the first round's questionnaire was built beforehand based on the literature, this study can be considered to have used the modified Delphi Technique.

Studies present various scales of measurement for the data collection instruments, such as a six-point Likert scale (Kelbaugh, 2003) or a 1-10 numerical scale (Rodríguez-Mañas et al., 2013; Tetzlaff et al., 2012). Other studies combine various metrics - such as the percentage of respondents who agreed with a certain element in the first round - with note assignment on a numerical scale in subsequent rounds (Cunha, 2007). Elwyn et al. (2006) use a 9-point scale (1 to 9) for the panelists to assess a set of 80 criteria regarding quality 
judgment. For this study, the numeric layover of 10 points (1-10) was chosen in light of the belief that it might be more efficient to assess the propositions quantitatively. The instruments from the other rounds derive from the first round and include new elements that might have emerged from the experts' suggestions.

A pre-test of the tool for the first round was performed to identify possible inconsistencies that might hinder the understanding of the propositions. The pre-test step was performed by submitting a preliminary version to be evaluated by five people: $3 \mathrm{Ph} . \mathrm{D}$. students in Accounting, 1 Ph.D. in Accounting, and 1 Ph.D. in Education, who made many comments to improve the inquiry. The questionnaire was available electronically on the online SurveyMonkey platform (http://www.surveymonkey.com). As a result, the instrument was fixed/adjusted and prepared to receive the respondents' answer online.

The final version of the first round's instrument was written entirely in Portuguese (Appendix G), with 53 statements (distributed in nine key categories) and 14 questions used to characterize the respondents. Additionally, there was one open space for comments and suggestions. The first round was electronically organized into 5 pages as follows:

- First page: informed consent (Appendix H);

- Second page: propositions regarding research design, research subjects, and data collection;

- Third page: propositions regarding data analysis, findings, and reporting;

- Fourth page: propositions regarding reflexivity and neutrality, ethical issues, and auditability; and

- Fifth page: questions that characterize the respondents and one free space (open question) for comments and suggestions regarding the research (optional).

Cronbach's alpha was calculated using the statistical package SPSS, version 23, to measure the reliability of the instrument based on the cases and items (propositions) of the first round. The results show that the instrument achieved a Cronbach's alpha level of $92.2 \%$, which is important evidence of reliability. Only the open question had an optional answer in the instrument.

The second instrument was based on the first, but with fewer statements (28 propositions) distributed over 3 pages, including the informed consent and the open space for comments. Although a three-round Delphi Technique has been proposed in the design, the results showed that it was not necessary to apply the third round because a saturation of the standard deviation of the propositions was identified between rounds one and two. 


\subsubsection{Measurement of consensus and classification of agreement levels of evidence}

The literature demonstrates various ways to measure consensus using the Delphi Technique, such as the frequency of answers to the most important items, the score (Deckers et al., 2015), median (Tetzlaff et al., 2012), 'equimedian' rates per expert group, differences between groups (F and p-value) (Elwyn et al., 2006), mean and consensus level (\%) (Jones \& Xiao, 2004; Kim et al., 2013), and score, mean, median, and variation coefficient (Cunha, 2007). Other examples include when " $80 \%$ of the ratings fell within two categories on the sixpoint Likert-type scale" (Kelbaugh, 2003, p. 153), and the percentage of answers rated $\geq 8$ or $\leq 3$ on a 10-point scale (Rodríguez-Mañas et al., 2013).

There are also various possibilities with respect to the classification of criteria into agreement levels. An example shows that one way to sort the results in terms of agreement or disagreement is to use labels such as "strong agreement ( $>80 \%$ of answers rated $\geq 8$ or $\leq 3$ ), moderate agreement $(70 \%-80 \%)$, low agreement $(50 \%-70 \%)$, and no agreement $(<50 \%)$ " (Rodríguez-Mañas et al., 2013, p. 63). Another model considered that "participants 'disagreed' if $30 \%$ or more of the ratings were in the lower third (ratings $1-3$ ) and $30 \%$ or more of the ratings were in the upper third (ratings 7-9)" on a 9-point scale (Elwyn et al., 2006, p. 3). These authors regarded "quality criteria with an overall equimedian rating of 7 to 9 (without disagreement) as 'important' and included them". Additionally, they considered "criteria rated as 4 to 6 (without disagreement) to be 'equivocal' and criteria rated with an equimedian of 1 to 3 as "not important'." (p. 3).

Based on these examples, some rules were established first to determine which statements individually could be considered to demonstrate consensus and then to choose the propositions for the next round:

- $75 \%$ or more of the respondents scored the proposition with grades of 1-3 or 8-10 (strong agreement);

- $25 \%$ or more of the respondents scored the proposition with grades of $1-3$ (disagreement);

- Variation of standard deviations $\leq 25 \%$ between rounds.

These percentages were chosen because they involve equal intervals in the statistical quartiles, representing a more careful consideration than the use of arbitrarily defined rates.

Considering the criteria for the classification of the results by levels (RodríguezMañas et al., 2013), an adjustment was made in the bands to line up with the $75 \%$ figure that 
had been chosen to characterize the previously defined consensus. Next, rules were created to group the final results using the percentage of the final score, as shown in Table 11.

Table 11:

Criteria for classifying the statements in accordance with agreement levels.

\begin{tabular}{lll}
\hline \multicolumn{1}{c}{ Rodríguez-Mañas et al. (2013) } & \multicolumn{1}{c}{ Adjusted model } & \multicolumn{1}{c}{ Agreement level } \\
\hline$>80 \%$ of answers rated $\geq 8$ or $\leq 3$ & $>75 \%$ of answers rated $\geq 8$ or $\leq 3$ & Strong agreement \\
$70 \%-80 \%$ & $65 \%-75 \%$ & Moderate agreement \\
$50 \%-70 \%$ & $50 \%-65 \%$ & Low agreement \\
$<50 \%$ & $<50 \%$ & No agreement \\
\hline
\end{tabular}

Sources: Rodríguez-Mañas et al. (2013), and adapted by the author.

The percentage of the final score was calculated based on the ratio of the sum of the grades obtained and the maximum possible score (number of responses multiplied by 10). For example, if a proposition had 41 valid answers, the maximum score is 410 because 10 is the highest score on the 10-point scale used by the data collection instrument. Supposing that the total score of that proposition is 380 , the percentage obtained is $92.68 \%(380 / 410)$.

\subsubsection{Application of the first round}

Before beginning data collection, the present study generated a password and 74 customized codes for the participants who had confirmed their availability. Each respondent's code was sent in the same individual e-mail that contained the password (Appendix I). The code definition was generated using an alphanumeric pattern that followed the model "delphiXXX"; the final three digits were a logical numerical combination to mitigate the risks of possible participation by another respondent whose data entry was incorrect (i.e., an interleaved - as opposed to an exact - sequence). In practice, in addition to allowing answers to be linked among the three rounds, the respondent code worked as a new password because it was specific to each participant. In the event of an error that would not permit the linkage of responses to a given member throughout all the stages, that member's answer was assessed to decide whether to discard it, thus avoiding any compromise of the quality of the Delphi in the final round. Control over the respondent's codes was the personal task of the researcher in charge, who made a restricted-access spreadsheet (with a PIN) to preserve the confidentiality and privacy of that information.

When visiting the Internet address/link provided by e-mail to begin the first round (http://pt.surveymonkey.com/r/QualiPPGCCFEAUSP), the expert was required by the opening screen to complete the password field, as shown in Figure 6: 
yMonkey Inc. [US] https://pt.surveymonkey.com/r/QualiPPGCCFEAUSP

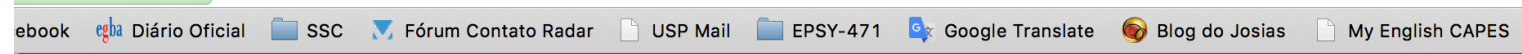

Qualidade no processo de produção científica em Ciências Contábeis no Brasil

Esta pesquisa exige uma senha.

Caso não saiba a senha, entre em contato com o autor da pesquisa para obter mais ajuda pelo e-mail jrsena@usp.br.

Digite a senha

Envie a senha

Figure 6: Initial screen to access the data collection instrument.

Source: data collection instrument on the SurveyMonkey.

The password for access, along with the customized respondent's code, had been sent through individual e-mails to each faculty member who responded positively regarding his or her availability to participate on the Delphi expert panel. After inserting the password, the first page of the collection instrument, which contained the informed consent form, was opened (Figure 7).

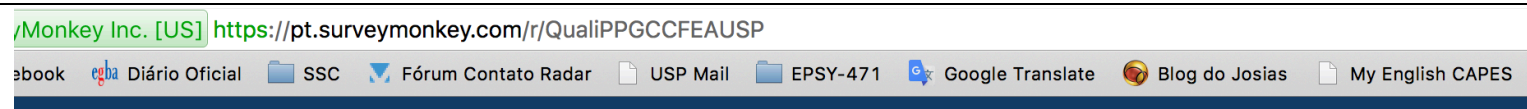
Qualidade no processo de produção cientifica em Ciências Contábeis no Brasil

1. Termo de Consentimento Livre e Esclarecido (TCLE)

Prezado (a) Pesquisador (a),

Você está sendo convidado (a) como voluntário (a) a participar da pesquisa intitulada "Qualidade no processo de produção científica em Ciências Contábeis no Brasil", como parte do projeto de tese cujo pesquisador responsável é JOSÉ RENATO SENA OLIVEIRA, discente do Doutorado Interinstitucional (parceria entre a Universidade de São Paulo e a Universidade Estadual de Feira de Santana e associadas) do Programa de PósGraduação em Controladoria e Contabilidade da Faculdade de Economia, Administração e Contabilidade da Universidade de São Paulo (PPGCC/FEA/USP). O pesquisador é orientado pelo Prof. Dr. Gilberto de Andrade Martins.

O objetivo do estudo é levantar e discorrer sobre atributos de qualidade de uma boa pesquisa no processo de construção da produção científica em Ciências Contábeis, em que serão levantados tais atributos nas práticas de investigação dos (das) respondentes e confrontados com aqueles identificados na literatura. O estudo é importante para compreender as práticas de produção científica na área, a fim de avaliar a qualidade da pesquisa a partir do seu processo de construção. Poderá contribuir para redefinir práticas e estratégias metodológicas, especialmente nos Programas de Pós-Graduação, bem como para identificar elementos que colaborem para maior aceitabilidade pela produção na comunidade científica.

A coleta de dados será feita eletronicamente com o uso da técnica Delphi modificada (com 3 rodadas para aplicação dos instrumentos de coleta),

Figure 7: Screen of the first part of informed consent.

Considering the principles of respecting and affording privacy to the respondents, the informed consent was shown on the first page of the online instrument. In addition to the 
informed consent, the page contained two mandatory fields in which to insert the participant's code and to express agreement with the informed consent. This procedure is justified by the need to allow connection (matching) between the respondent's answers in the three rounds and to avoid the inclusion of any personally identifiable information in the database. The bottom of the page also included a recommendation that a copy of the informed consent should be saved after completing the first page's fields that contained the explicit agreement and the respondent's code (Figure 8).

Following the informed consent, participants found the statements shown in Figure 9 on the next page; the answers were mandatory. For each statement, the expert had to assign a grade on a 1-10 scale, considering the adhesiveness level of the statement in relation to his/her research practices.

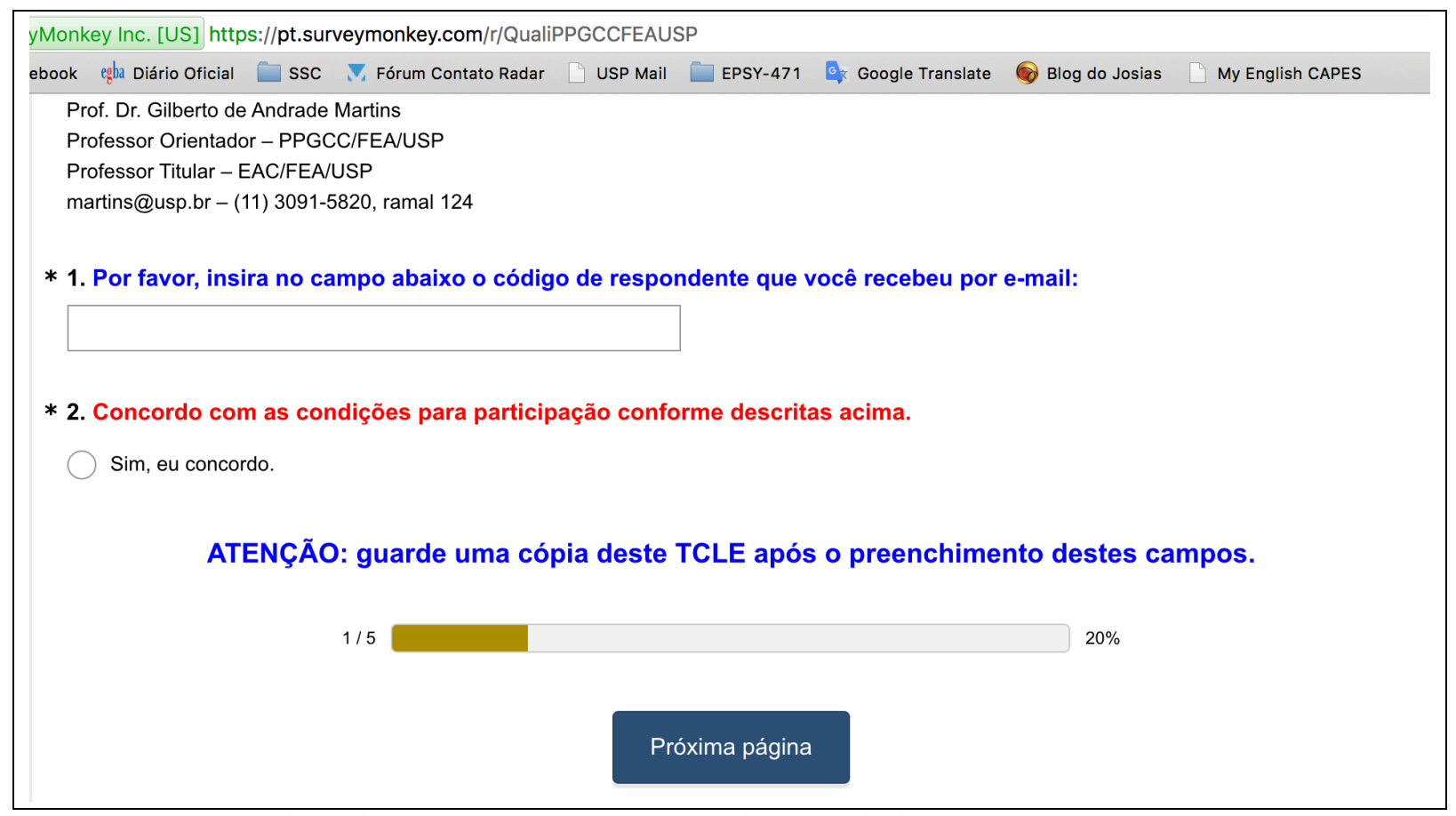

Figure 8: Screen with fields to insert the respondent's code and to declare agreement. 
yMonkey Inc. [US] https://pt.surveymonkey.com/r/QualiPPGCCFEAUSP

ebook egha Diário Oficial $\square$ SSC $\nabla$ Fórum Contato Radar $\square$ USP Mail $\square$ EPSY-471 G. Google Translate B Blog do Josias $\square$ My English CAPES

Qualidade no processo de produção científica em Ciências Contábeis no Brasil

2. Desenho da Pesquisa, Sujeitos da Pesquisa e Coleta dos Dados

Para as proposições a seguir, atribua uma nota em uma escala de 1 a 10, de acordo com o nível de concordância quanto à aderência da proposição à sua prática de pesquisa.

* 3. Desenho da Pesquisa

Meus estudos apresentam razões/justificativas para a escolha da estratégia de pesquisa.

Sou capaz de reconhecer os pressupostos da visão geral (paradigma ou lente teórica)

que guiam a construção dos meus estudos

Levo em conta um paradigma e seus pressupostos quando escolho a estratégia para

construir o desenho das minhas pesquisas.

Figure 9: Second page of the first round's tool (research design, research subjects, and data collection).

A customized e-mail with instructions for participating in the first round (Appendix I) was sent to each participant that provided a positive answer to the initial invitation. The deadline to finish this step was 12 days, which was extended for another five days via a reminder e-mail. In this first round, of the 74 experts who were willing to participate, 42 completed the entire questionnaire.

\subsubsection{Application of the second round}

Before beginning the second round, a customized report for each participant (Appendix J) was prepared that included the new instrument's propositions. To facilitate participation in the second round, the report also included the grades that the participant awarded to those statements in the previous round along with the median given by the group of respondents. The reports were generated as .pdf documents.

As mentioned in the section regarding the preparation of the data collection instruments, the second-round tool was organized into 3 pages, which contained informed consent (Figure 10), 28 statements organized by key features (Figure 11), and an open question. These items are holdovers from the first instrument. In addition, new elements were included. First, at the suggestion of some participants, the second-round tool included the option "never did/do not do research involving human beings" in the groups pertaining to data collection, ethical aspects, and auditability (Figure 12 and Appendix K). The purpose of including this option was to decrease possible biases in the analysis of certain propositions 
because there are experts whose research practice does not involve human beings as research subjects. This suggestion was also taken into account in the analysis of the data collected during the first round. Second, the concept of "research involving human beings" displayed in Resolution CNS n. 466/12 (Brasil, 2012) of the National Health Council was included. The electronic version of the second instrument was available from a SurveyMonkey link/address (http://pt.surveymonkey.com/r/DelphiQuali2).

To begin this round, the respondent's code and password were re-sent by e-mail (Appendix L). Additionally, the customized report was attached. Only the 42 respondents who participated in the first round received the message in this step. The instructions were similar to those of the first round, although the second-round instrument was shorter, so the deadline was only eight days later. However, access remained open for seven more days.

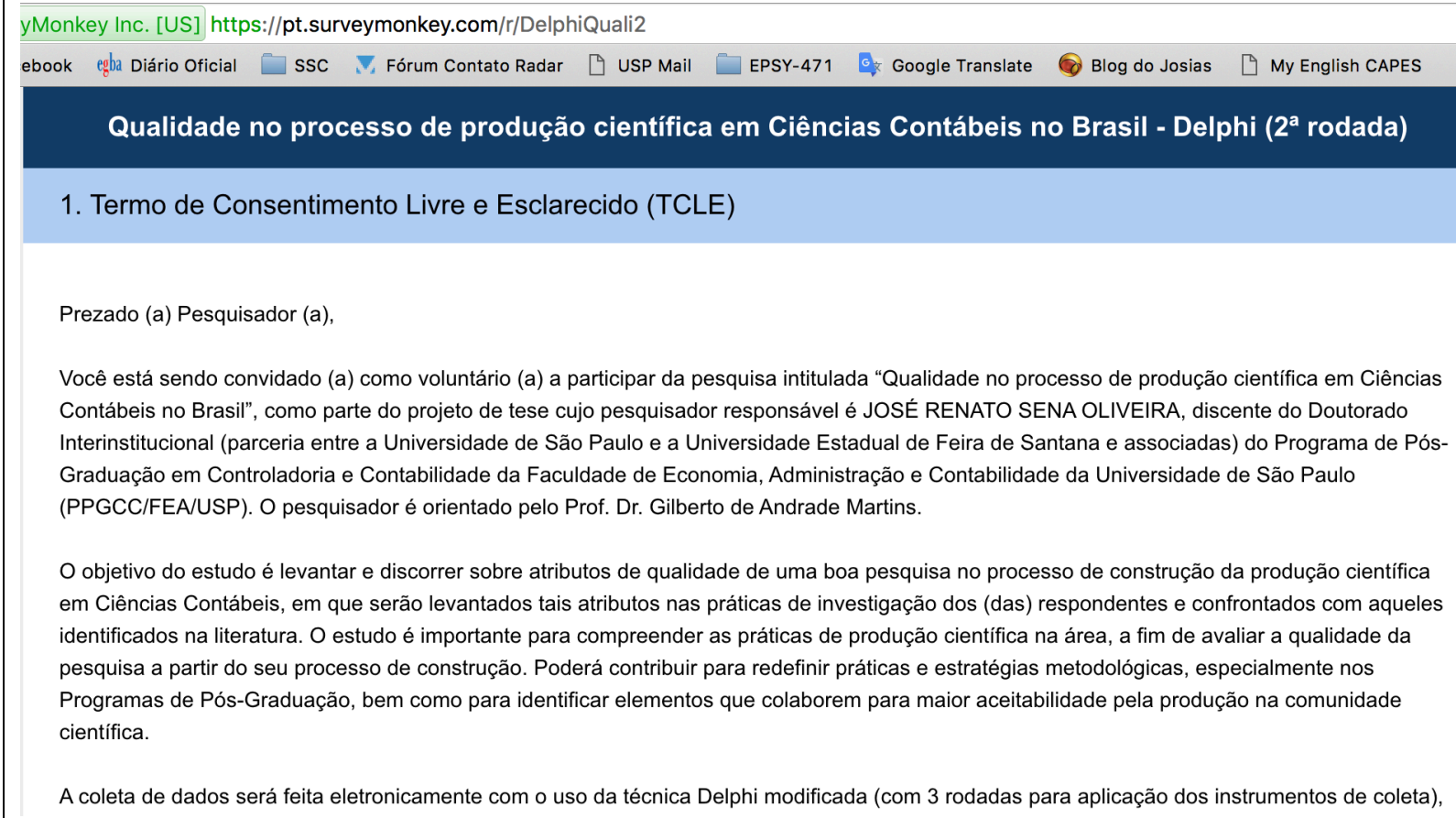

Prezado (a) Pesquisador (a),

Você está sendo convidado (a) como voluntário (a) a participar da pesquisa intitulada "Qualidade no processo de produção científica em Ciências Contábeis no Brasil", como parte do projeto de tese cujo pesquisador responsável é JOSÉ RENATO SENA OLIVEIRA, discente do Doutorado Interinstitucional (parceria entre a Universidade de São Paulo e a Universidade Estadual de Feira de Santana e associadas) do Programa de PósGraduação em Controladoria e Contabilidade da Faculdade de Economia, Administração e Contabilidade da Universidade de São Paulo (PPGCC/FEA/USP). O pesquisador é orientado pelo Prof. Dr. Gilberto de Andrade Martins.

O objetivo do estudo é levantar e discorrer sobre atributos de qualidade de uma boa pesquisa no processo de construção da produção científica em Ciências Contábeis, em que serão levantados tais atributos nas práticas de investigação dos (das) respondentes e confrontados com aqueles identificados na literatura. $\mathrm{O}$ estudo é importante para compreender as práticas de produção científica na área, a fim de avaliar a qualidade da pesquisa a partir do seu processo de construção. Poderá contribuir para redefinir práticas e estratégias metodológicas, especialmente nos Programas de Pós-Graduação, bem como para identificar elementos que colaborem para maior aceitabilidade pela produção na comunidade científica.

A coleta de dados será feita eletronicamente com o uso da técnica Delphi modificada (com 3 rodadas para aplicação dos instrumentos de coleta),

Figure 10: Second round's informed consent. 
Monkey Inc. [US] https://pt.surveymonkey.com/r/DelphiQuali2

book egba Diário Oficial $\square$ SSC $\nabla$ Fórum Contato Radar $\square$ USP Mail $\square$ EPSY-471 of Google Translate B Blog do Josias $\square$ My English CAPES

Qualidade no processo de produção cientifica em Ciências Contábeis no Brasil - Delphi (2 $2^{\mathrm{a}}$ rodada)

2. Desenho da Pesquisa, Sujeitos da Pesquisa, Coleta de Dados, Análise dos Dados, Achados e Relatório

Para as proposições a seguir, atribua uma nota em uma escala de 1 a 10, de acordo com o nível de concordância quanto à aderência da proposição à sua prática de pesquisa.

\section{* 3. Desenho da Pesquisa}

Levo em conta um paradigma e seus pressupostos quando escolho a estratégia para construir o desenho das minhas pesquisas.

Escolho uma estratégia de pesquisa baseado no tempo necessário para coletar os dados e apresentar os resultados.

Levo em conta o provável público-alvo dos meus estudos quando escolho a estratégia da pesquisa.

\section{* 4. Sujeitos da Pesquisa}

Meus estudos descrevem, formalmente, os métodos e os casos de inclusão/exclusão que têm impacto sobre a representatividade dos sujeitos da pesquisa.

Figure 11: Second page of the online data collection instrument (second round).

1onkey Inc. [US] https://pt.surveymonkey.com/r/DelphiQuali2

ook egba Diário Oficial $\square$ SSC $\nabla$ Fórum Contato Radar $\square$ USP Mail $\square$ EPSY-471 Go Google Translate Blog do Josias $\square$ My English CAPES

Qualidade no processo de produção científica em Ciências Contábeis no Brasil - Delphi (2 ${ }^{\mathrm{a}}$ rodada)

3. Reflexividade e Neutralidade, Aspectos Éticos e Auditabilidade

\section{* 9. Reflexividade e Neutralidade}

Discuto em meus estudos, de forma explícita, como erros ou viéses podem ter surgido durante o processo de pesquisa e como lidei com eles.

Discuto, de forma explícita, possiveis impactos decorrentes da minha participação (e da minha equipe) nas fases do processo de pesquisa (quando aplicável).

\section{* 10. Aspectos Éticos}


As with the first round, the results of the analysis consider the dispersion measures frequently used in the literature to evaluate the results (mean, median, and standard deviation). Additionally, to evaluate the consensus, the measures used are those detailed in Topic 3.3.3. There was one dropout during the second round. For ethical reasons and upon request, the data related to that expert's first-round answers were excluded from the database, leaving 41 participants in that step. In the end, 37 experts participated in the final step.

After the second round, few statements failed to meet the consensus criteria used in the study. No third round was convened because the number of propositions for which consensus was pending represented less than $15 \%$ of the analyzed propositions, and these divergences were discussed in the work. The data collection was completed in December 2015.

Considering the set of general criteria that have been chosen to analyze the research practices in this study, the final list of statements was distributed, as represented in Figure 13.

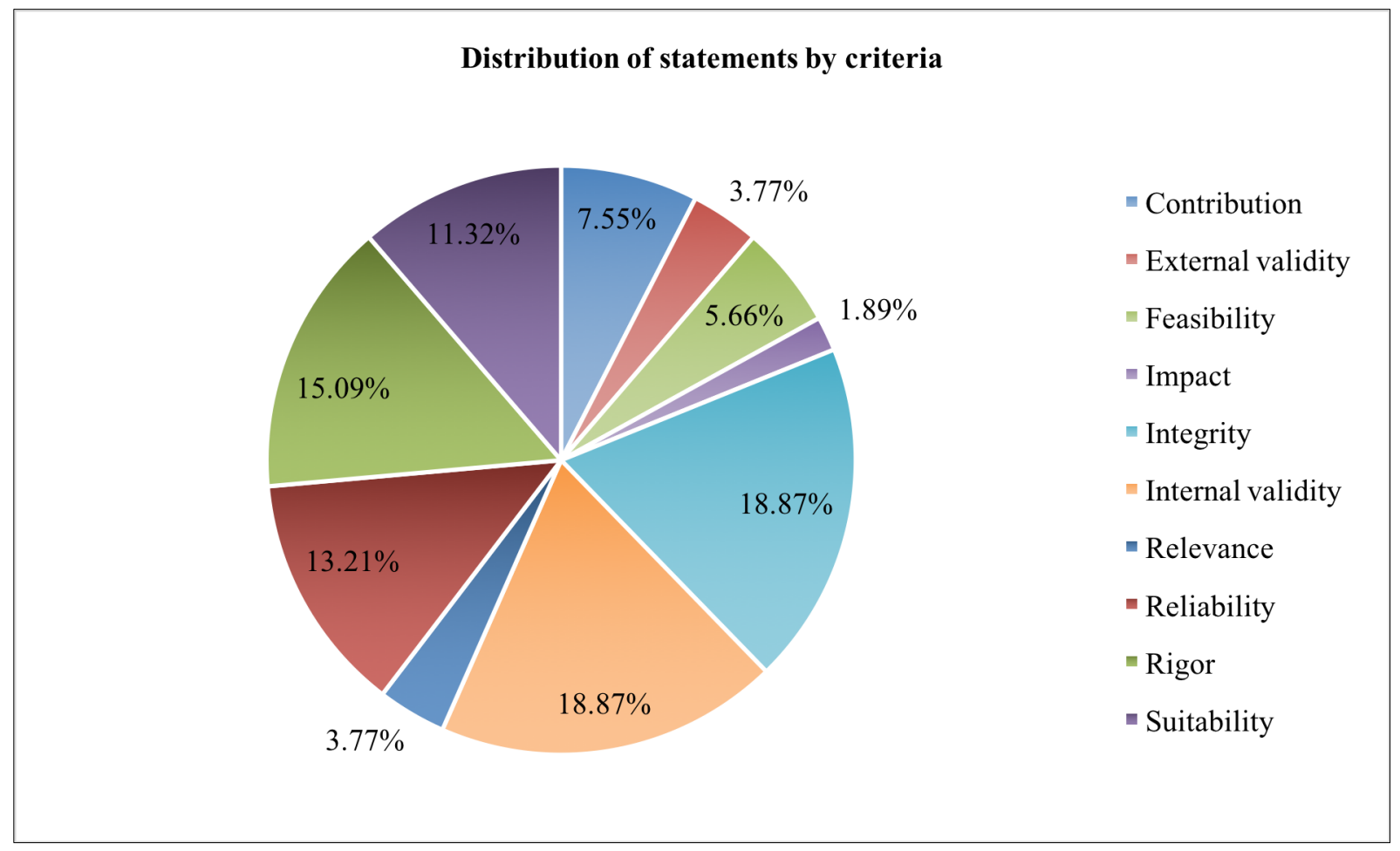

Figure 13: Distribution of statements by criteria.

Because the study's focus was trained on research practices, most of the propositions are primarily aimed at analyzing criteria such as integrity and internal validity/credibility or defensibility. 


\subsection{Stage 3: Comparing the Literature with the Findings}

This step compares the literature review on research quality with the study findings. After identifying the attributes of good research in the literature (Step 1) and generating the outcomes of the respondents' consensus with the Delphi Technique (Step 2), the evidence was compared to identify possible variations (Step 3).

Divergences and convergences were assessed against the criteria used to measure both consensus in the data collection instruments and their agreement level, after accounting for their adherence to the respondents' research practices. To complete this stage, the propositions were classified into groups based on degree of agreement, as explained in section 3.3.3. Additionally, the divergences that arose in some statements for which consensus was not formed after the second round were discussed.

The purpose was to attempt to determine similarities and differences in the researchers' practices to provide support for building an approach to judge research quality.

\subsection{Stage 4: An Approach to Judge the Quality of the Research Process in Accounting}

The development of the approach to judging research quality sought to include an analysis of the building process of scientific production, considering both the literature and the elements that emerged from the Delphi consensus. This approach focuses on issues that can address researchers' practices to mitigate problems in developing field studies and is an attempt to present a set of quality criteria and create an association between those criteria and various stages of the research process. To do so, domains beyond those of the investigation (Brinberg \& McGrath, 1985), key features (Mays \& Pope, 2006; Spencer et al., 2003) were considered.

To achieve this intent, the logic model used in the evaluation process, projects and programs (Taylor-Powell \& Henert, 2008) was selected to systematize the approach. This technique is based on a logical structure driven by a summarized model with inputs, outputs and processes that can be used to evaluate both outcomes and processes. Evaluation of processes is consistent with this study because it focuses on analyzing the scientific production process in the accounting field. The structure of this logic model is shown in Figure 14: 


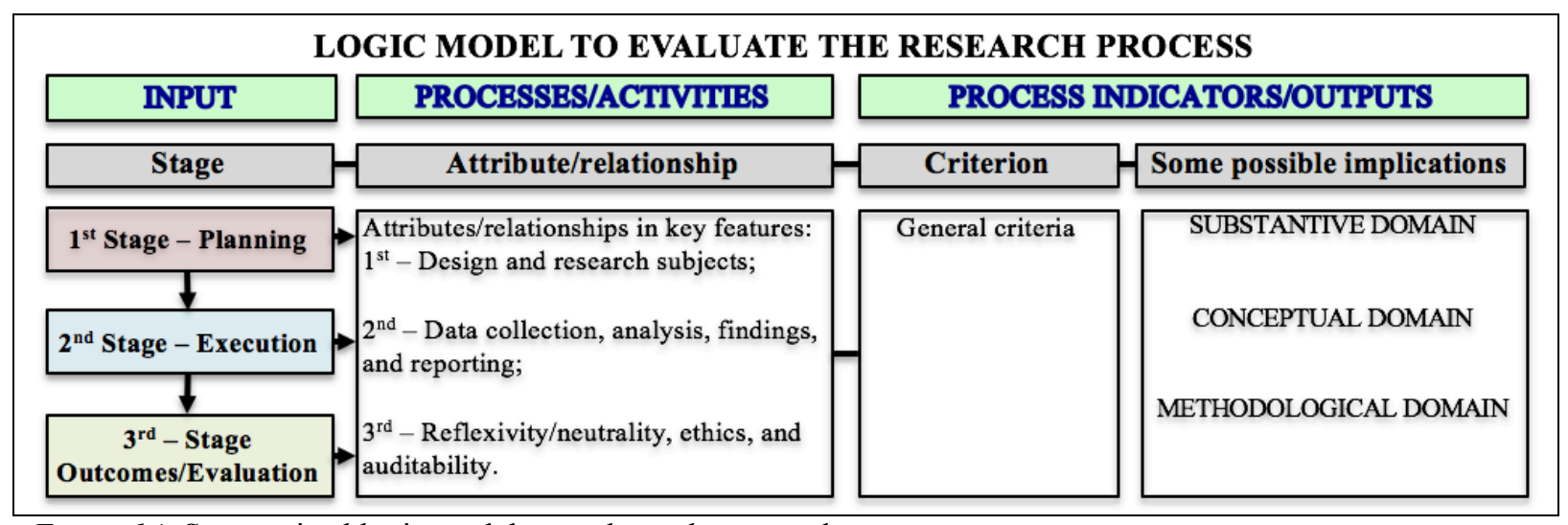

Figure 14: Summarized logic model to evaluate the research process.

This logic model was created by adapting examples provided by Prof. Thomas Schwandt during EPSY-470 Introduction to Evaluation Theory lectures in the graduate program of the Department of Educational Psychology at the College of Education at the University of Illinois at Urbana-Champaign (UIUC), in September 2014. At that time, the author was auditing the graduate program as a visiting scholar at UIUC.

According to Morell (2010), a logic model of evaluation aims to understand the relationships among a program's activities, its consequences, and its environment. From the perspective of a formative evaluation, this model seeks to analyze what a program needs so that it can work as expected. Research practice is closely linked both to the graduate programs and to the tripod of university action (teaching-research-extension). 



\section{CHAPTER 4 -}

\section{RESULTS AND DISCUSSION}

This chapter presents the results and discussion of data collection. With respect to the first topic, it shows the characteristics of respondents and the graduate programs in which they are faculty members. Next, the results of the implementation of two rounds of modified Delphi are displayed, with attributes/relationships linked to research quality criteria according to the key feature (or stage of research process) to which they refer. In sequence, attributes/relationships are grouped based on the respondents' level of agreement as to the final result. Finally, an approach based on attributes of a good research is presented to discuss the application of quality criteria to research practices in accounting.

\subsection{Characterization of Respondents}

To understand the profile of the 41 respondents, they were asked about some of the characteristics of their professional qualifications and experience. The findings revealed that $65.84 \%$ have a doctorate (Ph.D.) in accounting and that $70.73 \%$ of those respondents earned their doctorates in a different national institution from the one in which they work. Additionally, it was found that $85.36 \%$ of respondents did not participate in exchange programs (as visiting scholars) during graduate school, and $78.05 \%$ had not performed postdoctorate work. The data also revealed that $9.76 \%$ of respondents were involved in foreignexchange programs during their doctorates, and $14.63 \%$ did their postdoctoral studies in an international institution. These results suggest that the respondents have little experience in international activities, which may be reflected in a low level of insertion into international research networks.

Another important indicator is the endogeneity analysis in training faculty members. The findings revealed that only $9.75 \%$ of respondents obtained their doctoral degrees in the same program in which they work. According to the criteria used by CAPES in the triennial evaluation, programs with low endogeneity are considered higher quality. Additionally, programs with faculty members whose educational tracks are highly diversified tend to have researchers with different skills and worldviews, which may contribute to the emergence of more comprehensive, innovative studies that involve the combination of those researchers' various experiences. Finally, the length of the respondents' experience in graduate programs 
was analyzed. The findings showed that most of the respondents $(34.14 \%)$ have up to two years of experience as faculty members in this type of program. However, $26.83 \%$ have between 5-7 years of experience and 19.51\% have more than ten years, thus revealing heterogeneity in the distribution of respondents related to this feature. The details are shown in Table 12.

Table 12:

Characteristics of the respondents' professional qualifications and experience.

\begin{tabular}{llrr}
\hline \multicolumn{1}{c}{ Aspect } & \multicolumn{1}{c}{ Category } & $\boldsymbol{n}$ & $\mathbf{\%}$ \\
\hline Field of his/her doctorate (or & Accounting & 27 & 65.84 \\
Ph.D.). & Business/Finance & 5 & 12.20 \\
& Economics & 3 & 7.32 \\
& Education and technology & 1 & 2.44 \\
& Industrial engineering & 5 & 12.20 \\
\cline { 2 - 4 } & Total & 41 & 100.00 \\
\hline \multirow{3}{*}{ Where did he/she earn the } & In the same program in which I work & 4 & 9.75 \\
doctorate (Ph.D.). & At the same institution, but in a different program from the & \\
& one in which I work & 5 & 12.20 \\
& At another national institution & 70.73 \\
& At another international institution & 29 & 7.32 \\
\cline { 2 - 4 } & Total & 3 & 100.00 \\
\hline Exchange program (visiting & Yes, at another national institution & 41 \\
scholar) during the doctoral & Yes, at an international institution & 2 & 4.88 \\
degree & No, I did not & 4 & 9.76 \\
& Total & 35 & 85.36 \\
\hline Postdoctoral work & Yes, at another national institution & 41 & 100.00 \\
& Yes, at an international institution & 3 & 7.32 \\
& No, I did not & 6 & 14.63 \\
\cline { 2 - 4 } & Total & 32 & 78.05 \\
\hline Time in graduate program & $0-2$ years & 41 & 100.00 \\
\hline in years) & $3-4$ years & 14 & 34.14 \\
& $5-7$ years & 4 & 9.76 \\
& $8-10$ years & 11 & 26.83 \\
& More than 10 years & 4 & 9.76 \\
\cline { 2 - 4 } & Total & 8 & 19.51 \\
\hline & & 41 & 100.00 \\
\hline
\end{tabular}

Given that the respondents are members of an expert panel to analyze research practices, it is relevant to learn about their experience in these activities. The first two points analyzed concern the ability to raise funding for research. The findings revealed that $56.1 \%$ of respondents currently have projects funded by development institutions, and $24.39 \%$ have research productivity grants, as shown in Table 13. The receipt of research funding and productivity grants are indicators of the researcher's expertise in the relevant knowledge production in his field because funding opportunities are offered through public calls, and the researcher must be able to compete with other researchers both from other areas and from different institutions. 
The following items, also shown in Table 13, are related to the respondents' experience as part of the scientific publishing process. The data revealed that $43.9 \%$ of the respondents either work or have worked as editor of a journal ranked in the Qualis/CAPES strata (except Qualis C). Moreover, 63.41\% are or have been a member of the editorial board of a journal classified in these same strata. Finally, 100\% of the respondents act or have acted as referees for a journal that meets that same requirement. These data reveal that the panel participants have extensive experience related to the publishing process.

Table 13:

Respondents' research experience

\begin{tabular}{|c|c|c|c|c|c|c|c|c|c|c|}
\hline \multirow[t]{2}{*}{ Category } & \multicolumn{2}{|c|}{$\begin{array}{l}\text { Funding for } \\
\text { research }\end{array}$} & \multicolumn{2}{|c|}{$\begin{array}{c}\text { Productivity } \\
\text { grant }\end{array}$} & \multicolumn{2}{|c|}{ Journal editor } & \multicolumn{2}{|c|}{$\begin{array}{c}\text { Member of } \\
\text { editorial board }\end{array}$} & \multicolumn{2}{|c|}{$\begin{array}{c}\text { Scientific journal } \\
\text { referee }\end{array}$} \\
\hline & $n$ & $\%$ & $n$ & $\%$ & $n$ & $\%$ & $n$ & $\%$ & $n$ & $\%$ \\
\hline Yes & 23 & 56.10 & 10 & 24.39 & 18 & 43.90 & 26 & 63.41 & 41 & 100.00 \\
\hline No & 18 & 43.90 & 31 & 75.61 & 23 & 56.10 & 15 & 36.59 & 0 & 0.00 \\
\hline Total & 41 & 100.00 & 41 & 100.00 & 41 & 100.00 & 41 & 100.00 & 41 & 100.00 \\
\hline
\end{tabular}

To complete the analysis of the features related to research experience, a specific item asked respondents about their productivity in publishing journal articles that are considered high impact by Qualis/CAPES (called superior strata: A1, A2, and B1) in the previous triennial assessment (2010-2012). The results showed that $34.15 \%$ of respondents have published between one and two papers in journals evaluated in the upper strata; another $34.15 \%$ have published between three and five papers at these same levels. Finally, $29.27 \%$ have published more than five articles during the period, as shown in Figure 15. Only one respondent (i.e., 2.44\%) has had no article published during the triennial assessment.

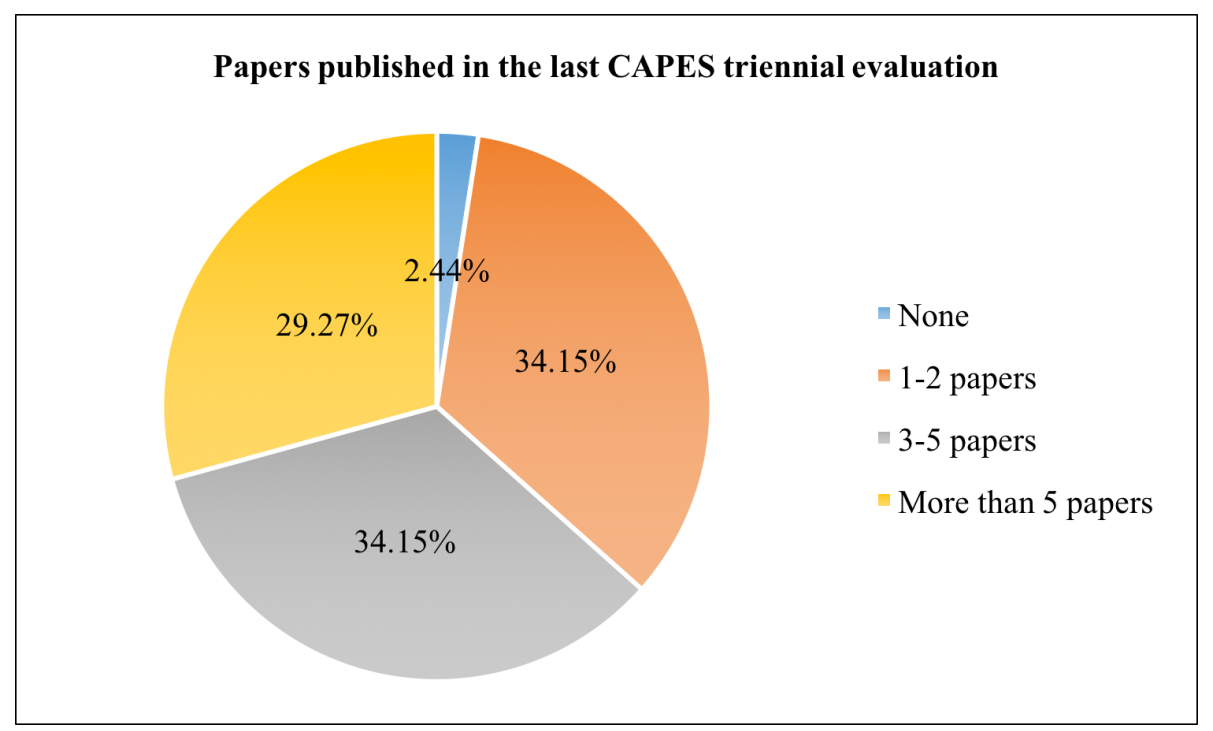

Figure 15: Distribution of the respondents by number of papers published in the last CAPES triennial evaluation. 
With respect to the characteristics of graduate programs to which respondents are attached, Figure 16 shows that $53.66 \%$ are linked to programs that offer master's and doctoral courses (M.Sc. and Ph.D.), and another $46.34 \%$ are faculty members in programs that have only master's programs. Additionally, 19 of Brazil's 23 graduate programs in accounting are represented in the Delphi expert panel; ten of those programs offer both degrees, as revealed in Figure 17. Finally, Figure 18 shows that most respondents (17 experts) perform their activities in graduate programs rated as Grade 4 in the CAPES evaluation, which is equivalent to $41.46 \%$ of the respondents. Grade 4 is considered the minimum for a graduate program to be accredited to offer a doctoral degree.

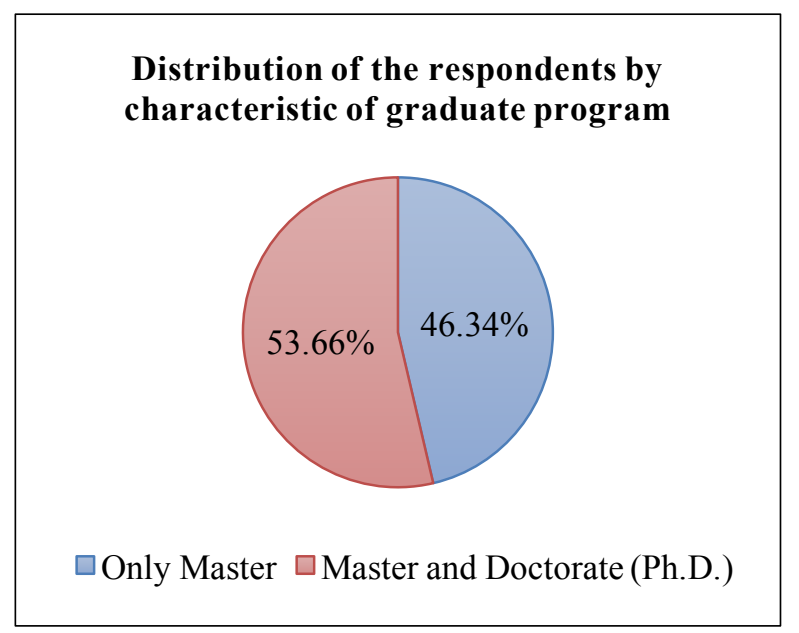

Figure 16: Distribution of the respondents by the characteristics of their graduate programs.

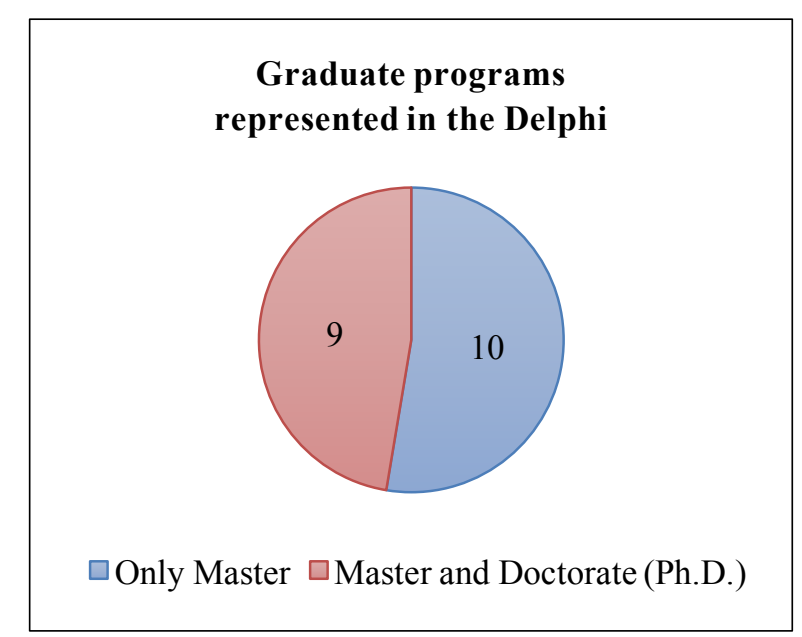

Figure 17: Distribution of the graduate programs represented in the Delphi by level.

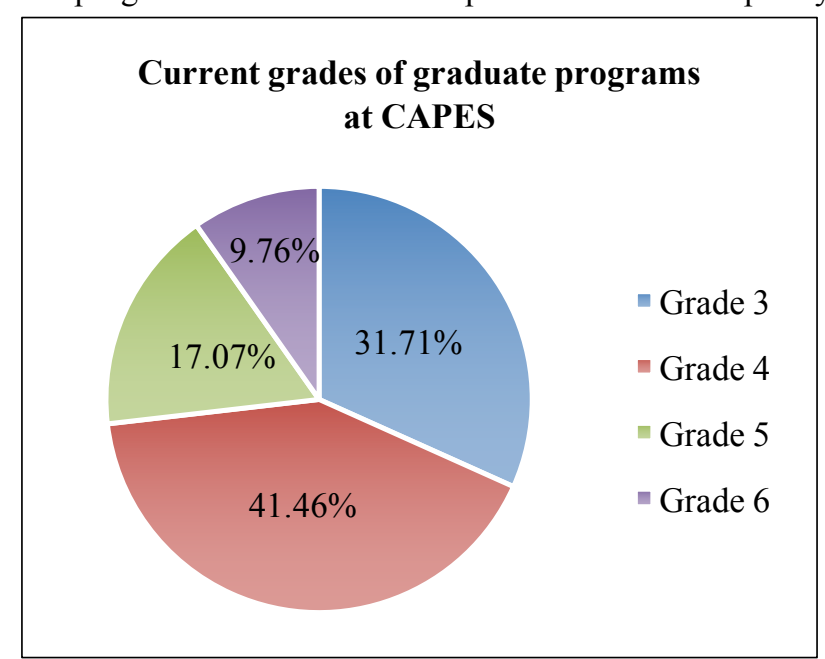

Figure 18: Distribution of the graduate programs by their current grades (CAPES).

Source: research data, 2016.

Another important finding was the low concentration of the respondents in the same program: the highest rate was equivalent to $12.20 \%$ (5 experts). 


\subsection{Application of the Delphi Technique}

As detailed in Chapter 3 (Methods), the technique used for data collection was the modified Delphi, characterized by the submission of preliminary statements based on the literature during the first round instead of entries based on the respondents' suggestions. The source of the findings presented in Tables 14-36 is the inquiry undertaken in two rounds of the Delphi. The tables are ordered based on nine key features (or stages of the research process) to which they relate and are shown in the same order as in the data collection instrument. Tables 14-32 are sorted in descending order based on the highest percentage of grades equal to or exceeding 8 (the sixth column of the tables). The inquiry consisted of 53 statements distributed in nine key features. Forty-one valid responses were obtained in the first round and 37 were obtained in the second round.

The codification of the propositions in the tables uses seven characters: the first two characters are related to the Delphi round, the next three characters are the first three letters of the word that defines the key feature, and the final two numbers refer to the position of the statement in the data collection instruments. For example, the code R1Des04 (the first of Table 14) means that the proposition refers to the first round, the research design is the feature, and the proposition is the fourth one in the questionnaire.

\subsubsection{Results of the first round}

The initial data for the first round of the Delphi are disclosed in Table 14, which presents the results of statements related to the research design and primarily involves the general criteria of feasibility and suitability.

Table 14:

First round - research design (descending order of percentage of grades $\geq 8$ )

\begin{tabular}{|c|c|c|c|c|c|c|c|c|c|}
\hline \multirow[t]{2}{*}{ Attribute/relationship } & \multicolumn{4}{|c|}{ Grade $\leq 3$ Grade $\geq 8$} & Min Max Mean Medion SD Conconcus & Max & Mean & Median & SD Consensus \\
\hline & $\mathbf{n}$ & $\%$ & $\mathbf{n}$ & $\%$ & & & & & \\
\hline R1Des04 Goal/problem shown precisely & 0 & 0.00 & 41 & 100.00 & 8 & 10 & 9.63 & 10.00 & $0.54 \mathrm{Yes}$ \\
\hline R1Des01 Useful strategy for purpose & 1 & 2.44 & 39 & 95.12 & 1 & 10 & 9.00 & 9.00 & $1.50 \mathrm{Yes}$ \\
\hline R1Des02 Clear overview that guides the study & 1 & 2.44 & 36 & 87.80 & 3 & 10 & 8.73 & 9.00 & $1.61 \mathrm{Yes}$ \\
\hline R1Des06 Arguments for technique choices & 1 & 2.44 & 36 & 87.80 & 3 & 10 & 8.93 & 9.00 & $1.47 \mathrm{Yes}$ \\
\hline R1Des05 Overview $x$ theory & 2 & 4.88 & 34 & 82.93 & 1 & 10 & 8.51 & 9.00 & $1.93 \mathrm{Yes}$ \\
\hline R1Des07 Access to the data & 0 & 0.00 & 33 & 80.49 & 5 & 10 & 8.56 & 9.00 & $1.40 \mathrm{Yes}$ \\
\hline R1Des03 Overview x strategy & 3 & 7.32 & 29 & 70.73 & 1 & 10 & 7.88 & 9.00 & $2.32 \mathrm{No}$ \\
\hline R1Des08 Time constraints & 8 & 19.51 & 21 & 51.22 & 1 & 10 & 6.44 & 8.00 & $2.92 \mathrm{No}$ \\
\hline R1Des09 Research strategy $x$ target audience & 6 & 14.63 & 19 & 46.34 & 1 & 10 & 6.76 & 7.00 & $2.55 \mathrm{No}$ \\
\hline
\end{tabular}

Note: in this round only the first two rules for building consensus presented in Topic 3.3.3 were considered, given that the third rule applies only to the comparison of the standard deviations between different rounds. 
The findings revealed that 'goal/problem shown precisely' was the item with the highest percentage, reaching $100 \%$ of answers with a score equal or greater than 8 . However, five of the nine propositions had at least one answer with a minimum score of 1 , showing a dispersion over the maximum range. Six items are also verified to reached consensus based on the criteria explained in Topic 3.3.3. The results of the statements related to research subjects and data collection are displayed in Tables 15 and 16.

Table 15:

First round - research subjects (descending order of percentage of grades $\geq 8$ )

\begin{tabular}{|c|c|c|c|c|c|c|c|c|}
\hline \multirow[t]{2}{*}{ Propos. } & \multirow[t]{2}{*}{ Attribute/relationship } & \multicolumn{2}{|c|}{ Grade $\leq 3$ Grade $\geq 8$} & \multirow{2}{*}{\multicolumn{5}{|c|}{ Min Max Mean Median SD Consensus }} \\
\hline & & n $\%$ & n $\%$ & & & & & \\
\hline & & 2.44 & 78.05 & 10 & 8.59 & 9.00 & 1.53 & Yes \\
\hline R1Sub02 & sentativeness of subjects & 4.88 & 73.17 & 10 & 8.15 & 9.00 & 1.99 & No \\
\hline
\end{tabular}

Table 16:

First round - data collection (descending order of percentage of grades $\geq 8$ )

\begin{tabular}{|c|c|c|c|c|c|c|c|c|c|}
\hline \multirow[t]{2}{*}{ Propos. } & \multicolumn{3}{|c|}{ Grade $\leq 3$ Grade $\geq 8$} & \multirow{2}{*}{\multicolumn{2}{|c|}{ Min Max }} & \multirow{2}{*}{\multicolumn{2}{|c|}{ Mean Median }} & \multirow{2}{*}{\multicolumn{2}{|c|}{ SD Consensus }} \\
\hline & n $\%$ & $\mathbf{n}$ & $\%$ & & & & & & \\
\hline R1Col03 Voluntar & 2.44 & 38 & 92.68 & 1 & 10 & 9.37 & 10.00 & 1.65 & Yes* \\
\hline R1Col01 Notes for & 0.00 & 33 & 80.49 & 6 & 10 & 8.80 & 9.00 & 1.25 & Yes \\
\hline R1Col02 Notes for $d$ & $0 \quad 0.00$ & 30 & 73.17 & 4 & 10 & 8.44 & 9.00 & 1.57 & No \\
\hline R1Col04 Formal agreement from humans & 819.51 & 21 & 51.22 & 1 & 10 & 6.90 & 8.00 & 3.28 & No \\
\hline
\end{tabular}

*This was included in the second round because this proposition is linked with ethical aspects.

The issues included in Tables 15 and 16 are associated with the criteria of internal validity/credibility or defensibility, rigor/thoroughness, and integrity. The item "representation of the subject" did not form consensus in the group "research subjects". With respect to data collection items, two of them reached agreement; however, the "voluntary participation of subjects" was included in the second round because of the connection to ethical issues. Table 17, in turn, presents the statements regarding the data analysis that are linked to the criteria of integrity, relevance, reliability/auditability, and rigor/thoroughness.

Table 17:

First round - analysis (descending order of percentage of grades $\geq 8$ )

\begin{tabular}{|c|c|c|c|c|c|c|c|c|c|}
\hline \multirow[t]{2}{*}{ Propos. } & \multicolumn{4}{|c|}{ Grade $\leq 3$ Grade $\geq 8$} & \multicolumn{5}{|c|}{ Min Max Mean Median SD Consensus } \\
\hline & $\mathbf{n}$ & $\%$ & n & $\%$ & & & & & \\
\hline R1Ana05 Significance of data to reaching aims & 1 & 2.44 & 36 & 87.80 & 1 & 10 & 8.56 & 9.00 & $1.55 \mathrm{Yes}$ \\
\hline R1Ana02 Description of tools and procedures & 0 & 0.00 & 35 & 85.37 & 6 & 10 & 8.73 & 9.00 & $1.12 \mathrm{Yes}$ \\
\hline R1Ana03 Context $\mathrm{x}$ impact on data analysis & 0 & 0.00 & 34 & 82.93 & 4 & 10 & 8.32 & 8.00 & $1.35 \mathrm{Yes}$ \\
\hline R1Ana01 Description of nature $\&$ form of data & 0 & 0.00 & 33 & 80.49 & 7 & 10 & 8.56 & 9.00 & $1.07 \mathrm{Yes}$ \\
\hline R1Ana06 Implicit/explicit links - find. $x$ aims & 0 & 0.00 & 33 & 80.49 & 5 & 10 & 8.51 & 9.00 & $1.27 \mathrm{Yes}$ \\
\hline R1Ana04 Other views to explain context & 3 & 7.32 & 18 & 43.90 & 1 & 10 & 7.07 & 7.00 & $1.95 \mathrm{No}$ \\
\hline
\end{tabular}


The findings revealed that most of the attributes and relationships of the data analysis stage obtained high acceptance rates, except for the item 'other views to know the context,' which is linked to the criterion of reliability/auditability and did not achieve consensus in the first round. The propositions included in Table 18, which relates to the findings, are associated with the criteria of contribution/quality of theoretical perspective, external validity or generalization/fittingness, internal validity/credibility or defensibility, relevance, and reliability/auditability.

Table 18:

First round - findings (descending order of percentage of grades $\geq 8$ )

\begin{tabular}{|c|c|c|c|c|c|c|c|c|c|c|}
\hline \multirow[t]{2}{*}{ Propos. } & \multirow[t]{2}{*}{ Attribute/relationship } & Gra & de $\leq 3$ & Gr & ade $\geq 8$ & Min & Max & Mean I & Median & Consensu \\
\hline & & $\mathbf{n}$ & $\%$ & n & $\%$ & & & & & \\
\hline R1Fin01 & Path to achieve conclusions & 0 & 0.00 & 39 & 95.12 & 7 & 10 & 8.76 & 9.00 & $0.86 \mathrm{Yes}$ \\
\hline R1Fin02 & Link between findings $\mathrm{x}$ evidence & 0 & 0.00 & 39 & 95.12 & 6 & 10 & 8.85 & 9.00 & $0.94 \mathrm{Yes}$ \\
\hline R1Fin07 & Check links of findings $\mathrm{x}$ purpose & 0 & 0.00 & 39 & 95.12 & 5 & 10 & 9.10 & 9.00 & $1.04 \mathrm{Yes}$ \\
\hline R1Fin0 & Previous findings $\mathrm{x}$ hypothesis & 0 & 0.00 & 36 & 87.80 & 7 & 10 & 9.00 & 9.00 & $1.12 \mathrm{Yes}$ \\
\hline R1Fin04 & New areas base & 0 & 0.00 & 35 & 85.37 & 7 & 10 & 8.80 & 9.00 & $1.10 \mathrm{Yes}$ \\
\hline R1Fin03 & Comparison re & 0 & 0.00 & 34 & 82.93 & 5 & 10 & 9.10 & 10.00 & $1.37 \mathrm{Yes}$ \\
\hline R1Fin08 & Does the context allow replication & 0 & 0.00 & 34 & 82.93 & 6 & 10 & 8.56 & 9.00 & $1.25 \mathrm{Yes}$ \\
\hline R1Fin05 & Insights for thinking about the field & 0 & 0.00 & 30 & 73.17 & 6 & 10 & 8.27 & 8.00 & $1.10 \mathrm{No}$ \\
\hline R1Fin09 & Impact from the nature of divergences & 2 & 4.88 & 25 & 60.98 & 1 & 10 & 7.44 & 8.00 & $1.83 \mathrm{No}$ \\
\hline
\end{tabular}

For these propositions, the findings showed high levels of acceptance in that three of the attributes and relationships associated with the internal validity criterion resulted in a higher percentage than $90 \%$. Another detail to note is that eight of nine statements had minimal scores equal to or greater than 5 , and only two items did not achieve consensus. Moreover, the item 'compare results with other studies' reached a median equal to 10 , which shows the respondents' confidence regarding the applicability of that relationship in their research practice. Table 19 presents statements on reporting that are associated with the criteria of the contribution/quality of a theoretical perspective, external validity or generalization/fittingness, impact, internal validity/credibility or defensibility, relevance, and reliability/auditability. Table 20 also shares the integrity criterion and addresses issues of reflexivity/neutrality. 
Table 19:

First round - reporting (descending order of percentage of grades $\geq 8$ )

\begin{tabular}{|c|c|c|c|c|c|c|c|c|c|}
\hline \multirow[t]{2}{*}{ Propos. } & \multicolumn{4}{|c|}{ Grade $\leq 3$ Grade $\geq 8$} & \multicolumn{5}{|c|}{ Min Max Mean Median SD Consensus } \\
\hline & $\mathbf{n}$ & $\%$ & $\mathbf{n}$ & $\%$ & & & & & \\
\hline R1Rep06 Theory to support pr & 0 & 0.00 & 39 & 95.12 & 7 & 10 & 9.05 & 9.00 & $0.86 \mathrm{Yes}$ \\
\hline R1Rep05 Literature review $\mathrm{x}$ main con & 0 & 0.00 & 38 & 92.68 & 6 & 10 & 9.10 & 9.00 & 0.94 Yes \\
\hline R1Rep07 Conclusions $x$ aim & 0 & 0.00 & 38 & 92.68 & 6 & 10 & 9.20 & 10.00 & $1.10 \mathrm{Yes}$ \\
\hline R1Rep08 Explicit possibility of generalization & 1 & 2.44 & 31 & 75.61 & 1 & 10 & 8.41 & 9.00 & $2.00 \mathrm{Yes}$ \\
\hline R1Rep02 Disclosure of limitations & 0 & 0.00 & 29 & 70.73 & 5 & 10 & 8.29 & 9.00 & $1.33 \mathrm{No}$ \\
\hline R1Rep01 Discussion of impact on knowledge & 0 & 0.00 & 28 & 68.29 & 4 & 10 & 7.90 & 8.00 & $1.14 \mathrm{No}$ \\
\hline R1Rep04 Boundaries of the study & 1 & 2.44 & 24 & 58.54 & 1 & 10 & 7.49 & 8.00 & $1.61 \mathrm{No}$ \\
\hline R1Rep03 Reasons for limitations & 0 & 0.00 & 22 & 53.66 & 4 & 10 & 7.46 & 8.00 & $1.53 \mathrm{No}$ \\
\hline R1Rep09 Appreciation of drafts by colleagues & 6 & 14.63 & 16 & 39.02 & 1 & 10 & 6.54 & 7.00 & $2.67 \mathrm{No}$ \\
\hline
\end{tabular}

Table 20:

First round - reflexivity and neutrality (descending order of percentage of grades $\geq 8$ )

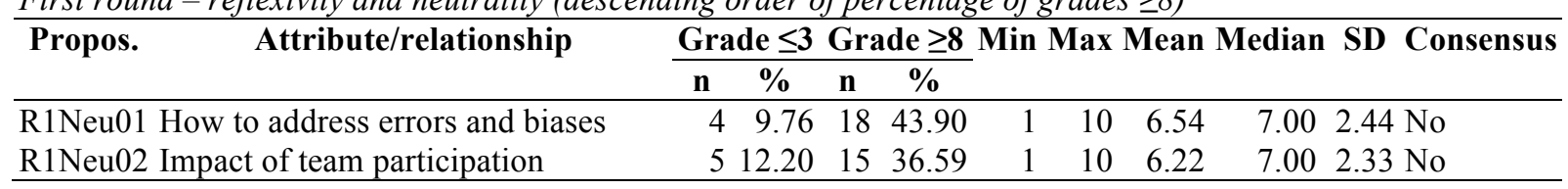

The results shown in Table 19 demonstrate that three of the attributes/relationships that focused on the evaluation of the internal validity/credibility or defensibility criterion resulted in acceptance rates greater than $90 \%$. In contrast, the statement 'Appreciation of drafts by colleagues,' which was associated with the same standard, presented an acceptance percentage of only $39.02 \%$. Notably, five of the nine attributes in Table 19, along with the propositions related to reflexivity/neutrality in Table 20, also did not achieve consensus.

The next group of statements in the data collection instrument concerns Ethics. Although a portion of the items reached consensus, the respondents' comments on the final question revealed that some do not perform research that involves human beings; the propositions did not include a 'not applicable' option. Some researchers work with studies based on archival, for instance, for which characteristics such as submission to an Ethics Committee in Research and presentation of informed consent do not make sense. For this reason, the results might produce a biased analysis, so it was decided to resubmit all the propositions concerning ethical issues for assessment in the second round, while the data obtained in the first round were not presented.

The final group of statements, which is presented in Table 21, addresses auditability; these statements are associated with the general criterion of relevance/auditability. 
Table 21:

First round - auditability (descending order of percentage of grades $\geq 8$ )

\begin{tabular}{|c|c|c|c|c|c|c|c|c|}
\hline \multirow[t]{2}{*}{ Attribute/relationship } & \multicolumn{3}{|c|}{ Grade $\leq 3$ Grade $\geq 8$} & \multirow{2}{*}{\multicolumn{5}{|c|}{ Min Max Mean Median SD Consensus }} \\
\hline & n $\%$ & $\mathbf{n}$ & $\%$ & & & & & \\
\hline R1Aud03 Safeguard database & 0.00 & 36 & 87.80 & 4 & 10 & 8.95 & 9.00 & $1.40 \mathrm{Yes}$ \\
\hline R1Aud01 Records of design changes & 9.76 & 29 & 70.73 & 1 & 10 & 7.68 & 8.00 & $2.61 \mathrm{No}$ \\
\hline R1Aud02 Records of the reasons for changes & 49.76 & 25 & 60.98 & 1 & 10 & 7.29 & 8.00 & $2.63 \mathrm{No}$ \\
\hline R1Aud04 Guard documents to reduce risks & 717.07 & 23 & 56.10 & 1 & 10 & 6.98 & 8.00 & $3.27 \mathrm{No}$ \\
\hline
\end{tabular}

The findings demonstrated that only the safekeeping of databases for future checks achieved consensus. The other items were kept for retesting in the second round. Notably, $17.07 \%$ of respondents attributed a grade equal to or less than 3 for the item on the storage of study-related documents, which shows a weakness in the proper maintenance of research records for possible subsequent verification of research procedures.

\subsubsection{Results of the second round}

Statements that did not achieve consensus in the previous round, along with those related to ethical issues, comprised the data collection instrument in the second round. Overall, 28 propositions in nine primary characteristics (or stages of research process) were distributed in Tables 22-30 on this topic. Table 22 refers to items related to the research design and analyzes the criteria of feasibility and suitability. Table 23 shows only a statement regarding research subjects and its primary criteria: internal validity/credibility or defensibility.

Table 22:

Second round - research design (descending order of percentage of grades $\geq 8$ )

\begin{tabular}{|c|c|c|c|c|c|c|c|c|}
\hline \multirow[t]{2}{*}{ Propos. } & \multicolumn{3}{|c|}{ Grade $\leq 3$ Grade $\geq 8$} & \multicolumn{5}{|c|}{ Min Max Mean Median SD Consensus } \\
\hline & n $\%$ & $\mathbf{n}$ & $\%$ & & & & & \\
\hline R2Des03 Overview & 2.70 & 30 & 81.08 & 10 & 8.54 & 9.00 & 1.64 & Yes \\
\hline R2Des09 Research & 8.11 & 22 & 59.46 & 10 & 7.14 & 8.00 & 2.19 & No \\
\hline R2Des08 Time constraints & 513.51 & 18 & 48.65 & 10 & 7.05 & 7.00 & 2.71 & No \\
\hline
\end{tabular}

Note: in this round, only the first two rules for building consensus presented in Topic 3.3.3 were considered given that the third rule applies only to the comparison of the standard deviations between rounds.

Table 23:

Second round - research subjects (descending order of percentage of grades $\geq 8$ )

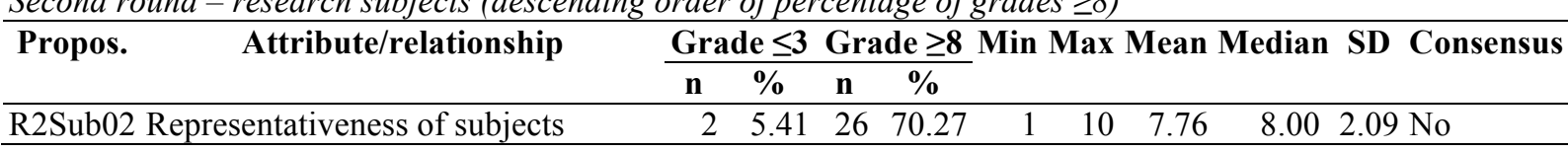

Only the 'overview x strategy' relationship achieved consensus in the two tables set forth above. For those propositions that did not attain agreement, high standard deviations 
above 2 remain, which shows that the respondents hold divergent opinions regarding the adequacy of these items for their research practices. Additionally, the 'time constraints' statement achieved a low median and a high standard deviation, which also suggests disagreement among experts related to the applicability of this aspect in their everyday research practice. Research design and research subjects may be associated with the first stage described by Brinberg and McGrath (1985) because they refer to a study's planning stage.

The key features denominated data collection, data analysis, findings, and reporting are associated with stage 2 of the VNS model proposed by Brinberg and McGrath (1985) because they relate to the research development stage. Tables 24 and 25 evaluate attributes/relationships related to data collection and data analysis and are associated with the criteria of integrity, rigor/thoroughness, and reliability/auditability.

Table 24:

Second round - data collection (descending order of percentage of grades $\geq 8$ )

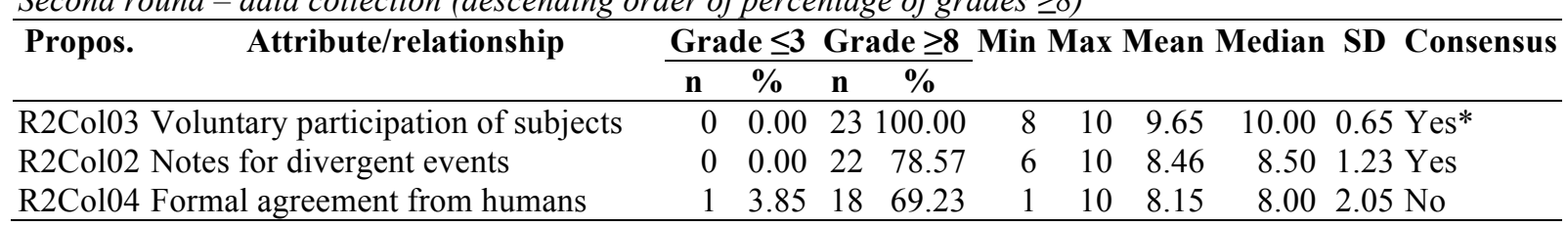

*This was included in the second round because this proposition is linked with ethical aspects.

Table 25:

Second round - analysis (descending order of percentage of grades $\geq 8$ )

\begin{tabular}{lccccccccc}
\hline Propos. & Attribute/relationship & \multicolumn{2}{c}{ Grade $\leq \mathbf{3}$} & Grade $\geq \mathbf{8}$ & Min Max Mean Median SD Consensus \\
\cline { 2 - 10 } & $\mathbf{n}$ & $\mathbf{\%}$ & $\mathbf{n}$ & $\mathbf{\%}$ & & & & \\
\hline R2Ana04 Other views to explain context & 0 & 0.00 & 19 & 51.35 & 4 & 10 & 7.51 & 8.00 & 1.33 No \\
\hline
\end{tabular}

To avoid bias in interpreting the data, the 'voluntary participation of subjects' item of Table 24 was included in the second round because of its connection with ethical aspects. Thus, the data collection instrument in the second round provided the 'never did/do not do research involving human subjects' item with the purpose of segregating those respondents who do not conduct that type of research. The results showed that 23 respondents, which equaled $100 \%$ of the researchers that conduct research with human beings, assigned equal or superior grades to 8 . As a result, this item and the items related to 'Notes for divergent events' reached consensus by a percentage of higher grades.

Tables 26 and 27 highlight the propositions of the last two features related to Stage 2. These statements are linked to the criteria of the contribution/quality of theoretical perspective, impact, integrity, and internal validity/credibility or defensibility. 
Table 26:

Second round - findings (descending order of percentage of grades $\geq 8$ )

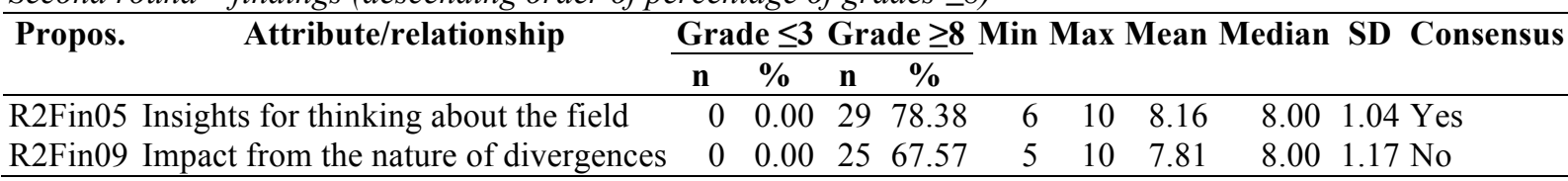

Table 27:

Second round - reporting (descending order of percentage of grades $\geq 8$ )

\begin{tabular}{|c|c|c|c|c|c|c|c|c|c|}
\hline \multirow[t]{2}{*}{ Propos. } & \multicolumn{4}{|c|}{ Grade $\leq 3$ Grad } & Min & \multirow{2}{*}{\multicolumn{3}{|c|}{ Max Mean Median }} & \multirow[t]{2}{*}{ SD Consensus } \\
\hline & $\mathbf{n}$ & $\%$ & n & $\%$ & & & & & \\
\hline R2Rep02 Disclosure of limitations & 0 & 0.00 & 30 & 81.08 & 6 & 10 & 8.51 & 9.00 & $1.10 \mathrm{Yes}$ \\
\hline R2Rep01 Discussion of impact on knowledge & 0 & 0.00 & 27 & 72.97 & 6 & 10 & 8.14 & 8.00 & $1.00 \mathrm{No}$ \\
\hline R2Rep03 Reasons for limitations & 0 & 0.00 & 27 & 72.97 & 5 & 10 & 7.92 & 8.00 & $1.09 \mathrm{No}$ \\
\hline R2Rep04 Boundaries of the study & 1 & 2.70 & 25 & 67.57 & 1 & 10 & 7.95 & 8.00 & $1.70 \mathrm{No}$ \\
\hline R2Rep09 Appreciation of drafts by colleagues & 8 & 21.62 & 14 & 37.84 & 1 & 10 & 6.19 & 7.00 & $2.93 \mathrm{No}$ \\
\hline
\end{tabular}

The tables discussed above show that only two of the seven attributes/relationships reached consensus in this round. In line with what was observed in the judgment of the proposition regarding time constraints (Table 22), it is noted in Table 27 that $21.62 \%$ of respondents attributed grades of equal to or less than 3 to the item 'appreciation of drafts by colleagues.' In addition, this statement achieved a low median and a high standard deviation, which also suggests the experts' disagreement on the applicability of this aspect of their research practices. The submission of drafts for assessment by colleagues is a practice that should be a habit among researchers because it helps identify weaknesses in papers before they are submitted for publication and might thus contribute to increasing acceptance rates.

Tables 28-30 are associated with the third stage of the Brinberg and McGrath (1985) schema and focus on reflexivity and neutrality, ethical issues, and auditability. The propositions that are in these tables are linked to the criteria of integrity, rigor/thoroughness, and reliability/auditability.

Table 28:

Second round - reflexivity and neutrality (descending order of percentage of grades $\geq 8$ )

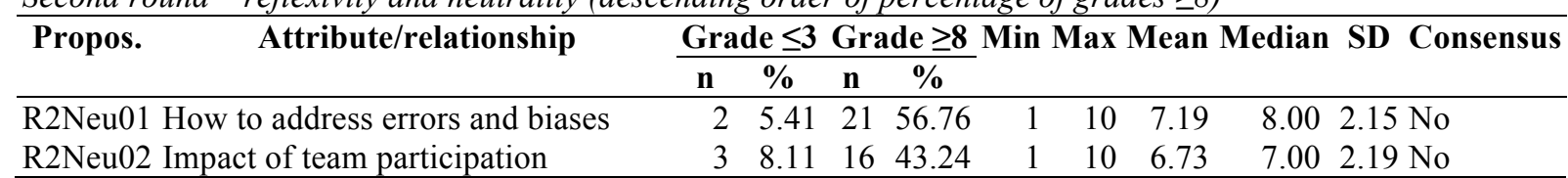


Table 29:

Second round - ethical issues (descending order of percentage of grades $\geq 8$ )

\begin{tabular}{|c|c|c|c|c|c|c|c|c|c|}
\hline \multirow[t]{2}{*}{ Attribute/relationship } & \multicolumn{4}{|c|}{ Grade $\leq 3$ Grade $\geq 8$} & \multirow{2}{*}{\multicolumn{2}{|c|}{ Min Max }} & \multirow{2}{*}{\multicolumn{2}{|c|}{ Mean Median }} & \multirow[t]{2}{*}{ SD Consensus } \\
\hline & $\mathbf{n}$ & $\%$ & n & $\%$ & & & & & \\
\hline R2Eth08 Confidentiality to participants' data & 0 & 0.00 & 25 & 96.15 & 7 & 10 & 9.54 & 10.00 & $0.81 \mathrm{Yes}$ \\
\hline R2Eth07 Strategy to mitigate possible harm & 2 & 7.69 & 21 & 80.77 & 1 & 10 & 8.15 & 9.00 & $2.48 \mathrm{Yes}$ \\
\hline R2Eth01 Registration of the study/CEP & 5 & 19.23 & 20 & 76.92 & 1 & 10 & 7.96 & 10.00 & 3.57 Yes \\
\hline R2Eth06 Formal respect for human subjects & 3 & 12.00 & 17 & 68.00 & 1 & 10 & 7.80 & 9.00 & $3.01 \mathrm{No}$ \\
\hline R2Eth05 Use of the principles of a code & 5 & 19.23 & 17 & 65.38 & 1 & 10 & 7.19 & 9.00 & $3.48 \mathrm{No}$ \\
\hline R2Eth02 Rules for registering studies/CEP & 5 & 20.00 & 16 & 64.00 & 1 & 10 & 7.04 & 9.00 & $3.55 \mathrm{No}$ \\
\hline R2Eth04 Compulsory submission to the CEP & 9 & 36.00 & 10 & 40.00 & 1 & 10 & 5.68 & 7.00 & $3.88 \mathrm{Yes}$ \\
\hline R2Eth03 Formal submission to the CEP & 7 & 28.00 & 9 & 36.00 & 1 & 10 & 5.76 & 6.00 & $3.50 \mathrm{Yes}$ \\
\hline
\end{tabular}

None of the propositions shown in Table 28 achieved consensus in this second round regarding the first two rules used to define them. Notably, the standard deviations were high: both exceeded 2. With respect to the propositions relating to ethical issues (Table 29), it is important to consider that the total number of considered responses is lower because of their specificity. The findings revealed high medians for issues relating to the confidentiality of participants' data and 'CEP to register the studies'. However, the statements 'compulsory submission to the ethics committee' and 'formal submission to the ethics committee' were the only ones that achieved consensus by more than $25 \%$ of the grades equal to or less than 3 . Finally, only three of these eight attributes/relationships did not achieve consensus based on the first two rules presented in Topic 3.3.3.

Table 30:

Second round - auditability (descending order of percentage of grades $\geq 8$ )

\begin{tabular}{lrllllllllll}
\hline \multirow{2}{*}{ Propos. Attribute/relationship } & \multicolumn{3}{c}{ Grade $\leq \mathbf{3}$} & Grade $\geq \mathbf{8}$ & Min Max Mean Median SD Consensus \\
\cline { 2 - 8 } & $\mathbf{n}$ & $\mathbf{\%}$ & $\mathbf{n}$ & $\mathbf{\%}$ & & & & & \\
\hline R2Aud01 Records of the design changes & 1 & 3.45 & 23 & 79.31 & 1 & 10 & 8.34 & 9.00 & 1.86 Yes \\
R2Aud02 Records of the reasons for changes & 1 & 3.45 & 21 & 72.41 & 1 & 10 & 8.17 & 8.00 & 1.91 No \\
R2Aud04 Guard of documents to reduce risks & 2 & 8.00 & 16 & 64.00 & 1 & 10 & 7.76 & 9.00 & 2.49 No \\
\hline
\end{tabular}

To complete the analysis of attributes/relationships evaluated in the second round of Delphi, Table 30 includes the attributes/relationships related to auditability. The findings revealed that the 'record of the design changes' item was the only one that achieved consensus at this stage. Nevertheless, the high standard deviation about the 'guard documents to reduce risks" item is highlighted. Similar to what happened to the propositions regarding data collection and ethics, items related to auditability also included the possibility of the choice of a specific alternative by researchers who do not conduct studies involving human subjects to avoid biased results. Table 31 shows the distribution of responses among researchers who did and did not conduct research involving human subjects; the reason for doing so is to identify 
the number of valid cases such that the results revealed in Tables 24,29 , and 30 can be calculated.

Table 31:

Distribution of respondents based on valid cases.

\begin{tabular}{|c|c|c|c|c|c|c|c|c|c|c|c|c|c|c|}
\hline Answer & $\begin{array}{c}\text { R2 } \\
\text { Col02 }\end{array}$ & $\begin{array}{c}\text { R2 } \\
\text { Col03 }\end{array}$ & $\begin{array}{c}\text { R2 } \\
\text { Col04 }\end{array}$ & $\begin{array}{c}\text { R2 } \\
\text { Eth01 }\end{array}$ & $\begin{array}{c}\text { R2 } \\
\text { Eth02 }\end{array}$ & $\begin{array}{c}\text { R2 } \\
\text { Eth03 }\end{array}$ & $\begin{array}{c}\text { R2 } \\
\text { Eth04 }\end{array}$ & $\begin{array}{c}\text { R2 } \\
\text { Eth05 }\end{array}$ & $\begin{array}{c}\text { R2 } \\
\text { Eth06 }\end{array}$ & $\begin{array}{c}\text { R2 } \\
\text { Eth07 }\end{array}$ & $\begin{array}{c}\text { R2 } \\
\text { Eth08 }\end{array}$ & $\begin{array}{c}\text { R2 } \\
\text { Aud01 }\end{array}$ & $\begin{array}{c}\text { R2 } \\
\text { Aud02 }\end{array}$ & $\begin{array}{c}\text { R2 } \\
\text { Aud04 }\end{array}$ \\
\hline Yes & 28 & 23 & 26 & 26 & 25 & 25 & 25 & 26 & 25 & 26 & 26 & 29 & 29 & 25 \\
\hline No & 9 & 14 & 11 & 11 & 12 & 12 & 12 & 11 & 12 & 11 & 11 & 8 & 8 & 12 \\
\hline Total & 37 & 37 & 37 & 37 & 37 & 37 & 37 & 37 & 37 & 37 & 37 & 37 & 37 & 37 \\
\hline
\end{tabular}

Yes $=$ respondent performs research that involves human beings.

The results in Table 31 showed some contradictions because of a change observed in the number of negative responses related to the use of research involving human subjects. First, on some items there was a variation in the number of respondents who declared that they conducted research involving human beings within a range of 8 to 14 respondents. Second, even for those attributes/relationships concerning data collection and auditability that did not refer to features involving studies with humans, some researchers preferred to select the differentiated alternative. As a result, nine respondents used that option in the 'Notes for divergent events' statement, which belongs to the data collection characteristic. Additionally, eight experts used the declarations 'records of design changes' and 'records of the reasons for changes,' both of which were linked to auditability and apply to all types of research.

To determine whether a third round of Delphi would be required, the results of the two previous rounds were summarized and matching was performed. In so doing, only the attributes/relationships that comprised the data collection instrument of the second round were considered. The rules described in Topic 3.3.3 - primarily the comparison of the variations of the standard deviations between the two rounds for those statements that did not achieve consensus - were taken into account, and the results are highlighted in Table 32. 
Table 32:

Consensus results after the second round.

\begin{tabular}{|c|c|c|c|c|c|c|c|c|c|c|}
\hline \multirow[t]{2}{*}{ Proposition } & \multirow[t]{2}{*}{ Key feature } & \multicolumn{3}{|c|}{$1^{\text {st }}$ round } & \multicolumn{3}{|c|}{$2^{\text {nd }}$ round } & \multirow{2}{*}{$\begin{array}{c}\% \text { variation } \\
\text { of } S D\end{array}$} & \multirow{2}{*}{$\begin{array}{c}\text { Variation } \\
\leq 25 \%\end{array}$} & \multirow{2}{*}{$\begin{array}{c}\text { Final } \\
\text { consensus }\end{array}$} \\
\hline & & Mean & SD & Cons. & Mean & SD & Cons. & & & \\
\hline R1Des03 & Design & 7.88 & 2.32 & No & 8.54 & 1.64 & Yes & 29.03 & No & Formed \\
\hline R1Des08 & & 6.44 & 2.92 & No & 7.05 & 2.71 & No & 7.15 & Yes & Formed \\
\hline R1Des09 & & 6.76 & 2.55 & No & 7.14 & 2.19 & No & 14.11 & Yes & Formed \\
\hline R1Sub02 & Subjects & 8.15 & 1.99 & No & 7.76 & 2.09 & No & -4.64 & Yes & Formed \\
\hline R1Col02 & Data coll. & 8.44 & 1.57 & No & 8.46 & 1.23 & Yes & 21.35 & Yes & Formed \\
\hline R1Col03 & & 9.37 & 1.65 & Yes & 9.65 & 0.65 & Yes & 60.88 & No & Formed \\
\hline R1Col04 & & 6.90 & 3.28 & No & 8.15 & 2.05 & No & 37.50 & No & Unformed \\
\hline R1Ana04 & Analysis & 7.07 & 1.95 & No & 7.51 & 1.33 & No & 32.18 & No & Unformed \\
\hline R1Fin05 & Findings & 8.27 & 1.10 & No & 8.16 & 1.04 & Yes & 5.00 & Yes & Formed \\
\hline R1Fin09 & & 7.44 & 1.83 & No & 7.81 & 1.17 & No & 35.84 & No & Unformed \\
\hline R1Rep01 & Reporting & 7.90 & 1.14 & No & 8.14 & 1.00 & No & 11.57 & Yes & Formed \\
\hline R1Rep02 & & 8.29 & 1.33 & No & 8.51 & 1.10 & Yes & 17.44 & Yes & Formed \\
\hline R1Rep03 & & 7.46 & 1.53 & No & 7.92 & 1.09 & No & 28.98 & No & Unformed \\
\hline R1Rep04 & & 7.49 & 1.61 & No & 7.95 & 1.70 & No & -5.23 & Yes & Formed \\
\hline R1Rep09 & & 6.54 & 2.67 & No & 6.19 & 2.93 & No & -9.65 & Yes & Formed \\
\hline R1Neu01 & Refl. /Neut. & 6.54 & 2.44 & No & 7.19 & 2.15 & No & 12.09 & Yes & Formed \\
\hline R1Neu02 & & 6.22 & 2.33 & No & 6.73 & 2.19 & No & 5.81 & Yes & Formed \\
\hline R1Eth01 & Ethical Issues & 7.49 & 3.61 & No & 7.96 & 3.57 & Yes & 0.96 & Yes & Formed \\
\hline R1Eth02 & & 6.66 & 3.81 & Yes & 7.04 & 3.55 & No & 6.79 & Yes & Formed \\
\hline R1Eth03 & & 5.95 & 3.63 & Yes & 5.76 & 3.50 & Yes & 3.38 & Yes & Formed \\
\hline R1Eth04 & & 5.56 & 3.91 & Yes & 5.68 & 3.88 & Yes & 0.80 & Yes & Formed \\
\hline R1Eth05 & & 7.02 & 3.45 & No & 7.19 & 3.48 & No & -0.87 & Yes & Formed \\
\hline R1Eth06 & & 7.22 & 3.11 & No & 7.80 & 3.01 & No & 3.11 & Yes & Formed \\
\hline R1Eth07 & & 8.12 & 2.91 & Yes & 8.15 & 2.48 & Yes & 14.84 & Yes & Formed \\
\hline R1Eth08 & & 9.07 & 1.63 & Yes & 9.54 & 0.81 & Yes & 50.34 & No & Formed \\
\hline R1Aud01 & Auditability & 7.68 & 2.61 & No & 8.34 & 1.86 & Yes & 28.90 & No & Formed \\
\hline R1Aud02 & & 7.29 & 2.63 & No & 8.17 & 1.91 & No & 27.35 & No & Unformed \\
\hline R1Aud04 & & 6.98 & 3.27 & No & 7.76 & 2.49 & No & 23.85 & Yes & Formed \\
\hline
\end{tabular}

As shown in the column in which the results of second round's consensus (yes/no) are presented, 11 of the 28 propositions comprising the data collection tool achieved consensus in the second round based on the first two rules specified in Topic 3.3.3. Next, the percentage variation of the standard deviations between the rounds was calculated, and the results are shown in the ninth column. Then, the items with a difference less than or equal to $25 \%$ to build consensus were found, as outlined in the rules, and the results are in the "Variation $\leq 25 \%$ column". Finally, items that did not result in consensus based on the parameters have been highlighted. Given these parameters, the results shaded in the last column of Table 32 showed that only five statements did not reach a consensus based on the rules described above. Because that number was less than $10 \%$ of all the attributes/relationships assessed, it was decided to eliminate the third Delphi round because the gain would only be marginal and there would be no guarantee that consensus would result for those items. 


\subsubsection{Final results}

Following the results of the two rounds of the Delphi and the determination that convening an additional round would not be relevant for data collection, the final numbers were evaluated. As previously detailed, the evaluation indicated that only five statements had not reached consensus and those statements did not justify the effort of convening another round because all of these not only displayed a high variation in standard deviations but also presented standard deviations greater than 1 , even after the second round.

The results the evaluation of the statements in the two rounds were consolidated into one list, and the outcomes obtained were considered in the stage in which consensus was built. These results were organized into a general table with eight columns: first, the key feature with which the proposition is associated; second, the assessed attributes/relationships; third, the number of valid answers; fourth, the round in which the consensus was reached; fifth, the absolute score; sixth, the relative score; seventh, the ranking by the highest relative score; and eighth, the level of agreement.

The absolute score is the sum of the grades received from the attribute/relationship in the round in which consensus was built. The relative score of each item was calculated from the proportion of the absolute score and the maximum score possible, which is the number of valid responses for each statement multiplied by the maximum score of the scale (10). This was considered the relative score, which was the basis for classifying the propositions in the rankings. Additionally, propositions have been classified into four levels based on an adaptation of the scale according to levels of agreement (Rodríguez-Mañas et al., 2013), as detailed in Topic 3.3.3. Finally, the issues that did not achieve consensus were included to provide the full list of the attributes/relationships analyzed. The results are shown in Tables 33-36 based on the level of agreement. Table 33 presents the results that reached the level of strong. 
Table 33:

Final classification - attributes/relationships with strong level of agreement.

\begin{tabular}{|c|c|c|c|c|c|c|c|}
\hline Key feat. & Attribute/relationship & $n$ & Round & Score & $\%$ & Ranking & Level \\
\hline Data coll. & Voluntary participation of subjects & 23 & 2 & 222 & 96.52 & $1^{\mathrm{o}}$ & Strong \\
\hline Design & Goal/problem shown precisely & 41 & 1 & 395 & 96.34 & $2^{\circ}$ & Strong \\
\hline Ethics & Confidentiality to participants' data & 26 & 2 & 248 & 95.38 & $3^{\circ}$ & Strong \\
\hline Reporting & Conclusions $\mathrm{x}$ aim & 41 & 1 & 377 & 91.95 & $4^{\mathrm{o}}$ & Strong \\
\hline Findings & Comparison results $\mathrm{x}$ other studies & 41 & 1 & 373 & 90.98 & $5^{\circ}$ & Strong \\
\hline Findings & Check links of findings $\mathrm{x}$ purpose & 41 & 1 & 373 & 90.98 & $5^{\circ}$ & Strong \\
\hline Reporting & Literature review $\mathrm{x}$ main concepts & 41 & 1 & 373 & 90.98 & $5^{\circ}$ & Strong \\
\hline Reporting & Theory to support propositions & 41 & 1 & 371 & 90.49 & $8^{\circ}$ & Strong \\
\hline Design & Useful strategy for purpose & 41 & 1 & 369 & 90.00 & $9^{\circ}$ & Strong \\
\hline Findings & Previous findings $\mathrm{x}$ hypothesis & 41 & 1 & 369 & 90.00 & $9^{\circ}$ & Strong \\
\hline Auditability & Safeguard databases for checks & 41 & 1 & 367 & 89.51 & $11^{\circ}$ & Strong \\
\hline Design & Arguments for technique choices & 41 & 1 & 366 & 89.27 & $12^{\circ}$ & Strong \\
\hline Findings & Link between findings $\mathrm{x}$ evidence & 41 & 1 & 363 & 88.54 & $13^{\circ}$ & Strong \\
\hline Data coll. & Notes for each research step & 41 & 1 & 361 & 88.05 & $14^{\circ}$ & Strong \\
\hline Findings & New areas based on the findings & 41 & 1 & 361 & 88.05 & $14^{\circ}$ & Strong \\
\hline Findings & Path to achieve conclusions & 41 & 1 & 359 & 87.56 & $16^{\circ}$ & Strong \\
\hline Design & Clear overview that guides the study & 41 & 1 & 358 & 87.32 & $17^{\circ}$ & Strong \\
\hline Analysis & Description of tools and procedures & 41 & 1 & 358 & 87.32 & $17^{\circ}$ & Strong \\
\hline Subjects & Criteria to design/select subjects & 41 & 1 & 352 & 85.85 & $19^{\circ}$ & Strong \\
\hline Design & Access to the data & 41 & 1 & 351 & 85.61 & $20^{\circ}$ & Strong \\
\hline Analysis & Description of nature $\&$ form of data & 41 & 1 & 351 & 85.61 & $20^{\circ}$ & Strong \\
\hline Analysis & Significance of data to reaching aims & 41 & 1 & 351 & 85.61 & $20^{\circ}$ & Strong \\
\hline Findings & Does the context allow replication & 41 & 1 & 351 & 85.61 & $20^{\circ}$ & Strong \\
\hline Design & Overview x strategy & 37 & 2 & 316 & 85.41 & $24^{\circ}$ & Strong \\
\hline Reporting & Disclosure of limitations & 37 & 2 & 315 & 85.14 & $25^{\circ}$ & Strong \\
\hline Design & Overview $\mathrm{x}$ theory & 41 & 1 & 349 & 85.12 & $26^{\circ}$ & Strong \\
\hline Analysis & Implicit/explicit links - find. $x$ aims & 41 & 1 & 349 & 85.12 & $26^{\circ}$ & Strong \\
\hline Data coll. & Notes for divergent events & 28 & 2 & 237 & 84.64 & $28^{\circ}$ & Strong \\
\hline Reporting & Explicit possibility of generalization & 41 & 1 & 345 & 84.15 & $29^{\circ}$ & Strong \\
\hline Auditability & Records of design changes & 29 & 2 & 242 & 83.45 & $30^{\circ}$ & Strong \\
\hline Analysis & Context $\mathrm{x}$ impact on data analysis & 41 & 1 & 341 & 83.17 & $31^{\circ}$ & Strong \\
\hline Findings & Insights for thinking about the field & 37 & 2 & 302 & 81.62 & $32^{\circ}$ & Strong \\
\hline Ethics & Strategy to mitigate possible harm & 26 & 2 & 212 & 81.54 & $33^{\circ}$ & Strong \\
\hline Reporting & Discussion of impact on knowledge & 37 & 2 & 301 & 81.35 & $34^{\circ}$ & Strong \\
\hline Ethics & Registration of the study/CEP & 26 & 2 & 207 & 79.62 & $35^{\circ}$ & Strong \\
\hline Reporting & Boundaries of the study & 37 & 2 & 294 & 79.46 & $36^{\circ}$ & Strong \\
\hline Ethics & Formal respect for human subjects & 25 & 2 & 195 & 78.00 & $37^{\circ}$ & Strong \\
\hline Auditability & Guard documents to reduce risks & 25 & 2 & 194 & 77.60 & $38^{\circ}$ & Strong \\
\hline Subjects & Representativeness of subjects & 37 & 2 & 287 & 77.57 & $39^{\circ}$ & Strong \\
\hline
\end{tabular}

The findings revealed that $73.58 \%$ of the propositions received the level of strong acceptance. Moreover, it appears that of the ten items that achieved the highest relative scores and those at the top of the ranking, the criteria of internal validity/credibility or defensibility stand out with four statements, and the criteria of integrity and suitability stand out with two statements each. The 'voluntary participation of subjects' attribute, which is linked to the criterion of integrity, achieved the highest relative score. However, it did not achieve the highest absolute score because it achieved consensus in the second round, when the number of answers was lower. The item that earned the highest absolute score was 'goal/problem 
shown precisely', which is related to the criterion of suitability and obtained 395 points out of a possible 410 .

With respect to the principal characteristics, the findings relating to the ten betterranked attributes/relationships revealed that 'findings' and 'reporting' had the highest number of items included in the top 10 ranking, each with three statements. With respect to the number of propositions linked to each general criterion, feasibility had the lowest percentage of items with a high level of acceptance, equivalent to $33.33 \%$, which is followed by integrity, with $50 \%$ of the items. Conversely, internal validity/credibility or defensibility obtained the highest number of statements with a high level of acceptance, with eight propositions that are equivalent to $80 \%$ of the declarations related to this criterion. Table 34 shows the group of propositions that were classified as having a moderate level of agreement.

Table 34:

Final classification - attributes/relationships with moderate level of agreement.

\begin{tabular}{lllrrrrr}
\hline \multicolumn{1}{c}{ Key feat. } & \multicolumn{1}{c}{ Attribute/relationship } & $\boldsymbol{n}$ & Round & Score & \% & Ranking & Level \\
\hline Ethics & Use of the principles of a code & 26 & 2 & 187 & 71.92 & $1^{\text {o }}$ & Moderate \\
Refl./Neutr. & How to address errors and biases & 37 & 2 & 266 & 71.89 & $2^{\text {o }}$ & Moderate \\
Design & Research strategy x target audience & 37 & 2 & 264 & 71.35 & $3^{\text {o }}$ & Moderate \\
Design & Time constraints & 37 & 2 & 261 & 70.54 & $4^{\text {o }}$ & Moderate \\
Ethics & Rules for registering studies/CEP & 25 & 2 & 176 & 70.40 & $5^{\text {o }}$ & Moderate \\
Refl./Neutr. & Impact of team participation & 37 & 2 & 249 & 67.30 & $6^{\text {o }}$ & Moderate \\
\hline
\end{tabular}

The findings revealed that six of the items were classified as having a moderate level of agreement and consensus on these statements was achieved in the second round. Moreover, it is noted that three of these items are associated with the integrity criterion and two are associated with feasibility and rigor. These findings suggest that some of these elements have no significant weight in the respondents' research practices, which might be cause for concern because crucial aspects of conducting those studies are included among the propositions with a moderate level of agreement. Examples of this inclusion include time constraints for carrying out the research, some aspects related to ethical issues, and disclosure of how the researcher addressed errors and biases arising during the study. With respect to the key features, the propositions with a moderate level of acceptance refer to ethics, reflexivity/neutrality, and research design. These findings, with lower acceptable levels, may suggest the existence of a possible misalignment between the methodological, substantive, and theoretical domains of the VNS (Brinberg \& McGrath, 1985; Brinberg, 1982; McGrath \& Brinberg, 1983). Table 35 shows the attributes/relationships that obtained a low level of agreement. 
Table 35:

Final classification - attributes/relationships with low level of agreement.

\begin{tabular}{lllrrrrr}
\hline \multicolumn{1}{c}{ Key feat. } & \multicolumn{1}{c}{ Attribute/relationship } & $\boldsymbol{n}$ & Round & Score & $\%$ & Ranking & Level \\
\hline Reporting & Appreciation of drafts by colleagues & 37 & 2 & 229 & 61.89 & $1^{\text {o }}$ & Low \\
Ethics & Formal submission to the CEP & 25 & 2 & 144 & 57.60 & $2^{\text {o }}$ & Low \\
Ethics & Compulsory submission to the CEP & 25 & 2 & 142 & 56.80 & $3^{\text {o }}$ & Low \\
\hline
\end{tabular}

Table 35 shows that the three items that have a low level of agreement are related to rigor/thoroughness and internal validity/credibility or defensibility. Moreover, the statement regarding appreciation of preliminary versions (drafts) by peers is associated with the reporting stage, and the other two statements are related to the ethical aspects of formal and compulsory submission of research projects to ethical committees.

The appraisal of preliminary versions of research reports by colleagues plays a significant role in identifying potential problems and suggesting points for improvement. Such appraisal also helps increase a paper's consistency and logical coherence. As a result, it is believed that such an appraisal may enhance the possibility of a manuscript being approved for conferences and publications because it reduces the effects of possible failures that might be identified in the peer review and that might lead to a rejected submission.

Findings relating to the formal and mandatory submission of research projects involving human beings to the Ethics Committee for Research (CEP) may suggest a certain weakness associated with rigor/thoroughness and integrity. As is the case internationally, Brazilian law requires that all studies involving human subjects be submitted for assessment and prior approval by an ethics committee in order to ensure that research complies with general ethical principles such as respect for each participant's dignity and autonomy. Thus, Brazilian legislation requires that the informed consent describes the study's purpose, goals, and procedures, clarify any possible discomfort and risks of participation, and specify the form of monitoring and assistance to which all participants have a right, even after completion of the study (Brasil, 2012, 2013). Additionally, studies must not only ensure that participants are granted full freedom but also assure their confidentiality and privacy during all stages of research. In this manner, the law guarantees not only human subjects' rights but also protection for the researcher and any institutions involved against possible risks. These practices are consistent with international principles of respect for persons, beneficence, and justice (National Institutes of Health, 1979), along with accountability, respect, and integrity (European Science Foundation, 2011; OADS, 2012). One of the respondents, for example, highlighted in the open question that his or her institution has a Research Ethics Committee for the submission and approval of research designs. However, only projects linked to 
graduate programs (dissertations and theses) are currently required to submit their research designs to the committee. Other studies involving human beings that do not fit within this rule are typically not submitted for committee approval.

There are at least three practical effects of compliance with ethical standards covering research involving humans:

(a) ensuring that the research complies with internationally accepted standards of integrity;

(b) mitigating risks for the researcher and the institution related to possible court challenges by participants who have felt harmed to some extent as a result of study participation; and

(c) increasing external validity and relevance, which may culminate in greater acceptance by the scientific community and a greater chance of obtaining funding.

Notably, the Operational Norm n. 001/2013 (Brasil, 2013) envisages that in cases of complaints and ethical infraction situations - particularly those that imply risks to research participants - there should be an examination that might involve sanctions, including a demand for an investigation by the Brazilian prosecution system. Table 36 shows the results of those propositions that have not achieved consensus.

Table 36:

Final classification - attributes/relationships with unformed consensus.

\begin{tabular}{lllrrrrrr}
\hline \multicolumn{1}{c}{ Key feat. } & \multicolumn{1}{c}{ Attribute/relationship } & $\boldsymbol{n}$ & Round & Score & \% & Ranking & Level \\
\hline Auditability & Records of the reasons for changes & 29 & 2 & 237 & 81.72 & $1^{\mathbf{o}}$ & Unformed \\
Data coll. & Formal agreement from humans & 26 & 2 & 212 & 81.54 & $2^{\text {o }}$ & Unformed \\
Reporting & Reasons for limitations & 37 & 2 & 293 & 79.19 & $3^{\text {o }}$ & Unformed \\
Findings & Impact from the nature of divergences & 37 & 2 & 289 & 78.11 & $4^{\text {o }}$ & Unformed \\
Analysis & Other views to explain context & 37 & 2 & 278 & 75.14 & $5^{\text {o }}$ & Unformed \\
\hline
\end{tabular}

The consensus definition unformed appearing in Table 36 was based on the failure to comply with the three rules set forth in Topic 3.3.3. The five attributes and relationships that did not achieve consensus are associated with the criteria of integrity and reliability/auditability (with two propositions each) and the criteria of internal validity/credibility or defensibility (with one proposition). Although the final scores are equivalent to a strong level of agreement, none of the items reached $75 \%$ for scores equal to or greater than 8 , which was one of the criteria required to establish consensus and which was shown in Table 32. Each of the stages of research process referred to is associated with a distinct feature. 
The two attributes/relationships related to integrity were 'formal agreement of human beings' concerning the declaration of agreement to participate in the study and 'reasons for limitations' on research. The first attribute must be expressly obtained by means of the participant's signature on the informed consent and is a means of protecting both the researcher and the participant regarding compliance with legal requirements for research involving human subjects. In turn, the item about limitations highlights the need to provide the target audience with a frank explanation of the reasons that contributed to generating those constraints. Furthermore, the exposure of study limitations contributes to increasing a study's external validity because the scope of findings becomes more obvious and researchers will be able to choose ways to mitigate limitations in future studies. The attributes/relationships relating to reliability/auditability are 'records of the reasons for changes' and 'other views to know the context'. The first is related to the proper and accurate representation the methodology followed in developing the study, comparing what was originally planned with what was actually done and recording the reasons for any changes. Therefore, this is a measure that enables checking procedures. The other views on understanding the context contribute to offering alternative solutions to the research problem; adequate characterization of the context is relevant because it allows a comparison of the findings with those of other studies. The final attribute/relationship is 'impact on the nature of divergences' and involves internal validity/credibility or defensibility. The discussion of the nature and source of possible divergences aims to highlight their potential effects on the study's findings. In addition to bringing more logical connection to the study, discussion of divergences augments consistency by showing how to reach the study's conclusions and is also associated with the possibility of identifying alternative approaches to solving the proposed problem in light of the data. Finally, Figure 19 shows the distribution of statements based on levels of agreement. 


\section{Distribution of statements by agreement levels}

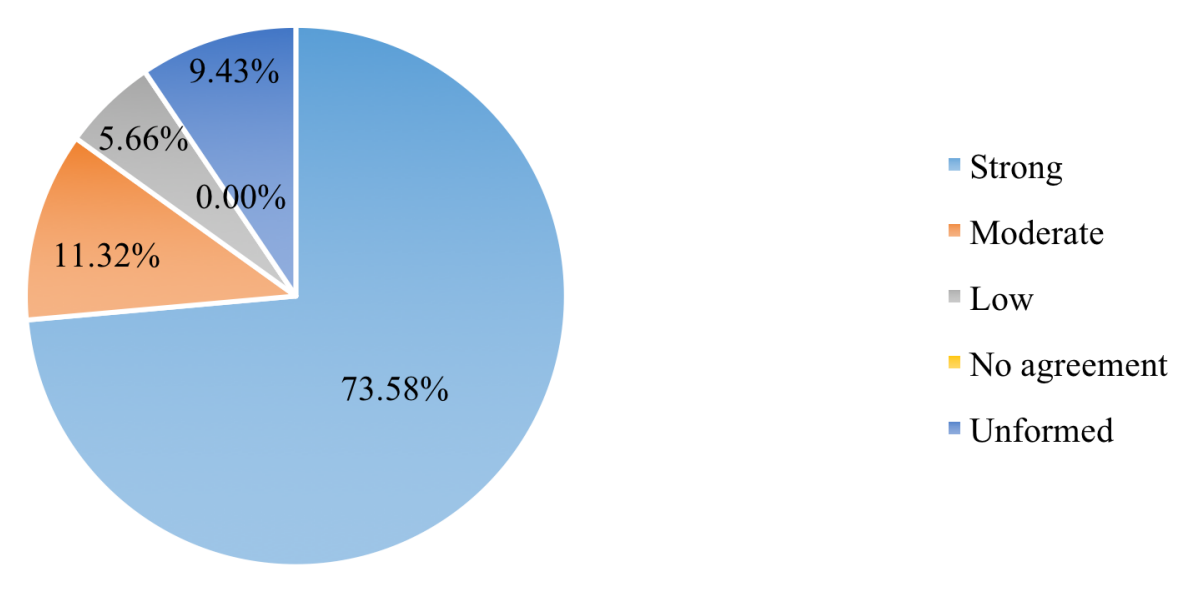

Figure 19: Distribution of statements by agreement levels.

As observed in Figure 19, approximately 3/4 of the statements showed a strong level of agreement. Moreover, considering the model adapted from Rodríguez-Mañas et al. (2013) for a definition of the agreement levels, there was no proposition with a relative score of less than $50 \%$, which would be characterized as no agreement.

\subsection{An Approach to Judging the Quality of the Research Process in Accounting}

After the presentation of the Delphi results, and after taking into account the importance of the link between research quality criteria and respondents' perceptions of the statements' consistency with their practices, it was decided to complete the analysis by presenting an approach to assess the quality of accounting research. Thus, the present study suggests a set of elements to evaluate the research process in the field from the stages of the research process (key features), attributes/relationships, general criteria for research quality, and domains of scientific investigation.

A visual representation of the distribution of criteria at each level was generated to more clearly highlight representativeness and to assess the respondents' levels of agreement as to the suitability/adherence of statements to their research practices. These results are displayed in Figure 20. 


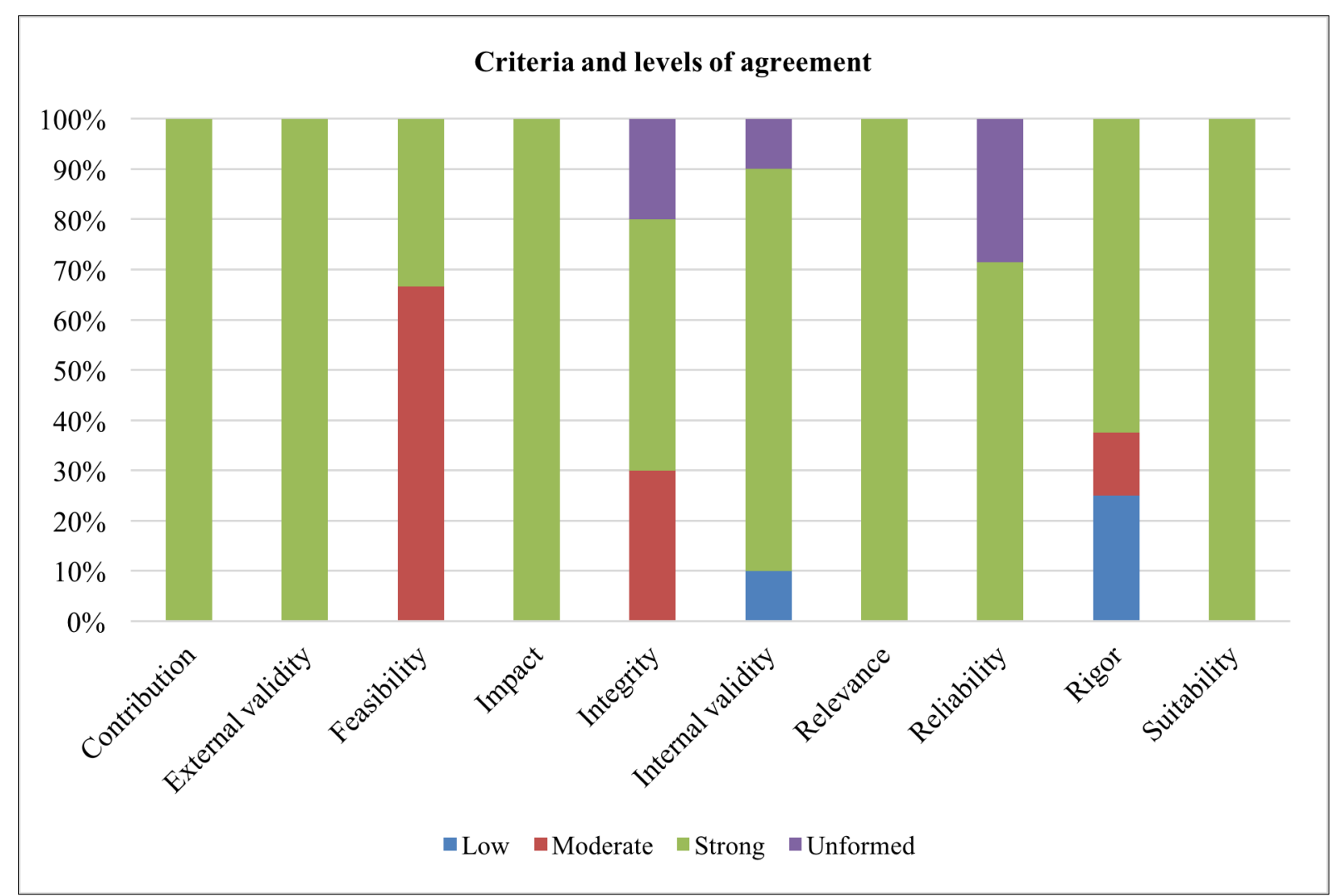

Figure 20: Criteria and levels of agreement.

The graphic representation reveals that statements regarding the contribution/quality of the theoretical perspective, external validity or generalization/fittingness, relevance, and suitability show a strong adherence in respondents' opinion. Approximately $65 \%$ of the items related to the feasibility criterion are at a moderate level. Although this level does not necessarily indicate the occurrence of serious failures, these results should be noted as studies are developed because they are associated with elements such as research design dimensioning when taking time constraints into account and considering the target audience when selecting one's research strategy. Another criterion that had moderate-level propositions was integrity, at 35\%, which requires attention to issues such as how the researcher addressed errors and biases and the impact of the research team's participation. Low-level assertions concentrated on the criteria of internal validity/credibility or defensibility and rigor. Notably, approximately $1 / 4$ of the items concerning rigor obtained a low level of agreement, indicating a point of concern to be considered by researchers in suggesting that there are weaknesses in the conduct of their studies.

The items that did not achieve consensus are associated with the integrity, internal validity/credibility or defensibility, and reliability/auditability criteria. The findings suggest that these are issues on which there are discrepancies or lower average acceptance among the 
respondents. This situation is clear when looking at the individual data, which reveal that between $26.92 \%$ and $43.24 \%$ of the respondents attributed grades 5-7 to such statements. Moreover, some of these statements had the highest possible grade range $(10,6,5,5$, and 10 , respectively), which indicates a dispersion of the data that led to the non-formation of consensus, even after having obtained high relative scores, as shown in Table 36.

Finally, as displayed in Table 31, it is notable that the number of valid responses to each statement has varied significantly, which explains why the same number of answers indicating a particular grade does not represent the same relative share compared with other propositions analyzed. In addition, it should be emphasized that there is an imbalance in the number of statements associated with each criterion, as demonstrated in Figure 12. As a result, the analysis of the relative share of one attribute/relationship in the level-based distribution of answers representing the criteria in figures on this topic is proportionally different. For example, whereas only one item is associated with impact, ten items are related to the criteria of integrity and internal validity/credibility or defensibility. Figure 21 shows the distribution by key features and levels of agreement.

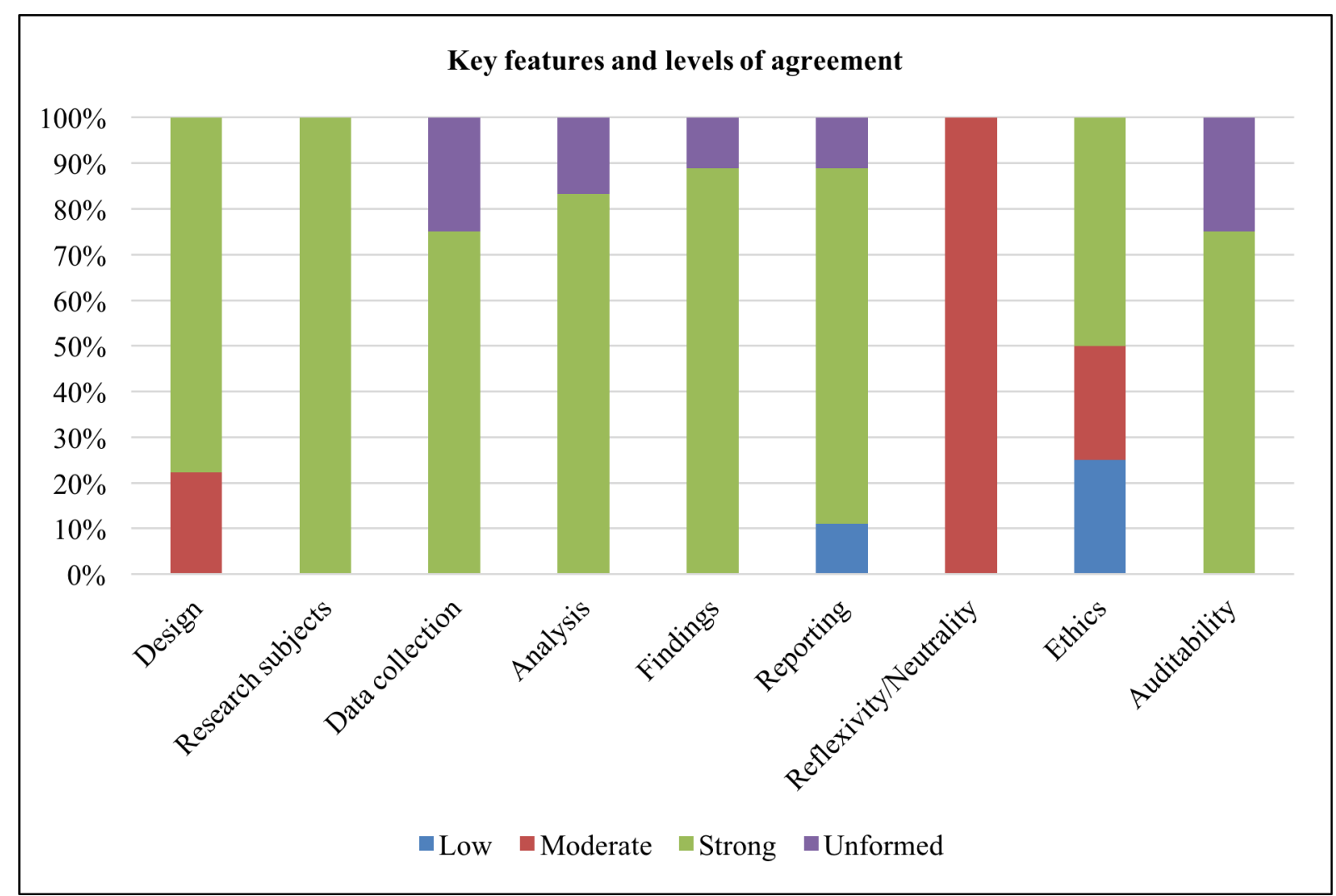

Figure 21: Key features and levels of agreement. 
By focusing on the essential features and levels of agreement, Figure 21 showed that 'research subjects' was the only characteristic with a strong level of acceptance. Conversely, reflexivity/neutrality showed the moderate level of all propositions. In addition, 'ethics' and 'reporting' were the features in which low-level statements were concentrated. Approximately $25 \%$ of the ethics-related propositions presented a low level of acceptance. This finding suggests that researchers must care more about such procedures, which in addition to the associated legal aspects can indicate not only a failure to fulfill the essential characteristics of research integrity but also weaknesses in methodological rigor in conducting the study. Ethical issues were the only feature that had statements at the three levels of agreement: low, moderate, and strong. Additionally, data collection, analysis, findings, reporting, and auditability have concentrated propositions whose consensus was not formed. Finally, for the data collection and auditability stages, this result represented $25 \%$ of the items.

Intending to structure the proposal for an approach to assess quality in the research process in accounting, the structure of the logic model was employed. This model is widely applied to evaluate programs and projects for both processes and outcomes (or variance). A logic model for process evaluation is structured in inputs, processes/activities, and process indicators/outputs. The approach based on the logic model considers as inputs the stages of the research process (Figure 22). Initially, this approach admitted the three phases proposed by Brinberg and McGrath (1985), which this work calls the first (planning), second (execution) and third (results monitoring - outcomes) phases. Additionally, the nine key features (Mays \& Pope, 2006; Spencer et al., 2003) were grouped into these three stages in the following distribution: (1) design and research subjects; (2) data collection, analysis, findings, and reporting; and (3) reflexivity/neutrality, ethics, and auditability.

The attributes and relationships used in the Delphi data collection instruments were considered to characterize the processes and activities proposed in the logic model. This association was made on the grounds that those attributes and relationships adequately represented the processes, considering that the building of the device itself was based on the respondents' research practices, i.e., in activities performed at different stages of their studies. The statements were grouped according to the key feature and the quality criterion that are associated with one another.

With respect to the process indicators/outputs, the criteria used to group the statements were allocated, i.e., they are associated with the attributes/relationships that are defined as processes/activities. Additionally, some potential implications of either violating or ignoring 
these criteria were submitted and therefore, used the domain structure of the validity network schema (VNS).

In conclusion, it must be emphasized that this approach intends to contribute to the discussion of quality criteria for building and performing research (the process). It is less focused on final results (product evaluation). This approach merely attempts to help accounting researchers self-evaluate their studies' quality. It does not intend to replace other frameworks for research evaluation. 
LOGIC MODEL TO EVALUATE THE RESEARCH PROCESS

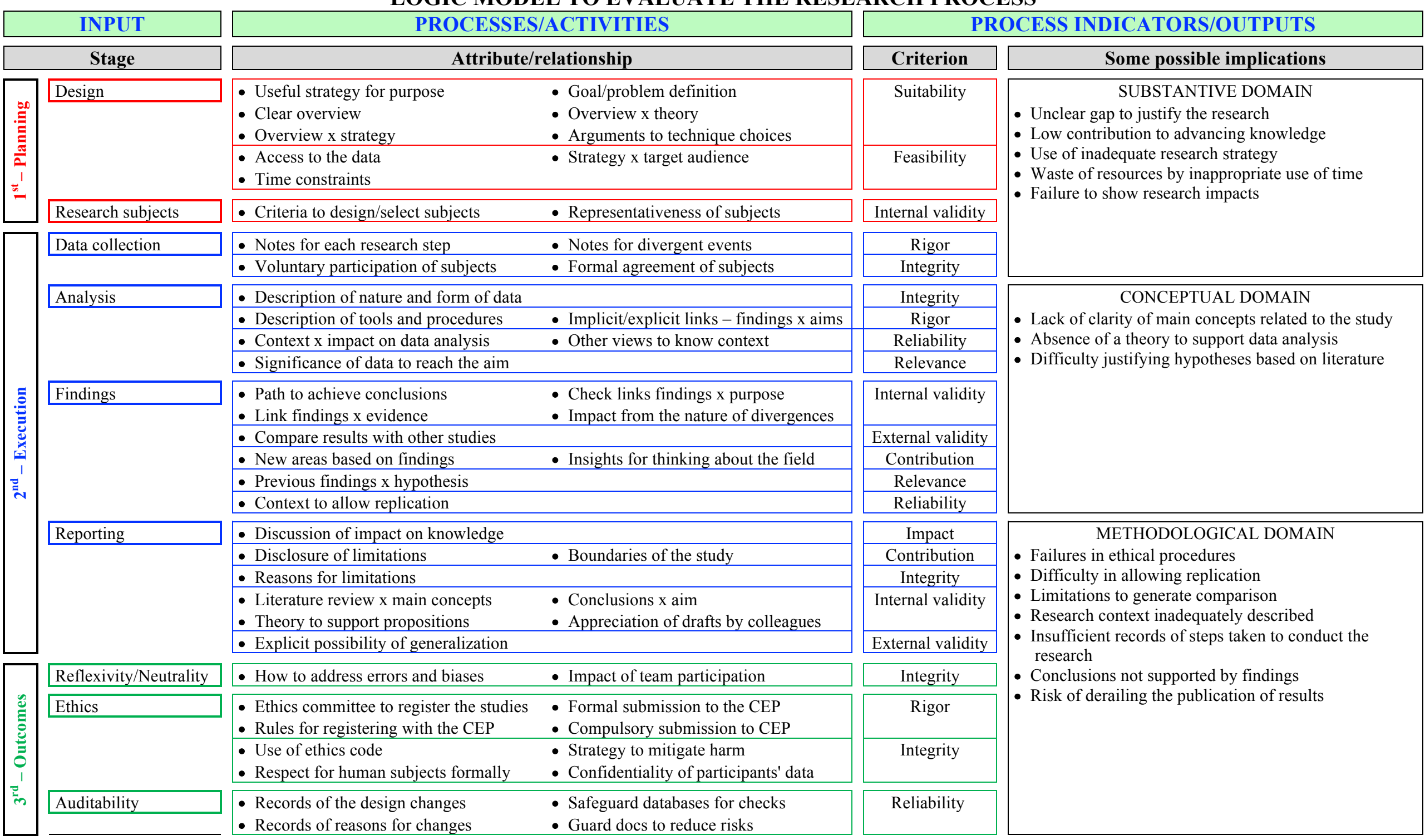

Figure 22: Logic model to evaluate the research process. 
This chapter presents the conclusions of the study and is divided into three topics. The first topic presents final remarks with a summary of the findings and a description of how the goals that were initially proposed were met (or not met). The second topic presents the impacts and recommendations of this study. The third topic makes suggestions for future studies.

\subsection{Final Remarks}

My personal motivation for discussing research quality arose just over five years ago and spurred my interest in developing this study during my graduate program. This motivation has encouraged me to participate in research forums, conferences, and other discussions and to deepen my reading of the aspects related to what may or may not direct the judgment of research quality in accounting in Brazil. Every research activity requires choices; here, the strategy selected was study perceptions and procedures using the Modified Delphi Technique. That technique was chosen because it has been shown to be feasible and allows experts to build a consensus regarding research practices. This technique has been widely used in other areas of knowledge, particularly in studies designed to assess quality attributes and to create clinical guidelines and protocols.

It must be remembered that there is always a risk associated with proposing a discussion of research quality that focuses on more general criteria. As evidenced in the literature review, different paradigms make different assumptions in analyzing a phenomenon, and the choice of particular criteria can always be a point of criticism, depending on who is making the judgment. Additionally, the literature shows that each stakeholder group will have its own yardstick for judging quality; moreover, each group judges quality beginning from different interests, a fact that in itself demonstrates the difficulty of selecting a set of general criteria to guide judgment regarding the process of producing scientific knowledge.

To identify the quality attributes of good research based on the literature, which was undertaken in Stage 1 as described in the research design, a search was performed that led to the identification of the VNS (Brinberg \& McGrath, 1985), and the framework for assessing research evidence (Mays \& Pope, 2006; Spencer et al., 2003), along with other sources that 
help elucidate the evaluation of the research process. The collected sources supported the choice of a set of 10 quality criteria and 53 attributes/relationships related to the research process to guide the construction of the data collection instrument for the first round of the modified Delphi. Additionally, criteria for evaluating the scientific production of graduate programs' faculty that were established by regulatory quality were presented. These standards are critical because they are considered not only in the definition of the triennial grade assigned to each graduate program but also by development institutions as a measure of the impact and relevance of a researcher's production during evaluation processes for research grants and funding.

Questions about respondents' characterization revealed that most of the experts surveyed have a doctoral degree in accounting that was obtained from another national institution, most did not participate in an exchange program during their doctorate work and did not undertake post-doctoral work, and more than $70 \%$ have less than seven years of experience in a graduate program. The data revealed that most of the respondents are members of an editorial board, all the respondents act as referees for scientific periodicals, most of the respondents have or have previously obtained research funding, approximately one-third of the respondents have productivity grants, and almost half of the respondents serve or have served as a journal editor. These findings demonstrate that the expert panel consisted of a qualified audience to evaluate the research process.

The first goal is to observe the stages of the research process in which the attributes of good research are revealed in the practices of Brazilian accounting researchers. To meet this goal, the second stage of the study was conducted by data collecting using the Modified Delphi Technique for consensus building. The first round of Delphi explored 53 attributes/relationships identified in the literature, and the findings revealed that 25 of those attributes/relationships achieved consensus during this step. The data revealed that the attributes are not distributed evenly among the nine stages of the research process used to organize the data collection. They also showed that the extent to which certain attributes/relationships are present in the research practices of Brazilian accounting researchers varies significantly, which is evidenced by the high range of answers, considering the scale used. Finally, it was observed that there is a high level of acceptance of certain attributes/relationships, shown by the number of proposals that have reached the consensus in the Delphi first round.

To achieve the second aim, which was to compare the literature attributes with those identified in accounting research practices, the consolidated results of two rounds of Delphi 
were examined. The purpose of this examination was to determine the extent to which the attributes/relationships adhered to research practices in Brazilian accounting; in other words, we sought to identify the level of acceptance of declarations related to those attributes/relationships through the respondents' perceptions. Approximately three-quarters of the statements indicated a strong level of agreement, and 10 of the statements achieved a percentage higher than $90 \%$. Conversely, attributes that achieved only low or moderate levels of acceptance presented significant elements that might compromise the quality and integrity of accounting research. The attributes related to formal and non-formal ethical principles, the need to demonstrate how researchers addressed errors and biases, and the disclosure of the impact of the research team's participation on the results all fit this description. Additionally, some attributes/relationships did not achieve consensus by obtaining a greater number of values between 5-7; those attributes/relationships also deserve attention for mitigating the possible effects that reduce the quality of scientific production in the accounting field.

The study's final goal was to present an approach based on the attributes of good research to judge the quality of scientific production in accounting. The first matter analyzed pursuant to this approach was the relationship between criteria and levels of agreement. A visual representation of that matter has shown that rigor/thoroughness and internal validity/credibility or defensibility have concentrated the low-level statements. In other words, there were evident discrepancies between the attributes/relationships derived from the literature and research practices' adherence to those attributes/relationships in the field, based on the respondents' perceptions. Additionally, more than half of the items associated with feasibility were classified at the moderate level, and most of the elements that did not achieve consensus concern reliability, followed by integrity and internal validity/credibility or defensibility. The second aspect analyzed in the approach was the relationship between criteria and key features. The visual representation stressed that the items with a low level of agreement are linked to ethics and reporting. Furthermore, all the propositions concerning reflexivity/neutrality reached the moderate level, which also occurred with some items related to ethics and research design. Finally, the statements that did not achieve consensus are distributed by five of the nine key features.

The findings that emerged from the Delphi Technique application - in addition to two aspects initially discussed in the approach - validate Hypothesis 1, which established that some current practices used in building the scientific-production process in accounting in Brazil do not adequately meet the quality attributes of good research described in the literature. This position is supported both by the high ranges characterizing the answers to 
several items, and by the low acceptance of elements related to ethics, for which Brazilian law does not provide flexibility. In turn, the occurrence of a low level of agreement on issues related to rigor and ethics, along with statements regarding integrity and feasibility that reached the moderate level, are consistent with the acceptance of Hypothesis 2. This second hypothesis stated that the Brazilian institutional environment contributes to reduce the quality of scientific production in accounting as the result of institutional failures that may have substantial effects on research integrity. One striking example of this phenomenon is the compulsory submission of research projects involving human subjects to ethics committees, which is required by Brazilian law but which has achieved only a low level of acceptance. Other ethical issues involving formal and non-formal elements also experienced moderate or low levels of acceptance.

To complete the approach regarding attributes of good research to judge the quality of production, a logic model was designed to help evaluate the research process. The model considered the stages of the research process as inputs, and the processes and activities were linked to attributes/relationships. Certain criteria and possible implications in every domain of scientific investigation were presented as part of the process indicators/outputs. It should be stressed that this approach is not intended to be a comprehensive guideline; instead, it only seeks to identify elements to enable researchers to self-evaluate their studies for compliance with the criteria for the planning, execution, and evaluation of research results.

Given these considerations, this study concludes that there is a clear answer to the research problem, based on the findings and the proposed approach, thus confirming the stated thesis that some Brazilian accounting researchers' practices, in combination with local institutional environments, contribute to reduce the quality of accounting research.

\subsection{Impacts and Recommendations}

Although the approach encompasses the three domains of investigation proposed in the VNS, the methodological dimension is considered to be better represented in statements because of the nature of such statements. The methodological dimension enables researchers to perceive/address the fact that choices made at each step can result in careful and useful research while helping researchers avoid mistakes discussed in the literature that compromise the quality and integrity of studies in the field.

With respect to this study's expected impacts, it is believed that the issues that it presents, along with the logic model used to evaluate the research process, can contribute to 
encouraging the target audience to reconsider their research strategies and re-orient certain practices that have developed that might not be consistent with good practices. Furthermore, it is expected that upon learning about the findings, graduate programs will seek to improve aspects of new researchers' training so that such weaknesses in knowledge production related to accounting can be avoided.

With respect to this study's recommendations, it is important to stress the need to intensify training related to ethical issues in graduate accounting programs to mitigate failures in the conduct of studies that might compromise those studies' integrity and even make it impossible to publish their results. Furthermore, graduate accounting programs are encouraged to specify that the submission of research projects involving human subjects is an internal requirement to sit for the qualification examination. Finally, it is recommended to require approval by the Ethics Committee on Research with Human Beings as a necessary condition for delivering a thesis or dissertation for final defense.

\subsection{Suggestions for Future Studies}

Studies involving analysis of research processes logically pique interest in evaluating not only each stage of the process but also the role of stakeholders in the production of knowledge. Therefore, future studies should be undertaken to understand graduate students' perceptions of the attributes/relationships analyzed to identify possible mistakes and failures related to training new accounting researchers. Additionally, another relevant inquiry might be to discuss the roles of editors and referees as responsible parties in validating quality, in contrast to their perception of research quality.

Other general topics also affect the quality of the scientific production process and can be the subject of future studies. For example, subjects of future studies might include the use of traditional and less innovative research designs, the relation between choices and methods to establish the research's actual contribution, consciousness of replication to avoid rehashing theory, and features regarding the endogeneity of referees who comprise the body of evaluators in the field's journals. Finally, institutional issues of research practice involving scientific production, such as ethical issues, productivism, and salami science to achieve scores established by the graduate regulator should also be considered as subjects of future research. 



\section{REFERENCES}

Abbagnano, N. (2007). Dicionário de Filosofia. São Paulo: Martins Fontes.

Adler, R., \& Liyanarachchi, G. (2011). An empirical examination of the editorial review processes of accounting journals. Accounting and Finance. http://doi.org/10.1111/j.1467629X.2010.00378.x

AEA, A. E. A. American Evaluation Association Guiding Principles For Evaluators (2004). Retrieved from http://www.eval.org/p/cm/ld/fid=51

Amara, N., \& Landry, R. (2012). Counting citations in the field of business and management: Why use Google Scholar rather than the Web of Science. Scientometrics, 93, 553-581. http://doi.org/10.1007/s11192-012-0729-2

Amara, N., Landry, R., \& Halilem, N. (2015). What can university administrators do to increase the publication and citation scores of their faculty members? Scientometrics, 103(2), 489-530. http://doi.org/10.1007/s11192-015-1537-2

Amin, M., \& Mabe, M. (2007). Impact factors: use and abuse. Perspectives in Publishing, 1(October), 1-6. Retrieved from http://cdn.elsevier.com/assets/pdf_file/0014/111425/Perspectives1.pdf

Andrade, J. X. (2011). Má conduta na pesquisa em ciências contábeis (Doctoral dissertation). Universidade de São Paulo. Retrieved from http://www.teses.usp.br/teses/disponiveis/12/12136/tde-10062011-172859/

André, M. (2001). Pesquisa em educação: buscando rigor e qualidade. Cadernos de Pesquisa, (113), 51-64. http://doi.org/10.1590/S0100-15742001000200003

Antunes, M. T. P., Mendonça Neto, O. R. de, Oyadomari, J. C. T., \& Okimura, R. T. (2011). Conduta ética dos pesquisadores em contabilidade: diferenças entre a crença e a práxis. Revista Contabilidade \& Finanças, 22(57), 319-337. http://doi.org/10.1590/S151970772011000300006

Aragão, I. R. B. N., Oliveira, J. R. S., \& Lima, G. A. S. F. de. (2014). Resonance of articles and impact factor of Brazilian Accounting Journals. Revista de Educação E Pesquisa Em Contabilidade (Journal of Education and Research in Accounting), 8(1), 5-21.

Babbie, E. R. (2010). The practice of social research (12th ed.). Belmont: Wadsworth/CENGAGE.

Ballas, A., \& Theoharakis, V. (2003). Exploring diversity in accounting through Faculty journal perceptions. Contemporary Accounting Research, 20(4), 619-44. http://doi.org/10.1506/MLWH-KBTM-ET47-LYKH

Baxter, J., \& Chua, W. W. F. (2003). Alternative management accounting research-whence and whither. Accounting, Organizations and Society, 28(2-3), 97-126. http://doi.org/10.1016/S0361-3682(02)00022-3

Beck, C. T. (1993). Qualitative Research: The Evaluation of Its Credibility, Fittingness, and 
Auditability. Western Journal of Nursing Research, 15(2), 263-266.

http://doi.org/10.1177/019394599301500212

Brasil. Resolução 466, de 12 de dezembro de 2012 (2012). Conselho Nacional de Saúde. Retrieved from http://conselho.saude.gov.br/resolucoes/2012/Reso466.pdf

Brasil. Norma Operacional CNS N 001 / 2013 (2013). Conselho Nacional de Saúde.

Retrieved from http://conselho.saude.gov.br/web_comissoes/conep/aquivos/CNS Norma Operacional 001 - conep finalizada 30-09.pdf

Brinberg, D. (1982). Validity Concepts in Research: an Integrative Approach. Advances in Consumer Research, 9(1), 40-44.

Brinberg, D., \& McGrath, J. E. (1985). Validity and the research process. Newbury Park: Sage Publications.

Brinn, T., Jones, M., \& Pendlebury, M. (2001). Why Do Uk Accounting and Finance Academics Not Publish in Top Us Journals? The British Accounting Review, 33(2), 223 232. http://doi.org/10.1006/bare.2001.0160

Brown, L. D., \& Gardner, J. C. (1985). Using Citation Analysis to Assess the Impact of Journals and Articles on Contemporary Accounting Research (CAR). Journal of Accounting Research, 23(1), 84-109. http://doi.org/10.2307/2490908

Brown, L. D., \& Huefner, R. J. (1994). The Familiarity with and Perceived Quality of Accounting Journals: Views of Senior Accounting Faculty in Leading U.S. MBA Programs. Contemporary Accounting Research, 11(1), 223-250. http://doi.org/10.1111/j.1911-3846.1994.tb00442.x

Campbell, S. M., Braspenning, J., Hutchinson, A., \& Marshall, M. (2002). Research methods used in developing and applying quality indicators in primary care. Quality and Safety in Health Care, 11(4), 358-364. http://doi.org/10.1136/qhc.11.4.358

CAPES, (Coordenação de Aperfeiçoamento de Pessoal de Nível Superior). (2012). Comunicado No. 002/2012 - Área de Administração, Ciências Contábeis e Turismo Atualização do Webqualis da Área. Brasília. Retrieved from https://www.capes.gov.br/images/stories/download/avaliacao/Qualis_Administracao.pdf

CAPES, (Coordenação de Aperfeiçoamento de Pessoal de Nível Superior). (2013). Documento de Área: Administração, Ciências Contábeis e Turismo, Avaliação Trienal 2013. Brasília, Brasil. Retrieved from https://www.capes.gov.br/images/stories/download/avaliacaotrienal/Docs_de_area/Admi nistração_doc_area_e_comissão_16out.pdf

CAPES, (Coordenação de Aperfeiçoamento de Pessoal de Nível Superior). (2015a). Ofício Circular $n^{\circ}$ 022/2015 - DAV/CAPES. Oficio Circular. Assunto: Divulgacão Da Atualização Do Qualis Periódicos 2013 E 2014.

CAPES, (Coordenação de Aperfeiçoamento de Pessoal de Nível Superior). (2015b). Relatório do processo de classificação de periódicos. Área de Administração, Ciências Contábeis e Turismo. Quadriênio 2013-2016 (Maio de 2015). Retrieved from https://www.capes.gov.br/images/documentos/RelatorioQualisAdministracao- 


\section{5final.pdf}

Carmona, S. (2006). Performance Reviews, the Impact of Accounting Research, and the Role of Publication Forms. Advances in Accounting, 22(06), 241-267.

http://doi.org/10.1016/S0882-6110(06)22011-X

Chan, K. C., Chang, C. H., Tong, J. Y., \& Zhang, F. (2012). An analysis of the accounting and finance research productivity in Australia and New Zealand in 1991-2010. Accounting and Finance, 52(July 2011), 249-265. http://doi.org/10.1111/j.1467629X.2011.00440.x

Clarkson, P. M. (2012). Publishing: art or science? Reflections from an editorial perspective. Accounting \& Finance, 52(2), 359-376. http://doi.org/10.1111/j.1467629X.2012.00472.x

Cooper, D. S., \& Schindler, P. S. (2003). Métodos de pesquisa em administração (7th ed.). Porto Alegre: Bookman.

Creswell, J. W., Klassen, L. a. C., Clark, V. L. P., \& Smith, L. K. C. (2011). Best practices for mixed methods research in the health sciences. Office of Behavioral and Social Sciences Research National Institutes of Health. Retrieved September, 29, 2011. Retrieved from https://tigger.uic.edu/jaddams/college/business_office/Research/Best_Practices_for_Mix ed_Methods_Research.pdf

Crotty, M. (1998). Introduction: the research process. In The foundations of social research: Meaning and perspective in the research process (p. 256). Sage Publications.

Cunha, J. V. A. da. (2007). Doutores em Ciências Contábeis da FEA/USP: análise sob a óptica da teoria do capital humano (Doctoral dissertation). Universidade de São Paulo. Retrieved from http://www.teses.usp.br/teses/disponiveis/12/12136/tde-17102007173046/pt-br.php

Davidson, E. J. (2005). Evaluation methodology basics: the nuts and bolts of sound evaluation. (Sage Publications, Ed.) (1st ed.). Thousand Oaks: Sage Publications.

Davies, D., \& Dodd, J. (2002). Qualitative Research and the Question of Rigor. Qualitative Health Research, 12(2), 279-289. http://doi.org/10.1177/104973230201200211

Deckers, K., van Boxtel, M. P., Schiepers, O. J., de Vugt, M., Muñoz Sánchez, J. L., Anstey, K. J., ... Köhler, S. (2015). Target risk factors for dementia prevention: a systematic review and Delphi consensus study on the evidence from observational studies. Int $J$ Geriatr Psychiatry, 30, 234-246. http://doi.org/10.1002/gps.4245

Denscombe, M. (2010). The Good Research Guide. Open University Press.

Doyle, J., \& Arthurs, A. (1995). Judging the quality of research in business schools: the UK as a case study. Omega, 23(3), 257-270. Retrieved from http://www.sciencedirect.com/science/article/pii/030504839500013E

Dunbar, A. E., \& Weber, D. P. (2014). What influences accounting research? A citationsbased analysis. Issues in Accounting Education, 29(1), 1-60. http://doi.org/10.2308/iace50603 
Elwyn, G., O’Connor, A., Stacey, D., Volk, R., Edwards, A., Coulter, A., ... Whelan, T. (2006). Developing a quality criteria framework for patient decision aids: online international Delphi consensus process. BMJ (Clinical Research Ed.), 333(7565), 417. http://doi.org/10.1136/bmj.38926.629329.AE

European Science Foundation. (2011). The European Code of Conduct for Research Integrity. Strasbourg. Retrieved from

http://www.esf.org/fileadmin/Public_documents/Publications/Code_Conduct_ResearchI ntegrity.pdf

Evans, J. H., Feng, M., Hoffman, V. B., Moser, D. V., \& Van der Stede, W. A. (2015). Points to Consider When Self-Assessing Your Empirical Accounting Research. Contemporary Accounting Research, 32(3), 1162-1192. http://doi.org/10.1111/1911-3846.12133

FAPESP. (2011). Boas práticas científicas: carta de encaminhamento da Diretoria Científica ao Conselho Superior da FAPESP. São Paulo: Fundação de Amparo à Pesquisa do Estado de São Paulo.

FAPESP. (2012a). Code of good scientific practice. Sao Paulo: Fundação de Amparo à Pesquisa do Estado de São Paulo.

FAPESP. (2012b). Código de boas práticas científicas. São Paulo: Fundação de Amparo à Pesquisa do Estado de São Paulo.

FAPESP. Portaria PR N 05 / 2013 - Dispõe sobre a divulgação das práticas de más condutas científicas apuradas pela FAPESP (2013). Brasil: Fundação de Amparo à Pesquisa do Estado de São Paulo.

Flick, U. (2009). Qualidade na pesquisa qualitativa (Coleção Pe). Porto Alegre: Artmed.

Garfield, E. (1972). Citation Analysis as a Tool in Journal Evaluation. Science (New York, N.Y.), 178(60), 471-479.

Garfield, E. (1999). Journal impact factor: a brief review. CMAJ: Canadian Medical Association Journal = Journal de l'Association Medicale Canadienne, 161(8), 979-980.

Gephart, R. (1999). Paradigms and research methods. Academy of Management Research Methods Forum, 4(Summer 1999).

Given, L. M. (2008). The Sage Encyclopedia of Qualitative Research Methods. The MIT Press. http://doi.org/10.4135/9781412963909

Godoy, A. S. (2005). Refletindo sobre critérios de qualidade da pesquisa qualitativa. Revista Eletrônica de Gestão Organizacional, 3(2, mai/ago.), 81-89. Retrieved from http://www.revista.ufpe.br/gestaoorg/index.php/gestao/article/viewFile/136/118

Graham, B., Regehr, G., \& Wright, J. G. (2003). Delphi as a method to establish consensus for diagnostic criteria. Journal of Clinical Epidemiology, 56(12), 1150-1156. http://doi.org/10.1016/S0895-4356(03)00211-7

Greene, J. C. (2007). Mixed Methods in Social Inquiry (1st ed.). San Francisco: Wiley. 
Greene, J. G. (1988). Stakeholder Participation and Utilization in Program Evaluation. Evaluation Review, 12(2), 91-116. http://doi.org/10.1177/0193841X8801200201

Guba, E. G., \& Lincoln, Y. S. (1994). Competing paradigms in qualitiative research. In N. K. Denzin \& Y. S. Lincoln (Eds.), Handbook of qualitative research (pp. 105-117). Sage Publications.

Healy, M., \& Perry, C. (2000). Comprehensive criteria to judge validity and reliability of qualitative research within the realism paradigm. Qualitative Market Research: An International Journal, 3(3), 118-126. http://doi.org/10.1108/13522750010333861

Hostetler, K. (2005). What Is "Good" Education Research? Educational Researcher, 34(6), 16-21. http://doi.org/10.3102/0013189X034006016

Hug, S. E., Ochsner, M., \& Daniel, H. D. (2013). Criteria for assessing research quality in the humanities: A delphi study among scholars of english literature, german literature and art history. Research Evaluation, 22(August), 369-383. http://doi.org/10.1093/reseval/rvt008

Jones, M. J., Brinn, T., \& Pendlebury, M. (1996). Judging the quality of research in business schools: A comment from accounting. Omega, 24(5), 597-602. http://doi.org/10.1016/0305-0483(96)00036-9

Jones, M. J., \& Xiao, J. Z. (2004). Financial reporting on the Internet by 2010: A consensus view. Accounting Forum, 28(July 2001), 237-263. http://doi.org/10.1016/j.accfor.2004.07.002

Justo, C. (2005). A Técnica Delphi de Formação de Consensos. Retrieved from http://www.opss.pt/sites/opss.pt/files/A-Tecnica-Delphi-de-Formacao-de-Consensos.pdf

Kalichman, M., \& Plemmons, D. (2007). Reported goals for responsible conduct of research courses. Academic Medicine, 82(9), 846-852. Retrieved from http://journals.lww.com/academicmedicine/Abstract/2007/09000/Reported_Goals_for_R esponsible_Conduct_of_Research.6.aspx

Kelbaugh, B. M. (2003). Exploration of teamwork in extension: identifying indicators of success using a modified delphi study (Ph.D. dissertation). The Ohio State University. Retrieved from https://etd.ohiolink.edu/ap:10:0:::10:P10_ACCESSION_NUM:osu1054604099

Kim, K. K., O’Bryan, C. a., Crandall, P. G., Ricke, S. C., \& Neal, J. a. (2013). Identifying baseline food safety training practices for retail delis using the Delphi expert consensus method. Food Control, 32(1), 55-62. http://doi.org/10.1016/j.foodcont.2012.10.009

Le Pair, C. (1995). Formal evaluation methods: their utility and limitations. International Forum on Information and Documentation, 20, 16-24 ST - Formal evaluation methods: Their utili. Retrieved from <Go to ISI $>$ :/WOS:A1995TV97400002

LeCompte, M. D., \& Goetz, J. P. (1982). Problems of Reliability and Validity in Ethnographic Research. Review of Educational Research, 52(1), 31-60. http://doi.org/10.3102/00346543052001031 
Libby, R., Bloomfield, R., \& Nelson, M. W. (2002). Experimental research in financial accounting. Accounting, Organizations and Society, 27(8), 775-810. http://doi.org/10.1016/S0361-3682(01)00011-3

Lowe, A., \& Locke, J. (2005). Perceptions of journal quality and research paradigm: results of a web-based survey of British accounting academics. Accounting, Organizations and Society, 30(1), 81-98. http://doi.org/10.1016/j.aos.2004.05.002

Lowensohn, S., \& Samelson, D. P. (2006). An Examination of Faculty Perceptions of Academic Journal Quality within Five Specialized Areas of Accounting Research. Issues in Accounting Education, 21(3), 219-239.

Martins, O. S., \& Lucena, W. G. L. (2014). Produtivismo acadêmico: as práticas dos docentes dos programas de pós-graduação em contabilidade. Advances in Scientific and Applied Accounting, 7(1), 66-96. http://doi.org/10.14392/asaa.2014070103

Mays, N., \& Pope, C. (1995). Qualitative Research: Rigour and qualitative research. BMJ, 311(6997), 109-112. http://doi.org/10.1136/bmj.311.6997.109

Mays, N., \& Pope, C. (2006). Quality in qualitative health research. In Qualitative research in health care (3rd ed., pp. 82-101). London: Blackwell Pub./BMJ Books. Retrieved from http://eprints.soton.ac.uk/64477/

McGrath, J. E., \& Brinberg, D. (1983). External Validity and the Research Process : A Comment on the Calder / Lynch Dialogue. Journal of Consumer Research, 10(1), 115124.

Mendonça Neto, O. R. de O., Riccio, E. L., \& Sakata, M. C. G. (2009). Dez anos de pesquisa contábil no Brasil: análise dos trabalhos apresentados nos Enanpads de 1996 a 2005. Revista de Administração de Empresas, 49(1), 62-73.

Meyrick, J. (2006). What is good qualitative research? A first step towards a comprehensive approach to judging rigour/quality. Journal of Health Psychology, 11(5), 799-808. http://doi.org/10.1177/1359105306066643

Michaelis. (2012). Michaelis Moderno Dicionário da Língua Portuguesa (versão online). Editora Melhoramentos. Retrieved from http://michaelis.uol.com.br/moderno/portugues/index.php

Miranda, G. J., Azevedo, R. F. L., \& Martins, G. de A. (2011). Teses das teses em contabilidade na USP. REPEC Revista de Educação E Pesquisa Em Contabilidade, 5(2, mai/ago), 21-42.

Moizer, P. (2009). Publishing in accounting journals: A fair game? Accounting, Organizations and Society, 34(2), 285-304. http://doi.org/10.1016/j.aos.2008.08.003

Morell, J. A. (2010). Logic Models - Beyond the Traditional View: Metrics, Methods, Expected and Unexpected Change. In American Evaluation Association Annual Meeting - November 2-5. Anaheim, California: American Evaluation Association.

National Institutes of Health. (1979). The Belmont Report. The Belmont Report Ethical Principles and Guidelines for the Protection of Human Subjects of Research, 4-6. 
Retrieved from http://www.salesianos-cadiz.com/Descargas/Escolar/ESOBachillerato/Bachillerato/2do Bachillerato/2do A/InformeBelmont.pdf

Northcott, D., \& Linacre, S. (2010). Producing spaces for academic discourse: The impact of research assessment exercises and journal quality rankings. Australian Accounting Review, 20, 38-54. http://doi.org/10.1111/j.1835-2561.2010.00079.x

OADS. (2012). CDC Guidance on Scientific Integrity. Retrieved from http://www.cdc.gov/od/science/docs/CDCSIGuide_021612.pdf

OHRP, \& DHHS. (2009). Code of Federal Regulations - Title 45: Public Welfare and Title 46: Protection of Human Subjects. 45 CFR 46, 1-14. Retrieved from papers2://publication/uuid/9C582C3B-CB51-4C48-A6D0-4AC885DDB8FA

Patton, M. Q. (2002). Qualitative research \& evaluation methods (3rd ed.). Thousand Oaks: Sage Publications.

Pinto, L. A. (2008). Cientometria: é possível avaliar qualidade da pesquisa científica? Scientia, 18(2, abr./jun.), 64-65.

Pozzebon, M. (2004). Conducting and evaluating critical interpretative research: examining criteria as a key component in building a research tradition. Information Systems Research: Relevant Theory and ..., (July 2002), 1-20. Retrieved from http://link.springer.com/content/pdf/10.1007/1-4020-8095-6_16.pdf

Reiter, S. A., \& Williams, P. F. (2002). The structure and progressivity of accounting research: the crisis in the academy revisited. Accounting, Organizations and Society, 27(6), 575-607. http://doi.org/10.1016/S0361-3682(01)00050-2

Rodríguez-Mañas, L., Féart, C., Mann, G., Viña, J., Chatterji, S., Chodzko-Zajko, W., ... Vega, E. (2013). Searching for an operational definition of frailty: A delphi method based consensus statement. the frailty operative definition-consensus conference project. Journals of Gerontology - Series A Biological Sciences and Medical Sciences, 68(1), 6267. http://doi.org/10.1093/gerona/gls119

Rossi, P. H., Lipsey, M. W., \& Freeman, H. E. (2004). Evaluation: a systematic approach (7th ed.). Thousand Oaks: Sage Publications.

Rynes, S., \& Gephart, R. P. (2004). From the editors: Qualitative Research and the Academy of Management Journal. Academy of Management Journal, 47(4), 454-462. http://doi.org/10.5465/AMJ.2004.14438580

Sakamoto, A. (2011). Inovação em rede de PMEs: fatores determinantes e consequências sociais. Fundação Getúlio Vargas. Retrieved from http://bibliotecadigital.fgv.br/dspace/handle/10438/8188

Schwartzman, S. (1988). Qualidade e relevância da pesquisa universitária: 10 teses para discussão. Retrieved from http://www.schwartzman.org.br/simon/10teses.htm

Shamoo, A., \& Resnik, D. (2003). Responsible conduct of research. New York: Oxford University Press. Retrieved from http://books.google.com/books?hl=en\&lr=\&id=RLZinf9eooC\&oi $=$ fnd \&pg $=$ PA3\&dq $=$ responsible + conduct + of + research\&ots $=$ RGF $5 \mathrm{kYyHAc} \&$ 
sig=qubYPUXknzdQJEw7JEdDeIabm9s

Skulmoski, G. J., Graham, F. T., \& Krahn, J. (2007). The Delphi method for graduate research. Journal of Information Technology Education, 6, 1-21. Retrieved from http://bern.library.nenu.edu.cn/upload/soft/0-article/+03/JITEv6p001021Skulmoski212.pdf

Smith, J. K. (1984). Judging Interpretive Inquiry. Educational Evaluation and Policy Analysis, 6(4), 379-391.

Spencer, L., Ritchie, J., Lewis, J., \& Dillon, L. (2003). Quality in Qualitative Evaluation : A framework for assessing research evidence A Quality Framework. Social Research, 108(21/08/05), 170.

Steneck, N. H. (2007). ORI Introduction to the Responsible Conduct of Research. Department of Health \& Human Services-USA.

Stufflebeam, D. L. (2000). Lessons in Contracting for Evaluations. American Journal of Evaluation, 21(3), 293-314. http://doi.org/10.1177/109821400002100302

Taylor-Powell, E., \& Henert, E. (2008). Developing a logic model : Teaching and training guide.

Taylor, J. (2011). The assessment of research quality in UK universities: Peer review or metrics? British Journal of Management, 22(2), 202-217. http://doi.org/10.1111/j.14678551.2010.00722.x

Tetzlaff, J. M., Moher, D., \& Chan, A.-W. (2012). Developing a guideline for clinical trial protocol content: Delphi consensus survey. Trials, 13, 176. http://doi.org/10.1186/17456215-13-176

Theóphilo, C., \& Iudícibus, S. (2005). Uma análise crítico-epistemológica da produção científica em contabilidade no Brasil. UnB Contábil, 8(2, jul/dez), 147-175. Retrieved from http://www.cgg-amg.unb.br/index.php/contabil/article/viewArticle/164

Uncles, M. D., \& Kwok, S. (2013). Designing research with in-built differentiated replication. Journal of Business Research, 66(9), 1398-1405.

http://doi.org/10.1016/j.jbusres.2012.05.005

Valentine, J. C. (2009). Judging the quality of primary research. In H. Cooper, L. V Hedges, \& J. C. Valentine (Eds.), The Handbook of Research Synthesis and Meta-Analysis (pp. 129-146). Russell Sage Foundation.

Van de Ven, A. H., \& Poole, M. S. (2005). Alternative Approaches for Studying Organizational Change. Organization Studies, 26(9), 1377-1404. http://doi.org/10.1177/0170840605056907

Van der Stede, W. a., Young, S. M., \& Chen, C. X. (2005). Assessing the quality of evidence in empirical management accounting research: The case of survey studies. Accounting, Organizations and Society, 30(7-8), 655-684. http://doi.org/10.1016/j.aos.2005.01.003

Webster, J., \& Watson, R. T. (2002). Analyzing the Past to Prepare for the Future: Writing a 
Literature Review. MIS Quarterly, 26, xiii - xxiii. http://doi.org/10.1.1.104.6570

Weiss, C. H. (1997). Evaluation (2nd ed.). New Jersey: Prentice Hall.

Whittemore, R., Chase, S. K., \& Mandle, C. L. (2001). Validity in qualitative research. Qualitative Health Research, 11(4), 522-537. http://doi.org/10.1177/104973201129119299

Williams, P. F. (2014). The Myth of Rigorous Accounting Research. Accounting Horizons, 28(4), 869-887. http://doi.org/10.2308/acch-50880

Worrell, J. L., Di Gangi, P. M., \& Bush, A. A. (2013). Exploring the use of the Delphi method in accounting information systems research. International Journal of Accounting Information Systems, 14(3), 193-208. http://doi.org/10.1016/j.accinf.2012.03.003

Yarbrough, D. B., Shulha, L. M., Hopson, R. K., \& Caruthers, F. A. (2011). The program evaluation standards: a guide for evaluators and evaluation users (3rd ed.). Thousand Oaks: Sage Publications. 

Appendix A: Matrix of Orientation for Data Collection Instruments (Delphi Online)

\begin{tabular}{|c|c|c|c|c|c|c|c|c|c|}
\hline N. & Stage & Dom. & $\begin{array}{l}\text { Key Feature } \\
\text { Spencer et al. }\end{array}$ & Criterion & Focus & Source(s) & Question (Spencer et al) & Attribute/ Relationship & Statement for Delphi \\
\hline 1 & One & $\mathrm{S}$ & Design & Suitability & Usefulness & Denscombe & How defensible is the research design? & $\begin{array}{l}\text { Useful strategy for } \\
\text { purpose }\end{array}$ & $\begin{array}{l}\text { My studies show reasons/justification } \\
\text { for choosing the research strategy. }\end{array}$ \\
\hline 2 & One & $\mathrm{S}$ & Design & Suitability & Appropriateness & Denscombe & How defensible is the research design? & $\begin{array}{l}\text { Clear overview that } \\
\text { guides the study }\end{array}$ & $\begin{array}{l}\text { I am able to recognize the assumptions } \\
\text { of the overview (paradigm or theoretical } \\
\text { lens) that guides the building of my } \\
\text { studies. }\end{array}$ \\
\hline 3 & One & $\mathrm{S}$ & Design & Suitability & Appropriateness & Denscombe & How defensible is the research design? & Overview x strategy & $\begin{array}{l}\text { I consider a particular overview and its } \\
\text { assumptions when I choose the strategy } \\
\text { to build my research design. }\end{array}$ \\
\hline 4 & One & $\mathrm{S}$ & Design & Suitability & Appropriateness & Denscombe & How defensible is the research design? & $\begin{array}{l}\text { Goal/problem shown } \\
\text { precisely }\end{array}$ & $\begin{array}{l}\text { My studies show precisely the } \\
\text { goal/problem that they want to reach or } \\
\text { solve. }\end{array}$ \\
\hline 5 & One & $\mathrm{C}$ & Design & Suitability & Appropriateness & Denscombe & How defensible is the research design? & Overview $\mathrm{x}$ theory & $\begin{array}{l}\text { I consider a particular paradigm and its } \\
\text { assumptions when I choose the theory to } \\
\text { support my research (theoretical } \\
\text { platform). }\end{array}$ \\
\hline 6 & One & $\mathrm{S}$ & Design & Suitability & Usefulness & Denscombe & How defensible is the research design? & $\begin{array}{l}\text { Arguments for } \\
\text { technique choices }\end{array}$ & $\begin{array}{l}\text { I present arguments for choosing } \\
\text { techniques and procedures to gather and } \\
\text { analyze the data for my research. }\end{array}$ \\
\hline 7 & One & $\mathrm{M}$ & Design & Feasibility & $\begin{array}{l}\text { Access to data } \\
\text { sources }\end{array}$ & Denscombe & How defensible is the research design? & Access to the data & $\begin{array}{l}\text { The research strategy is chosen } \\
\text { considering the access to the data } \\
\text { sources that are required to perform the } \\
\text { research. }\end{array}$ \\
\hline 8 & One & $\mathrm{M}$ & Design & Feasibility & Time constraints & Denscombe & How defensible is the research design? & Time constraints & $\begin{array}{l}\text { I choose the research strategy based on } \\
\text { the time required to collect the data and } \\
\text { present the results in accordance with } \\
\text { the purpose of the research. }\end{array}$ \\
\hline 9 & One & $\mathrm{S}$ & Design & Feasibility & Audience & Denscombe & How defensible is the research design? & $\begin{array}{l}\text { Research strategy } \mathrm{x} \\
\text { target audience }\end{array}$ & $\begin{array}{l}\text { I consider the profile of the likely } \\
\text { audience of my study when I choose the } \\
\text { research strategy. }\end{array}$ \\
\hline 10 & One & $\mathrm{M}$ & $\begin{array}{l}\text { Research } \\
\text { subjects }\end{array}$ & $\begin{array}{l}\text { Internal validity / } \\
\text { credibility or } \\
\text { defensibility }\end{array}$ & Representativeness & $\begin{array}{l}\text { André, Brinberg \& } \\
\text { Mcgrath, Spencer } \\
\text { et al }\end{array}$ & $\begin{array}{l}\text { How well defended is the sample } \\
\text { design/target collection of } \\
\text { cases/documents? }\end{array}$ & $\begin{array}{l}\text { Criteria to design/select } \\
\text { subjects }\end{array}$ & $\begin{array}{l}\text { I present the criteria used to } \\
\text { design/select the research subjects } \\
\text { explicitly based on the population of } \\
\text { interest. }\end{array}$ \\
\hline 11 & One & $\mathrm{M}$ & $\begin{array}{l}\text { Research } \\
\text { subjects }\end{array}$ & $\begin{array}{l}\text { Internal validity / } \\
\text { credibility or } \\
\text { defensibility }\end{array}$ & Logical coherence & $\begin{array}{l}\text { Spencer et al, } \\
\text { Brinberg \& } \\
\text { Mcgrath }\end{array}$ & $\begin{array}{l}\text { Sample composition/case inclusion- } \\
\text { how well is the eventual coverage } \\
\text { described? }\end{array}$ & $\begin{array}{l}\text { Representativeness of } \\
\text { subjects }\end{array}$ & $\begin{array}{l}\text { My studies formally describe methods } \\
\text { and inclusion/exclusion cases that might } \\
\text { have an impact on the representativeness } \\
\text { of the research subjects. }\end{array}$ \\
\hline
\end{tabular}




\begin{tabular}{|c|c|c|c|c|c|c|c|c|c|}
\hline N. & Stage & Dom. & $\begin{array}{l}\text { Key Feature } \\
\text { Spencer et al. }\end{array}$ & Criterion & Focus & Source(s) & Question (Spencer et al) & Attribute/ Relationship & Statement for Delphi \\
\hline 12 & Two & M & Data collection & $\begin{array}{l}\text { Rigor / } \\
\text { thoroughness }\end{array}$ & $\begin{array}{l}\text { Methodological } \\
\text { rigor }\end{array}$ & $\begin{array}{l}\text { Spencer et al, } \\
\text { Brinberg \& } \\
\text { Mcgrath }\end{array}$ & $\begin{array}{l}\text { How well was the data collection } \\
\text { carried out? }\end{array}$ & $\begin{array}{l}\text { Notes for each research } \\
\text { step }\end{array}$ & $\begin{array}{l}\text { Typically, I take notes on the steps and } \\
\text { actions performed during data } \\
\text { collection. }\end{array}$ \\
\hline 13 & Two & M & Data collection & $\begin{array}{l}\text { Rigor/ } \\
\text { thoroughness }\end{array}$ & $\begin{array}{l}\text { Methodological } \\
\text { rigor }\end{array}$ & $\begin{array}{l}\text { Spencer et al, } \\
\text { Brinberg \& } \\
\text { Mcgrath }\end{array}$ & $\begin{array}{l}\text { How well was the data collection } \\
\text { carried out? }\end{array}$ & $\begin{array}{l}\text { Notes for divergent } \\
\text { events }\end{array}$ & $\begin{array}{l}\text { I typically write down details about } \\
\text { events that diverge from the research } \\
\text { design that arise during data collection. }\end{array}$ \\
\hline 14 & Two & M & Data collection & Integrity & Ethics & Denscombe & $\begin{array}{l}\text { What evidence is there of attention to } \\
\text { ethical issues? }\end{array}$ & $\begin{array}{l}\text { Voluntary participation } \\
\text { of subjects }\end{array}$ & $\begin{array}{l}\text { When my study involves human beings, } \\
\text { they are invited, and they participate } \\
\text { only voluntarily. }\end{array}$ \\
\hline 15 & Two & M & Data collection & Integrity & Ethics & Denscombe & $\begin{array}{l}\text { What evidence is there of attention to } \\
\text { ethical issues? }\end{array}$ & $\begin{array}{l}\text { Formal agreement from } \\
\text { humans }\end{array}$ & $\begin{array}{l}\text { All the participants of my studies that } \\
\text { involve human beings agree to and sign } \\
\text { (or expressly declare) informed consent. }\end{array}$ \\
\hline 16 & Two & M & Analysis & Integrity & Logic of inquiry & $\begin{array}{l}\text { Spencer et al, } \\
\text { Brinberg \& } \\
\text { Mcgrath }\end{array}$ & $\begin{array}{l}\text { How well has the approach to and } \\
\text { formulation of the analysis been } \\
\text { conveyed? }\end{array}$ & $\begin{array}{l}\text { Description of nature } \\
\text { and form of data }\end{array}$ & $\begin{array}{l}\text { My studies show a detailed description } \\
\text { of the nature and form of the collected } \\
\text { original data. }\end{array}$ \\
\hline 17 & Two & M & Analysis & $\begin{array}{l}\text { Rigor / } \\
\text { thoroughness }\end{array}$ & $\begin{array}{l}\text { Methodological } \\
\text { rigor }\end{array}$ & $\begin{array}{l}\text { Spencer et al, } \\
\text { Brinberg \& } \\
\text { Mcgrath }\end{array}$ & $\begin{array}{l}\text { How well has the approach to and } \\
\text { formulation of the analysis been } \\
\text { conveyed? }\end{array}$ & $\begin{array}{l}\text { Description of tools and } \\
\text { procedures }\end{array}$ & $\begin{array}{l}\text { Tools and procedures for data analysis } \\
\text { are carefully presented. }\end{array}$ \\
\hline 18 & Two & $\mathrm{S}$ & Analysis & $\begin{array}{l}\text { Reliability / } \\
\text { auditability }\end{array}$ & Consistency & $\begin{array}{l}\text { Spencer et al, } \\
\text { Brinberg \& } \\
\text { Mcgrath }\end{array}$ & $\begin{array}{l}\text { Contexts of data sources - how well are } \\
\text { they retained and portrayed? }\end{array}$ & $\begin{array}{l}\text { Context } \mathrm{x} \text { impact on } \\
\text { data analysis }\end{array}$ & $\begin{array}{l}\text { I show details of the context in which } \\
\text { the data were collected that might } \\
\text { have/have had an impact on the data } \\
\text { analysis. }\end{array}$ \\
\hline 19 & Two & $\mathrm{S}$ & Analysis & $\begin{array}{l}\text { Reliability / } \\
\text { auditability }\end{array}$ & Consistency & $\begin{array}{l}\text { Spencer et al, } \\
\text { Brinberg \& } \\
\text { Mcgrath }\end{array}$ & $\begin{array}{l}\text { How well has diversity of perspective } \\
\text { and content been explored? }\end{array}$ & $\begin{array}{l}\text { Other views provided to } \\
\text { explain context }\end{array}$ & $\begin{array}{l}\text { I present other views/perspectives so } \\
\text { that the reader may better understand the } \\
\text { context of the analysis. }\end{array}$ \\
\hline 20 & Two & $\mathrm{S}$ & Analysis & Relevance & Significance & $\begin{array}{l}\text { André, Brinberg \& } \\
\text { Mcgrath, Spencer } \\
\text { et al }\end{array}$ & $\begin{array}{l}\text { How well has detailed, depth and } \\
\text { complexity (i.e. richness) of the data } \\
\text { been conveyed? }\end{array}$ & $\begin{array}{l}\text { Significance of data to } \\
\text { reaching goals }\end{array}$ & $\begin{array}{l}\text { I discuss the significance of the data to } \\
\text { achieving the study's goals. }\end{array}$ \\
\hline 21 & Two & $\mathrm{S}$ & Analysis & $\begin{array}{l}\text { Rigor / } \\
\text { thoroughness }\end{array}$ & Logic of inquiry & $\begin{array}{l}\text { André, Brinberg \& } \\
\text { Mcgrath, Spencer } \\
\text { et al }\end{array}$ & $\begin{array}{l}\text { How well has detailed, depth and } \\
\text { complexity (i.e. richness) of the data } \\
\text { been conveyed? }\end{array}$ & $\begin{array}{l}\text { Implicit/explicit links - } \\
\text { findings x aims }\end{array}$ & $\begin{array}{l}\text { I discuss implicit and explicit links } \\
\text { between data/findings and the purpose } \\
\text { of my studies. }\end{array}$ \\
\hline 22 & Two & $\mathrm{C}$ & Findings & $\begin{array}{l}\text { Internal validity / } \\
\text { credibility or } \\
\text { defensibility }\end{array}$ & Logical coherence & $\begin{array}{l}\text { Spencer et al, } \\
\text { Mays \& Pope }\end{array}$ & How credible are the findings? & $\begin{array}{l}\text { Path to achieve } \\
\text { conclusions }\end{array}$ & $\begin{array}{l}\text { My studies clearly show the target } \\
\text { audience how I arrived at my } \\
\text { conclusions from the findings reported. }\end{array}$ \\
\hline 23 & Two & $\mathrm{C}$ & Findings & $\begin{array}{l}\text { Internal validity / } \\
\text { credibility or } \\
\text { defensibility }\end{array}$ & $\begin{array}{l}\text { Support for data and } \\
\text { evidence }\end{array}$ & $\begin{array}{l}\text { Spencer et al, } \\
\text { Mays \& Pope }\end{array}$ & How credible are the findings? & $\begin{array}{l}\text { Link between findings } \mathrm{x} \\
\text { evidence }\end{array}$ & $\begin{array}{l}\text { The conclusions of my studies explicitly } \\
\text { present the correspondence between } \\
\text { findings and the data/evidence. }\end{array}$ \\
\hline 24 & Two & $\mathrm{C}$ & Findings & $\begin{array}{l}\text { External validity } \\
\text { or generalization } \\
\text { / fittingness }\end{array}$ & Applicability & $\begin{array}{l}\text { Spencer et al, } \\
\text { Mays \& Pope }\end{array}$ & How credible are the findings? & $\begin{array}{l}\text { Comparison of results } \\
\text { with those of other } \\
\text { studies }\end{array}$ & $\begin{array}{l}\text { I use the empirical findings of previous } \\
\text { studies to compare with my results } \\
\text { (when applicable). }\end{array}$ \\
\hline
\end{tabular}




\begin{tabular}{|c|c|c|c|c|c|c|c|c|c|}
\hline N. & Stage & Dom. & $\begin{array}{l}\text { Key Feature } \\
\text { Spencer et al. }\end{array}$ & Criterion & Focus & Source(s) & Question (Spencer et al) & Attribute/ Relationship & Statement for Delphi \\
\hline 25 & Two & $\mathrm{S}$ & Findings & $\begin{array}{l}\text { Contribution / } \\
\text { quality of the } \\
\text { theoretical } \\
\text { perspective }\end{array}$ & $\begin{array}{l}\text { New areas for future } \\
\text { studies }\end{array}$ & $\begin{array}{l}\text { Spencer et al, } \\
\text { Mays \& Pope }\end{array}$ & $\begin{array}{l}\text { How has knowledge/understanding } \\
\text { been extended by the research? }\end{array}$ & $\begin{array}{l}\text { New areas based on the } \\
\text { findings }\end{array}$ & $\begin{array}{l}\text { My research highlights new areas for } \\
\text { investigation based on findings. }\end{array}$ \\
\hline 26 & Two & $\mathrm{S}$ & Findings & $\begin{array}{l}\text { Contribution / } \\
\text { quality of the } \\
\text { theoretical } \\
\text { perspective }\end{array}$ & $\begin{array}{l}\text { Advancement of } \\
\text { knowledge }\end{array}$ & $\begin{array}{l}\text { Spencer et al, } \\
\text { Mays \& Pope }\end{array}$ & $\begin{array}{l}\text { How has knowledge/understanding } \\
\text { been extended by the research? }\end{array}$ & $\begin{array}{l}\text { Insights for thinking } \\
\text { about the field }\end{array}$ & $\begin{array}{l}\text { Findings are presented in a way that } \\
\text { creates perspectives (insights) of } \\
\text { thinking about the field. }\end{array}$ \\
\hline 27 & Two & $\mathrm{S}$ & Findings & Relevance & Gap & $\begin{array}{l}\text { Spencer et al, } \\
\text { Brinberg \& } \\
\text { Mcgrath }\end{array}$ & $\begin{array}{l}\text { How well does the evaluation address } \\
\text { its original aims and purpose? }\end{array}$ & $\begin{array}{l}\text { Previous findings } \mathrm{x} \\
\text { hypothesis }\end{array}$ & $\begin{array}{l}\text { I use empirical findings from previous } \\
\text { studies to justify my propositions or } \\
\text { hypotheses (when applicable). }\end{array}$ \\
\hline 28 & Two & M & Findings & $\begin{array}{l}\text { Internal validity / } \\
\text { credibility or } \\
\text { defensibility }\end{array}$ & Logical coherence & $\begin{array}{l}\text { Spencer et al, } \\
\text { Brinberg \& } \\
\text { Mcgrath }\end{array}$ & $\begin{array}{l}\text { How well does the evaluation address } \\
\text { its original aims and purpose? }\end{array}$ & $\begin{array}{l}\text { Check links of findings } \\
\text { x purpose }\end{array}$ & $\begin{array}{l}\text { I check whether my findings are clearly } \\
\text { linked to the purpose of my studies. }\end{array}$ \\
\hline 29 & Two & $\mathrm{S}$ & Findings & $\begin{array}{l}\text { Reliability / } \\
\text { auditability }\end{array}$ & Robustness & $\begin{array}{l}\text { Spencer et al, } \\
\text { Brinberg \& } \\
\text { Mcgrath }\end{array}$ & $\begin{array}{l}\text { Scope for drawing wider inference - } \\
\text { how well is this explained? }\end{array}$ & $\begin{array}{l}\text { Does the context allow } \\
\text { replication }\end{array}$ & $\begin{array}{l}\text { To allow future replications, I describe } \\
\text { in detail the context in which my studies } \\
\text { were conducted. }\end{array}$ \\
\hline 30 & Two & M & Findings & $\begin{array}{l}\text { Internal validity / } \\
\text { credibility or } \\
\text { defensibility }\end{array}$ & Logical coherence & $\begin{array}{l}\text { Spencer et al, } \\
\text { Mays \& Pope }\end{array}$ & $\begin{array}{l}\text { How clear is the basis of evaluative } \\
\text { appraisal? }\end{array}$ & $\begin{array}{l}\text { Impact from the nature } \\
\text { of any divergences }\end{array}$ & $\begin{array}{l}\text { My studies precisely discuss the nature } \\
\text { and sources of possible divergences in } \\
\text { the data that might impact the } \\
\text { conclusions. }\end{array}$ \\
\hline 31 & Two & $\mathrm{S}$ & Reporting & Impact & $\begin{array}{l}\text { Advancement of } \\
\text { knowledge }\end{array}$ & $\begin{array}{l}\text { Spencer et al, } \\
\text { Mays \& Pope }\end{array}$ & $\begin{array}{l}\text { How has knowledge/understanding } \\
\text { been extended by the research? }\end{array}$ & $\begin{array}{l}\text { Discussion of impact on } \\
\text { knowledge }\end{array}$ & $\begin{array}{l}\text { My reports discuss the impacts of } \\
\text { findings to clearly expand knowledge. }\end{array}$ \\
\hline 32 & Two & M & Reporting & $\begin{array}{l}\text { Contribution / } \\
\text { quality of the } \\
\text { theoretical } \\
\text { perspective }\end{array}$ & Limitations & $\begin{array}{l}\text { Spencer et al, } \\
\text { Brinberg \& } \\
\text { Mcgrath }\end{array}$ & $\begin{array}{l}\text { How has knowledge/understanding } \\
\text { been extended by the research? }\end{array}$ & Disclosure of limitations & $\begin{array}{l}\text { My reports explicitly include } \\
\text { information about the limitations of my } \\
\text { findings. }\end{array}$ \\
\hline 33 & Two & M & Reporting & Integrity & Limitations & $\begin{array}{l}\text { Spencer et al, } \\
\text { Brinberg \& } \\
\text { Mcgrath }\end{array}$ & $\begin{array}{l}\text { How well does the evaluation address } \\
\text { its original aims and purpose? }\end{array}$ & Reasons for limitations & $\begin{array}{l}\text { I present a discussion about the reasons } \\
\text { for my study's limitations. }\end{array}$ \\
\hline 34 & Two & M & Reporting & $\begin{array}{l}\text { Contribution / } \\
\text { quality of the } \\
\text { theoretical } \\
\text { perspective }\end{array}$ & Boundaries & $\begin{array}{l}\text { Spencer et al, } \\
\text { Brinberg \& } \\
\text { Mcgrath }\end{array}$ & $\begin{array}{l}\text { How has knowledge/understanding } \\
\text { been extended by the research? }\end{array}$ & Boundaries of the study & $\begin{array}{l}\text { My research reports formally describe } \\
\text { the boundaries (scope) of my studies. }\end{array}$ \\
\hline 35 & Two & $\mathrm{C}$ & Reporting & $\begin{array}{l}\text { Internal validity / } \\
\text { credibility or } \\
\text { defensibility }\end{array}$ & Logical coherence & $\begin{array}{l}\text { Spencer et al, } \\
\text { Brinberg \& } \\
\text { Mcgrath }\end{array}$ & $\begin{array}{l}\text { How clear and coherent is the } \\
\text { reporting? }\end{array}$ & $\begin{array}{l}\text { Literature review } \mathrm{x} \text { main } \\
\text { concepts }\end{array}$ & $\begin{array}{l}\text { My literature reviews describe the } \\
\text { central concepts inherent in the studied } \\
\text { topics. }\end{array}$ \\
\hline 36 & Two & $\mathrm{C}$ & Reporting & $\begin{array}{l}\text { Internal validity / } \\
\text { credibility or } \\
\text { defensibility }\end{array}$ & Logical coherence & $\begin{array}{l}\text { Brinberg \& } \\
\text { McGrath }\end{array}$ & $\begin{array}{l}\text { How clear and coherent is the } \\
\text { reporting? }\end{array}$ & $\begin{array}{l}\text { Theory to support } \\
\text { propositions }\end{array}$ & $\begin{array}{l}\text { I provide theory-based explanations to } \\
\text { justify the propositions in my studies. }\end{array}$ \\
\hline
\end{tabular}




\begin{tabular}{|c|c|c|c|c|c|c|c|c|c|}
\hline N. & Stage & Dom. & \begin{tabular}{|l|} 
Key Feature \\
Spencer et al.
\end{tabular} & Criterion & Focus & Source(s) & Question (Spencer et al) & Attribute/ Relationship & Statement for Delphi \\
\hline 37 & Two & M & Reporting & $\begin{array}{l}\text { Internal validity / } \\
\text { credibility or } \\
\text { defensibility }\end{array}$ & Logical coherence & $\begin{array}{l}\text { Spencer et al, } \\
\text { Brinberg \& } \\
\text { Mcgrath }\end{array}$ & $\begin{array}{l}\text { How well does the evaluation address } \\
\text { its original aims and purpose? }\end{array}$ & Conclusions $\mathrm{x}$ aim & $\begin{array}{l}\text { My conclusions show explicit linkage to } \\
\text { my study's goals. }\end{array}$ \\
\hline 38 & Two & M & Reporting & $\begin{array}{l}\text { External validity } \\
\text { or generalization } \\
\text { / fittingness }\end{array}$ & Scope & $\begin{array}{l}\text { Spencer et al, } \\
\text { Mays \& Pope }\end{array}$ & $\begin{array}{l}\text { Scope for drawing wider inference - } \\
\text { how well is this explained? }\end{array}$ & $\begin{array}{l}\text { Explicit possibility of } \\
\text { generalization }\end{array}$ & $\begin{array}{l}\text { The possibility of generalization (when } \\
\text { applicable) is explicitly evinced based } \\
\text { on the scope of my study. }\end{array}$ \\
\hline 39 & Two & M & Reporting & $\begin{array}{l}\text { Internal validity / } \\
\text { credibility or } \\
\text { defensibility }\end{array}$ & Logical coherence & $\begin{array}{l}\text { Brinberg \& } \\
\text { McGrath }\end{array}$ & $\begin{array}{l}\text { How clear are the links between data, } \\
\text { interpretation and conclusions - i.e. } \\
\text { how well can the route to any } \\
\text { conclusions be seen? }\end{array}$ & $\begin{array}{l}\text { Appreciation of drafts } \\
\text { by colleagues }\end{array}$ & $\begin{array}{l}\text { I submit my drafts to colleagues before } \\
\text { making a final submission to a } \\
\text { journal/conference. }\end{array}$ \\
\hline 40 & Three & M & $\begin{array}{l}\text { Reflexivity and } \\
\text { neutrality }\end{array}$ & Integrity & Robustness & $\begin{array}{l}\text { Spencer et al, } \\
\text { Mays \& Pope }\end{array}$ & $\begin{array}{l}\text { How clear are the assumptions/ } \\
\text { theoretical perspectives/values that } \\
\text { have shaped the form and output of the } \\
\text { evaluation? }\end{array}$ & $\begin{array}{l}\text { How to address errors } \\
\text { and biases }\end{array}$ & $\begin{array}{l}\text { I explicitly discuss in my studies any } \\
\text { errors or biases may have arisen during } \\
\text { the search process and how I managed } \\
\text { them. }\end{array}$ \\
\hline 41 & Three & M & $\begin{array}{l}\text { Reflexivity and } \\
\text { neutrality }\end{array}$ & Integrity & Robustness & $\begin{array}{l}\text { Spencer et al, } \\
\text { Brinberg \& } \\
\text { Mcgrath }\end{array}$ & $\begin{array}{l}\text { How clear are the assumptions/ } \\
\text { theoretical perspectives/values that } \\
\text { have shaped the form and output of the } \\
\text { evaluation? }\end{array}$ & $\begin{array}{l}\text { Impact of team } \\
\text { participation on the } \\
\text { research }\end{array}$ & $\begin{array}{l}\text { I explicitly discuss the possible impact } \\
\text { of my participation (and that of my } \\
\text { team) in the various phases of the } \\
\text { research process (where applicable). }\end{array}$ \\
\hline 42 & All & M & Ethics & $\begin{array}{l}\text { Rigor / } \\
\text { thoroughness }\end{array}$ & Ethics & $\begin{array}{l}\text { Denscombe, CNS, } \\
\text { Brasil (2012, } \\
\text { 2013) }\end{array}$ & $\begin{array}{l}\text { What evidence is there of attention to } \\
\text { ethical issues? }\end{array}$ & $\begin{array}{l}\text { Registration of the study } \\
\text { with the Ethics } \\
\text { Committee (CEP) }\end{array}$ & $\begin{array}{l}\text { My institution/academic unit has a } \\
\text { Research Ethics Committee to register } \\
\text { research designs. }\end{array}$ \\
\hline 43 & All & M & Ethics & $\begin{array}{l}\text { Rigor / } \\
\text { thoroughness }\end{array}$ & Ethics & $\begin{array}{l}\text { Denscombe, CNS, } \\
\text { Brasil (2012, } \\
\text { 2013) }\end{array}$ & $\begin{array}{l}\text { What evidence is there of attention to } \\
\text { ethical issues? }\end{array}$ & $\begin{array}{l}\text { Rules for registering } \\
\text { studies with the CEP }\end{array}$ & $\begin{array}{l}\text { My institution/academic unit has clear } \\
\text { rules about submitting research designs } \\
\text { to the Research Ethics Committee. }\end{array}$ \\
\hline 44 & All & M & Ethics & $\begin{array}{l}\text { Rigor / } \\
\text { thoroughness }\end{array}$ & Ethics & $\begin{array}{l}\text { Denscombe, CNS, } \\
\text { Brasil (2012, } \\
\text { 2013) }\end{array}$ & $\begin{array}{l}\text { What evidence is there of attention to } \\
\text { ethical issues? }\end{array}$ & $\begin{array}{l}\text { Formal submission to } \\
\text { the CEP }\end{array}$ & $\begin{array}{l}\text { My studies that involve human beings } \\
\text { are formally submitted to the Research } \\
\text { Ethics Committee. }\end{array}$ \\
\hline 45 & All & M & Ethics & $\begin{array}{l}\text { Rigor / } \\
\text { thoroughness }\end{array}$ & Ethics & $\begin{array}{l}\text { Denscombe, CNS, } \\
\text { Brasil (2012, } \\
\text { 2013), André }\end{array}$ & $\begin{array}{l}\text { What evidence is there of attention to } \\
\text { ethical issues? }\end{array}$ & $\begin{array}{l}\text { Compulsory submission } \\
\text { to the CEP }\end{array}$ & $\begin{array}{l}\text { The submission of the research projects } \\
\text { to Research Ethics Committee is } \\
\text { compulsory in my university/academic } \\
\text { unit. }\end{array}$ \\
\hline 46 & All & M & Ethics & Integrity & Code of Ethics & Denscombe & $\begin{array}{l}\text { What evidence is there of attention to } \\
\text { ethical issues? }\end{array}$ & $\begin{array}{l}\text { Use of the principles of } \\
\text { an ethics code }\end{array}$ & $\begin{array}{l}\text { I use principles of ethics in research, as } \\
\text { formally described in an Ethics Code (of } \\
\text { a development institution, for example), } \\
\text { to guide my studies. }\end{array}$ \\
\hline 47 & All & M & Ethics & Integrity & $\begin{array}{l}\text { Respect for human } \\
\text { subjects }\end{array}$ & $\begin{array}{l}\text { Denscombe, } \\
\text { National Institute } \\
\text { of Health, } \\
\text { Conama, FAPESP. }\end{array}$ & $\begin{array}{l}\text { What evidence is there of attention to } \\
\text { ethical issues? }\end{array}$ & $\begin{array}{l}\text { Formal respect for } \\
\text { human subjects }\end{array}$ & $\begin{array}{l}\text { I provide informed consent to human } \\
\text { subjects involved in my studies, with } \\
\text { details about the research purpose, risks, } \\
\text { and other aspects foreseen by the } \\
\text { legislation. }\end{array}$ \\
\hline
\end{tabular}




\begin{tabular}{|c|c|c|c|c|c|c|c|c|c|}
\hline N. & Stage & Dom. & $\begin{array}{l}\text { Key Feature } \\
\text { Spencer et al. }\end{array}$ & Criterion & Focus & Source(s) & Question (Spencer et al) & Attribute/ Relationship & Statement for Delphi \\
\hline 48 & All & $M$ & Ethics & Integrity & $\begin{array}{l}\text { Respect for human } \\
\text { subjects }\end{array}$ & $\begin{array}{l}\text { Denscombe, } \\
\text { National Institute } \\
\text { of Health, CNS, } \\
\text { FAPESP. } \\
\end{array}$ & $\begin{array}{l}\text { What evidence is there of attention to } \\
\text { ethical issues? }\end{array}$ & $\begin{array}{l}\text { Strategy to mitigate } \\
\text { possible harm }\end{array}$ & $\begin{array}{l}\text { I take care to choose the research } \\
\text { strategy that brings the least harm to the } \\
\text { subjects involved in my studies. }\end{array}$ \\
\hline 49 & All & M & Ethics & Integrity & Confidentiality & $\begin{array}{l}\text { Denscombe, } \\
\text { National Institute } \\
\text { of Health, CNS, } \\
\text { FAPESP. } \\
\end{array}$ & $\begin{array}{l}\text { What evidence is there of attention to } \\
\text { ethical issues? }\end{array}$ & $\begin{array}{l}\text { Confidentiality to } \\
\text { participants' data }\end{array}$ & $\begin{array}{l}\text { My studies provide specific procedures } \\
\text { to treat participants' data in a } \\
\text { confidential manner. }\end{array}$ \\
\hline 50 & All & $\mathrm{M}$ & Auditability & $\begin{array}{l}\text { Reliability / } \\
\text { auditability }\end{array}$ & $\begin{array}{l}\text { Methodological } \\
\text { rigor }\end{array}$ & $\begin{array}{l}\text { Denscombe, } \\
\text { Spencer et al., } \\
\text { Mays \& Pope }\end{array}$ & $\begin{array}{l}\text { How adequately has the research } \\
\text { process been documented? }\end{array}$ & $\begin{array}{l}\text { Records of design } \\
\text { changes }\end{array}$ & $\begin{array}{l}\text { I safely store complete records of } \\
\text { changes to the design of investigations } \\
\text { that have altered the scope/extent of the } \\
\text { research process. }\end{array}$ \\
\hline 51 & All & $\mathrm{M}$ & Auditability & $\begin{array}{l}\text { Reliability / } \\
\text { auditability }\end{array}$ & Consistency & $\begin{array}{l}\text { Denscombe, } \\
\text { Spencer et al., } \\
\text { Mays \& Pope }\end{array}$ & $\begin{array}{l}\text { How adequately has the research } \\
\text { process been documented? }\end{array}$ & $\begin{array}{l}\text { Records of the reasons } \\
\text { for changes }\end{array}$ & $\begin{array}{l}\text { I safely store complete records of the } \\
\text { reasons for the changes made to the } \\
\text { studies' design. }\end{array}$ \\
\hline 52 & All & $\mathrm{M}$ & Auditability & $\begin{array}{l}\text { Reliability / } \\
\text { auditability }\end{array}$ & Consistency & $\begin{array}{l}\text { Denscombe, } \\
\text { Spencer et al., } \\
\text { Mays \& Pope }\end{array}$ & $\begin{array}{l}\text { How adequately has the research } \\
\text { process been documented? }\end{array}$ & $\begin{array}{l}\text { Safeguard databases for } \\
\text { checks }\end{array}$ & $\begin{array}{l}\text { For future checks, I save databases of } \\
\text { my studies with an adequate description } \\
\text { of their composition. }\end{array}$ \\
\hline 53 & All & $\mathrm{M}$ & Auditability & $\begin{array}{l}\text { Reliability / } \\
\text { auditability }\end{array}$ & $\begin{array}{l}\text { Methodological } \\
\text { rigor }\end{array}$ & $\begin{array}{l}\text { Denscombe, } \\
\text { Spencer et al., } \\
\text { Mays \& Pope }\end{array}$ & $\begin{array}{l}\text { How adequately has the research } \\
\text { process been documented? }\end{array}$ & $\begin{array}{l}\text { Guard documents to } \\
\text { reduce risks }\end{array}$ & $\begin{array}{l}\text { The informed consents signed (or } \\
\text { formally stated) by each individual } \\
\text { participant in my research are safely } \\
\text { stored to preserve the subjects' consent } \\
\text { to possible risks. }\end{array}$ \\
\hline
\end{tabular}

Note: Only a few sources were included in the matrix. Other sources that have provided support are explored in the literature review. 
Appendix B: Matrix of Orientation for Data Collection Instruments (Delphi Online) (in Portuguese)

MATRIZ DE ORIENTAÇÃO PARA A CONSTRUÇÃO DO INSTRUMENTO DE COLETA DE DADOS (DELPHI ONLINE)

\begin{tabular}{|c|c|c|c|c|c|c|c|c|c|}
\hline N. & Fase & Dom. & $\begin{array}{l}\text { Caract. chave } \\
\text { Spencer et al. }\end{array}$ & Critério & Foco & Fonte (s) & Questão (Spencer et al) & Atributo/Relação & Proposição para a Delphi \\
\hline 1 & $\mathrm{Um}$ & $\mathrm{S}$ & Desenho & Adequabilidade & Utilidade & Denscombe & $\begin{array}{l}\text { Quão defensável é o desenho da } \\
\text { pesquisa? }\end{array}$ & $\begin{array}{l}\text { Estratégia útil ao } \\
\text { propósito }\end{array}$ & $\begin{array}{l}\text { Meus estudos apresentam } \\
\text { razões/justificativas para a escolha da } \\
\text { estratégia de pesquisa. }\end{array}$ \\
\hline 2 & $\mathrm{Um}$ & $\mathrm{S}$ & Desenho & Adequabilidade & Adequação & Denscombe & $\begin{array}{l}\text { Quão defensável é o desenho da } \\
\text { pesquisa? }\end{array}$ & $\begin{array}{l}\text { Clara visão geral que } \\
\text { orienta o estudo }\end{array}$ & $\begin{array}{l}\text { Sou capaz de reconhecer os pressupostos da } \\
\text { visão geral (paradigma ou lente teórica) que } \\
\text { guiam a construção dos meus estudos. }\end{array}$ \\
\hline 3 & $\mathrm{Um}$ & $\mathrm{S}$ & Desenho & Adequabilidade & Adequação & Denscombe & $\begin{array}{l}\text { Quão defensável é o desenho da } \\
\text { pesquisa? }\end{array}$ & $\begin{array}{l}\text { Visão geral x } \\
\text { estratégia }\end{array}$ & $\begin{array}{l}\text { Levo em conta um paradigma e seus } \\
\text { pressupostos quando escolho a estratégia } \\
\text { para construir o desenho das minhas } \\
\text { pesquisas. }\end{array}$ \\
\hline 4 & $\mathrm{Um}$ & $\mathrm{S}$ & Desenho & Adequabilidade & Adequação & Denscombe & $\begin{array}{l}\text { Quão defensável é o desenho da } \\
\text { pesquisa? }\end{array}$ & $\begin{array}{l}\text { Objetivo/problema } \\
\text { evidenciado } \\
\text { precisamente }\end{array}$ & $\begin{array}{l}\text { Meus estudos apresentam, precisamente, o } \\
\text { objetivo/problema que se pretende alcançar } \\
\text { ou resolver. }\end{array}$ \\
\hline 5 & $\mathrm{Um}$ & $\mathrm{C}$ & Desenho & Adequabilidade & Adequação & Denscombe & $\begin{array}{l}\text { Quão defensável é o desenho da } \\
\text { pesquisa? }\end{array}$ & Visão geral $\mathrm{x}$ teoria & $\begin{array}{l}\text { Levo em conta um paradigma e seus } \\
\text { pressupostos quando escolho a teoria para } \\
\text { suportar meus estudos (plataforma teórica). }\end{array}$ \\
\hline 6 & $\mathrm{Um}$ & $\mathrm{S}$ & Desenho & Adequabilidade & Utilidade & Denscombe & $\begin{array}{l}\text { Quão defensável é o desenho da } \\
\text { pesquisa? }\end{array}$ & $\begin{array}{l}\text { Argumentos para a } \\
\text { escolha da técnica }\end{array}$ & $\begin{array}{l}\text { Apresento argumentos para a escolha das } \\
\text { técnicas e procedimentos para coleta e } \\
\text { análise dos dados das minhas pesquisas. } \\
\end{array}$ \\
\hline 7 & $\mathrm{Um}$ & $M$ & Desenho & Viabilidade & $\begin{array}{l}\text { Acesso às fontes de } \\
\text { dados }\end{array}$ & Denscombe & $\begin{array}{l}\text { Quão defensável é o desenho da } \\
\text { pesquisa? }\end{array}$ & Acesso aos dados & $\begin{array}{l}\text { A estratégia de pesquisa é escolhida } \\
\text { considerando o acesso às fontes de dados } \\
\text { para realizar os meus estudos. }\end{array}$ \\
\hline 8 & $\mathrm{Um}$ & $\mathrm{M}$ & Desenho & Viabilidade & Restrições de tempo & Denscombe & $\begin{array}{l}\text { Quão defensável é o desenho da } \\
\text { pesquisa? }\end{array}$ & Restrições de tempo & $\begin{array}{l}\text { Escolho uma estratégia de pesquisa baseado } \\
\text { no tempo necessário para coletar os dados e } \\
\text { apresentar os resultados. }\end{array}$ \\
\hline 9 & $\mathrm{Um}$ & $\mathrm{S}$ & Desenho & Viabilidade & Público-alvo & Denscombe & $\begin{array}{l}\text { Quão defensável é o desenho da } \\
\text { pesquisa? }\end{array}$ & $\begin{array}{l}\text { Estratégia de pesquisa } \\
\text { x público-alvo }\end{array}$ & $\begin{array}{l}\text { Levo em conta o provável público-alvo dos } \\
\text { meus estudos quando escolho a estratégia da } \\
\text { pesquisa. }\end{array}$ \\
\hline 10 & Um & $M$ & $\begin{array}{l}\text { Sujeitos da } \\
\text { Pesquisa }\end{array}$ & $\begin{array}{l}\text { Validade interna/ } \\
\text { credibilidade ou } \\
\text { defensibilidade }\end{array}$ & Representatividade & $\begin{array}{l}\text { André, Brinberg } \\
\text { \& Mcgrath, } \\
\text { Spencer et al }\end{array}$ & $\begin{array}{l}\text { Quão bem defendido é o desenho da } \\
\text { amostra/coleção de casos-alvo/ } \\
\text { documentos? }\end{array}$ & $\begin{array}{l}\text { Critérios para } \\
\text { desenho/seleção de } \\
\text { sujeitos }\end{array}$ & $\begin{array}{l}\text { Apresento, explicitamente, os critérios } \\
\text { usados para desenhar/selecionar os sujeitos } \\
\text { da pesquisa baseada na população de } \\
\text { interesse. }\end{array}$ \\
\hline 11 & Um & $M$ & $\begin{array}{l}\text { Sujeitos da } \\
\text { Pesquisa }\end{array}$ & $\begin{array}{l}\text { Validade interna/ } \\
\text { credibilidade ou } \\
\text { defensibilidade }\end{array}$ & Coerência lógica & $\begin{array}{l}\text { Spencer et al, } \\
\text { Brinberg \& } \\
\text { Mcgrath }\end{array}$ & $\begin{array}{l}\text { Composição da amostra / inclusão de } \\
\text { casos - o quão bem descrita está a } \\
\text { eventual cobertura? }\end{array}$ & $\begin{array}{l}\text { Representatividade } \\
\text { dos sujeitos }\end{array}$ & $\begin{array}{l}\text { Meus estudos descrevem, formalmente, os } \\
\text { métodos e os casos de inclusão/exclusão que } \\
\text { têm impacto sobre a representatividade dos } \\
\text { sujeitos da pesquisa. }\end{array}$ \\
\hline
\end{tabular}




\begin{tabular}{|c|c|c|c|c|c|c|c|c|c|}
\hline N. & Fase & Dom. & $\begin{array}{l}\text { Caract. chave } \\
\text { Spencer et al. }\end{array}$ & Critério & Foco & Fonte (s) & Questão (Spencer et al) & Atributo/Relação & Proposição para a Delphi \\
\hline 12 & Dois & $M$ & Coleta de dados & $\begin{array}{l}\text { Rigor/ } \\
\text { meticulosidade }\end{array}$ & Rigor metodológico & $\begin{array}{l}\text { Spencer et al, } \\
\text { Brinberg \& } \\
\text { Mcgrath }\end{array}$ & $\begin{array}{l}\text { Quão bem realizada foi a coleta de } \\
\text { dados? }\end{array}$ & $\begin{array}{l}\text { Anotações de cada } \\
\text { passo da pesquisa }\end{array}$ & $\begin{array}{l}\text { Normalmente, tomo nota dos passos e ações } \\
\text { realizadas durante a coleta de dados. }\end{array}$ \\
\hline 13 & Dois & $\mathrm{M}$ & Coleta de dados & $\begin{array}{l}\text { Rigor/ } \\
\text { meticulosidade }\end{array}$ & Rigor metodológico & $\begin{array}{l}\text { Spencer et al, } \\
\text { Brinberg \& } \\
\text { Mcgrath }\end{array}$ & $\begin{array}{l}\text { Quão bem realizada foi a coleta de } \\
\text { dados? }\end{array}$ & $\begin{array}{l}\text { Anotações dos } \\
\text { eventos divergentes }\end{array}$ & $\begin{array}{l}\text { Normalmente, tomo nota de detalhes das } \\
\text { ocorrências divergentes do desenho da } \\
\text { pesquisa que aparecem durante a coleta de } \\
\text { dados. }\end{array}$ \\
\hline 14 & Dois & $\mathrm{M}$ & Coleta de dados & Integridade & Ética & Denscombe & $\begin{array}{l}\text { Que evidências existem de atenção às } \\
\text { questões éticas? }\end{array}$ & $\begin{array}{l}\text { Participação } \\
\text { voluntária dos sujeitos }\end{array}$ & $\begin{array}{l}\text { Quando meus estudos envolvem seres } \\
\text { humanos, estes são convidados e } \\
\text { participarem voluntariamente. }\end{array}$ \\
\hline 15 & Dois & $\mathrm{M}$ & Coleta de dados & Integridade & Ética & Denscombe & $\begin{array}{l}\text { Que evidências existem de atenção às } \\
\text { questões éticas? }\end{array}$ & $\begin{array}{l}\text { Concordância formal } \\
\text { dos sujeitos humanos }\end{array}$ & $\begin{array}{l}\text { Todos os participantes dos meus estudos que } \\
\text { envolvam seres humanos assinam (ou } \\
\text { declaram expressamente) um Termo de } \\
\text { Consentimento Livre e Esclarecido. }\end{array}$ \\
\hline 16 & Dois & $\mathrm{M}$ & Análise & Integridade & $\begin{array}{l}\text { Lógica de } \\
\text { investigação }\end{array}$ & $\begin{array}{l}\text { Spencer et al, } \\
\text { Brinberg \& } \\
\text { Mcgrath }\end{array}$ & $\begin{array}{l}\text { Quão bem transmitida foi a } \\
\text { abordagem para e a formulação da } \\
\text { análise? }\end{array}$ & $\begin{array}{l}\text { Descrição da natureza } \\
\text { e forma dos dados }\end{array}$ & $\begin{array}{l}\text { Meus estudos apresentam uma descrição } \\
\text { detalhada da natureza e forma dos dados } \\
\text { originais coletados. }\end{array}$ \\
\hline 17 & Dois & $\mathrm{M}$ & Análise & $\begin{array}{l}\text { Rigor/ } \\
\text { meticulosidade }\end{array}$ & Rigor metodológico & $\begin{array}{l}\text { Spencer et al, } \\
\text { Brinberg \& } \\
\text { Mcgrath }\end{array}$ & $\begin{array}{l}\text { Quão bem transmitida foi a } \\
\text { abordagem para e a formulação da } \\
\text { análise? }\end{array}$ & \begin{tabular}{|l|} 
Descrição das \\
ferramentas e \\
procedimentos
\end{tabular} & $\begin{array}{l}\text { Ferramentas e procedimentos para análise de } \\
\text { dados são, cuidadosamente, apresentados. }\end{array}$ \\
\hline 18 & Dois & $\mathrm{S}$ & Análise & $\begin{array}{l}\text { Confiabilidade/ } \\
\text { auditabilidade }\end{array}$ & Consistência & $\begin{array}{l}\text { Spencer et al, } \\
\text { Brinberg \& } \\
\text { Mcgrath }\end{array}$ & $\begin{array}{l}\text { Contextos de fontes de dados - o } \\
\text { quão bem mantidos e retratados eles } \\
\text { estão? }\end{array}$ & $\begin{array}{l}\text { Contexto } \mathrm{x} \text { impacto } \\
\text { sobre a análise dos } \\
\text { dados }\end{array}$ & $\begin{array}{l}\text { Explicito os detalhes do contexto em que os } \\
\text { dados foram coletados e o que pode ter/tem } \\
\text { impacto na análise de dados. }\end{array}$ \\
\hline 19 & Dois & $\mathrm{S}$ & Análise & $\begin{array}{l}\text { Confiabilidade/ } \\
\text { auditabilidade }\end{array}$ & Consistência & $\begin{array}{l}\text { Spencer et al, } \\
\text { Brinberg \& } \\
\text { Mcgrath }\end{array}$ & $\begin{array}{l}\text { Quão bem exploradas foram a } \\
\text { diversidade de perspectivas e o } \\
\text { conteúdo? }\end{array}$ & $\begin{array}{l}\text { Visões alternativas } \\
\text { para entender o } \\
\text { contexto }\end{array}$ & $\begin{array}{l}\text { Apresento outras visões/perspectivas } \\
\text { possíveis para que o leitor possa entender } \\
\text { melhor o contexto da análise dos meus dados. }\end{array}$ \\
\hline 20 & Dois & $\mathrm{S}$ & Análise & Relevância & Significância & $\begin{array}{l}\text { André, Brinberg } \\
\text { \& Mcgrath, } \\
\text { Spencer et al }\end{array}$ & $\begin{array}{l}\text { Quão bem detalhada e transmitida foi } \\
\text { a profundidade e complexidade (i.e. } \\
\text { riqueza) dos dados? }\end{array}$ & $\begin{array}{l}\text { Significância dos } \\
\text { dados para alcançar o } \\
\text { objetivo }\end{array}$ & $\begin{array}{l}\text { Discuto a significância dos dados para } \\
\text { alcançar os objetivos em meus estudos. }\end{array}$ \\
\hline 21 & Dois & $\mathrm{S}$ & Análise & $\begin{array}{l}\text { Rigor/ } \\
\text { meticulosidade }\end{array}$ & $\begin{array}{l}\text { Lógica de } \\
\text { investigação }\end{array}$ & $\begin{array}{l}\text { André, Brinberg } \\
\text { \& Mcgrath, } \\
\text { Spencer et al }\end{array}$ & $\begin{array}{l}\text { Quão bem detalhada e transmitida foi } \\
\text { a profundidade e complexidade (i.e. } \\
\text { riqueza) dos dados? }\end{array}$ & $\begin{array}{l}\text { Links implícitos/ } \\
\text { explícitos - achados x } \\
\text { objetivos }\end{array}$ & $\begin{array}{l}\text { Discuto os links, implícitos e explícitos, entre } \\
\text { os dados/achados e o propósito nos meus } \\
\text { estudos. }\end{array}$ \\
\hline 22 & Dois & $\mathrm{C}$ & Achados & $\begin{array}{l}\text { Validade interna/ } \\
\text { credibilidade ou } \\
\text { defensibilidade }\end{array}$ & Coerência lógica & $\begin{array}{l}\text { Spencer et al, } \\
\text { Mays \& Pope }\end{array}$ & Quão críveis são os achados? & $\begin{array}{l}\text { Caminho para chegar } \\
\text { às conclusões }\end{array}$ & $\begin{array}{l}\text { Meus estudos apresentam ao público-alvo, de } \\
\text { maneira clara, como cheguei às conclusões a } \\
\text { partir dos achados reportados. }\end{array}$ \\
\hline 23 & Dois & $\mathrm{C}$ & Achados & $\begin{array}{l}\text { Validade interna/ } \\
\text { credibilidade ou } \\
\text { defensibilidade }\end{array}$ & $\begin{array}{l}\text { Apoio em dados e } \\
\text { evidências }\end{array}$ & $\begin{array}{l}\text { Spencer et al, } \\
\text { Mays \& Pope }\end{array}$ & Quão críveis são os achados? & $\begin{array}{l}\text { Links entre achados } x \\
\text { evidências }\end{array}$ & $\begin{array}{l}\text { As conclusões dos meus estudos apresentam, } \\
\text { de maneira explícita, a correspondência entre } \\
\text { achados e evidências/dados. }\end{array}$ \\
\hline 24 & Dois & $\mathrm{C}$ & Achados & $\begin{array}{l}\text { Validade externa } \\
\text { ou generalização/ } \\
\text { conformidade }\end{array}$ & Aplicabilidade & $\begin{array}{l}\text { Spencer et al, } \\
\text { Mays \& Pope }\end{array}$ & Quão críveis são os achados? & $\begin{array}{l}\text { Comparação de } \\
\text { resultados com outros } \\
\text { estudos }\end{array}$ & $\begin{array}{l}\text { Uso achados empíricos de estudos anteriores } \\
\text { para comparar com os meus achados (quando } \\
\text { aplicável). }\end{array}$ \\
\hline
\end{tabular}




\begin{tabular}{|c|c|c|c|c|c|c|c|c|c|}
\hline N. & Fase & Dom. & $\begin{array}{l}\text { Caract. chave } \\
\text { Spencer et al. }\end{array}$ & Critério & Foco & Fonte (s) & Questão (Spencer et al) & Atributo/Relação & Proposição para a Delphi \\
\hline 25 & Dois & $\mathrm{S}$ & Achados & $\begin{array}{l}\text { Contribuição/ } \\
\text { qualidade da persp. } \\
\text { teórica. }\end{array}$ & $\begin{array}{l}\text { Novas áreas para } \\
\text { futuros estudos }\end{array}$ & $\begin{array}{l}\text { Spencer et al, } \\
\text { Mays \& Pope }\end{array}$ & $\begin{array}{l}\text { Como o conhecimento/entendimento } \\
\text { foi ampliado pela pesquisa? }\end{array}$ & $\begin{array}{l}\text { Novas áreas baseadas } \\
\text { nos achados }\end{array}$ & $\begin{array}{l}\text { Baseados nos achados, meus estudos } \\
\text { sugerem novas áreas para investigação. }\end{array}$ \\
\hline 26 & Dois & $\mathrm{S}$ & Achados & $\begin{array}{l}\text { Contribuição/ } \\
\text { qualidade da persp. } \\
\text { teórica. }\end{array}$ & $\begin{array}{l}\text { Avanço do } \\
\text { conhecimento }\end{array}$ & $\begin{array}{l}\text { Spencer et al, } \\
\text { Mays \& Pope }\end{array}$ & $\begin{array}{l}\text { Como o conhecimento/entendimento } \\
\text { foi ampliado pela pesquisa? }\end{array}$ & $\begin{array}{l}\text { Insights para pensar o } \\
\text { campo de } \\
\text { conhecimento }\end{array}$ & $\begin{array}{l}\text { Os achados são apresentados de uma maneira } \\
\text { que cria perspectivas (insights) de pensar o } \\
\text { conhecimento na área. }\end{array}$ \\
\hline 27 & Dois & $\mathrm{S}$ & Achados & Relevância & Lacuna/Gap & $\begin{array}{l}\text { Spencer et al, } \\
\text { Brinberg \& } \\
\text { Mcgrath }\end{array}$ & $\begin{array}{l}\text { Quão bem a avaliação leva em conta } \\
\text { seus objetivos e propósito originais? }\end{array}$ & $\begin{array}{l}\text { Achados anteriores } \mathrm{x} \\
\text { hipóteses }\end{array}$ & $\begin{array}{l}\text { Uso achados empíricos de estudos anteriores } \\
\text { para suportar minhas proposições e/ou } \\
\text { hipóteses (quando aplicável). }\end{array}$ \\
\hline 28 & Dois & $\mathrm{M}$ & Achados & $\begin{array}{l}\text { Validade interna/ } \\
\text { credibilidade ou } \\
\text { defensibilidade }\end{array}$ & Coerência lógica & $\begin{array}{l}\text { Spencer et al, } \\
\text { Brinberg \& } \\
\text { Mcgrath }\end{array}$ & $\begin{array}{l}\text { Quão bem a avaliação leva em conta } \\
\text { seus objetivos e propósito originais? }\end{array}$ & $\begin{array}{l}\text { Checagem da ligação } \\
\text { dos achados } \mathrm{x} \\
\text { propósito }\end{array}$ & $\begin{array}{l}\text { Checo se meus achados estão, claramente, } \\
\text { ligados ao propósito dos meus estudos. }\end{array}$ \\
\hline 29 & Dois & $\mathrm{S}$ & Achados & $\begin{array}{l}\text { Confiabilidade/ } \\
\text { auditabilidade }\end{array}$ & Robustez & $\begin{array}{l}\text { Spencer et al, } \\
\text { Brinberg \& } \\
\text { Mcgrath }\end{array}$ & $\begin{array}{l}\text { Quão bom é o escopo para obter } \\
\text { maior inferência explicada? }\end{array}$ & $\begin{array}{l}\text { Contexto para permitir } \\
\text { replicação }\end{array}$ & $\begin{array}{l}\text { Descrevo em detalhes o contexto no qual os } \\
\text { estudos foram conduzidos, a fim de permitir } \\
\text { replicações. }\end{array}$ \\
\hline 30 & Dois & $M$ & Achados & $\begin{array}{l}\text { Validade interna/ } \\
\text { credibilidade ou } \\
\text { defensibilidade }\end{array}$ & Coerência lógica & $\begin{array}{l}\text { Spencer et al, } \\
\text { Mays \& Pope }\end{array}$ & $\begin{array}{l}\text { Quão clara é a base da apreciação } \\
\text { valorativa? }\end{array}$ & $\begin{array}{l}\text { Impacto da natureza } \\
\text { das fontes }\end{array}$ & $\begin{array}{l}\text { Meus estudos discutem, precisamente, a } \\
\text { natureza e a origem de possíveis divergências } \\
\text { nos dados que poderiam impactar as } \\
\text { conclusões. }\end{array}$ \\
\hline 31 & Dois & $\mathrm{S}$ & Relatório & Impacto & $\begin{array}{l}\text { Avanço do } \\
\text { conhecimento }\end{array}$ & $\begin{array}{l}\text { Spencer et al, } \\
\text { Mays \& Pope }\end{array}$ & $\begin{array}{l}\text { Como o conhecimento/entendimento } \\
\text { foi ampliado pela pesquisa? }\end{array}$ & $\begin{array}{l}\text { Discussão sobre o } \\
\text { impacto para o } \\
\text { conhecimento }\end{array}$ & $\begin{array}{l}\text { Meus relatórios apresentam, claramente, a } \\
\text { discussão sobre o impacto dos achados para a } \\
\text { expansão do conhecimento na área. }\end{array}$ \\
\hline 32 & Dois & $\mathrm{M}$ & Relatório & $\begin{array}{l}\text { Contribuição/ } \\
\text { qualidade da persp. } \\
\text { teórica. }\end{array}$ & Limitações & $\begin{array}{l}\text { Spencer et al, } \\
\text { Brinberg \& } \\
\text { Mcgrath }\end{array}$ & Quão claro e coerente é o relatório? & $\begin{array}{l}\text { Evidenciação de } \\
\text { limitações }\end{array}$ & $\begin{array}{l}\text { Meus relatórios contêm, explicitamente, as } \\
\text { limitações dos achados das minhas pesquisas. }\end{array}$ \\
\hline 33 & Dois & M & Relatório & Integridade & Limitações & $\begin{array}{l}\text { Spencer et al, } \\
\text { Brinberg \& } \\
\text { Mcgrath }\end{array}$ & $\begin{array}{l}\text { Quão bem a avaliação leva em conta } \\
\text { seus objetivos e propósito originais? }\end{array}$ & Razões das limitações & $\begin{array}{l}\text { Apresento discussão acerca das razões que } \\
\text { geraram as limitações dos meus estudos. }\end{array}$ \\
\hline 34 & Dois & M & Relatório & $\begin{array}{l}\text { Contribuição/ } \\
\text { qualidade da persp. } \\
\text { teórica. }\end{array}$ & Fronteiras & $\begin{array}{l}\text { Spencer et al, } \\
\text { Brinberg \& } \\
\text { Mcgrath }\end{array}$ & $\begin{array}{l}\text { Como o conhecimento/entendimento } \\
\text { foi ampliado pela pesquisa? }\end{array}$ & Fronteiras do estudo & $\begin{array}{l}\text { Meus relatórios de pesquisa evidenciam, } \\
\text { formalmente, as fronteiras (alcance) dos } \\
\text { achados dos meus estudos. }\end{array}$ \\
\hline 35 & Dois & $\mathrm{C}$ & Relatório & $\begin{array}{l}\text { Validade interna/ } \\
\text { credibilidade ou } \\
\text { defensibilidade }\end{array}$ & Coerência lógica & $\begin{array}{l}\text { Spencer et al, } \\
\text { Brinberg \& } \\
\text { Mcgrath }\end{array}$ & Quão claro e coerente é o relatório? & $\begin{array}{l}\text { Revisão de literatura } \mathrm{x} \\
\text { conceitos principais }\end{array}$ & $\begin{array}{l}\text { As revisões de literatura que faço descrevem } \\
\text { os conceitos-chave inerentes aos assuntos } \\
\text { estudados. }\end{array}$ \\
\hline 36 & Dois & $\mathrm{C}$ & Relatório & $\begin{array}{l}\text { Validade interna/ } \\
\text { credibilidade ou } \\
\text { defensibilidade }\end{array}$ & Coerência lógica & $\begin{array}{l}\text { Brinberg \& } \\
\text { McGrath }\end{array}$ & Quão claro e coerente é o relatório? & $\begin{array}{l}\text { Teoria para apoiar } \\
\text { proposições }\end{array}$ & $\begin{array}{l}\text { Uso explicação baseada na teoria para } \\
\text { justificar as proposições dos meus estudos. }\end{array}$ \\
\hline 37 & Dois & $M$ & Relatório & $\begin{array}{l}\text { Validade interna/ } \\
\text { credibilidade ou } \\
\text { defensibilidade }\end{array}$ & Coerência lógica & $\begin{array}{l}\text { Spencer et al, } \\
\text { Brinberg \& } \\
\text { Mcgrath }\end{array}$ & $\begin{array}{l}\text { Quão bem a avaliação leva em conta } \\
\text { seus objetivos e propósito originais? }\end{array}$ & Conclusões $\mathrm{x}$ objetivo & $\begin{array}{l}\text { Minhas conclusões mostram, explicitamente, } \\
\text { a ligação com os objetivos dos estudos. }\end{array}$ \\
\hline
\end{tabular}




\begin{tabular}{|c|c|c|c|c|c|c|c|c|c|}
\hline N. & Fase & Dom. & $\begin{array}{l}\text { Caract. chave } \\
\text { Spencer et al. }\end{array}$ & Critério & Foco & Fonte (s) & Questão (Spencer et al) & Atributo/Relação & Proposição para a Delphi \\
\hline 38 & Dois & $\mathrm{M}$ & Relatório & $\begin{array}{l}\text { Validade externa } \\
\text { ou generalização/ } \\
\text { conformidade }\end{array}$ & Escopo & $\begin{array}{l}\text { Spencer et al, } \\
\text { Mays \& Pope }\end{array}$ & $\begin{array}{l}\text { Quão bom é o escopo para obter } \\
\text { maior inferência explicada? }\end{array}$ & $\begin{array}{l}\text { Possibilidade explícita } \\
\text { de generalização }\end{array}$ & $\begin{array}{l}\text { A possibilidade de generalização (quando } \\
\text { aplicável) é explicitamente evidenciada, com } \\
\text { base no escopo dos meus estudos. }\end{array}$ \\
\hline 39 & Dois & $\mathrm{M}$ & Relatório & $\begin{array}{l}\text { Validade interna/ } \\
\text { credibilidade ou } \\
\text { defensibilidade }\end{array}$ & Coerência lógica & $\begin{array}{l}\text { Brinberg \& } \\
\text { McGrath }\end{array}$ & $\begin{array}{l}\text { Quão claras são as ligações entre } \\
\text { dados, interpretação e conclusões - } \\
\text { i.e. quão bem pode ser visto o } \\
\text { caminho até as conclusões? }\end{array}$ & $\begin{array}{l}\text { Apreciação de } \\
\text { rascunhos por colegas }\end{array}$ & $\begin{array}{l}\text { Submeto minhas versões preliminares } \\
\text { (drafts) para a apreciação de colegas antes da } \\
\text { submissão final a um periódico/evento. }\end{array}$ \\
\hline 40 & Três & $\mathrm{M}$ & $\begin{array}{l}\text { Reflexividade e } \\
\text { neutralidade }\end{array}$ & Integridade & Robustez & $\begin{array}{l}\text { Spencer et al, } \\
\text { Mays \& Pope }\end{array}$ & $\begin{array}{l}\text { Quão claras são as } \\
\text { suposições/perspectivas } \\
\text { teóricas/valores que moldaram a } \\
\text { forma e saídas da avaliação? }\end{array}$ & $\begin{array}{l}\text { Como lidou com erros } \\
\text { e vieses }\end{array}$ & $\begin{array}{l}\text { Discuto em meus estudos, de forma explícita, } \\
\text { como erros ou viéses podem ter surgido } \\
\text { durante o processo de pesquisa e como lidei } \\
\text { com eles. }\end{array}$ \\
\hline 41 & Três & $\mathrm{M}$ & $\begin{array}{l}\text { Reflexividade e } \\
\text { neutralidade }\end{array}$ & Integridade & Robustez & $\begin{array}{l}\text { Spencer et al, } \\
\text { Brinberg \& } \\
\text { Mcgrath }\end{array}$ & $\begin{array}{l}\text { Quão claras são as } \\
\text { suposições/perspectivas } \\
\text { teóricas/valores que moldaram a } \\
\text { forma e saídas da avaliação? }\end{array}$ & $\begin{array}{l}\text { Impactos da } \\
\text { participação da equipe } \\
\text { sobre a pesquisa }\end{array}$ & $\begin{array}{l}\text { Discuto, de forma explícita, possíveis } \\
\text { impactos decorrentes da minha participação } \\
\text { (e da minha equipe) nas fases do processo de } \\
\text { pesquisa (quando aplicável). }\end{array}$ \\
\hline 42 & Todas & $\mathrm{M}$ & Ética & $\begin{array}{l}\text { Rigor/ } \\
\text { meticulosidade }\end{array}$ & Ética & $\begin{array}{l}\text { Denscombe, } \\
\text { CNS, Brasil } \\
(2012,2013)\end{array}$ & $\begin{array}{l}\text { Que evidências existem de atenção às } \\
\text { questões éticas? }\end{array}$ & $\begin{array}{l}\text { Comitê de Ética } \\
\text { (CEP) para registrar } \\
\text { os estudos }\end{array}$ & $\begin{array}{l}\text { Minha Instituição/Unidade Acadêmica tem } \\
\text { um Comitê de Ética em Pesquisa para } \\
\text { submissão e aprovação dos projetos de } \\
\text { pesquisa. }\end{array}$ \\
\hline 43 & Todas & $\mathrm{M}$ & Ética & $\begin{array}{l}\text { Rigor/ } \\
\text { meticulosidade }\end{array}$ & Ética & $\begin{array}{l}\text { Denscombe, } \\
\text { CNS, Brasil } \\
(2012,2013)\end{array}$ & $\begin{array}{l}\text { Que evidências existem de atenção às } \\
\text { questões éticas? }\end{array}$ & $\begin{array}{l}\text { Regras para registrar } \\
\text { os estudos no CEP }\end{array}$ & $\begin{array}{l}\text { Minha Instituição/Unidade Acadêmica tem } \\
\text { regras claras para submissão dos projetos de } \\
\text { pesquisa ao Comitê de Ética em Pesquisa. }\end{array}$ \\
\hline 44 & Todas & $\mathrm{M}$ & Ética & $\begin{array}{l}\text { Rigor/ } \\
\text { meticulosidade }\end{array}$ & Ética & $\begin{array}{l}\text { Denscombe, } \\
\text { CNS, Brasil } \\
(2012,2013)\end{array}$ & $\begin{array}{l}\text { Que evidências existem de atenção às } \\
\text { questões éticas? }\end{array}$ & $\begin{array}{l}\text { Submissão formal ao } \\
\text { CEP }\end{array}$ & $\begin{array}{l}\text { Meus estudos que envolvem seres humanos } \\
\text { são, formalmente, submetidos ao Comitê de } \\
\text { Ética em Pesquisa. }\end{array}$ \\
\hline 45 & Todas & $\mathrm{M}$ & Ética & $\begin{array}{l}\text { Rigor/ } \\
\text { meticulosidade }\end{array}$ & Ética & $\begin{array}{l}\text { Denscombe, } \\
\text { CNS, Brasil } \\
(2012,2013), \\
\text { André }\end{array}$ & $\begin{array}{l}\text { Que evidências existem de atenção às } \\
\text { questões éticas? }\end{array}$ & $\begin{array}{l}\text { Submissão } \\
\text { compulsória ao CEP }\end{array}$ & $\begin{array}{l}\text { A submissão dos projetos de pesquisa que } \\
\text { envolvem seres humanos ao Comitê de Ética } \\
\text { é compulsória em minha Instituição/Unidade } \\
\text { Acadêmica. }\end{array}$ \\
\hline 46 & Todas & $\mathrm{M}$ & Ética & Integridade & Código de Ética & Denscombe & $\begin{array}{l}\text { Que evidências existem de atenção às } \\
\text { questões éticas? }\end{array}$ & $\begin{array}{l}\text { Uso de princípios de } \\
\text { um Código de Ética }\end{array}$ & $\begin{array}{l}\text { Uso princípios de ética na pesquisa descritos } \\
\text { formalmente em um Código de Ética (de uma } \\
\text { instituição de fomento, por exemplo), para } \\
\text { orientar meus estudos. }\end{array}$ \\
\hline 47 & Todas & $\mathrm{M}$ & Ética & Integridade & $\begin{array}{l}\text { Respeito aos } \\
\text { sujeitos humanos }\end{array}$ & \begin{tabular}{|l|} 
Denscombe, \\
National Institute \\
of Health, \\
Conama, Fapesp.
\end{tabular} & $\begin{array}{l}\text { Que evidências existem de atenção às } \\
\text { questões éticas? }\end{array}$ & $\begin{array}{l}\text { Respeito aos subjeitos } \\
\text { humanos formalmente }\end{array}$ & $\begin{array}{l}\text { Entrego o Termo de Consentimento aos } \\
\text { sujeitos humanos envolvidos em meus } \\
\text { estudos, com detalhes sobre propósito do } \\
\text { estudo, riscos e outros aspectos previstos na } \\
\text { legislação. }\end{array}$ \\
\hline
\end{tabular}




\begin{tabular}{|c|c|c|c|c|c|c|c|c|c|}
\hline N. & Fase & Dom. & $\begin{array}{l}\text { Caract. chave } \\
\text { Spencer et al. }\end{array}$ & Critério & Foco & Fonte (s) & Questão (Spencer et al) & Atributo/Relação & Proposição para a Delphi \\
\hline 48 & Todas & $\mathrm{M}$ & Ética & Integridade & $\begin{array}{l}\text { Respeito aos } \\
\text { sujeitos humanos }\end{array}$ & \begin{tabular}{|l|} 
Denscombe, \\
National Institute \\
of Health, CNS, \\
Fapesp. \\
\end{tabular} & $\begin{array}{l}\text { Que evidências existem de atenção às } \\
\text { questões éticas? }\end{array}$ & $\begin{array}{l}\text { Estratégia para mitigar } \\
\text { possíveis danos }\end{array}$ & $\begin{array}{l}\text { Me preocupo em escolher a estratégia de } \\
\text { pesquisa que traga os menores danos para os } \\
\text { sujeitos envolvidos nos meus estudos. }\end{array}$ \\
\hline 49 & Todas & $\mathrm{M}$ & Ética & Integridade & Confidencialidade & \begin{tabular}{|l|} 
Denscombe, \\
National Institute \\
of Health, CNS, \\
Fapesp. \\
\end{tabular} & $\begin{array}{l}\text { Que evidências existem de atenção às } \\
\text { questões éticas? }\end{array}$ & $\begin{array}{l}\text { Confidencialidade } \\
\text { para os dados dos } \\
\text { participantes }\end{array}$ & $\begin{array}{l}\text { Minhas pesquisas fornecem procedimentos } \\
\text { específicos para tratar os dados dos } \\
\text { participantes de maneira confidencial. }\end{array}$ \\
\hline 50 & Todas & $\mathrm{M}$ & Auditabilidade & $\begin{array}{l}\text { Confiabilidade/ } \\
\text { auditabilidade }\end{array}$ & Rigor metodológico & \begin{tabular}{|l|} 
Denscombe, \\
Spencer et al., \\
Mays \& Pope \\
\end{tabular} & $\begin{array}{l}\text { Quão adequadamente documentado é } \\
\text { o processo de pesquisa? }\end{array}$ & $\begin{array}{l}\text { Registros das } \\
\text { mudanças no desenho }\end{array}$ & $\begin{array}{l}\text { Mantenho registros completos das alterações } \\
\text { feitas no desenho das pesquisas que } \\
\text { modificaram o alcance/amplitude destas. }\end{array}$ \\
\hline 51 & Todas & M & Auditabilidade & $\begin{array}{l}\text { Confiabilidade/ } \\
\text { auditabilidade }\end{array}$ & Consistência & \begin{tabular}{|l|} 
Denscombe, \\
Spencer et al., \\
Mays \& Pope \\
\end{tabular} & $\begin{array}{l}\text { Quão adequadamente documentado é } \\
\text { o processo de pesquisa? }\end{array}$ & $\begin{array}{l}\text { Registros das razões } \\
\text { para as mudanças }\end{array}$ & $\begin{array}{l}\text { Mantenho registros completos das razões que } \\
\text { motivaram as alterações feitas no desenho } \\
\text { das pesquisas. }\end{array}$ \\
\hline 52 & Todas & $\mathrm{M}$ & Auditabilidade & $\begin{array}{l}\text { Confiabilidade/ } \\
\text { auditabilidade }\end{array}$ & Consistência & \begin{tabular}{|l} 
Denscombe, \\
Spencer et al., \\
Mays \& Pope
\end{tabular} & $\begin{array}{l}\text { Quão adequadamente documentado é } \\
\text { o processo de pesquisa? }\end{array}$ & \begin{tabular}{|l|} 
Salvaguarda das bases \\
de dados para \\
verificações
\end{tabular} & $\begin{array}{l}\text { Mantenho as bases de dados dos meus } \\
\text { estudos, com adequada descrição da sua } \\
\text { composição, para futuras verificações. }\end{array}$ \\
\hline 53 & Todas & M & Auditabilidade & $\begin{array}{l}\text { Confiabilidade/ } \\
\text { auditabilidade }\end{array}$ & Rigor metodológico & $\begin{array}{l}\text { Denscombe, } \\
\text { Spencer et al., } \\
\text { Mays \& Pope }\end{array}$ & $\begin{array}{l}\text { Quão adequadamente documentado é } \\
\text { o processo de pesquisa? }\end{array}$ & $\begin{array}{l}\text { Guarda de } \\
\text { documentos para } \\
\text { reduzir riscos }\end{array}$ & $\begin{array}{l}\text { Os termos de consentimento, assinados (ou } \\
\text { com declaração explícita) individualmente } \\
\text { por cada participante, são mantidos em } \\
\text { segurança para preservar os sujeitos das } \\
\text { pesquisas de possíveis riscos. }\end{array}$ \\
\hline
\end{tabular}

Nota: Apenas algumas fontes foram incluídas na matriz. Outras fontes que deram suporte estão exploradas na revisão de literatura. 


\section{Appendix C: Registration with the Ethical Committee for Human Beings (in Portuguese)}

\section{PLATAFORMA BRASIL}

http://aplicacao.saude.gov.br/plataformabrasil/login.jsf

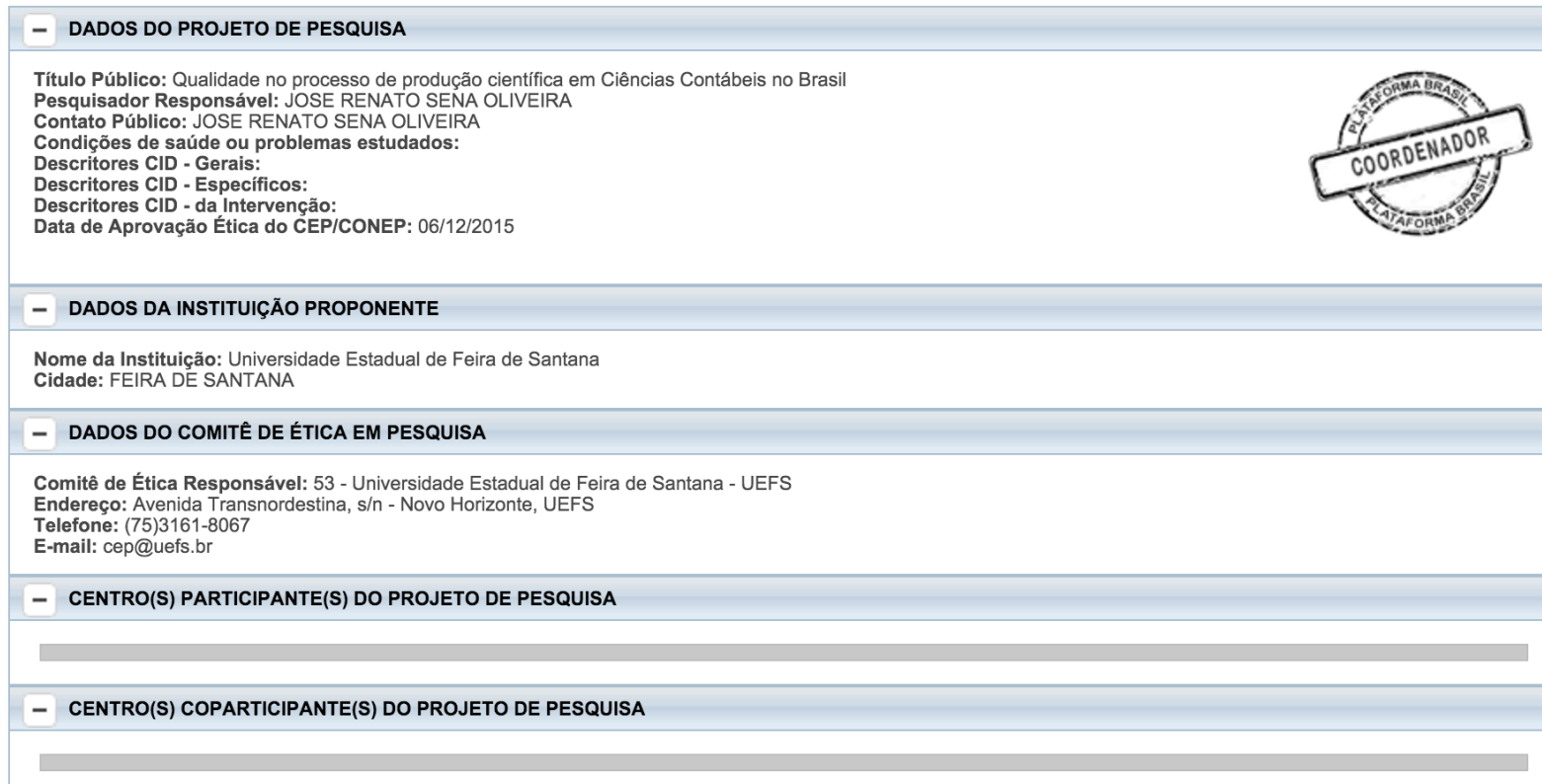


Appendix D: List of Selected Graduate Programs (in Portuguese)

\section{LISTA DE PROGRAMAS DE PÓS-GRADUAÇÃO SELECIONADOS}

GRANDE ÁREA: CIÊNCIAS SOCIAIS APLICADAS

ÁREA: ADMINISTRAÇÃO

\begin{tabular}{|c|c|c|c|c|c|c|c|c|}
\hline N. & PROGRAMA & IES & UF & M & D & $\mathbf{F}$ & WEBSITE & E-MAIL \\
\hline 1 & Administração e Controladoria & UFC & $\mathrm{CE}$ & 4 & 4 & - & http://www.ppac.ufc.br/index.php/pt-br/ & maac@ufc.br \\
\hline 2 & Ciências Contábeis & UNB & DF & 4 & 4 & - & http://ppgcont.unb.br & ppgcont@unb.br \\
\hline 3 & Ciências Contábeis & UFES & ES & 3 & - & - & http://www.cienciascontabeis.ufes.br/ & pos.cienciascontabeis@ufes.br \\
\hline 4 & Ciências Contábeis & FUCAPE & ES & 4 & 4 & - & http://fucape.br/cursos/mestradoacademicocontabeis/ & arilton@fucape.br \\
\hline 5 & Ciências Contábeis & UFMG & MG & 4 & - & - & http://cepcon.face.ufmg.br/ & cepcon@face.ufmg.br \\
\hline 6 & Ciências Contábeis & UFU & MG & 3 & - & - & http://www.ppgcc.facic.ufu.br/ & lailamelo@facic.ufu.br \\
\hline 7 & Ciências Contábeis & UFPB/J.P. & PB & 4 & 4 & - & http://www.ccsa.ufpb.br/ppgcc/ & ppgcc@ccsa.ufpb.br \\
\hline 8 & Ciências Contábeis & UFPE & $\mathrm{PE}$ & 4 & - & - & https://www.ufpe.br/ppgcontabeis/ & mestrado.contabeis@ufpe.br \\
\hline 9 & Ciências Contábeis & UEM & $\mathrm{PR}$ & 3 & - & - & http://www.pco.uem.br/ & sec-pco@uem.br \\
\hline 10 & Ciências Contábeis & UFRJ & RJ & 5 & 4 & - & http://ppgcc.ufrj.br/ & ppgcc@facc.ufrj.br \\
\hline 11 & Ciências Contábeis & UERJ & $\mathrm{RJ}$ & 3 & - & - & http://ppgcc.faf.uerj.br/ & ppgcc@uerj.br \\
\hline 12 & Ciências Contábeis & UFRN & RN & 3 & - & - & $\begin{array}{l}\text { https://sigaa.ufrn.br/sigaa/public/programa/equipe.jsf?lc=pt_BR\&id } \\
=9066\end{array}$ & ppgcc@ccsa.ufrn.br \\
\hline 13 & Ciências Contábeis & UNISINOS & $\mathrm{RS}$ & 5 & 4 & - & http://www.unisinos.br/mestrado-e-doutorado/ciencias-contabeis & ppgeconomicas@unisinos.br \\
\hline 14 & Ciências Contábeis & FURB & $\mathrm{SC}$ & 4 & 4 & - & $\begin{array}{l}\text { http://www.furb.br/web/1854/cursos/programa-pos- } \\
\text { graduacao/ciencias-contabeis/apresentacao }\end{array}$ & ppgcc-mestrado@furb.br \\
\hline 15 & Ciências Contábeis & UNIFECAP & SP & 4 & - & - & http://www.fecap.br/portalinstitucional/mestrado/ & secretaria.mestrado@fecap.br \\
\hline 16 & Ciências Contábeis e Atuariais & $\mathrm{PUC} / \mathrm{SP}$ & SP & 3 & - & - & $\begin{array}{l}\text { http://www.pucsp.br/pos-graduacao/mestrado-e- } \\
\text { doutorado/ciencias-contabeis-e-atuariais }\end{array}$ & poscont@pucsp.br \\
\hline 17 & Contabilidade & UFBA & BA & 3 & - & - & http://www.contabeis.ufba.br/ & ppgcont@ufba.br \\
\hline 18 & Contabilidade & UFPR & PR & 4 & 4 & - & http://www.ppgcontabilidade.ufpr.br/ & ppgccont@ufpr.br \\
\hline 19 & Contabilidade & UNIOESTE & PR & 3 & - & - & http://www.unioeste.br/pos/cienciascontabeis/ & cascavel.ppgc@unioeste.br \\
\hline 20 & Contabilidade & UFSC & $\mathrm{SC}$ & 4 & 4 & - & http://www.ppgc.ufsc.br/ & ppgc@contato.ufsc.br \\
\hline 21 & Controladoria & UFRPE & $\mathrm{PE}$ & 3 & - & - & http://www.prppg.ufrpe.br/ & cppg@prppg.ufrpe.br \\
\hline 22 & Controladoria E Contabilidade & USP & $\mathrm{SP}$ & 6 & 6 & - & http://prpg.usp.br/ppgcc & ppgcc@usp.br \\
\hline 23 & Controladoria E Contabilidade & USP/RP & SP & 4 & 4 & - & http://www.fearp.usp.br/pt-br/ppgcc.html & rcc@fearp.usp.br \\
\hline
\end{tabular}

Fonte: SNPG.

Data Atualização: 20/03/2015

Data da Coleta: 04/09/2015. 


\title{
Appendix E: Invitation Letter to the Researchers (in Portuguese)
}

São Paulo, de outubro de 2015.

Prezado (a) Pesquisador (a),

A qualidade da produção científica deve ser objeto constante de reflexões da comunidade acadêmica, na busca de ampliar as fronteiras do conhecimento e oferecer soluções aos problemas sociais, com rigor e relevância. É um elemento importante para os PPG, dado o seu impacto sobre o que é produzido e sua influência nas avaliações periódicas dos mesmos.

Neste sentido, pedimos a sua participação em uma pesquisa de doutorado "Qualidade no processo de produção científica em Ciências Contábeis no Brasil", para uma tese a ser defendida no PPGCC/FEA/USP. O estudo utilizará a técnica Delphi e a coleta será feita por questionários eletrônicos com questões fechadas, com uso de login e senha. Serão apenas 3 rodadas e a previsão é que sejam necessários menos de 20 minutos para concluir cada rodada. Sua função será a de compor o painel de especialistas da Delphi para formação de consensos sobre aspectos da qualidade, a partir de suas práticas nos diferentes estágios do processo de pesquisa.

Ao final do estudo, teremos prazer de encaminhar um sumário com os principais achados e conclusões. Caso concorde, pedimos que responda a este e-mail até o dia 17 de outubro de 2015. Em seguida, encaminharemos uma mensagem com o endereço eletrônico e instruções para acesso e participação na primeira rodada.

Quaisquer dúvidas, sinta-se à vontade para nos contatar. Desde já agradecemos.

Cordialmente,

\author{
José Renato Sena Oliveira \\ Doutorando em Controladoria e Contabilidade - PPGCC/FEA/USP \\ jrsena@usp.br / jrsenna@uefs.br
}

Prof. Dr. Gilberto de Andrade Martins

Professor Orientador - PPGCC/FEA/USP

Professor Titular - EAC/FEA/USP

martins@usp.br - (11) 3091-5820, ramal 124. 


\section{Appendix F: Invitation Letter to the Graduate Coordinators (in Portuguese)}

São Paulo, de outubro de 2015

Prezado (a) Coordenador (a),

A qualidade da produção científica deve ser objeto constante de reflexões da comunidade acadêmica, na busca de ampliar as fronteiras do conhecimento e oferecer soluções aos problemas sociais, com rigor e relevância. É um elemento importante para os PPG, dado o seu impacto sobre o que é produzido e sua influência nas avaliações periódicas dos mesmos.

Neste sentido, pedimos a sua colaboração no sentido de incentivar os (as) docentes do seu Programa a participarem, voluntariamente, da pesquisa "Qualidade no processo de produção científica em Ciências Contábeis no Brasil”, para a tese do doutorando José Renato Sena Oliveira, a ser defendida no PPGCC/FEA/USP, sob a orientação do Prof. Dr. Gilberto de Andrade Martins. Os (as) docentes serão convidados (as) a comporem o painel de especialistas da Delphi sobre aspectos da prática cotidiana, relativos à qualidade, em diferentes estágios do processo de pesquisa.

Quaisquer dúvidas, sinta-se à vontade para nos contatar ou para entrar em contato com o doutorando pelos e-mails jrsena@,usp.brou jrsenna@uefs.br.

Agradecemos sua colaboração.

Cordialmente,

Prof. Dr. Andson Braga de Aguiar

Coordenador do PPGCC/FEA/USP

ppgcc@usp.br - (11) 3091-5920.

Prof. Dr. Gilberto de Andrade Martins

Professor Orientador - PPGCC/FEA/USP

martins@usp.br-(11)3091-5820, ramal 124. 


\section{Appendix G: Data Collection Instrument - First Round (in Portuguese)}

\section{INSTRUMENTO DE COLETA DE DADOS (DELPHI: 1ª RODADA)}

INSTRUÇÃO:

Para as proposições a seguir, atribua uma nota em uma escala de 1 a 10, de acordo com o nível de concordância quanto à aderência da proposição à sua prática de pesquisa.

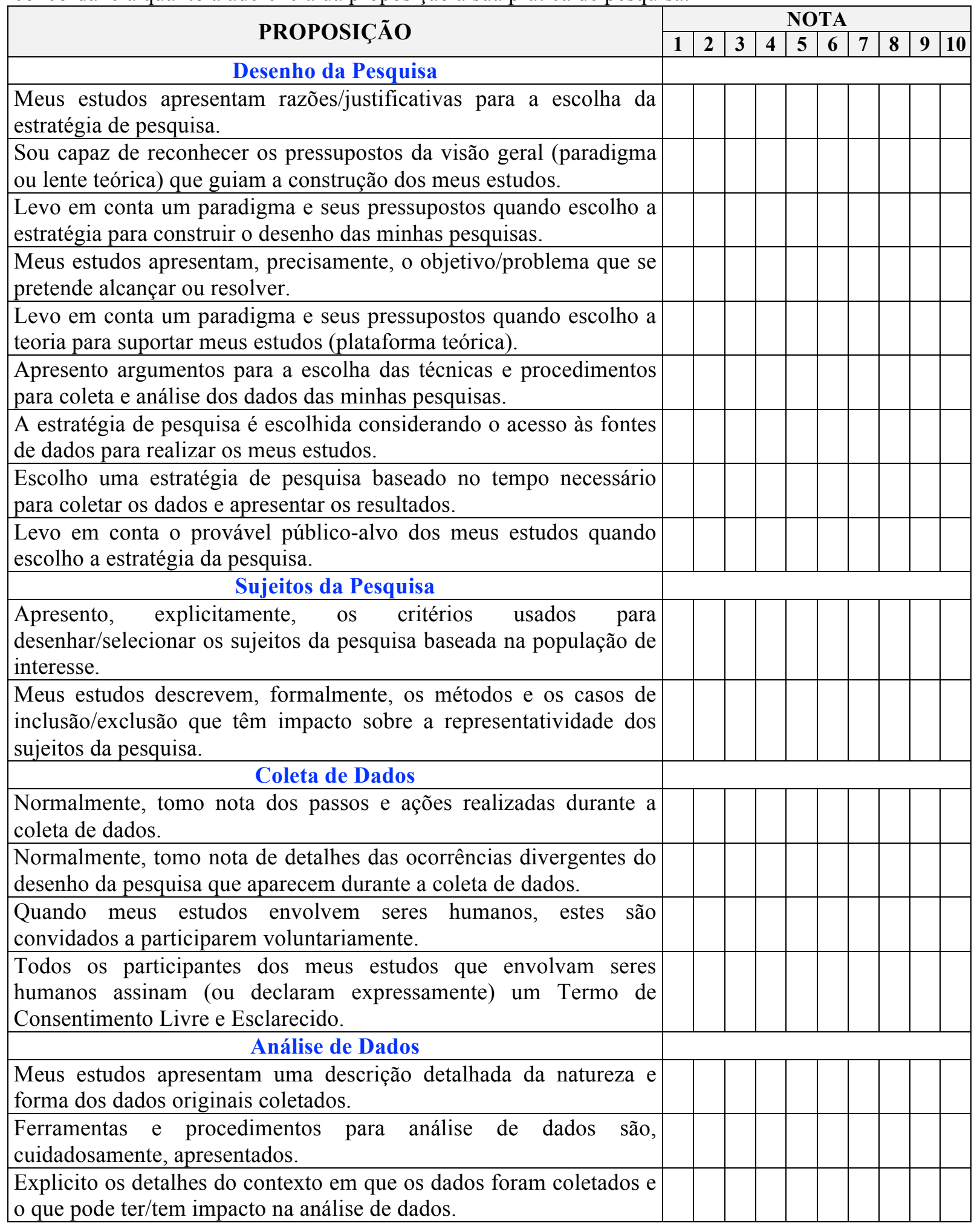




\section{PROPOSIÇÃO}

\begin{tabular}{|l|l|l|l|l|l|l|l|l|l|}
\hline 10 & $\mathbf{1 1}$ \\
\hline & 2 & 3 & 4 & 5 & 6 & 7 & 8 & 9 & 10 \\
\hline
\end{tabular}

Apresento outras visões/perspectivas possíveis para que o leitor possa entender melhor o contexto da análise dos meus dados.

Discuto a significância dos dados para alcançar os objetivos em meus estudos.

Discuto os links, implícitos e explícitos, entre os dados/achados e o propósito nos meus estudos.

\section{Achados}

Meus estudos apresentam ao público-alvo, de maneira clara, como cheguei às conclusões a partir dos achados reportados.

As conclusões dos meus estudos apresentam, de maneira explícita, a correspondência entre achados e evidências/dados.

Uso achados empíricos de estudos anteriores para comparar com os meus achados (quando aplicável).

Baseados nos achados, meus estudos sugerem novas áreas para investigação.

Os achados são apresentados de uma maneira que cria perspectivas (insights) de pensar o conhecimento na área.

Uso achados empíricos de estudos anteriores para suportar minhas proposições e/ou hipóteses (quando aplicável).

Checo se meus achados estão, claramente, ligados ao propósito dos meus estudos.

Descrevo em detalhes o contexto no qual os estudos foram conduzidos, a fim de permitir replicações.

Meus estudos discutem, precisamente, a natureza e a origem de possíveis divergências nos dados que poderiam impactar as conclusões.

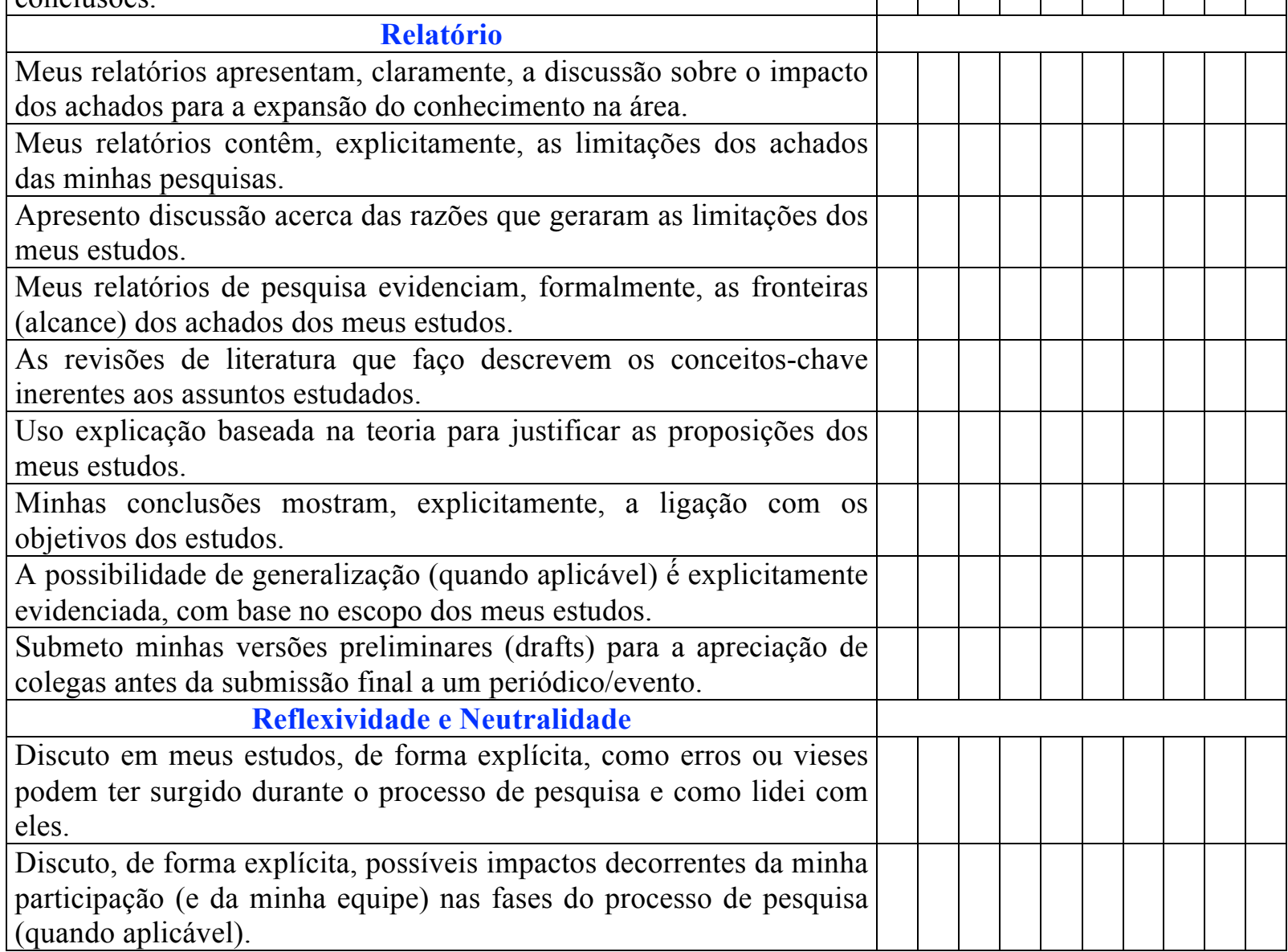




\begin{tabular}{|c|c|c|c|c|c|c|c|c|c|c|}
\hline \multirow{2}{*}{ PROPOSIÇÃO } & \multicolumn{10}{|c|}{ NOTA } \\
\hline & 1 & 2 & 3 & 4 & \begin{tabular}{|c|}
5 \\
\end{tabular} & \begin{tabular}{|c|}
6 \\
\end{tabular} & 7 & 8 & 9 & 10 \\
\hline Aspectos Éticos & & & & & & & & & & \\
\hline $\begin{array}{l}\text { Minha Instituição/Unidade Acadêmica tem um Comitề de Ética em } \\
\text { Pesquisa para submissão e aprovação dos projetos de pesquisa. }\end{array}$ & & & & & & & & & & \\
\hline $\begin{array}{l}\text { Minha Instituição/Unidade Acadêmica tem regras claras para } \\
\text { submissão dos projetos de pesquisa ao Comitê̂ de Ética em Pesquisa. }\end{array}$ & & & & & & & & & & \\
\hline $\begin{array}{l}\text { Meus estudos que envolvem seres humanos são, formalmente, } \\
\text { submetidos ao Comitề de Ética em Pesquisa. }\end{array}$ & & & & & & & & & & \\
\hline $\begin{array}{l}\text { A submissão dos projetos de pesquisa que envolvem seres humanos } \\
\text { ao Comitề de Ética é compulsória em minha Instituição/Unidade } \\
\text { Acadêmica. }\end{array}$ & & & & & & & & & & \\
\hline $\begin{array}{l}\text { Uso princípios de ética na pesquisa descritos formalmente em um } \\
\text { Código de Ética (de uma instituição de fomento, por exemplo), para } \\
\text { orientar meus estudos. }\end{array}$ & & & & & & & & & & \\
\hline $\begin{array}{l}\text { Entrego o Termo de Consentimento aos sujeitos humanos envolvidos } \\
\text { em meus estudos, com detalhes sobre propósito do estudo, riscos e } \\
\text { outros aspectos previstos na legislação. }\end{array}$ & & & & & & & & & & \\
\hline $\begin{array}{l}\text { Me preocupo em escolher a estratégia de pesquisa que traga os } \\
\text { menores danos para os sujeitos envolvidos nos meus estudos. }\end{array}$ & & & & & & & & & & \\
\hline $\begin{array}{l}\text { Minhas pesquisas fornecem procedimentos específicos para tratar os } \\
\text { dados dos participantes de maneira confidencial. }\end{array}$ & & & & & & & & & & \\
\hline Auditabilidade & & & & & & & & & & \\
\hline $\begin{array}{l}\text { Mantenho registros completos das alterações feitas no desenho das } \\
\text { pesquisas que modificaram o alcance/amplitude destas. }\end{array}$ & & & & & & & & & & \\
\hline $\begin{array}{l}\text { Mantenho registros completos das razões que motivaram as } \\
\text { alterações feitas no desenho das pesquisas. }\end{array}$ & & & & & & & & & & \\
\hline $\begin{array}{l}\text { Mantenho as bases de dados dos meus estudos, com adequada } \\
\text { descrição da sua composição, para futuras verificações. }\end{array}$ & & & & & & & & & & \\
\hline $\begin{array}{l}\text { Os termos de consentimento, assinados (ou com declaração explícita) } \\
\text { individualmente por cada participante, são mantidos em segurança } \\
\text { para preservar os sujeitos das pesquisas de possíveis riscos. }\end{array}$ & & & & & & & & & & \\
\hline
\end{tabular}

Aqui termina a parte sobre a qualidade no processo de pesquisa.

Por fim, deixe-nos saber um pouco sobre você e o PPG onde atua.

\section{2. Área de conhecimento do seu Doutorado:}

Administração/Finanças

Ciências Sociais

Contabilidade/Controladoria

Economia

\begin{tabular}{|l|l}
\hline & Educação \\
\hline & Engenharia de Produção \\
& Matemática/Estatística \\
& Outra (qual?)
\end{tabular}

13. Sobre o seu Doutorado, escolha a opção que melhor o caracteriza:

Fiz o Doutorado no mesmo PPG onde atuo.

Fiz o Doutorado na mesma Instituição, mas em um PPG diferente do que atuo.

Fiz o Doutorado em outra Instituição nacional.

Fiz o Doutorado em uma Instituição estrangeira. 
14. Fez Estágio Doutoral (sanduíche) durante o Doutorado?

Não fiz.

Sim, fiz Estágio Doutoral em outra Instituição nacional.

Sim, fiz Estágio Doutoral em uma Instituição estrangeira.

15. Já fez Pós-doutorado?

Não fiz.

Sim, fiz Pós-doutorado em uma Instituição nacional.

Sim, fiz Pós-doutorado em uma Instituição estrangeira.

16. Tempo de atuação como membro do corpo docente do PPG (em anos):

17. Seu credenciamento para orientação de discentes do PPG é:

Somente para Mestrado

Somente para Doutorado

Para Mestrado e Doutorado

18. Possui projeto de pesquisa financiado por Instituição de Fomento?

Sim Não

19. Possui bolsa de produtividade em pesquisa fornecida por Instituição de Fomento? Sim

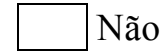

20. Atua ou já atuou como Editor (a) de periódico classificado nos estratos do Qualis/CAPES (exceto Qualis C)?

$\square$ Sim

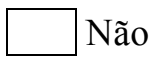

21. É ou já foi membro de Conselho Editorial de periódico classificado nos estratos do Qualis/CAPES (exceto Qualis C)?

$\square \operatorname{Sim}$

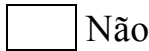

22. É ou já foi Avaliador (a) de periódico classificado nos estratos do Qualis/CAPES (exceto Qualis C)?

$\square \operatorname{Sim}$

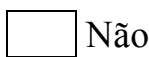

23. Considerando a última Avaliação Trienal, quantos artigos você publicou em periódico classificado nos estratos superiores (A1, A2 ou B1) do Qualis/CAPES?
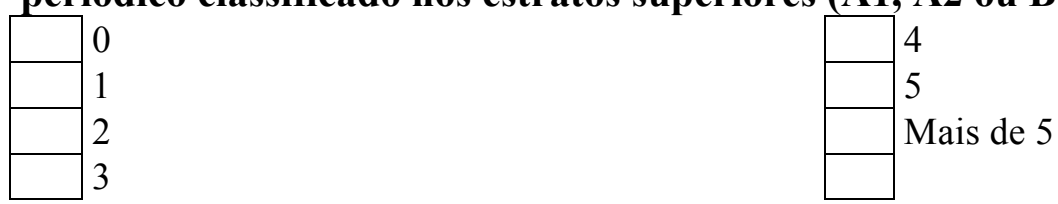

24. Característica do PPG onde atua:

Oferece apenas Mestrado 
25. Nota atual do PPG onde atua na avaliação da CAPES: 3

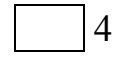
4 5
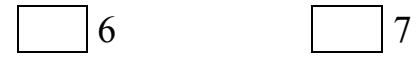

26. Use este espaço para deixar seu comentário, crítica ou sugestão (opcional)

Esta primeira rodada da Delphi termina aqui.

Em breve você receberá um novo e-mail com um resumo das respostas e o link para acesso ao questionário da próxima rodada.

Muito obrigado! 


\title{
Appendix H: Informed Consent (in Portuguese)
}

\section{TERMO DE CONSENTIMENTO LIVRE E ESCLARECIDO (TCLE)}

\author{
Prezado (a) Pesquisador (a),
}

Você está sendo convidado (a) como voluntário (a) a participar da pesquisa intitulada “Qualidade no processo de produção científica em Ciências Contábeis no Brasil”, como parte do projeto de tese cujo pesquisador responsável é JOSÉ RENATO SENA OLIVEIRA, discente do Doutorado Interinstitucional (parceria entre a Universidade de São Paulo e a Universidade Estadual de Feira de Santana e associadas) do Programa de Pós-Graduação em Controladoria e Contabilidade da Faculdade de Economia, Administração e Contabilidade da Universidade de São Paulo (PPGCC/FEA/USP). O pesquisador é orientado pelo Prof. Dr. Gilberto de Andrade Martins.

O objetivo do estudo é levantar e discorrer sobre atributos de qualidade de uma boa pesquisa no processo de construção da produção científica em Ciências Contábeis, em que serão levantados tais atributos nas práticas de investigação dos (das) respondentes e confrontados com aqueles identificados na literatura. $\mathrm{O}$ estudo é importante para compreender as práticas de produção científica na área, a fim de avaliar a qualidade da pesquisa a partir do seu processo de construção. Poderá contribuir para redirecionar ações, redefinir práticas e estratégias metodológicas, especialmente nos Programas de Pós-Graduação, bem como para identificar elementos que colaborem para maior aceitabilidade pela produção na comunidade científica.

A coleta de dados será feita eletronicamente com o uso da técnica Delphi modificada (com 3 rodadas para aplicação dos instrumentos de coleta), a fim de formar consenso entre os respondentes. Em cada rodada você responderá a um questionário objetivo, cujo acesso para a primeira rodada será pelo site http://pt.surveymonkey.com/r/QualiPPGCCFEAUSP, com senha e código de respondente personalizado que você receberá em seu e-mail. O código de respondente é individual e tem a finalidade de permitir a conexão entre as respostas de cada respondente nas diferentes rodadas. A fim de preservar a sua privacidade, o código não guarda qualquer associação que permita identificação dos (das) respondentes na base de dados.

Você deverá atribuir uma nota (1 a 10) sobre o seu nível de concordância a cada proposição relativa a uma determinada característica das diferentes fases do processo de pesquisa. Como a finalidade é a formação do consenso sobre as práticas, o questionário será modificado nas fases seguintes em função do resultado alcançado e de sugestões dos (das) experts na fase anterior. $O$ questionário da primeira rodada da Delphi apresentará, também, algumas questões para caracterização do perfil dos (das) participantes. A previsão é que sejam necessários menos de 20 minutos para cada rodada. Você receberá por e-mail um resumo personalizado com a sua nota e com a mediana do grupo para cada proposição, após cada rodada.

Considerando que a coleta de dados ocorrerá por meio eletrônico, há um risco associado a uma possível identificação de senha e/ou código de respondente do (da) participante. Para minimizálo, recomenda-se a manutenção do e-mail sem acesso por terceiros, bem como evitar a impressão da mensagem eletrônica. Outro aspecto é um possível desconforto com alguma questão específica e, a fim de mitigá-lo, os dados não serão analisados individualmente, mas no agregado da formação do consenso dos (das) respondentes para que não haja exposição individual. Quando aos benefícios esperados à comunidade científica, estão explicitados nas contribuições esperadas apresentadas no parágrafo relativo ao objetivo e às justificativas.

Você será esclarecido (a) sobre os aspectos relativos a esta pesquisa sempre que desejar. Você é livre para recusar-se a participar, retirar seu consentimento ou interromper a participação a qualquer momento. A sua participação é voluntária e a recusa em participar não irá acarretar qualquer penalidade. Os pesquisadores tratarão a sua identidade com padrões profissionais de sigilo e os dados serão analisados de forma agregada, sem identificação individual de participantes. Os dados serão divulgados na tese e em futuras publicações de natureza científica, seguindo as diretrizes éticas da pesquisa e assegurando a privacidade dos (das) respondentes. Caberá ao pesquisador responsável a 
preservação do sigilo e a guarda dos dados, os quais serão mantidos em meio eletrônico indefinidamente para uso em futuras publicações de natureza científica. Entretanto, os dados que possam representar risco à privacidade dos (das) respondentes serão destruídos após a defesa da tese.

A participação no estudo não acarretará custos para você e não será disponibilizada nenhuma compensação financeira. Qualquer dano que, porventura, o (a) participante vier a sofrer como resultado da participação dele (a) nesta pesquisa é de responsabilidade dos pesquisadores e das Instituições envolvidas, conforme previsto na Res. CNS n. 466/12 e será apurado nos termos da legislação em vigor. Ao final do estudo, teremos prazer de encaminhar a você, por e-mail, um sumário com os principais achados e conclusões.

Em caso de dúvidas você pode indagar ao pesquisador José Renato Sena Oliveira pelos meios de contato ou no Departamento de Ciências Sociais Aplicadas da UEFS, situado à Av. Transnordestina, S/N, Módulo 3, MA 34 - Novo Horizonte - Feira de Santana/BA. Alternativamente, indagar ao pesquisador e/ou seu orientador pelos meios de contato ou no Departamento de Contabilidade e Atuária da FEA/USP, situado à Av. Prof. Luciano Gualberto, 908 - Butantã - São Paulo/SP. Para dúvidas de natureza ética, você poderá contatar o Comitê de Ética em Pesquisa da UEFS (CEP/UEFS), pelo e-mail cep@uefs.br ou no endereço Av. Transnordestina, S/N, Módulo 1, MA 17, Bairro Novo Horizonte - Feira de Santana/BA.

Cordialmente,

\author{
José Renato Sena Oliveira \\ Doutorando em Controladoria e Contabilidade - PPGCC/FEA/USP \\ jrsena@usp.br/jrsenna@uefs.br \\ Prof. Dr. Gilberto de Andrade Martins \\ Professor Orientador - PPGCC/FEA/USP \\ Professor Titular - EAC/FEA/USP \\ martins@usp.br-(11) 3091-5820, ramal 124
}

Por favor, insira no campo abaixo o código de respondente que você recebeu por e-mail:

Concordo com as condições para participação conforme descritas acima.

ATENÇÃO: guarde uma cópia deste TCLE após o preenchimento destes campos. 


\title{
Appendix I: Invitation Letter for Delphi First Round (in Portuguese)
}

\author{
Prezado (a) Pesquisador (a),
}

Inicialmente, gostaríamos de agradecer por ter aceito o convite para participar voluntariamente do painel de especialistas da Delphi no estudo "Qualidade no processo de produção científica em Ciências Contábeis no Brasil", como parte do projeto de tese de José Renato Sena Oliveira no PPGCC/FEA/USP, sob a orientação do Prof. Dr. Gilberto de Andrade Martins.

A partir da presente data estamos iniciando a coleta de dados da primeira rodada da Delphi. A fim de preservar a privacidade dos (das) respondentes, na base de dados não haverá qualquer identificação pessoal. Cada usuário (a) deverá utilizar senha e Código de Respondente individual, que foi criado de modo a não apresentar qualquer elemento de identificação e, ao mesmo tempo, permitir o vínculo das respostas nas diferentes rodadas. Pedimos que preserve estes dados, pois são importantes para que possamos fazer tal vínculo.

Seus dados personalizados são:

SENHA: $\mathrm{xxxxxxx \times xx}$

CÓDIGO DE RESPONDENTE: delphixxx

Para acessar o instrumento visite o endereço http://pt.surveymonkey.com/r/QualiPPGCCFEAUSP. A tela de abertura já requererá esta senha.

Na tela seguinte você encontrará o Termo de Consentimento Livre e Esclarecido (TCLE), com informações adicionais sobre o estudo. Antes de passar para a página seguinte, pedimos que insira este Código de Respondente no campo ao final do TCLE e sugerimos que gere e guarde uma cópia do referido Termo.

O instrumento ficará disponível até o dia de encaminharemos um novo e-mail com as instruções para a próxima rodada. Qualquer dúvida, sinta-se à vontade para nos contatar.

Agradecemos por sua disponibilidade.

Cordialmente,

José Renato Sena Oliveira

Doutorando em Controladoria e Contabilidade - PPGCC/FEA/USP

jrsena@usp.br/jrsenna@uefs.br

Prof. Dr. Gilberto de Andrade Martins

Professor Orientador - PPGCC/FEA/USP

Professor Titular - EAC/FEA/USP

martins@usp.br - (11) 3091-5820, ramal 124 


\section{Appendix J: Customized Report for Experts (in Portuguese)}

USUÁRIO: delphiXXX

\begin{tabular}{|c|c|c|c|}
\hline & \\
\hline ETAPA & PROPOSIÇÃO & Sua Nota & Mediana \\
\hline \multirow[t]{9}{*}{ Desenho } & Meus estudos apresentam razões/justificativas para a escolha da estratégia... & 5 & 9.00 \\
\hline & Sou capaz de reconhecer os pressupostos da visão geral (paradigma... & 5 & 9.00 \\
\hline & Levo em conta um paradigma e seus pressupostos quando escolho a estratégia... & 5 & 9.00 \\
\hline & Meus estudos apresentam, precisamente, o objetivo/problema... & 5 & 10.00 \\
\hline & Levo em conta um paradigma e seus pressupostos quando escolho a teoria... & 5 & 9.00 \\
\hline & Apresento argumentos para a escolha das técnicas e procedimentos para coleta... & 5 & 9.00 \\
\hline & A estratégia de pesquisa é escolhida considerando o acesso às fontes de dados... & 5 & 9.00 \\
\hline & Escolho uma estratégia de pesquisa baseado no tempo necessário para coletar... & 5 & 8.00 \\
\hline & Levo em conta o provável público-alvo dos meus estudos quando escolho... & 5 & 7.00 \\
\hline \multirow{2}{*}{$\begin{array}{c}\text { Sujeitos da } \\
\text { Pesquisa }\end{array}$} & Apresento, explicitamente, os critérios usados para desenhar/selecionar... & 5 & 9.00 \\
\hline & Meus estudos descrevem, formalmente, os métodos e os casos... & 5 & 9.00 \\
\hline \multirow{4}{*}{$\begin{array}{c}\text { Coleta de } \\
\text { Dados }\end{array}$} & Normalmente, tomo nota dos passos e ações realizadas durante a coleta... & 5 & 9.00 \\
\hline & Normalmente, tomo nota de detalhes das ocorrências divergentes do desenho... & 5 & 9.00 \\
\hline & Quando meus estudos envolvem seres humanos, estes são convidados... & 5 & 10.00 \\
\hline & Todos os participantes dos meus estudos que envolvam seres humanos assinam & 5 & 8.00 \\
\hline \multirow{6}{*}{$\begin{array}{c}\text { Análise dos } \\
\text { Dados }\end{array}$} & Meus estudos apresentam uma descrição detalhada da natureza e forma... & 5 & 9.00 \\
\hline & Ferramentas e procedimentos para análise de dados são, cuidadosamente,... & 5 & 9.00 \\
\hline & Explicito os detalhes do contexto em que os dados foram coletados e o que pode... & 5 & 8.00 \\
\hline & Apresento outras visões/perspectivas possíveis para que o leitor... & 5 & 7.00 \\
\hline & Discuto a significância dos dados para alcançar os objetivos em meus estudos. & 5 & 9.00 \\
\hline & Discuto os links, implícitos e explícitos, entre os dados/achados e o propósito... & 5 & 9.00 \\
\hline \multirow[t]{9}{*}{ Achados } & Meus estudos apresentam ao público-alvo, de maneira clara, como cheguei... & 5 & 9.00 \\
\hline & As conclusões dos meus estudos apresentam, de maneira explícita, a... & 5 & 9.00 \\
\hline & Uso achados empíricos de estudos anteriores para comparar com os meus... & 5 & 10.00 \\
\hline & Baseados nos achados, meus estudos sugerem novas áreas para investigação. & 5 & 9.00 \\
\hline & Os achados são apresentados de uma maneira que cria perspectivas (insights) ... & 5 & 8.00 \\
\hline & Uso achados empíricos de estudos anteriores para suportar minhas proposições... & 5 & 9.00 \\
\hline & Checo se meus achados estão, claramente, ligados ao propósito... & 5 & 9.00 \\
\hline & Descrevo em detalhes o contexto no qual os estudos foram conduzidos, ... & 5 & 9.00 \\
\hline & Meus estudos discutem, precisamente, a natureza e a origem de possíveis... & 5 & 8.00 \\
\hline \multirow[t]{9}{*}{ Relatório } & Meus relatórios apresentam, claramente, a discussão sobre o impacto... & 5 & 8.00 \\
\hline & Meus relatórios contêm, explicitamente, as limitações dos achados... & 5 & 9.00 \\
\hline & Apresento discussão acerca das razões que geraram as limitações... & 5 & 8.00 \\
\hline & Meus relatórios de pesquisa evidenciam, formalmente, as fronteiras (alcance)... & 5 & 8.00 \\
\hline & As revisões de literatura que faço descrevem os conceitos-chave ... & 5 & 9.00 \\
\hline & Eu uso explicação baseada na teoria para justificar as proposições... & 5 & 9.00 \\
\hline & Minhas conclusões mostram, explicitamente, a ligação com os objetivos ... & 5 & 10.00 \\
\hline & A possibilidade de generalização (quando aplicável) é explicitamente... & 5 & 9.00 \\
\hline & Submeto minhas versões preliminares (drafts) para a apreciação de colegas ... & 5 & 7.00 \\
\hline \multirow{2}{*}{$\begin{array}{l}\text { Reflexivid. } \\
\text { Neutralid. }\end{array}$} & Discuto em meus estudos, de forma explícita, como erros ou viéses podem... & 5 & 7.00 \\
\hline & Discuto, de forma explícita, possíveis impactos decorrentes da minha particip... & 5 & 7.00 \\
\hline \multirow{8}{*}{$\begin{array}{c}\text { Aspectos } \\
\text { Éticos }\end{array}$} & Minha Instituição/Unidade Acadêmica tem um Comitê de Ética para submissão... & 5 & 10.00 \\
\hline & Minha Instituição/Unidade Acadêmica tem regras claras para submissão... & 5 & 9.00 \\
\hline & Meus estudos que envolvem seres humanos são, formalmente, submetidos... & 5 & 6.00 \\
\hline & A submissão dos projetos de pesquisa que envolvem seres humanos ao Comitê... & 5 & 6.00 \\
\hline & Uso princípios de ética na pesquisa descritos formalmente em um Código de... & 5 & 9.00 \\
\hline & Entrego o Termo de Consentimento aos sujeitos humanos envolvidos... & 5 & 8.00 \\
\hline & Me preocupo em escolher a estratégia de pesquisa que traga os menores danos... & 5 & 9.00 \\
\hline & Minhas pesquisas fornecem procedimentos específicos para tratar os dados... & 5 & 10.00 \\
\hline \multirow[t]{4}{*}{ Auditabil. } & Mantenho registros completos das alterações feitas no desenho... & 5 & 8.00 \\
\hline & Mantenho registros completos das razões que motivaram as alterações... & 5 & 8.00 \\
\hline & Mantenho as bases de dados dos meus estudos, com adequada descrição... & 5 & 9.00 \\
\hline & Os termos de consentimento, assinados individualmente por cada participante... & 5 & 8.00 \\
\hline
\end{tabular}




\title{
Appendix K: Invitation Letter - Second Round (in Portuguese)
}

\author{
Prezado (a) Pesquisador (a),
}

Mais uma vez gostaríamos de agradecer por sua valiosa e voluntária contribuição como especialista no painel da Delphi no estudo "Qualidade no processo de produção científica em Ciências Contábeis no Brasil", como parte do projeto de tese de José Renato Sena Oliveira no PPGCC/FEA/USP, sob a orientação do Prof. Dr. Gilberto de Andrade Martins.

A partir de hoje iniciamos a coleta de dados da segunda rodada da Delphi. Fizemos alguns ajustes no novo instrumento:

- Por sugestão de alguns (mas) participantes, incluímos a alternativa "Nunca fiz/não faço pesquisas envolvendo seres humanos" aos grupos Coleta de Dados, Aspectos Éticos e Auditabilidade, a fim de evitar possíveis vieses na análise de algumas proposições. A sugestão também será levada em conta na análise dos dados já coletados na primeira rodada;

- Foi incluído o conceito de "pesquisa envolvendo seres humanos" previsto na Resolução no 466/12 do Conselho Nacional de Saúde;

- As proposições que já atenderam aos critérios e parâmetros de consenso formado que estamos utilizando no estudo não fazem mais parte desta segunda rodada. Como efeito, o novo instrumento de coleta é significativamente menor.

Seus dados personalizados são:

SENHA: $\operatorname{xxxxxxxxxx}$

CÓDIGO DE RESPONDENTE: delphixxx

Para acessar o novo instrumento visite o endereço: http://pt.surveymonkey.com/r/DelphiQuali2. As orientações são idênticas às do questionário anterior.

A fim de facilitar suas respostas nesta etapa, segue anexo um sumário personalizado com suas notas e as medianas das notas atribuídas pelo grupo de especialistas na primeira rodada, mas apenas com as proposições que farão parte desta segunda rodada. Para cada item você poderá optar por manter a mesma nota ou escolher outra alternativa disponível como resposta.

O novo instrumento ficará disponível até o dia _ de Após o término desta etapa encaminharemos um novo e-mail com as instruções para a rodada final, caso seja necessária.

Qualquer dúvida, sinta-se à vontade para nos contatar.

Agradecemos por sua disponibilidade.

Cordialmente,

José Renato Sena Oliveira

Doutorando em Controladoria e Contabilidade - PPGCC/FEA/USP

jrsena@usp.br/jrsenna@uefs.br

Prof. Dr. Gilberto de Andrade Martins

Professor Orientador - PPGCC/FEA/USP

Professor Titular - EAC/FEA/USP

martins@usp.br - (11) 3091-5820, ramal 124 


\section{Appendix L: Data Collection Instrument - Second Round (in Portuguese)}

\section{INSTRUMENTO DE COLETA DE DADOS (DELPHI: $2^{\text {a }}$ RODADA)}

\section{INSTRUÇÃO:}

Para as proposições a seguir, atribua uma nota em uma escala de 1 a 10, de acordo com o nível de concordância quanto à aderência da proposição à sua prática de pesquisa.

\begin{tabular}{|c|c|c|c|c|c|c|c|c|c|c|}
\hline \multirow{2}{*}{ PROPOSIÇÃO } & \multicolumn{10}{|c|}{ NOTA } \\
\hline & 1 & 2 & 3 & 4 & 5 & 6 & 7 & 8 & & 10 \\
\hline Desenho da Pesquisa & & & & & & & & & & \\
\hline $\begin{array}{l}\text { Levo em conta um paradigma e seus pressupostos quando escolho a } \\
\text { estratégia para construir o desenho das minhas pesquisas. }\end{array}$ & & & & & & & & & & \\
\hline $\begin{array}{l}\text { Escolho uma estratégia de pesquisa baseado no tempo necessário } \\
\text { para coletar os dados e apresentar os resultados. }\end{array}$ & & & & & & & & & & \\
\hline $\begin{array}{l}\text { Levo em conta o provável público-alvo dos meus estudos quando } \\
\text { escolho a estratégia da pesquisa. }\end{array}$ & & & & & & & & & & \\
\hline Sujeitos da Pesquisa & & & & & & & & & & \\
\hline $\begin{array}{l}\text { Meus estudos descrevem, formalmente, os métodos e os casos de } \\
\text { inclusão/exclusão que têm impacto sobre a representatividade dos } \\
\text { sujeitos da pesquisa. }\end{array}$ & & & & & & & & & & \\
\hline
\end{tabular}

\begin{tabular}{|c|c|c|c|c|c|c|c|c|c|}
\hline \multirow{2}{*}{ PROPOSIÇÃO } & \multicolumn{9}{|c|}{ NOTA } \\
\hline & 1 & 2 & 3 & 4 & 56 & 7 & 8 & 9 & $\overline{10}$ \\
\hline Coleta de Dados & & & & & & & & & \\
\hline $\begin{array}{l}\text { Normalmente, tomo nota de detalhes das ocorrências divergentes } \\
\text { do desenho da pesquisa que aparecem durante a coleta de dados. }\end{array}$ & & & & & & & & & \\
\hline $\begin{array}{l}\text { Quando meus estudos envolvem seres humanos, estes são } \\
\text { convidados e participarem voluntariamente**. }\end{array}$ & & & & & & & & & \\
\hline $\begin{array}{l}\text { Todos os participantes dos meus estudos que envolvam seres } \\
\text { humanos assinam (ou declaram expressamente) um Termo de } \\
\text { Consentimento Livre e Esclarecido. }\end{array}$ & & & & & & & & & \\
\hline
\end{tabular}

* Nunca fiz/não faço pesquisas envolvendo seres humanos.

** De acordo com a Resolução 466/2012 do Conselho Nacional de Saúde, pesquisa envolvendo seres humanos é a "pesquisa que, individual ou coletivamente, tenha como participante o ser humano, em sua totalidade ou partes dele, e o envolva de forma direta ou indireta, incluindo o manejo de seus dados, informações ou materiais biológicos" (Res. CNS n. 466/2012, item II.14).

\begin{tabular}{|l|l|l|l|l|l|l|l|l|l|l|}
\hline \multicolumn{1}{|c|}{ PROPOSIÇÃo } & \multicolumn{5}{|c|}{ NOTA } \\
\hline \multicolumn{1}{|c|}{ Análise de Dados } & $\mathbf{1}$ & $\mathbf{2}$ & $\mathbf{3}$ & $\mathbf{4}$ & $\mathbf{5}$ & $\mathbf{6}$ & $\mathbf{7}$ & $\mathbf{8}$ & $\mathbf{9}$ & $\mathbf{1 0}$ \\
\hline \multicolumn{1}{|c|}{ Achados } \\
\hline $\begin{array}{l}\text { Apresento outras visões/perspectivas possíveis para que o leitor } \\
\text { possa entender melhor o contexto da análise dos meus dados. }\end{array}$ & & & & & & & \\
\hline $\begin{array}{l}\text { Os achados são apresentados de uma maneira que cria perspectivas } \\
\text { (insights) de pensar o conhecimento na área. }\end{array}$ & & & & & & & & \\
\hline $\begin{array}{l}\text { Meus estudos discutem, precisamente, a natureza e a origem de } \\
\text { possíveis divergências nos dados que poderiam impactar as } \\
\text { conclusões. }\end{array}$ & & & & & & & & & \\
\hline
\end{tabular}




\begin{tabular}{|c|c|c|c|c|c|c|c|c|c|c|}
\hline \multirow{2}{*}{ PROPOSIÇÃO } & \multicolumn{10}{|c|}{ NOTA } \\
\hline & 1 & 2 & 3 & 4 & 5 & 6 & 7 & 8 & 9 & 10 \\
\hline \multicolumn{11}{|l|}{ Relatório } \\
\hline \multicolumn{11}{|l|}{$\begin{array}{l}\text { Meus relatórios apresentam, claramente, a discussão sobre o impacto } \\
\text { dos achados para a expansão do conhecimento na área. }\end{array}$} \\
\hline \multicolumn{11}{|l|}{$\begin{array}{l}\text { Meus relatórios contém, explicitamente, as limitações dos achados } \\
\text { das minhas pesquisas. }\end{array}$} \\
\hline \multicolumn{11}{|l|}{$\begin{array}{l}\text { Apresento discussão acerca das razões que geraram as limitações dos } \\
\text { meus estudos. }\end{array}$} \\
\hline \multicolumn{11}{|l|}{$\begin{array}{l}\text { Meus relatórios de pesquisa evidenciam, formalmente, as fronteiras } \\
\text { (alcance) dos achados dos meus estudos. }\end{array}$} \\
\hline \multicolumn{11}{|l|}{$\begin{array}{l}\text { Submeto minhas versões preliminares (drafts) para a apreciação de } \\
\text { colegas antes da submissão final a um periódico/evento. }\end{array}$} \\
\hline \multicolumn{11}{|l|}{$\begin{array}{l}\text { Reflexividade e Neutralidade } \\
\end{array}$} \\
\hline \multicolumn{11}{|l|}{$\begin{array}{l}\text { Discuto em meus estudos, de forma explícita, como erros ou vieses } \\
\text { podem ter surgido durante o processo de pesquisa e como lidei com } \\
\text { eles. }\end{array}$} \\
\hline $\begin{array}{l}\text { Discuto, de forma explícita, possíveis impactos decorrentes da minha } \\
\text { participação (e da minha equipe) nas fases do processo de pesquisa } \\
\text { (quando aplicável). }\end{array}$ & & & & & & & & & & \\
\hline
\end{tabular}

\begin{tabular}{|c|c|c|c|c|c|c|c|c|c|c|c|}
\hline \multirow{2}{*}{ PROPOSIÇÃO } & \multicolumn{10}{|c|}{ NOTA } & \\
\hline & 1 & 2 & 3 & 4 & 5 & 6 & 7 & 8 & 9 & & \\
\hline \multicolumn{12}{|l|}{ Aspectos Éticos } \\
\hline \multicolumn{12}{|l|}{$\begin{array}{l}\text { Minha Instituição/Unidade Acadêmica tem um Comitế de Ética } \\
\text { em Pesquisa para submissão e aprovação dos projetos de pesquisa. }\end{array}$} \\
\hline \multicolumn{12}{|l|}{$\begin{array}{l}\text { Minha Instituição/Unidade Acadêmica tem regras claras para } \\
\text { submissão dos projetos de pesquisa ao Comitê de Ética em } \\
\text { Pesquisa. }\end{array}$} \\
\hline \multicolumn{12}{|l|}{$\begin{array}{l}\text { Meus estudos que envolvem seres humanos são, formalmente, } \\
\text { submetidos ao Comitề de Ética em Pesquisa. }\end{array}$} \\
\hline \multicolumn{12}{|l|}{$\begin{array}{l}\text { A submissão dos projetos de pesquisa que envolvem seres } \\
\text { humanos ao Comitê̂ de Ética é compulsória em minha } \\
\text { Instituição/Unidade Acadêmica. }\end{array}$} \\
\hline \multicolumn{12}{|l|}{$\begin{array}{l}\text { Uso princípios de ética na pesquisa descritos formalmente em um } \\
\text { Código de Ética (de uma instituição de fomento, por exemplo), } \\
\text { para orientar meus estudos. }\end{array}$} \\
\hline \multicolumn{12}{|l|}{$\begin{array}{l}\text { Entrego o Termo de Consentimento aos sujeitos humanos } \\
\text { envolvidos em meus estudos, com detalhes sobre propósito do } \\
\text { estudo, riscos e outros aspectos previstos na legislação. }\end{array}$} \\
\hline \multicolumn{12}{|l|}{$\begin{array}{l}\text { Me preocupo em escolher a estratégia de pesquisa que traga os } \\
\text { menores danos para os sujeitos envolvidos nos meus estudos. }\end{array}$} \\
\hline \multicolumn{12}{|l|}{$\begin{array}{l}\text { Minhas pesquisas fornecem procedimentos específicos para tratar } \\
\text { os dados dos participantes de maneira confidencial. }\end{array}$} \\
\hline \multicolumn{12}{|l|}{\begin{tabular}{|c|} 
Auditabilidade \\
\end{tabular}} \\
\hline \multicolumn{12}{|l|}{$\begin{array}{l}\text { Mantenho registros completos das alterações feitas no desenho das } \\
\text { pesquisas que modificaram o alcance/amplitude destas. }\end{array}$} \\
\hline \multicolumn{12}{|l|}{$\begin{array}{l}\text { Mantenho registros completos das razões que motivaram as } \\
\text { alterações feitas no desenho das pesquisas. }\end{array}$} \\
\hline $\begin{array}{l}\text { Os termos de consentimento, assinados (ou com declaração } \\
\text { explícita) individualmente por cada participante, são mantidos em } \\
\text { segurança para preservar os sujeitos das pesquisas de possíveis } \\
\text { riscos. }\end{array}$ & & & & & & & & & & & \\
\hline
\end{tabular}


Use este espaço para deixar seu comentário, crítica ou sugestão (opcional)

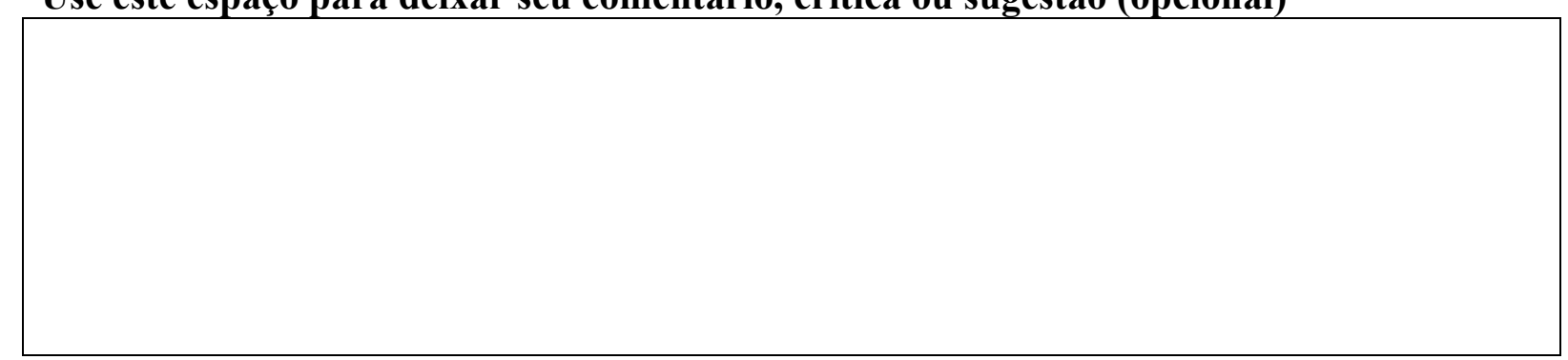

Esta segunda rodada da Delphi termina aqui.

Em breve você receberá um novo e-mail com um resumo das respostas e o link para acesso ao questionário da rodada final, se necessário.

Muito obrigado! 


\section{Appendix M: Thank You Letter for Participating in the Delphi Panel (in Portuguese)}

Prezado (a) Pesquisador (a),

Chegamos ao final da segunda e última rodada da Delphi no estudo "Qualidade no processo de produção científica em Ciências Contábeis no Brasill", como parte do projeto de tese de José Renato Sena Oliveira no PPGCC/FEA/USP, sob a orientação do Prof. Dr. Gilberto de Andrade Martins. Agradecemos por sua valiosa e voluntária contribuição como especialista no painel.

Para a composição do painel foram convidados (as) os (as) docentes dos 23 Programas de Pós-Graduação acadêmicos da área contábil reconhecidos/recomendados pela CAPES, com base nos dados do Portal da CAPES e da Plataforma Sucupira (set/2015). Ao final, contamos com a participação de docentes de 19 dos 23 PPG (10 mestrados e 9 mestrados/doutorados).

Após a segunda rodada os resultados indicaram uma saturação do desvio-padrão, razão pela qual não realizaremos a terceira rodada.

Em respeito ao nosso compromisso firmado no Termo de Consentimento, após a defesa da tese encaminharemos um sumário dos principais achados a todos (as) os (as) participantes do painel.

Também agradecemos pelos comentários e sugestões, os quais ajudaram no ajuste do instrumento para a segunda rodada, bem como ajudarão na análise dos dados.

Colocamo-nos à disposição.

Cordialmente,

José Renato Sena Oliveira

Doutorando em Controladoria e Contabilidade - PPGCC/FEA/USP

jrsena@usp.br/jrsenna@uefs.br

Prof. Dr. Gilberto de Andrade Martins

Professor Orientador - PPGCC/FEA/USP

Professor Titular - EAC/FEA/USP

martins@usp.br - (11) 3091-5820, ramal 124 


\section{Appendix N: Summary of Final Results}

Design - final classification (ordered by proposition)

\begin{tabular}{cllllllllll}
\hline Propos. & \multicolumn{1}{c}{ Attribute/relationship } & $\mathrm{N}$ Round & Score & $\%$ & Mean & Median Ranking & Level & Criterion \\
\hline R1Des01 & Useful strategy for purpose & 41 & 1 & 369 & 90.00 & 9.00 & 9.00 & $2^{\circ}$ & Strong & Suitability \\
R1Des02 & Clear overview that guides the study & 41 & 1 & 358 & 87.32 & 8.73 & 9.00 & $4^{\text {o }}$ & Strong & Suitability \\
R2Des03 & Overview x strategy & 37 & 2 & 316 & 85.41 & 8.54 & 9.00 & $6^{\text {o }}$ & Strong & Suitability \\
R1Des04 & Goal/problem shown precisely & 41 & 1 & 395 & 96.34 & 9.63 & 10.00 & $1^{\text {o }}$ & Strong & Suitability \\
R1Des05 & Overview x theory & 41 & 1 & 349 & 85.12 & 8.51 & 9.00 & $7^{\text {o }}$ & Strong & Suitability \\
R1Des06 & Arguments for technique choices & 41 & 1 & 366 & 89.27 & 8.93 & 9.00 & $3^{\text {o }}$ & Strong & Suitability \\
R1Des07 & Access to the data & 41 & 1 & 35185.61 & 8.56 & 9.00 & $5^{\text {o }}$ & Strong & Feasibility \\
R2Des08 & Time constraints & 37 & 2 & 261 & 70.54 & 7.05 & 7.00 & $9^{\text {o }}$ & Moderate Feasibility \\
R2Des09 & Research strategy x target audience & 37 & 2 & 264 & 71.35 & 7.14 & 8.00 & $8^{\text {o }}$ & Moderate Feasibility \\
\hline
\end{tabular}

Research Subjects - final classification (ordered by proposition)

\begin{tabular}{ccccccccccc}
\hline Propos. & Attribute/relationship & \multicolumn{1}{c}{ N Round Score } & $\%$ & Mean Median Ranking & Level & Criterion \\
\hline R1Sub01 & Criteria to design/select subjects & 41 & 1 & 352 & 85.85 & 8.59 & 9.00 & $1^{\circ}$ & Strong & Internal validity \\
R2Sub02 & Representativeness of subjects & 37 & 2 & 287 & 77.57 & 7.76 & 8.00 & $2^{\text {o }}$ & Strong & Internal validity \\
\hline
\end{tabular}

Data collection - final classification (ordered by proposition)

\begin{tabular}{clllllllllll}
\hline Propos. & \multicolumn{1}{c}{ Attribute/relationship } & \multicolumn{3}{c}{ N Round } & Score & $\%$ & Mean Median Ranking & Level & Criterion \\
\hline R1Co101 & Notes for each research step & 41 & 1 & 361 & 88.05 & 8.80 & 9.00 & $2^{\text {o }}$ & Strong & Rigor \\
R2Co102 & Notes for divergent events & 28 & 2 & 237 & 84.64 & 8.46 & 9.65 & $3^{\text {o }}$ & Strong & Rigor \\
R2Co103 & Voluntary participation of subjects & 23 & 2 & 222 & 96.52 & 9.65 & 8.15 & $1^{\text {o }}$ & Strong & Integrity \\
R2Col04 & Formal agreement from humans & 26 & 2 & 212 & 81.54 & 8.15 & 7.51 & $4^{\text {o }}$ & Strong & Integrity \\
\hline
\end{tabular}

Analysis - final classification (ordered by proposition)

\begin{tabular}{|c|c|c|c|c|c|c|c|c|c|}
\hline Attribute/relationship & $\mathrm{N}$ & Round & Score & $\%$ & Mean & Median & Ranking & Level & Criterion \\
\hline R1Ana01 Description of nature \& form of data & 41 & 1 & 351 & 85.61 & 8.56 & 9.00 & $2^{\circ}$ & Strong & Integrity \\
\hline R1Ana02 Description of tools and procedures & 41 & 1 & 358 & 87.32 & 8.73 & 9.00 & $1^{\mathrm{o}}$ & Strong & Rigor \\
\hline R1Ana03 Context $\mathrm{x}$ impact on data analysis & 41 & 1 & 341 & 83.17 & 8.32 & 8.00 & $5^{\circ}$ & Strong & Reliability \\
\hline R2Ana04 Other views to explain context & 37 & 2 & 278 & 75.14 & 7.51 & 8.00 & $6^{\mathrm{o}}$ & Strong & Reliability \\
\hline R1Ana05 Significance of data to reaching aims & 41 & 1 & 351 & 85.61 & 8.56 & 9.00 & $2^{\circ}$ & Strong & Relevance \\
\hline R1Ana06 Implicit/explicit links - find. $x$ aims & 41 & 1 & 349 & 85.12 & 8.51 & 9.00 & $4^{\circ}$ & Strong & Rigor \\
\hline
\end{tabular}

Findings - final classification (ordered by proposition)

\begin{tabular}{|c|c|c|c|c|c|c|c|c|c|c|}
\hline Propos. & Attribute/relationship & $\mathrm{N}$ & Round & Score & $\%$ & Mean & Median & Ranking & Level & Criterion \\
\hline R1Fin01 & Path to achieve conclusions & 41 & 1 & 359 & 87.56 & 8.76 & 9.00 & $6^{\circ}$ & Strong & Internal validity \\
\hline R1Fin02 & Link between findings $\mathrm{x}$ evidence & 41 & 1 & 363 & 88.54 & 8.85 & 9.00 & $4^{\circ}$ & & Internal validity \\
\hline R1Fin03 & Comparison results $\mathrm{x}$ other studies & 41 & 1 & 373 & 90.98 & 9.10 & 10.00 & $1^{\mathrm{o}}$ & & External validity \\
\hline 1Fin04 & the findings & 41 & 1 & 361 & 88.05 & 8.80 & 9.00 & $5^{\circ}$ & Strong & Contribut \\
\hline R2Fin05 & ing about the field & 37 & 2 & 302 & 81.62 & 8.16 & 8.00 & $8^{\circ}$ & Strong & Contribu \\
\hline R1Fin06 & Previous findings $\mathrm{x}$ hypothesis & 41 & 1 & 369 & 90.00 & 9.00 & 9.00 & $3^{\circ}$ & Strong & Relevance \\
\hline R1Fin07 & Check links of findings $\mathrm{x}$ purpose & 41 & 1 & 373 & 90.98 & 9.10 & 9.00 & $1^{\mathrm{o}}$ & Stro & Internal validity \\
\hline 1Fin 08 & Does the context allow replication & 41 & 1 & 351 & 85.61 & 8.56 & 9.00 & & Strong & Reliability \\
\hline R2Fin09 & Impact from the nature of divergences & 37 & 2 & 289 & 78.11 & 7.81 & 8.00 & $9^{\circ}$ & Strong & Internal validity \\
\hline
\end{tabular}

\begin{tabular}{|c|c|c|c|c|c|c|c|c|c|c|}
\hline Propos. & Attribute/relationship & $\mathrm{N}$ & Round & Score & $\%$ & Mean & Median & Ranking & Level & Criterion \\
\hline R2Rep01 & Discussion of impact on knowledge & 37 & 2 & 301 & 81.35 & 8.14 & 8.00 & $6^{\circ}$ & Strong & Impact \\
\hline R2Rep02 & Disclosure of limitations & 37 & 2 & 315 & 85.14 & 8.51 & 9.00 & $4^{\circ}$ & Strong & Contribution \\
\hline R2Rep03 & Reasons for limitations & 37 & 2 & 293 & 79.19 & 7.92 & 8.00 & $8^{\circ}$ & Strong & Integrity \\
\hline R2Rep04 & Boundaries of the study & 37 & 2 & 294 & 79.46 & 7.95 & 8.00 & $7^{\circ}$ & Strong & Contribution \\
\hline R1Rep05 & Literature review $\mathrm{x}$ main concepts & 41 & 1 & 373 & 90.98 & 9.10 & 9.00 & $2^{\mathrm{o}}$ & Strong & Internal validity \\
\hline R1Rep06 & Theory to support propositions & 41 & 1 & 371 & 90.49 & 9.05 & 9.00 & $3^{\circ}$ & Strong & Internal validity \\
\hline R1Rep07 & Conclusions $\mathrm{x}$ aim & 41 & 1 & 377 & 91.95 & 9.20 & 10.00 & $1^{\mathrm{o}}$ & Strong & Internal validity \\
\hline R1Rep08 & Explicit possibility of generalization & 41 & 1 & 345 & 84.15 & 8.41 & 9.00 & $5^{\circ}$ & Strong & External validity \\
\hline R2Rep09 & Appreciation of drafts by colleagues & 37 & 2 & 229 & 61.89 & 6.19 & 7.00 & $9^{\circ}$ & Low & Internal validity \\
\hline
\end{tabular}

$\underline{\text { Reflexivity and Neutrality - final classification (ordered by proposition) }}$

\begin{tabular}{cccccccccc}
\hline Propos. & Attribute/relationship & \multicolumn{2}{c}{ N Round } & Score & $\%$ & Mean Median Ranking & Level & Criterion \\
\hline R1Neu01 & How to address errors and biases & 37 & 2 & 266 & 71.89 & 7.19 & 8.00 & $1^{\circ}$ & Moderate Integrity \\
R1Neu02 & Impact of team participation & 37 & 2 & 249 & 67.30 & 6.73 & 7.00 & $2^{\text {o }}$ & Moderate Integrity \\
\hline
\end{tabular}


Ethics - final classification (ordered by proposition)

\begin{tabular}{cllllllllll}
\hline Propos. & \multicolumn{1}{c}{ Attribute/relationship } & \multicolumn{3}{c}{ N Round Score } & $\%$ & Mean Median Ranking & Level & Criterion \\
\hline R2Eth01 & Registration of the study/CEP & 26 & 2 & 207 & 79.62 & 7.96 & 10.00 & $3^{\text {o }}$ & Strong & Rigor \\
R2Eth02 & Rules for registering studies/CEP & 25 & 2 & 176 & 70.40 & 7.04 & 9.00 & $6^{\text {o }}$ & Moderate Rigor \\
R2Eth03 & Formal submission to the CEP & 25 & 2 & 14457.60 & 5.76 & 6.00 & $7^{\text {o }}$ & Low & Rigor \\
R2Eth04 & Compulsory submission to the CEP & 25 & 2 & 14256.80 & 5.68 & 7.00 & $8^{\text {o }}$ & Low & Rigor \\
R2Eth05 & Use of the principles of a code & 26 & 2 & 18771.92 & 7.19 & 9.00 & $5^{\text {o }}$ & Moderate Integrity \\
R2Eth06 & Formal respect for human subjects & 25 & 2 & 19578.00 & 7.80 & 9.00 & $4^{\text {o }}$ & Strong & Integrity \\
R2Eth07 & Strategy to mitigate possible harm & 26 & 2 & 212 & 81.54 & 8.15 & 9.00 & $2^{\text {o }}$ & Strong & Integrity \\
R2Eth08 & Confidentiality to participants' data & 26 & 2 & 248 & 95.38 & 9.54 & 10.00 & $1^{\text {o }}$ & Strong & Integrity \\
\hline
\end{tabular}

Auditability - final classification (ordered by proposition)

\begin{tabular}{llllllllllll}
\hline Propos. & \multicolumn{1}{c}{ Attribute/relationship } & \multicolumn{1}{c}{ N Round Score } & $\%$ & Mean Median Ranking & Level & Criterion \\
\hline R2Aud01 Records of design changes & 29 & 2 & 242 & 83.45 & 8.34 & 9.00 & $2^{\circ}$ & Strong & Reliability \\
R2Aud02 Records of the reasons for changes & 29 & 2 & 237 & 81.72 & 8.17 & 8.00 & $3^{\circ}$ & Strong & Reliability \\
R1Aud03 Safeguard databases for checks & 41 & 1 & 367 & 89.51 & 8.95 & 9.00 & $1^{\text {o }}$ & Strong & Reliability \\
R2Aud04 Guard documents to reduce risks & 25 & 2 & 194 & 77.60 & 7.76 & 9.00 & $4^{\text {o }}$ & Strong & Reliability \\
\hline
\end{tabular}




\section{Appendix O: Summary of Statements by Criterion, Key Feature, and Level of Agreement}

\begin{tabular}{|c|c|c|c|c|c|c|c|c|c|c|}
\hline Row Labels & Analysis & Auditability & Data & Design & Ethics & Findings & Neutrality & Reporting & Subjects & Total \\
\hline Contribution & 0 & 0 & 0 & 0 & 0 & 2 & 0 & 2 & 0 & 4 \\
\hline Strong & 0 & 0 & 0 & 0 & 0 & 2 & 0 & 2 & 0 & 4 \\
\hline External validity & 0 & 0 & 0 & 0 & 0 & 1 & 0 & 1 & 0 & 2 \\
\hline Strong & 0 & 0 & 0 & 0 & 0 & 1 & 0 & 1 & 0 & 2 \\
\hline Feasibility & 0 & 0 & 0 & 3 & 0 & 0 & 0 & 0 & 0 & 3 \\
\hline Moderate & 0 & 0 & 0 & 2 & 0 & 0 & 0 & 0 & 0 & 2 \\
\hline Strong & 0 & 0 & 0 & 1 & 0 & 0 & 0 & 0 & 0 & 1 \\
\hline Impact & 0 & 0 & 0 & 0 & 0 & 0 & 0 & 1 & 0 & 1 \\
\hline Strong & 0 & 0 & 0 & 0 & 0 & 0 & 0 & 1 & 0 & 1 \\
\hline Integrity & 1 & 0 & 2 & 0 & 4 & 0 & 2 & 1 & 0 & 10 \\
\hline Moderate & 0 & 0 & 0 & 0 & 1 & 0 & 2 & 0 & 0 & 3 \\
\hline Strong & 1 & 0 & 1 & 0 & 3 & 0 & 0 & 0 & 0 & 5 \\
\hline Unformed & 0 & 0 & 1 & 0 & 0 & 0 & 0 & 1 & 0 & 2 \\
\hline Internal validity & 0 & 0 & 0 & 0 & 0 & 4 & 0 & 4 & 2 & 10 \\
\hline Low & 0 & 0 & 0 & 0 & 0 & 0 & 0 & 1 & 0 & 1 \\
\hline Strong & 0 & 0 & 0 & 0 & 0 & 3 & 0 & 3 & 2 & 8 \\
\hline Unformed & 0 & 0 & 0 & 0 & 0 & 1 & 0 & 0 & 0 & 1 \\
\hline Relevance & 1 & 0 & 0 & 0 & 0 & 1 & 0 & 0 & 0 & 2 \\
\hline Strong & 1 & 0 & 0 & 0 & 0 & 1 & 0 & 0 & 0 & 2 \\
\hline Reliability & 2 & 4 & 0 & 0 & 0 & 1 & 0 & 0 & 0 & 7 \\
\hline Strong & 1 & 3 & 0 & 0 & 0 & 1 & 0 & 0 & 0 & 5 \\
\hline Unformed & 1 & 1 & 0 & 0 & 0 & 0 & 0 & 0 & 0 & 2 \\
\hline Rigor & 2 & 0 & 2 & 0 & 4 & 0 & 0 & 0 & 0 & 8 \\
\hline Low & 0 & 0 & 0 & 0 & 2 & 0 & 0 & 0 & 0 & 2 \\
\hline Moderate & 0 & 0 & 0 & 0 & 1 & 0 & 0 & 0 & 0 & 1 \\
\hline Strong & 2 & 0 & 2 & 0 & 1 & 0 & 0 & 0 & 0 & 5 \\
\hline Suitability & 0 & 0 & 0 & 6 & 0 & 0 & 0 & 0 & 0 & 6 \\
\hline Strong & 0 & 0 & 0 & 6 & 0 & 0 & 0 & 0 & 0 & 6 \\
\hline Grand Total & 6 & 4 & 4 & 9 & 8 & 9 & 2 & 9 & 2 & 53 \\
\hline
\end{tabular}

